
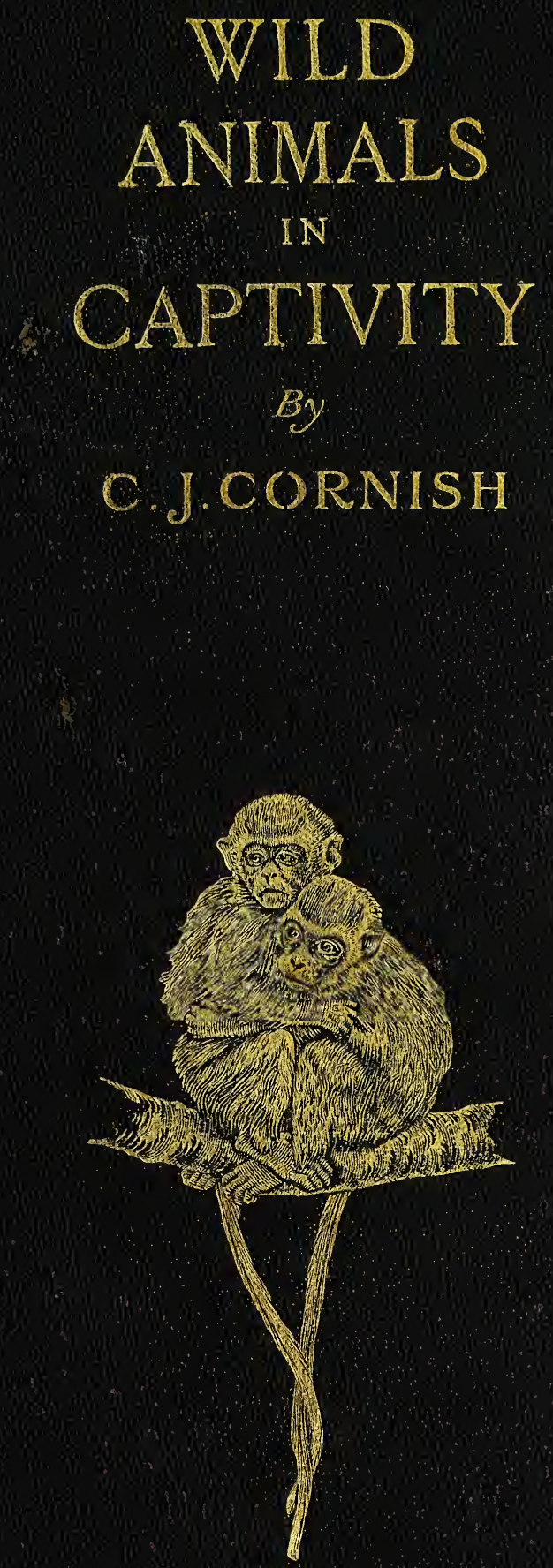
DR. R. L. WALKER,

No.งด2,

1897, 
Pol, Waltir, Jer 189\%, 




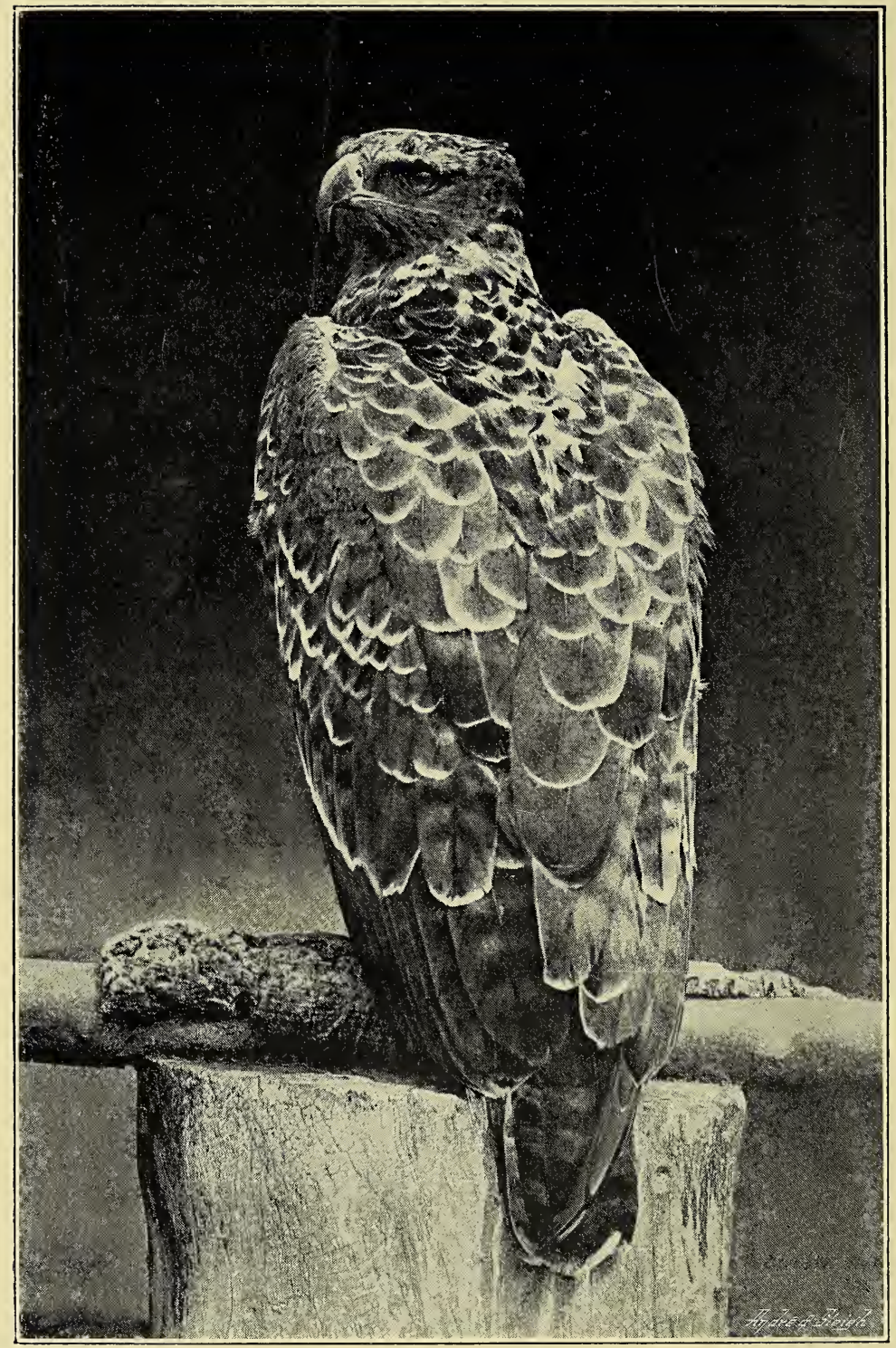

Martial. Hawk Eagle. From a photograph by Gambier Bolton. 


\title{
Wild Animals in Captivity
}

\author{
OR, ORPHEUS AT THE ZOO \\ AND OTHER PAPERS
}

BY

- C. J. CORNISH

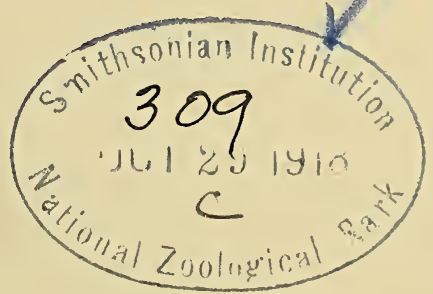

With Illustrations

from Photographs by' Gambier Bolton, F.Z.S. and from Japanese Drawings

NEW YORK

M A C I L L A N A D CO.

I 894 



\section{PREFACE}

ThE chapters on Animal Æsthetics, included in these notes, dealing with the sensibility of the inmates of the Zoo to music, will be found under the title of "Orpheus at the Zoo," by which they originally appeared in the Spectator, to the editors of which paper the author owes his thanks for suggesting many subjects of interest at the Zoo which would not have occurred to him, and for their kind permission to publish these, as well as other chapters in an extended form. He hopes that both these, and the unpublished chapters which are now added, present a fair picture of the many-sided present, as well as some glimpses of the past, of the famous menagerie in Regent's Park.

For the insertion of animal drawings by Japanese artists, in addition to $\mathrm{Mr}$. Gambier Bolton's photographs, the writer must plead the conviction, which he has long maintained, that their truth to Nature is of its kind unrivalled.

Orford House, Chiswick Mall,

$$
\text { C. J. Cornish. }
$$

September 28, 1894. 



\section{CONTENTS}

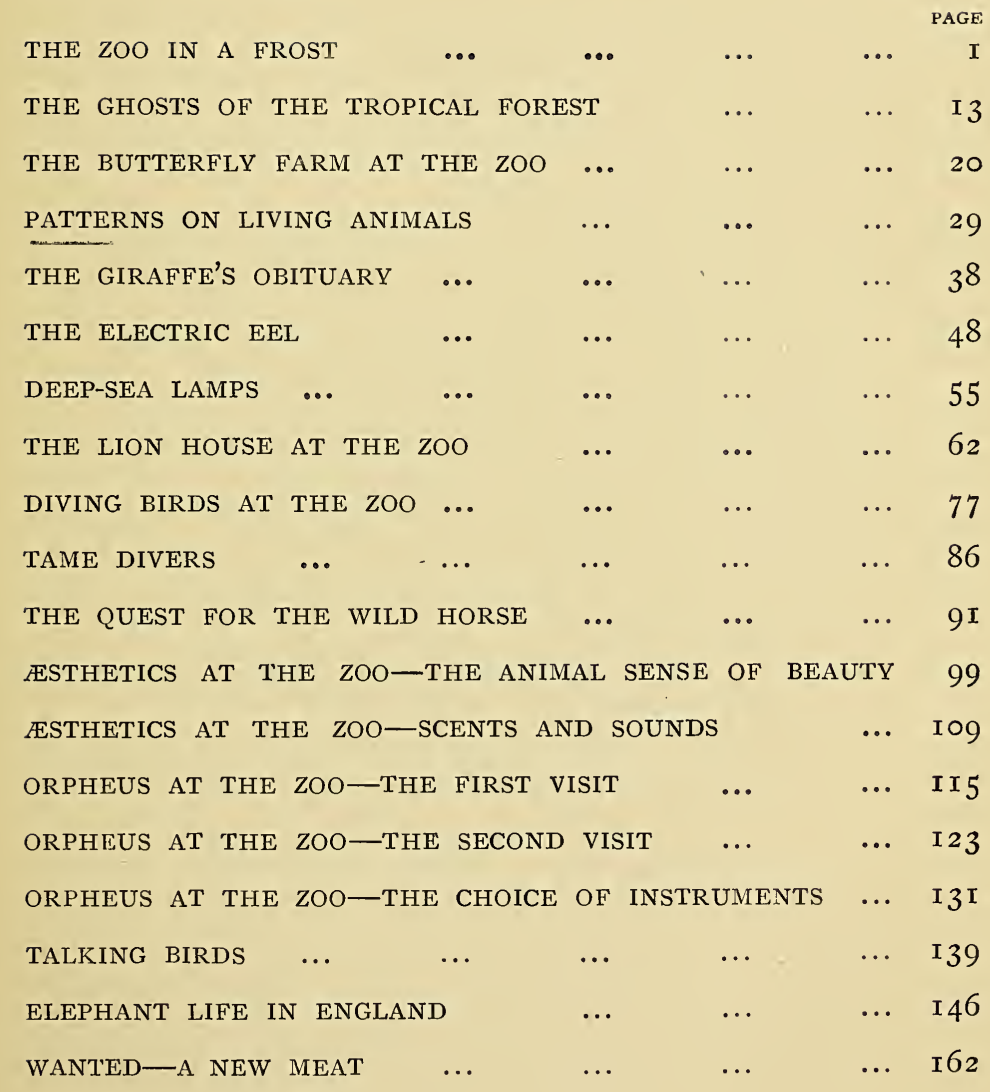




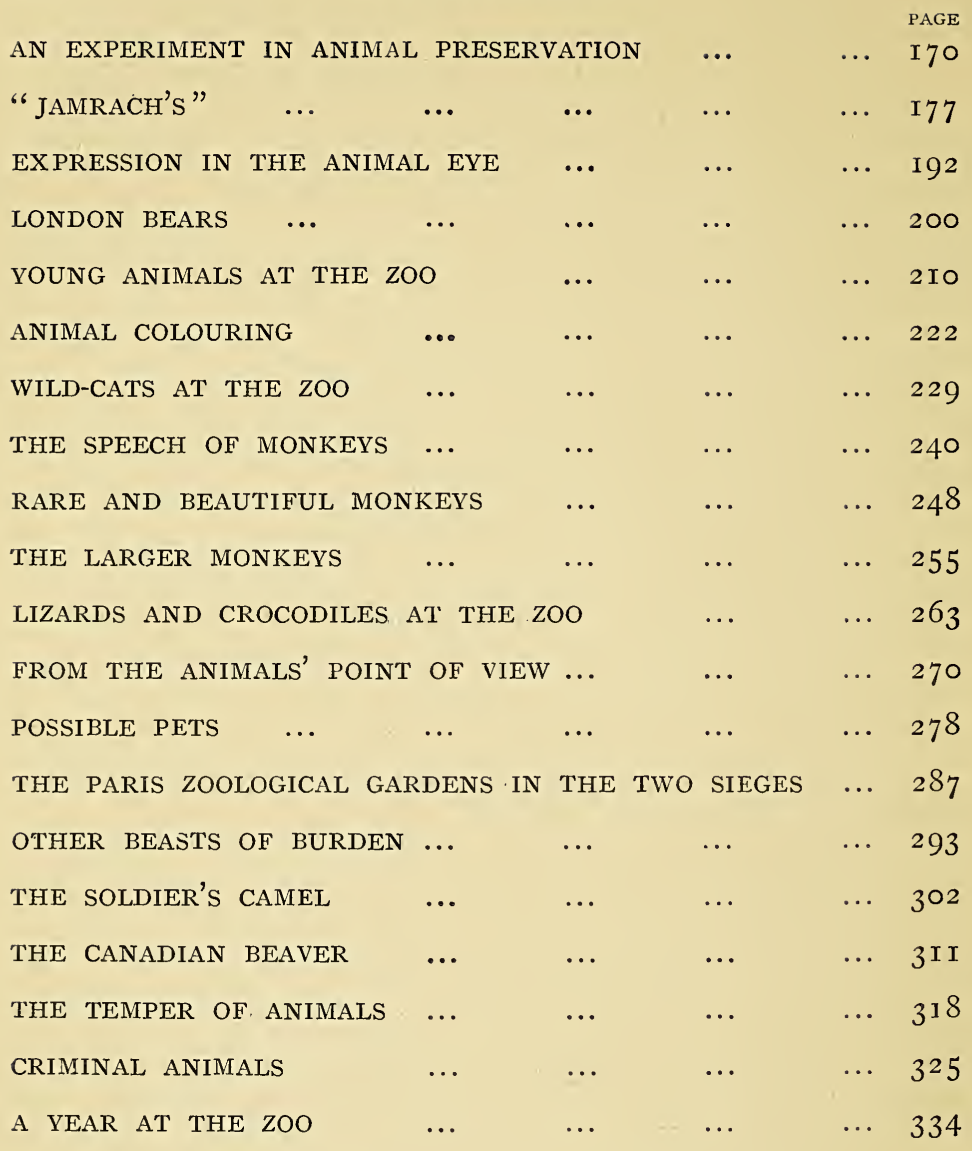




\section{LIST OF ILLUSTRATIONS}

\begin{tabular}{|c|c|c|c|c|c|}
\hline MARTIAL HAWK EAGLE & $\ldots$ & $\ldots$ & \multicolumn{2}{|c|}{ Frontispiece } & PAGE \\
\hline POLAR BEAR & $\ldots$ & $\ldots$ & $\ldots$ & $\ldots$ & 6 \\
\hline THE LAST GIRAFFE & $\cdots$ & $\cdots$ & $\cdots$ & ... & $3^{8}$ \\
\hline PUMAS $\quad \ldots$ & $\ldots$ & $\ldots$ & $\ldots$ & $\ldots$ & 62 \\
\hline LION AND LIONESS & $\cdots$ & $\ldots$ & $\ldots$ & $\ldots$ & 72 \\
\hline TIGER AFTER SMELLING LA & VENDE & R-WATER & $\ldots$ & $\ldots$ & I IO \\
\hline AXIS DEER LISTENING & ... & $\cdots$ & ... & ... & I I 8 \\
\hline TIGER LISTENING TO SOFT & MUSIC & ... & ... & ... & 136 \\
\hline JAPANESE PUG AND CAT & $\ldots$ & $\ldots$ & $\ldots$ & $\ldots$ & 180 \\
\hline THE QUEEN'S LION CUB & $\ldots$ & $\cdots$ & $\ldots$ & $\cdots$ & 210 \\
\hline OTTER PURSUING FISH & $\cdots$ & $\cdots$ & $\cdots$ & $\cdots$ & 220 \\
\hline ARABIAN BABOON $\ldots$ & $\cdots$ & $\cdots$ & ... & ... & 240 \\
\hline MACAQUE MONKEYS & ... & $\cdots$ & $\cdots$ & $\ldots$ & 248 \\
\hline MONKEYS PELTING COOLIES & WITH & FIR-CONES & $\cdots$ & $\cdots$ & $25^{8}$ \\
\hline ALLIGATOR & $\ldots$ & ... & $\ldots$ & $\ldots$ & 264 \\
\hline BACTRIAN CAMEL $\ldots$ & $\ldots$ & $\ldots$ & $\ldots$ & $\cdots$ & 302 \\
\hline
\end{tabular}





\section{LIFE AT THE ZOO}

\section{THE ZOO IN A FROST}

Sudden and severe cold, however trying to human constitutions, seems almost harmless to animal health, provided the weather be dry, frosty, and undimmed by fog. On the last Friday of November I 893, the thermometer fell so rapidly that in a few hours it registered sixteen degrees below freezing-point. On the following morning, though the sun was shining brightly, every pool and pond was sheeted with ice, and the gravel walks were as hard as granite. Yet at the Zoological Gardens, birds and beasts from tropical or semi-tropical regions, such as Burmah, Assam, Malacca, and Brazil, were abroad and enjoying the keen air; and others, which are usually invisible and curled up in their sleeping apartments till late in the day, were already abroad, sniffing at the frost and icicles, and as indifferent to the cold as Mr. Samuel Weller's polar bear "ven he was a-practising his skating." A visit to the Gardens in such weather 
suggests a modification of too rigid ideas of the limitation of certain types of animals to warm or torrid climates, and illustrates the gradual and reluctant character of the retreat of species before the advance of the glacial cold in remote ages. No creatures are, as a rule, more sensitive to cold than the whole monkey tribe. Yet there is at least one species of monkey which habitually endures the rigours of a northern winter. One of the cleverest antique Japanese drawings at South Kensington represents a troop of monkeys caught in an avalanche of snow. The grotesque discomfiture of these pink-faced monkeys rolling down the hillside, helplessly clutching at each other's bodies and limbs, grinning and grimacing as their heads emerge from the powdery snow, is something more than the fancy of a Japanese painter. The incident is probably drawn from an actual scene, and one of the creatures, the Tcheli monkey from the mountains of Pekin, was in an open cage in the gardens, and in far better health and spirits than in the height of summer. Its fur had grown thick and close, and the naked face had assumed the dark madder-pink with which it was adorned in the drawing. When presented with sticks crusted with frozen ice, it sucked the chilly dainty with great relish, and only showed signs of sensitiveness to cold by putting its fingers in its mouth, and then sitting on its hands to warm them. The behaviour of this northern monkey is only strange by contrast with the general habits of its kind. But the indifference to 
cold of the capybara, a gigantic water guinea-pig from the warm rivers of Brazil, is not easy to explain. Two of these quaint creatures had left their snug sleeping apartments, and were stepping gaily among pools of half-frozen water and broken ice. One had gained an extra coat by burrowing in its straw and then emerging with a pile upon its back; and, when this fell off, retired and shuffled on another pile; but the other seemed quite content to sit without protection in the sunniest corner of its enclosure. The whole colony of porcupines (six in number), which, like most semi-nocturnal animals, are very loath to appear in public during the day unless enticed by food of a more than usually tempting character, were abroad and in the highest spirits, erecting and rattling their quills, and sitting up to inspect their visitors like gigantic rabbits. It is difficult to conceive that a coat of quills can impart much warmth to its wearer; but towards Christmas the quaint black-andwhite garment of the porcupine has almost the appearance of a mantle of stiff feathers; and the crest on the head and shoulders, sloping backwards along the spine, combines, with the black face and Roman nose, to suggest a comical resemblance between the fullyfledged porcupine and one of Buffalo Bill's Sioux warriors in full costume of eagles' plumes.

During the first cold of winter the plumage of the birds and the coats of the fur-bearing animals in the Zoo are hardly inferior to those of their wild kindred. Both the eagle and the American bison are in con- 
dition to excite the cupidity of an Indian brave. The bull bison, which in summer has a strangely ragged and "moth-eaten" appearance, with big patches of bare skin showing on its flanks, is now covered with a "buffalo-robe" of magnificent proportions and the richest colour and texture. From shoulders to tail, the body is wrapped in a mass of brown felted fur. The mane hangs down below the knees, and a shock of black and silky hair covers the head and face, almost concealing the horns and the sullen, bloodshot eye. This bull is said to be the largest of its race in this country, and is probably as fine a specimen of the male bison as ever led its band across the frozen plains of the North-West. It was brought to England by Lord Lorne after the completion of his stay in Canada as Viceroy of the Dominion, and spent its earlier days at the Home Park at Windsor, whence it was transferred on exchange to the Zoo.

The golden and sea-eagles never present so fine an appearance as in these bright winter days. Those who see them with their wings and tails ragged and broken in the summer and early autumn, would hardly recognize them in their compact and close-set winter plumage, as they scream aloud in the frosty air, and fly to and fro in their large aviary on pinions undisfigured by a single broken feather. The Gayal, an immense bison from the jungles of Assam, with a coat as smooth and sleek as the bison's is shaggy and unkempt, drinks the iced water in its pen, and stamps the frozen ground-while the steam rises from its 
broad nostrils into the cold English air-with all the vigour of a shorthorn bull in a Surrey straw-yard; and the wild swine, whether from India or Europe, are equally indifferent to the weather. It would seem that all those species, such as the wild boar, or the buffalo and bison, which are widely distributed on many continents, adapt themselves rapidly to changed conditions of climate; and those wild boars which have been bred for several generations in this country and in Scotland, are rapidly developing a thicker and rougher coat of hair than their Indian cousins. It is probable that the tiger from Turkestan, if allowed the use of the outer cages, from which the Indian tigers and other large carnivora are withdrawn during the winter, would develop the thick and beautiful coat with which the northern tiger is represented in Chinese paintings. The bears, though so well wrapped up, take the frost as a hint to hibernate, and were for the most part fast asleep. Those which occupy cages facing the morning sun uncurl as the day grows brighter, and exhibit coats in the utmost perfection of winter growth. The black, brown, and cinnamon bears have at this time a bloom upon their fur which the utmost skill of the furrier fails to reproduce if the animal is killed at any other period of the year. In Southern and Central Russia many proprietors own large estates devoted to breeding horses and cattle. A menagerie of bears is often added to this. These are killed at the right season, and their skins sold in the best condition. Cloaks made from the skins of 
the six-months-old cubs have been sold for from $£ 600$ to $£$ iooo. Of the Polar bears, one, the older and larger, seems disposed to follow the example of the brown and black species, and to doze through the cold weather. The she-bear, much smaller and younger than its mate, takes its bath as usual, and plays with the floating ice like a baby with the soap. There it exhibits the most astonishing antics, turning back-somersaults, and standing on its head, or flinging out plates of ice with its nose and paws. No creature suggests such perfect indifference to cold as this Arctic bear, with icicles hanging to its fur, as it plunges again and again into its freezing bath.

The beavers are, of course, invisible, having long ago provided against the frost by plastering the wooden sides of the new house with mud and turf, and dragged a supply of dead branches as far as they could be forced to enter the narrow door. Though they are fed every day, and have nothing to fear from the weather, the instinct of winter storage is as strong as in the wild state. One is tempted to speculate whether this prudence is accompanied by any rational knowledge of the probable inadequacy of their stock to meet their natural wants. If their sense of quantity bears any proportion to their industry and skill in engineering, they must be full of anxiety and misgivings, for the few branches given to them are only make-believe, and they are wholly dependent on their captors for food. For some reason the rare European beavers, from the banks of the Rhone, have not 


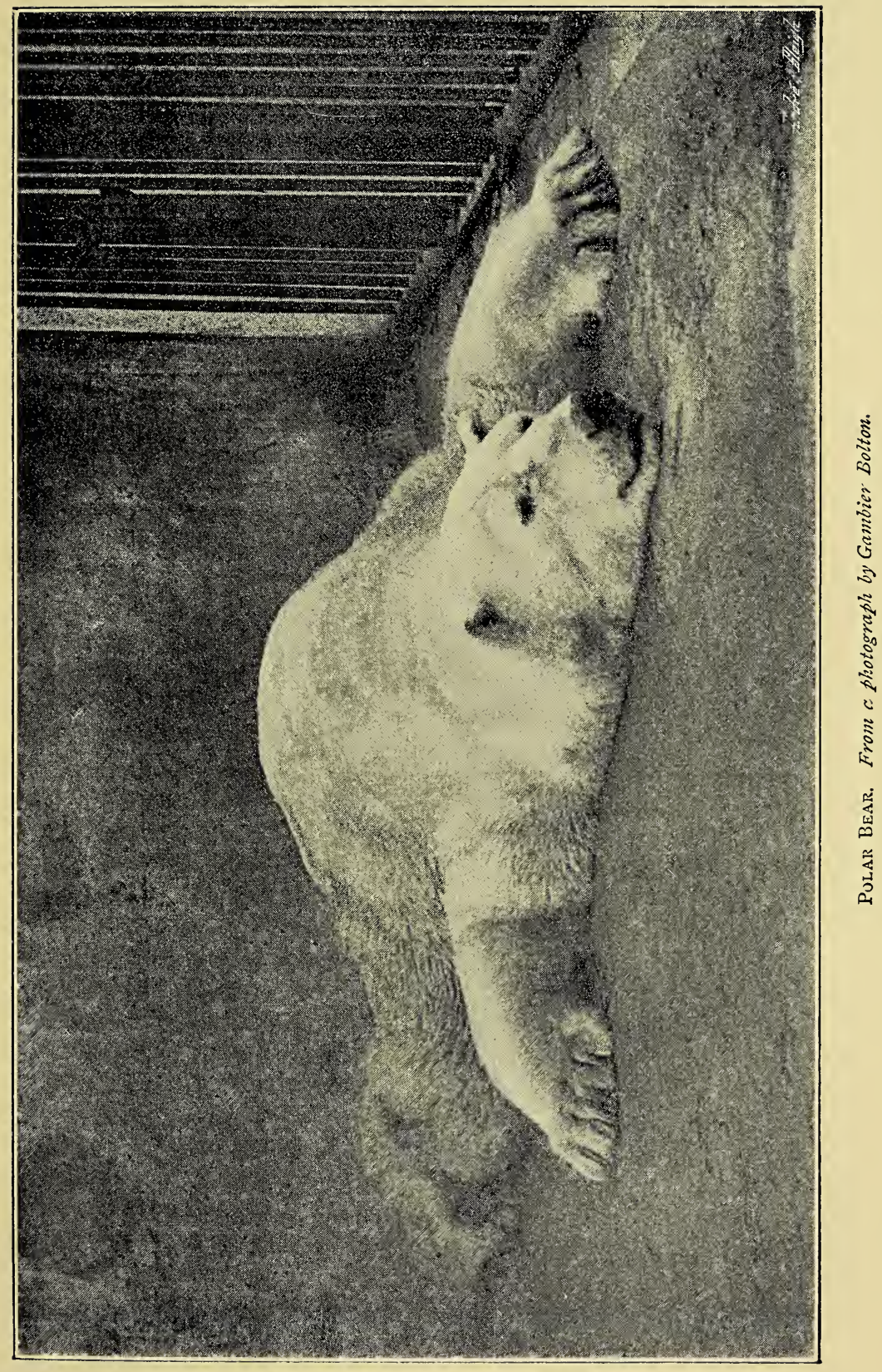



thriven at the Zoo. Four out of six had died at the date at which this visit was made, and only one is now left in the Gardens.

The demeanour of the inmates of the artificiallywarmed houses ought not to differ greatly in frost, as the ordinary temperature is nominally preserved. In the Elephant and Antelope Houses such a day as that which we describe has little effect beyond giving an added briskness of demeanour to such creatures as are not, like the elephant and rhinoceros, too bulky and majestic to be exhilarated by mere accidents of temperature.

The Antelope House is redolent with a delicious perfume of the finest hay, and its graceful inmates nibble at their fragrant breakfast with the same dainty selectness which marks their habits at meals on less appetizing days. Many of the larger kinds, lying in their neat stalls, look like some glorified form of Oriental cattle. The eland, couched placidly on a bed of golden straw, with its satin-like biscuitcoloured skin gathered into soft little wrinkles at the folded joints, and its dark full eye turned to gaze mildly at the visitors, seems a type of what the domesticated antelope should be, shielded from the weather, eating artificially prepared food, lying on the straw of civilization, and dependent for its food on the stockman's punctuality. The only creature which showed some effects of the exhilaration in the frosty air was the beautiful little Nagore antelope, the only living specimen, we beliere, of this rare animal now 
in Europe. In form it is almost like a large gazelle, with lyre-shaped horns, a golden fawn-coloured skin, of perfectly uniform tone, set off by large and brilliant black eyes. This antelope was unusually actire and friendly, standing on its slender hind feet, and reaching its head up to be caressed and fed.

In the open paddocks and runs of the smaller deer and wild-fowl, there was great good-temper and content. The Japanese deer were all curled up sleeping in the cold air round their food-box, which was filled with chopped straw, bran, and oats, and swarming with impudent $\mathrm{Z}_{\mathrm{oo}}$ sparrows. These little robbers, as also the Zoo starlings, are in such good case from the abundance of food left at their disposal by the fastidious strangers in the cages and paddocks, that, like the owls during the plagues of mice on the Pampas, they defy the weather and the seasons, and marry and bring up irregular families irrespective of the almanac. Dozens of them, as well as many of the starlings, had selected this particular cold morning of all others to take a bath. The gradually sloping drinking-pools in most of the runs, especially the tortoises' baths, which have a wide shallow entrance, exactly suit their wants. Many were washing and splashing in the pools in the swine runs, while others were drying themselves in rows on the sunny wall above the styes, with an immense amount of fuss and vulgarly loud conversation.

The gulls were particularly noisy, and playing at a new game with bits of ice, which they picked up from 
the broken edges of their ponds, and let fall on the sound ice. They then scrambled and fought for the pieces as they slid on the slippery surface. One big gull swallowed a large triangular piece, which stuck for some time in its throat, and evidently gave it much discomfort until the sharp edges melted. The ravens in the crow-cages were also much pleased with the broken ice, and were busy hiding all the pieces in holes round the edges of their aviary. One of the birds was evidently not satisfied with the concealment offered by the cranny into which it had poked a large fragment, so after considering for some time, it drew it out again, rubbed it in sand till it was well covered with grit, and then pushed it back, protected by a coating of colour "adapted to environment."

The heating of the Monkey House had been carefully looked to during the night, and beyond showing a disposition to huddle together and sleep, the common monkeys betrayed little obvious sensibility to the bright dry cold outside. But the delicate little marmosets and small tropical South American species were, with the exception of the Capuchins, removed to the warmer inner room behind the glass palace. One creature only seemed penetrated by the frost, a sleeping lemur. It was clinging to the bars of its cage, its hands grasping the rods, its two front arms stretched out, and its head, heavy with sleep, drooping between them. Yet, though steeped in slumber, it was shaken from moment to moment by spasms of shivering, its body conscious and responsive to the cold, though its 
drowsy brain was insensible to the warnings of physical malaise.

Winter in the Insect House is the time of incubation and sleep. All the beautiful forms of tropical moths and insects, which burst into life in the butterfly form in May, are sleeping in their pitcher-shaped cocoons, or buried in moss and mould. Only the great Goliath beetle, with a body' like a well-blacked boot on which cream has been spilt, and immense stag-like horns, was alternately eating melon and sipping highlysweetened tea, two indigestible forms of food on which it had made an almost uninterrupted meal for seven weeks.

From another point of view the demeanour of the semi-tropical birds in this sudden wave of cold was even more interesting than the power of adaptation to climate shown by so many quadrupeds. The whole pheasant tribe, perhaps the most beautiful, as a class, of any family of birds, are in the acme of plumage and condition. The Himalayas and China are the main homes of these gorgeous creatures, and we are not surprised to see in Regent's Park the metallic lustre of the Monauls, or the scarlet, orange, and gold of the rarer Chinese varieties, in equal perfection with that attained in the glens of Nepaul, or the mountains of Pekin. But the Argus pheasant is a native of Sumatra and Borneo, the companion of the trogons and the ourang-outang; yet the cock-bird was displaying its beauties in the open air, among leaves and grass tipped with hoar-frost, and showed plumage so close and 
perfect, that it was impossible to doubt that the colder climate had, if possible, added a lustre to its unrivalled wealth of ornament. It is to be regretted that the eggs laid in the previous summer were not fertile, else the development of perhaps the most perfect instance of animal pattern might have received further explanation from the processes of growth in the plumage of the young. One tender nestling from the tropics was being reared at the Zoo, though not exposed to the rigour of December frost. In October r 893 a young king vulture arrived from South America-a round, fluffy ball of white down, with a smooth black head like a negro baby, and as helpless as a young pigeon. It grew rapidly, and at the time when this paper was written, was the most interesting and intelligent specimen of a young carnivorous bird that the writer has yet seen. As a rule nothing could well be more morose and forbidding than the eaglet or the young of any hawk or falcon. They are helpless, savage, and unresponsive to any form of kindness. But the young vulture is almost as tame and intelligent as a puppy. It follows its keeper in the warm house, which it shares with the tortoises, sitting down when he stops, and rising and running with a half-bird, half-quadruped gait which is irresistibly comic. When frightened or shy in the presence of strangers, it lays its head on the ground and "shams dead," like a young plover, though almost as large as a turkey. But it soon loses all fear, and takes food or pulls at the garments of its visitors with amusing confidence. But the 
young vulture is an accidental visitor. The frosts of winter are mainly interesting at the Zoo as the time when the inmates exhibit the full beauty and vitality of vigorous maturity.

Note.-Since the above notes were written, the young king vulture has grown to full maturity, and is an even more interesting bird than its early promise indicated. At the end of July 1894 it was full-grown and in perfect plumage, every feather being distinct and unbroken. It is black from the crown to the legs, without a single white feather, and has none of the unpleasant appearance of the less noble vultures. So devoted is it to its keeper, that when some of the gigantic Seychelles tortoises were introduced into the large house in which it lives, it rushed at them to drive them away the moment he entered the house to feed it, and stood between him and the horny monsters, its wings wide stretched and its beak open and hissing. It still lies down to be caressed, and is in every way a very handsome and interesting bird. 


\section{THE GHOSTS OF THE TROPICAL} FOREST.

Perhaps the rarest, certainly the least known to man of all the creatures which, by a strange chance, find their way to the Gardens of the Zoological Society in Regent's Park, are the denizens of the Tropical Forest. We say forest, because, though divided by the dissociable ocean, there is only one great forest which belts the globe. The notion of the physical symmetry of the world, which fascinated the old geographers, and led Herodotus to surmise that the course of the great river of Africa must of necessity conform in the main to that of the Danube in the opposite continent, was wrong in theory and application. But shifting the guiding forces from the control of original and plastic design to the influence of the dominant Sun, the theory still holds good; and while the tropical heats remain constant and undisturbed, so must the tropical forest flourish and endure, with its inseparable concomitants of vegetable growth overpowering and replacing the marvellous rapidity of vegetable decay. 
To the naturalist, the most marked feature of the great tropical forest south of the Equator, is the inequality in the balance of Nature between vegetable and animal life. From the forests of Brazil to the forests of the Congo, through the wooded heights of northern Madagascar, to the tangled jungles of the Asiatic Archipelago and the impenetrable woods of New Guinea, the boundless profusion of vegetable growth is unmatched by any similar abundance in animal forms. A few brilliant birds of strange shape and matchless plumage, such as the toucans of Guinea and the Amazon, or the birds of paradise in the Moluccas or the Papuan Archipelago, haunt the loftiest trees, and from time to time fall victims to the blow-pipe or arrow of the natives, who scarcely dare to penetrate that foodless region, even for such rich spoils, until incantation and sacrifice have propitiated the offended spirits of the woods; but except the sloth and the giant ant-eater, there is hardly to be found in the tropical regions of the New World a quadruped which can excite the curiosity of the naturalist, or form food even for the wildest of mankind. In the corresponding tracts of Africa and the Asiatic Archipelago, the rare four-footed animals that live in the solitary forests are, for the most part, creatures of the night. Unlike the lively squirrels and marten-cats of temperate regions, they do not leave their hidingplaces till the tropical darkness has fallen on the forest, when they seek their food, not on the surface of the ground, but, imitating the birds, ascend to the upper 
surface of the ocean of trees, and at the first approach of dawn seek refuge from the hateful day in the dark recesses of some aged and hollow trunk. There is nothing like the loris or the lemur in the fauna of temperate Europe. We may rather compare them to a race of arboreal moles, the condition of whose life is darkness and invisibility. But, unlike the moles, the smaller members of these rarely seen tribes are among the most beautiful and interesting creatures of the tropics, though the extreme difficulty of capturing creatures whose whole life is spent on the loftiest forest trees, is further increased by the reluctance of the natives to enter the deserted and pathless forests. The beautiful lemurs, most of which are found in Madagascar, are further believed by the Malagasi to embody the spirits of their ancestors; and the weird and plaintive cries with which they fill the groves at night, uttered by creatures whose bodies, as they cling to the branches, are invisible, and whose delicate movements are noiseless, may well have left a doubt on the minds of the first discoverers of the island as to whether these were not in truth the cries and wailings of true lemures, the unquiet ghosts of the departed.

Several of the larger lemurs are to be found at the Zoo, and though these suffer so much if unduly exposed to the light that before long they lose their sight, they may occasionally be seen in their cages. Others, the rarest and most delicate members of the race, are so entirely creatures of darkness that their 
exposure to daylight seems to benumb all their faculties. They appear drugged and stupefied, and, though capable of movement, seem indisposed either to attempt escape when handled, or to move in any other direction than that of shelter from the odious day. Even food is refused before nightfall, and, unlike the epicure's ortolans, which awake and feed in a darkened room whenever the rays of a lamp suggest the sunrise, the lemur only consumes its meal of fruit and insects when nightfall has aroused its drowsy wits. These midnight habits clearly unfit it for public exhibition at the $Z_{0 o}$, and the last and rarest of the tribe which have arrived in London occupy a private room adjacent to the monkey palace, in common with other lemurs and loris, and a few of the most delicate marmosets and tropical monkeys which have escaped the rigours of an English winter. One large cage, which, in spite of the label "Coquerel's Lemur" placed upon it, seemed at the time of our last visit to contain nothing but a pile of hay, is the dwelling-place of these latest guests. After displacing layer after layer of the hay, the two sleeping beauties were discovered lying in a ball, each with its long furry tail wrapped round the other, in the deepest and most unconscious repose. When at last the two were separated, and the least reluctant was taken in the hand, the extreme beauty of the little "ghost" was at once apparent. In colour it is a rich cinnamon, fading to lavender beneath. The texture of the fur is like nothing but that of the finest and best-finished seal- 
skin jacket, only far deeper and closer, so that the hand sinks into it as into a bed of moss. The head is large and most intelligent, the face being set with a pair of very large, round, hazel eyes, in which the lines of the orbit seem not to radiate from the centre, but to be arranged in circles, like the layers of growth in the section of a tree. The long tail is at the base almost as wide as the body, tapering to a point, and covered with deep fur. But the greatest beauty of form which this lemur owns is the shape of its hands and feet. These exquisite little members are so far an exact reproduction of the human hand, that not only the hands, but also the feet, own a fully-developed thumb. But each finger, as well as the thumb, expands into a tiny disc, as in certain tree-frogs, so that the little hands may cling to the tree with the tightness of an air-pump. It is plain, as the halfsleeping lemur climbs over the arms and shoulders of its visitor, that it takes him for a tree. The arms are stretched wide apart, the thumbs and fingers are spread, and grasp each fold of the coat with the anxious care of one who thinks that a slip will cause a fall of a hundred feet, and the soft body and tail half envelop the limb down which they are descending, fitting to the surface like some warm enveloping boa. As soon as it reaches the hay-pile in its cage the lemur instantly burrows, its long tail vanishing like a snake, and in a minute it is once more asleep, and unconscious of the world.

A near relation of the lemurs is a beautiful little 
creature, whose uncouth native name has not been replaced, called the "moholi." It only differs from the lemurs in the shape of the ears, which in the moholi are either pricked up, like those of a bat, or folded down on its lead at will. It has the same wonderful brown eyes, so large and round that they seem to occupy the greater part of the head; the moholi is, in fact, "all eyes." As it stretches its slender arms out wide against the keeper's chest, and turns its head to look at the visitors, it has the most winning expression of any quadruped we have ever seen. The coat, of a pinkish-grey above, turns into light saffron below, and the texture is less deep than the lemur's fur. In touch it resembles floss silk, thickly piled. The "Slow Loris," from Malacca, is a tailless lemur. In exchange it has received a fretful temper, which seems a permanent trait in this species. When wakened it growls, bites, and fights, until once more allowed to sleep in peace. This loris hardly falls short of the beauty of the lemurs. The fur is cream-coloured, with a cinnamon stripe running from the head down the back. Of the three species which we have described, the first seems to combine some of the characteristics of the monkey and the mole, the second of the squirrel and the bat, the last those of the monkey and the weasel tribe. The "Slender Loris" is a still greater puzzle. It has all the characteristic "points" of the lemurs, without the tail. In size it resembles a squirrel; but its movements are so strange and deliberate, and so unlike those of any 
other quadruped, that it seems impossible to guess either at its habits or its purpose in creation. Each hand or foot is slowly raised from the branch on which it rests, brought forward, and set down again; the fingers then close on the wood until its grasp is secure, when the other limbs begin to move, like those of a mechanical toy. As we looked, its "affinities" with other types presently suggested themselves. It is a furry-coated chameleon. The round, protruding eyes, the slow mechanical movements, and the insectfeeding habits, are identical, except that the loris hunts by night and the chameleon by day. The loris even possesses an auxiliary tongue, which aids it in catching moths, just as the development of the same member marks the insect-catching lizard. From dawn till dusk all the lemurs are the very bond-slaves of sleep, hypnotized in the literal sense, drugged and steeped in slumber. Had the old poets known them, had the Phœnician sailors brought them back when they visited the land of Ophir, they would have been the consecrated companions of Somnus. Ovid's famous picture of the Cave of Sleep, and the noiseless hall where

"A couch of down, raised high on ebony, Self-coloured, sombre, draped with sable pall, Stands in the midst, whereon that god doth lie, While all his limbs relaxed in slumber fall,"

wants but one touch to complete the drowsy theme -a sleeping lemur curled up on Somnus' dusky pillow. 


\section{THE BUTTERFLY FARM AT THE ZOO}

A collection of tropical butterflies and moths reared in the Zoological Gardens was exhibited in the rooms of the Royal Society at their annual soiree in 189.3. The fact that such perfect and beautiful examples of the frail and fantastic forms which by night fill the place taken by the hummingbirds by day, in the steaming tropical forest, have lived in the precincts of a London park, is sufficient justification, if any be required, for their presence among such practical and progressive surroundings. Readers of Kenelm Chillingly, one of the latest and most extravagant of Bulwer Lytton's romances, may remember that one of the airy fancies of his youthful and impossible heroine, is to keep pet butterflies in cages, and to shed floods of tears over their untimely death. They manage things better in the butterfly farm at the $Z_{0 o}$, where the brilliant insects, after their brief day is over, pass by a kind of metempsychosis from the catalogue of living to that of dead specimens, and figure anew in the list of "additions to the collections of the Society." 
It would be difficult to picture a more elegant or more interesting sight than the hatching of the butterfly-broods in the Insect House during the first days of summer heat. The glass cases, filled with damp moss and earth, and adorned with portions of tree-trunks or plants suited to the habits of the moths, are peopled by these exquisite and delicate creatures, as one after another separates itself from the chrysalis-case in which it has been sleeping all the winter, and, fluttering upwards with weak and uncertain movements, exposes its beauties to the light. The wings of the largest kind, such as the great orange-brown "Atlas" moth, are as wide as those of a missel-thrush; and the great size of this and other species increases the strange likeness to bird-forms which is so marked, even in the smaller English hawk-moths. The giant moths of the tropics, unlike the rest of the insect world, have faces and features not devoid of expression. Some resemble birds; others cats. Some are covered with long, soft plumage, like the feathers of the marabout, or the plumes of swans. Others are wrapped in a silky mantle like an Angora kitten, or clothed in ermine and sables. The depth and softness of these downy mantles make the impulse to stroke them suggest itself at once; yet when the head-keeper lifts them from the branch on which they rest, as a falconer lifts his hawk, the feeling that they are neither moths nor animals, but long-winged birds, is equally irresistible. Form and texture suggest endless 
analogies with the higher animals; but the scheme of colour is peculiar to the tribe of which these are the most beautiful examples. In the Cecropian silkmoths, for example, some five or six of which, at the time this paper was written, were preening their feathery wings on the lichen-covered bark of an ancient oak-trunk. The body seems thickly wrapped in feathers, and, like the wings, is of an exquisite mottled grey, the colour of the natural wool of the Cashmere goat. But the legs, antennæ, and parts of the wings are boldly painted a rich red madder-brown. The Indian moon-moth is perhaps the most delicate in colouring of all. The wings are of the palest green, and as wide as those of a swallow, the tint of the aqua-marine. The uniform faint colour is only broken by a few crescent spots of a darker tint. But the whole of the front edge of the wing is "bound" in velvet, of the colour of dark-red wine. The body is wrapped in thick and downy feathers of the purest white, from which the soft legs and feet emerge, stained to match the claret edging of the wing. Across the head, and lying back against the dark shoulders, are the fern-shaped antennæ of pale green. Thus, this lovely creature possesses but three hues,-pale green, claret-colour, and white; but these are so graded and distributed, and so modified by the contrasted beauty of the texture of the semitransparent wing, the thick and downy body, and the delicate flesh-like legs, that the creature seems rather the realization of some painter's dream than one among 
hundreds of silk-producing insects. We once heard the generic difference between angels and fairies stated with all the certainty which was due to the youth of the speaker:- "Angels have birds" wings, and fairies have butterflies' wings, of course!" was the indignant answer to the difficulty raised. Imps, too, have bats' wings. But the wings of the moth have not yet been appropriated to the human embodiment of the unseen denizens of the air. There is a softness and reserve of colouring, and an uncertainty of outline in the moth's wing, which mark it at once as something distinct from the sharply cut, and brilliantly coloured forms of their butterfly relations.

Perhaps the most brightly coloured moths which are raised in the house are the Eacles regalis, which are covered with a net-work of orange, rivalling in colour the inner flesh of a melon, on a ground of greenish-grey; and the Eacles imperialis, in which an exquisite shade of "old rose" invades and is lost in a rich cream-coloured ground.

Not the least beautiful among the giant moths is the splendid creature from the cocoons of which the wild silks of India are wound. This is a far larger and finer moth than that which produces the Chinese tussur-silk. Its wings are "old gold" in colour, with two large transparent eyes on each, fringed with rosecolour. These, according to Hindoo superstition, are the finger-marks of the god Vishnu, and the Tussur moth is, therefore, sacred to that deity. But it is among the wild demon-worshipping Santhals 
that the Indian silk-moth has its native home. In the boundless upland forests, the trees on which it feeds are covered with thousands of the cocoons, which are gathered by these wild tribes, and sold to the silk-winders of the plains. Numbers of these fine cocoons line the cases at the $Z_{o o}$, each with living pupa inside. The cocoons are beautiful objects in themselves, nearly the size of a walnut in the rind, and hanging by stalks firmly twisted to the supporting twigs, like rows of melons. Their colour varies through all shades of silvery or purplish-grey, streaked all over, like the eggs of the yellow-hammer, with fine irregular dark-purple lines. The silk threads of which they are woven are flat, like tape, not round, like the ordinary floss-silk of Europe; and it is to this flat and irregular form of the thread that the beauty of woven tussur-silk is mainly due. It may be doubted whether the cultivation of the Tussur moth will spread to the West, like that of the common "silkworm." But the time is not far distant when this, and probably others of the fiftynine species of silk-producing larvæ which were exhibited in the Colonial and Indian Exhibition, will become an additional source of wealth in the wide forest-regions of our Indian Empire.

The area of the jungle forest in the Santhal country, in which grow the trees whose leaves form the best food of these silkworms, is vast beyond any probable use which the most enterprising silk-grower conceives. "As far as the eye could reach from any rising. 
ground," writes Mr. Thomas Wardle, in his History of the Growth of the 'Tussur Silk Industry, "and for hundreds of square miles, there lay a forest in which it seemed that any quantity of the tussur of the future might be cultivated, and I think it is worthy of the attention of the Government of India to encourage in every way a greatly increased production, and not to be behind China in this respect, remembering that when I showed how tussur-silk could be used, the demand which sprang up was chiefly met by the greater quickness of the Chinese."

Not only the moths, but even the caterpillars, or larvæ. of the various silk-moths, are as beautiful as any fabric which is woven from the glossy fibres of their cocoons. Let no one despise "worms and creeping things" after once seeing these exquisitely formed and coloured creatures. The larvæ of most may be seen in late July in the Insect House, feeding on green leaves in the cases. The finest are those of the Cecropian silk-moth; they are of a blue-green, with a soft bloom like that on some succulent plant. The whole body is clothed with alternate lines of turquoise and amber studs, specked with black, polished and shining like jewels. Those that have spun their cocoons are wrapped in jackets of lightbrown silk, into which strips of green leaves of the plum-tree are twisted for protection. The Ailanthus silk-moth has a pale-grey larva, with little ornaments in rows, shaped like the flowers of the stone-crop, and dotted with black. The moth itself is strangely 
beautiful, fawn-coloured, with bold wavy lines of black, grey, and pink. The Promethean silk-moth has a larva of pale Cambridge blue, with yellow and crimson studs. Not even the sea anemones in their native waters are more beautiful than these fugitive forms assumed by the undeveloped silk-moths of the East.

In their scheme of colour, the butterflies are to the moths what the fabrics of Europe are to the webs of Cashmere or the carpets of Daghestan. A score of the lovely swallow-tailed butterfly may often be seen fluttering in their cage. The bottom of their glass mansion is covered with short pieces of osier-stick, each one of which is pierced up the centre with a tunnel, at the end of which lies the pupa of that strange instance of protective mimicry, the hornet clear-wing. Another case is full of the scarce pale variety of the swallow-tail, and a third of the American swallow-tail, the female of which is black, spangled with what seems a shining dust of sapphires. But perhaps the most beautiful of all the butterfly broods is the swarm of Papilio Cresphontes. At the time of hatching, the case is full of these lovely butterflies, black above, with beaded spots of pale yellow; yellow below, with beaded lines of black. When last seen by the writer, some were flying from side to side of the cage; some had alighted, or were in the act of alighting, and others on the moss at the bottom were sipping the juices of ripe grapes.

Among the butterfly cages is a glass case which, 
since its inmates first found their way to the $Z_{o o}$, has never failed to excite the utmost interest and curiosity. On the floor of the box, partly sheltered by a few green plants, are ten or a dozen gold buttons, with a red-gold centre, on a lighter gold setting, edged by a round, semi-transparent rim. If watched attentively, the buttons presently move about on invisible legs, and perhaps one suddenly splits, puts out a pair of wings, and flies. These astonishing beetles, which are at present unnamed, are from Ceylon. Above, they exactly resemble an embossed gold sleeve-button, with a rim of yellow talc. Laid on their backs, the underside of a golden beetle appears, surrounded with the same semi-transparent rim. Trap-door spiders also flourish in the Insect House, and have made several caves, with most ingenious doors, in a large piece of rotten wood with rugged lichen-covered bark. The doors are quite irregular in shape, made to fit the surface of the hole in which the spider lives, and are of all sizes, from that of a walnut-shell to a pea. The door exactly fits the orifice, however irregular its shape, and is so cleverly covered with pieces of wood and lichen woven into the fabric, that it exactly resembles the surrounding bark; and even a prying tit might omit to probe it with its bill.

The one hideous and repulsive creature in this good company is the great tarantula spider. It is like a long-legged, hairy crab, quite seven inches from claw to claw, with enormous brown poison fangs like a beak. Two of these spiders, discovered in a tent at 
Assouan, occupied by officers of the Heavy Camel Corps, put the whole of the inmates to flight in their pyjamas, and the only wonder is that they ever ventured to return before daylight. There is something strangely repulsive in this low type of life, which nevertheless makes a prey of such beautiful and highly-developed animals as humming-birds, and even the small and fragile quadrupeds of the tropical forest. 


\section{PATTERNS ON LIVING ANIMALS.}

EARLY in the spring of 1893 , the Marquis of Hamilton brought with him from Trinidad a number of little fish, less in size than a half-grown minnow, which were presented to the Zoological Society, and were to be seen at Easter swimming in a glass bowl, among a thin growth of water weeds, in the warm chamber in which the tropical moths and butterflies are hatched.

Being small and elegant, they have a long and ugly scientific name, the Girardinus Guppyi. In the absence of a label, the writer mistook them for the gudgeon, which form the food of the more rapacious fishes, and was about to suggest that they would be interesting material for an experiment with the electric eels, when a ray of sunlight flashing through the bowl revealed the astonishing fact that these tiny fishes possessed beauties of ornament not exceeded in kind by any of the most exquisite birds of the tropics.

Each of the little creatures, though so frail and so 
delicately formed that its body offered a scarcely greater obstacle to the passage of the sunlight than the water in which it swam; was decorated on either side by one, or sometimes two, of those exquisite ornaments seen in the greatest perfection in the train of the peacock, which are perhaps best described as the "peacock-eye." It was no mere spot, lying in a ring of a different colour, such as decorates the sides of a trout or salmon, but a perfectly-developed peacock-gem, lying in its gorgeous rings of blue, green, and gold, equally rich and dark in tint, and even more striking from its contrast with the colourless and semitransparent body of the creature it adorned. The analogy with the pattern on the peacock's tail was eren more complete than that which a first glance disclosed; for on many of the fish a third or rudimentary eye appeared, fainter and elongated, like a smudge of wet colour, and corresponding exactly with the gradation or evolutionary process of ornament, which Charles Darwin noted in the side-feathers of the peacock-train. This wonderful decoration, which was assumed, like the brilliant red and emerald of the English sticklebacks, for the period of courtship only, disappears later in the year; and the creatures abide in plain clothes till next spring. But the character of the ornament they wear suggests a further and separate interest, beyond that which their beauty naturally claims. Pattern, by which we mean the repetition of certain and regular forms, so as to produce an ornament which pleases the eye without making any 
demands on the mind, is by no means a common form of natural decoration in the higher animals. Contrasts of brilliant colours, as in the plumage of the birds of paradise, and of the parrots and lorys, are the usual and beautiful adornments of birds. Any visitor to the cases of a good natural history collection, will find a hundred instances of this form of decoration for one of true pattern. Even the wings of butterflies, though spangled with colours in dots, lines, and spots, are usually devoid of pattern, though the juxtaposition of a number of the same species would instantly produce the effect of pattern. But that effect, so far as it is given in a single individual, is, as a rule, only due to the fact that the creature is itself symmetrical, and that the lines and markings on one side of the body are repeated upon the other. The stripes upon a tiger's skin, for instance, though in the nature of ornament, are not a pattern, though a number of tigers' skins laid side by side might produce to the eye the effect of pattern. The patterns themselves are also few in number; and these limited and favourite forms of enrichment are applied indiscriminately, and with a certain indifference to congruity of species, yet with unfailing success in the result, to the most widely different forms in the animal creation. Take, for example, the most complex, and perhaps the most beautiful of all, natural ornaments, which appears in the "eyes" in the peacock's tail. The same pattern, with slight variations, is found, not only on the feathers of the beautiful grouse-like Polyplectron of Malacca, 
though modified, as Darwin noted, by the white edging, which makes it even more conspicuous than the bronze circle round the peacock-eye, but also in the peacockpheasant, and the Ocelated Turkey of Honduras. In this splendid bird, the "eyes" are placed in a row at the end of the tail-feathers, and upon some of the upper tail-coverts, and are rimmed with gold. The same pattern, by a leap from an order of birds not distantly connected, appears in undiminished beauty in the little fish from Trinidad; and with an almost incredible difference of subject and sameness in effect, in the peacock-butterfly and eyed hawk-moth of England, in the emperor-moth, and a number of allied insects; and lastly, with a startling resemblance, in the centre of the beautiful peacock iris, which is now cultivated in English gardens. It would, perhaps, not be difficult to add to the instances of repetition of this particular pattern which we have given, by a careful survey of the specimens exhibited in the Natural History Museum at South Kensington. But the fact of the repetition of the "peacock-eye" as ornament in the case of birds, fishes, moths, butterflies, and lastly of a common and beautiful flower, will sufficiently illustrate the fact to which we draw attention. The pattern, if less elaborate and exact in reproduction when found among the moths and butterflies, is an "impressionist" rendering of the same scheme, and if it were the reproduction of some human hand, would leave no doubt as to the identity of the motive and idea in each. The remaining natural patterns, even 
though of less complex form, may almost be counted on the fingers of the hand, and are applied with the same careless profusion to the adornment of creatures, like and unlike, without distinction, though the range is in most cases far more limited than in that of the peacock-eye. The most perfect form of the cup-andball pattern, which is seen in the feathers of the Argus pheasant, seems only to reappear on the wings of the Brahma moth, and of the eyed tortoise, though in one or two other small tortoises the effect of the ball ornament is produced by an actual embossing of the shell. Yet even in this case, not only is the form of the pattern reproduced, but also the beautiful brown colouring, which, by its soberness and exquisite gradation, produces the effect of low relief in monochrome. The wave-line, the spot, the scale-pattern, the barpattern, and, in rare instances, a chequer or diaper in black and white, almost exhaust the list of other natural patterns, and these, like the peacock-eye, recur in non-allied species in exactly the same arrangement, not only of form, but of colour. A most effective spot-pattern is that in which a rich chestnut ground is covered with minute white or cream-coloured spots. The result is most rich and beautiful, and it seems to be reserved for use in highly-decorated creatures of any class or family. It is seen at its best on the breast of the lovely harlequin-duck, in which the whole surface shines like enamel. But exactly the same pattern in the same colours appears on the neck of such a widely-different species as the chestnut-eared 
finch of Australia; and with the order of colour reversed, under the wings of the bar-breasted finch, both of which may be seen in the Parrot House at the Zoological Gardens. In the smaller wing-feathers of the Argus pheasant, this spot-pattern is reproduced on almost the same minute scale as on the harlequinduck and the little finches. Then by a sudden change it is found on the back of the larvæ of the Gallium hawk-moth, a chestnut-coloured insect, with a row of minute white spots down the middle of its back, and two rows of rather larger white spots, one on each side. The larvæ of the spurge hawk-moth, of the white-satin moth, and of the sycamore daggermoth, also show it. Among butterflies, the Salatura Melanippus has a border of white spots on chestnut ground round the edges of its wings; and the same arrangement may be seen on a shell-some kind of Gastropoda, if we remember rightly-which is "commonly observed" on cottage mantelpieces. The "scale pattern " is generally due in the case of birds to the natural shape of the feathers, and not to surfacepattern. A good example is the neck of the Amherst pheasant, in which the feathers are scale-shaped, and being edged with black, produce a beautiful pattern, and the neck of the golden pheasant, in which the corresponding feathers have square ends, and the black edging merely falls into parallel lines. The perfect rectangular diaper pattern is extremely rare in birds, but not uncommon in the larvæ of moths and butterflies. It is seen in perfection on the backs of 
the great northern diver and its relations; and in a faint reproduction on the wings of the wood-leopard moth. A very elegant and decorative ornament is the "wave-line" pattern. This, like the chestnut ground and white spot, is constantly reproduced in the same colours, black on grey, or grey on black. It appears on the side of the wild duck, on Swinhoe's pheasant, in which bird it is the main form of ornament, on the neck of the grass-parakeet, on the sand-grouse, on several common species of iris, and on the wings of the Brahma moths, surrounding the ball ornament to which we have referred. The inference to be drawn from these coincidences must be left to practical zoologists. But the fact that natural patterns, as applied to animals and plants, while at times showing the utmost elaboration of design, are so limited in number, and applied with so little modification in colour or form to birds, fishes, insects, and plants alike, seems an inviting subject for inquiry.

Meantime it would be a charming amusement to any one who desires a new and not too exacting intellectual interest in a visit to the Zoological Gardens, to go from the aviaries to the wild-fowl ponds, and from the pheasants in their runs to the finches in their cages in the Parrot House, and make a complete list of the possessors of each form of these distinct and arbitrary animal patterns. By so doing, he would incidentally secure an acquaintance with the most beautiful of all the birds, for the possessors of these ornaments are generally among the most elaborately 
marked of any of their species. The list given above is far from exhaustive, and as the first, and often the most pleasing, part of these minor inquiries into nature consists in the collection and classifying of likenesses, it offers an attraction as great as any obvious inducements to observation in the Society's collection. Some day we shall perhaps see in the cases at South Kensington a collection of examples of the repetition of ornament, as well as of the evolution of ornament in nature. The origin of the first is now explained. But on what hypothesis can we account for the second :

The observation of these patterns should extend throughout the year if it is to be complete. The typical pheasants are only in perfect plumage in winter, and these delicate ornaments are much affected by the physical condition of the wearer. In the fish, as we have seen, they almost entirely disappear after the bodily vigour of the spring season has departed. In late summer and early autumn the pheasants and peacocks are moulting; the tropical moths, on the other hand, which have such beautiful analogies with the bird plumage, are hatching out in May. The pretty little tropical finches take far less time to moult than some of the larger birds, or are less affected in plumage, and the minute but accurate reproductions of the patterns on the wood-duck, wild duck, and jungle-fowl which appear on their diminutive bodies may be seen at almost any season in the Parrot House. The flower gardening at the Zoo is now maintained at 
so high a pitch of elaboration and beauty, that it would not be difficult to provide instances of animal pattern in beds of peacock iris, and of other plants which reproduce the less elaborate but equally distinct forms of pattern of which examples have been given above. 


\section{THE GIRAFFE'S OBITUARY.}

THE winter of the year 1892 , like the days of pestilence before the walls of Troy, was fatal both to man and beast. Even the carefully tended inmates of the Zoological Society's Gardens did not escape; and as the new year opened with the death within a week of "Sally," most human and most intelligent of . apes, and of her neighbour "Tim," the silver gibbon, who was almost as great a favourite of the London public as the educated chimpanzee, so the spring saw the death of the two beautiful giraffes, the sole survivors left in the collection. The experience which the Society has had in maintaining its stock of these interesting creatures has not, however, been altogether discouraging. Since the first four specimens were brought to England in I 836 , no less than seventeen fawns have been born in the Gardens, and many of these lived to grow up. But the stock gradually diminished, until in I 866 two were burnt to death in their stable, and a third died of old age, leaving only the pair now lost.

The time of their death, unfortunately, coincide 


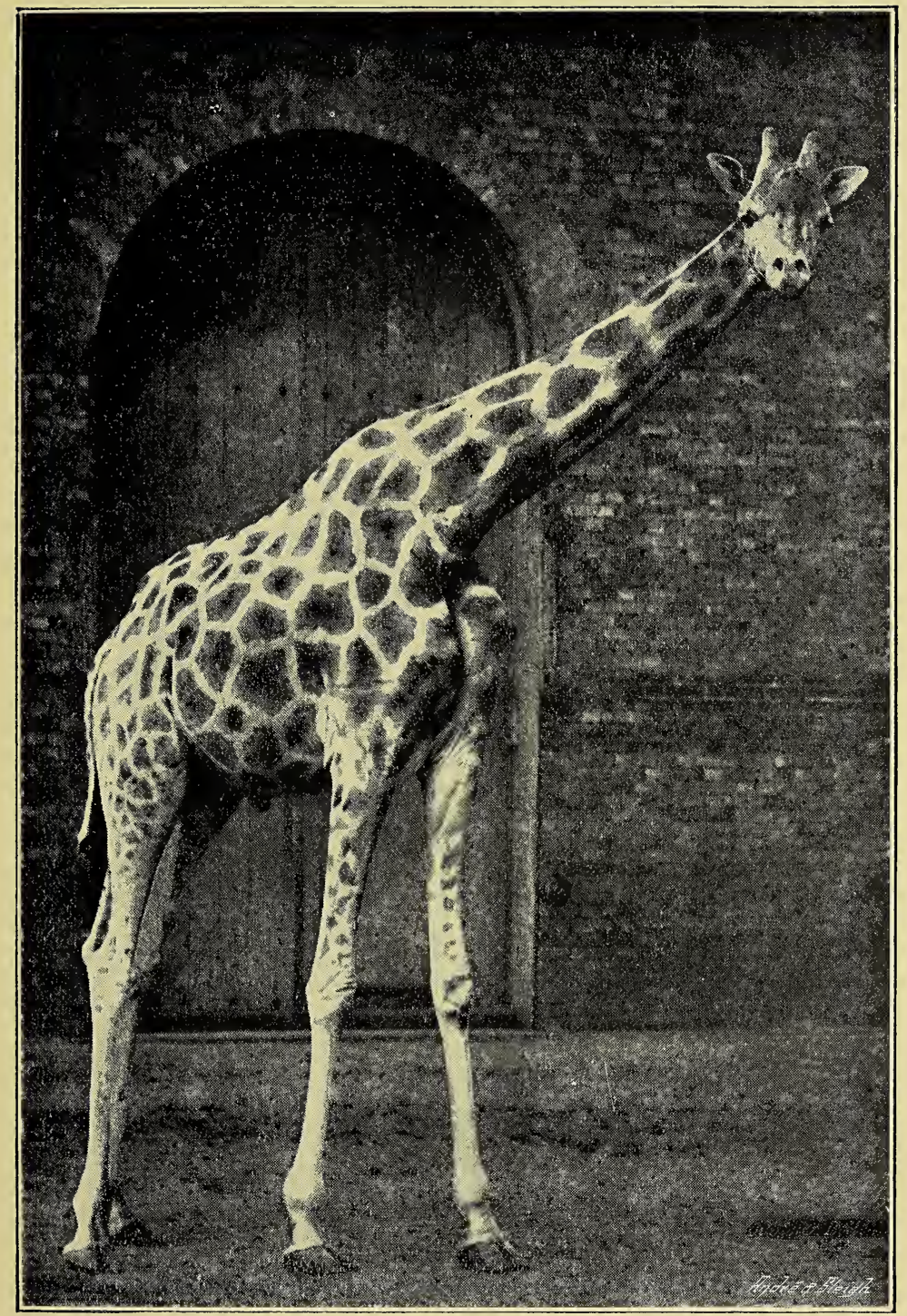

The Last Giraffe. From a photograph by Gambier Bolton. 

with the complete interruption of the ancient trade in wild animals up the Valley of the Nile by the Mahdi's occupation of the Soudan, a trade as old as the days of Solomon, never organized, often interrupted for centuries, yet always ready to spring up again, and always dependent for its rarest products on the free navigation of the river of Egypt. Giraffes-which, not excepting the hippopotamus, have most excited the imagination of European capitals after the long intervals in which they have remained unseen by the nations of the West-seem always to have found their way hither from the land of the Pharaohs. The first seen in Europe since the "tertiary epoch" was obtained from Alexandria by Julius Cæsar, and exhibited at the Circensian Games to crowds who expected, from its name, "camelopard," to find in it a combination of the size of a camel and the ferocity of a panther. Pliny, who described it, echoed the public disappointment. "It was as quiet," he wrote, 'as a sheep." The trade probably reached its maximum after it became the fashion to exhibit combats of wild beasts at Rome; yet even then giraffes seem to have been scarce in the popular shows, though Pompey could exhibit five hundred lions at a time, and the Emperor Titus, at the dedication of his new theatre, caused the slaughter of five thousand wild beasts. Either the number of wild animals in the provinces must have been beyond anything since known, or the Roman Governors must have used their despotic powers freely to oblige their friends. 
No doubt they did this. Cælius, Cicero's gossiping correspondent, says, when writing to him in Cilicia"In nearly every letter I have written to you about panthers. It is a great shame. Pray send to Pamphylia, where most are said to be taken. You have only to give an order, and the thing is done. You know I hate trouble, while you like it, and yet you will not do this, which is no trouble. I have sent men to look after them and bring them here."

Despots are the best collectors; and from the fall of the Roman Empire till the arrival of those placed in the Zoological Gardens in 1836 , the rare appearances of the giraffe in Europe were in each case due to the munificence of Eastern Sultans and Pashas. The Prince of Damascus gave one to the Emperor Frederick II. in I215; and the Soldan of Egypt presented another to Lorenzo the Magnificent, which became the pet of Florence, and used to be allowed to walk in the streets, and take the presents of fruit and cakes extended to it from the balconies. From this time the giraffe was not seen in Europe until, in I 827, the Pasha of Egypt sent four to Constantinople, Venice, England, and France respectively. The giraffe sent to England was in bad health, and soon died; but the Parisians went wild with excitement over the Pasha's present. It had spent the winter at Marseilles, and throve there on the milk of the cows which the Pasha had sent over for its use from Egypt. The Prefect of Marseilles had the arms of France embroidered on its body-cloth, and it entered Paris 
escorted by a Darfour negro, Hassan, an Arab, a Marseilles groom, a mulatto interpreter, the Prefect of Marseilles himself, and a professor from the Jardin des Plantes, while troops kept back the crowd. Thousands came every day to see it, and men and women wore gloves, gowns, and waistcoats of the colour of its spots. But the successful expedition by which, in 1836 , M. Thibaut procured a stock of giraffes for the Zoological Society, owed nothing to the patronage of the Pasha of Egypt, beyond permission to enter the Soudan. The caravan left the Nile near Dongola, and thence passed on to the desert of Kordofan. There M. Thibaut engaged the services of the Arab sword-hunters, whose skill and courage were of such service to Sir Samuel Baker in his expedition thirty years later to the sources of the Nile tributaries; and in two days they sighted the giraffes. A female with a fawn was first pursued by the Arabs, who killed the animal with their swords, and next day tracked and caught the fawn in the thorny mimosa scrub. For four days the young giraffe was secured by a cord, the end of which was held by one of the Arabs; at the end of that time it was perfectly tame, and trotted after the caravan with the female camels which had been brought to supply it with milk. The Arabs were excellent nurses, and taught the young creature to drink milk by putting their fingers into its mouth and so inducing it to suck. Four others which M. Thibaut caught died in the cold weather in the desert. But he replaced three of these, and 
brought four, including that first taken, down the Nile to Alexandria, and then by ship to Malta. "Providence alone," he wrote, "enabled me to surmount these difficulties."

The Report of the Council of the Society as to the progress of this great undertaking is worth quoting in full.

"The Council are now (April I 836) looking forward with interest to the completion of an attempt in which the Society is engaged for the importation of several giraffes, which they hope to see added to the Society's collection in a very few weeks. In the earlier days of the Society's existence, the acquisition of this singular and rare animal was among the most important objects to which the attention of the Council was directed, and they made many inquiries as to the probable means of effecting it, and then named a price which would be paid for one or two of them, on their being delivered, in good health, at the Society's Gardens.

"In 1833 the inquiries were again resumed, through Mr. Bourchier of Malta, to whose valuable aid on numerous occasions the Society is almost incessantly indebted. Through his intervention, and the kindness of Colonel Campbell, her Majesty's Consul-General for Egypt, an arrangement was made during the close of that year with M. Thibaut, who was then at Cairo, and he agreed to proceed to Nubia for the purpose of procuring giraffes on the Society's behalf. The terms of his agreement imposed upon him the whole 
risk of the undertaking, previously to the delivery of the animals in Malta, and it was not until his landing them in that island that he was entitled to receive the stipulated price, which was at a fixed rate for each individual, diminishing in proportion to the number he should bring with him."

After a brief reference to the capture of the animals, the report states that he reached Malta in safety with his raluable charges, three males and a female, on Norember 2 I, I834. "Having thus fulfilled his engagement, $M$. Thibaut became entitled to receive

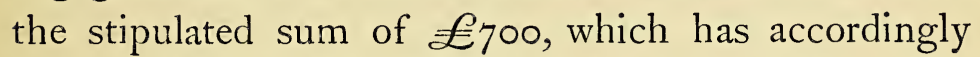
been paid him. But the Council has considered it so desirable to avail themselves of his experience with respect to these valuable animals, that they have arranged with him for the continuation of his services until their arrival in England. For the conveyance of the giraffes to this country, the Council have availed themselves of the Manchester, a steam vessel of great size and power, which proceeded to Lisbon at the beginning of the present month, having been specially engaged for the service of Prince Ferdinand of Portugal. From Lisbon the Manchester is to proceed to Malta, whence she will return to London. Her arrival may be expected before the end of May. For the conveyance of the animals to England $£_{\text {I }}$ ooo will be paid, and the necessary fittings for the accommodation of the giraffes will be prepared at the cost of the Society in her Majesty's dockyard at Malta, orders to that effect having been sent thither by the Lords 
of the Admiralty." Thus the giraffes came to this country under circumstances almost as imposing as those which marked the reception of that sent by the Pasha of Egypt to Paris. They travelled in one of the first steam vessels of the mercantile marine, one which had just conveyed a prince, and their comfort was provided for by the Admiralty and the Royal Dockyards.

All four were safely lodged in the Zoological Gardens on May 24, I836, an event which the Council of the Society justly claimed as highly creditable to its resources. One died in the following winter, but the rest continued in excellent health, and became the greatest public favourites in the menagerie.

At the time of their arrival the largest was then about I I ft. high, the height of an adult male being I $2 \mathrm{ft}$. at the shoulder and $\mathrm{r} 8 \mathrm{ft}$. at the head. For many years, as we have said, the giraffes throve and multiplied. They readily took to European food, and ate hay and fresh grass from the tall racks with which their stables were fitted. Onions and sugar were their favourite delicacies, and in search of sugar they would follow their keeper, and slip their long prehensile tongues into his hands or pockets. But they always retained a liking for eating flowers, a reminiscence, perhaps, of the days when their parents feasted on mimosa blossoms in the desert. Some years ago, one was seen to stretch its neck over the railings, and to delicately nip off an artificial rose in a young lady's 
hat. They were most affectionate creatures, and, as M. Thibaut noticed when in charge of them in Upper Egypt, would shed tears if they missed their companions or their usual attendants. But the development of the lachrymal ducts, which enables the giraffe to express its emotions in this very human fashion, is less obvious than the wonderful size and beauty of the eyes themselves, which are far larger than those of any other quadruped. On May 27, 1840, four years after their arrival, the female giraffe bore and afterwards reared a fine fawn, and it was not until they had been eleven years in the menagerie that the death occurred of one of the pair of males which had survived the first year in England. In I 849 two more males and one female giraffe were waiting the Society's pleasure at Cairo, and the stock continued to increase by births in the menagerie. In 1867 the straw in the giraffes' house caught fire at night, and a female and her fawn were suffocated. A sum of $£_{545}$ was claimed as compensation for their loss, and duly paid to the Society by the "Sun" Fire Insurance Office, probably the first claim of the kind paid in Europe. For curiosity, now that we have no living giraffe left in England, we would suggest a comparison of the beautifully-stuffed giraffe heads in Mr. Rowland $\mathrm{W}$ ard's collection in Piccadilly, with the innumerable specimens of other large game, such as wapiti, buffaloes, hippopotami, or rhinoceros, which fill the rooms. In all these, the size and character of the eye has been carefully reproduced, though no art could preserve 
the lustre and softness of the eye of the giraffe in life. While the Mahdi's power remains unbroken at Khartoum, there is little probability that the Soudan traders will be able to supply any to occupy the empty house in Regent's Park. Yet the southern range of these beautiful creatures, though it has greatly receded, still extends to the North Kalahari Desert, and to part of Khama's country, where the "camel-thorn," as the Boers call the giraffe-acacia, abounds. There the great chief carefully preserves the giraffes, and allows only his own people, or his own white friends, to kill them. The other point at which the giraffe country is still accessible to European hunters or naturalists is Somaliland, and the "unknown horn" of Africa. This district is so far accessible, that parties of English sportsmen yearly penetrate it from Berbera, making Aden their starting-point from British territory. But from the point of view of those who would delay as long as possible the extermination of the large game of Africa, the Dervish empire is not altogether matter for regret. No doubt the Arabs will still kill giraffes to make their shields from the hides, as they have done for centuries; but for the present the Soudan giraffes will be protected from raids like that in which those in the Kalahari Desert were destroyed in hundreds, because the price of "sjambok whips" had doubled. The Mahdi is, in fact, the involuntary protector of the wild animals of Central Africa, to which Sir Samuel Baker bore unconscious testimony when he lamented that, "owing to British interference 
in Egypt, where the 'courbatch' (hippopotamus whip) has been abolished, the hippopotamus will remain undisturbed on the great White Nile, monarch of the river upon which fifteen British steamers were flying when the Soudan was abandoned by the despotic order of Great Britain, and handed back to savagedom and wild beasts." 


\section{THE ELECTRIC EEL.}

IF the rational basis of legend and fable is worth exploring at all, we may well ask why the possession of electric power, the most strange, and until recently the most inexplicable, attribute of any of the inhabitants of the water, does not play a greater part in the marvellous narratives of ancient voyages? The remora, or sucking-fish, magnified a thousand times in imaginations excited by a world of strange and new experience, was the besetting foe of mariners in Northern waters. Clinging to the keel, it kept their barques for weeks in the mare pigrum, the sluggish sea of drifting ice. Whales, rising like sandbanks above the waves, tempted the weary crews to make fast to their treacherous bulk, and then plunged to the bottom, carrying with them both ships and sailors. Gigantic squids thrust their slimy arms down the hatchways, and plucked sleeping seamen from their berths and strangled them before their comrades' eyes. But the "torpedo"-the paralyzer-though as well-known then to the fishers of the Mediterranean as it is now known, under the name of the "cramp- 
fish," or electric ray, to the trawlers of Cornwall or the Channel, seems to have appealed less to the fancies of the sailors of old, than the new though less mysterious powers of the monsters, great and small, which rushed beneath their keels in hyperborean seas. Possibly the powers of the "torpedo" were too well known to excite curiosity, though it is difficult to believe that a creature which sometimes reaches a bulk of $100 \mathrm{lbs}$. weight, and can emit an electrical discharge strong enough to kill a duck, or to cause in the human arm a "creeping sensation felt in the whole limb up to the shoulder, accompanied by a violent trembling, and sharp pain in the elbow," followed by loss of sensation for an hour, was not as suggestive to sailors' fancies as the tentacles of the cuttle-fish, or the sucking-discs of the remora. But if the fabulous terrors of the last were enough to deter the boldest mariners who sailed beyond Thule, it is matter for congratulation that early explorers were unacquainted with the powers and proportions of a monster of still more formidable mould, the electric eel of Southern America. Its mere aspect is lurid, sombre, and repulsive. Its belly glows like red-hot iron, as if fresh from the lake of living fire. Its back is dark and shiny, as if tinged by inky Cocytus. Around its lips and jaws are glowing spots like bubbles of hot metal. The colours meet in a line along the side; and the creature, when drawn from the water, looks as though formed of two welded portions of iron, the one hot, the other cold, just 
plunged into the blacksmith's cistern. Small eyes, blue and bleared, are set in the top of a blunt ferocious head, from which the strong and muscular body tapers gradually to a point at the tail. Such, at least, is the appearance of the two electric eels at the Zoo, of whose power the writer, with curiosity stimulated by Baron Humboldt's unique description of these creatures in the inland pools of tropical America, recently made trial. Neither the size of the fish, nor their physical condition in the small tank in which they exist at present, could reasonably be expected to produce such results as the great traveller witnessed in the stagnant pools of the llanos of Caraccas, when the Indians drove a herd of horses into the water to face the electric discharges of the fish. "These yellowish livid eels," he writes, "resembling large aquatic snakes, swim near the surface of the water, and crowd under the bellies of the horses and mules. The struggle between animals of so different an organization affords a very interesting sight. The Indians, armed with harpoons and long slender reeds, closely surround the pool, and by their wild shouts and long reeds prevent the horses from coming to the bank. The eels seek to defend themselves by repeated discharges of their electric batteries, and for a long time it seems as if theirs would be the victory. Several horses sink under the violence of the invisible blows which they receive in the most vital parts, and, benumbed by the force and frequency of the shocks, disappear beneath the surface. Others, 
with name erect and haggard eyes, raise themselves and endeavour to escape, but are driven back by the Indians. Within five minutes a couple of horses are killed. The eel, which is five feet long, presses its body against the belly of the horse, and attacks at once the heart, the viscera, and the group of abdominal nerves. It is natural," the author adds, "that the effect which a horse experiences should be more powerful than that produced by the same fish on man, when it touches him only at one of the extremities. The horses are probably not killed, but stunned, and are drowned amid the confusion of the struggle between the other horses and eels."

The truth of Humboldt's account of the taking of the electric eels is sometimes doubted. But apart from the credit due to the deliberate utterances of one of the greatest minds of modern days, the accuracy of whose views, even when he put them forward as mere probable surmise, is being constantly verified by later experience, the powers of the creatures, even of the small specimen brought to this country, are so astonishing as to make Humboldt's account not err on the side of the marvellous.

It would be difficult, unless the opportunity existed of taking a plunge into a tank large enough to swim in, and well stocked with electric eels, to realize by personal experience the precise effect of the shocks upon the horses; but a record of the writer's sensations when in personal contact with these uncanny creatures may perhaps give some notion of the strength 
of their electric power. The largest of the pair in Regent's Park, about $4 \frac{1}{2} \mathrm{ft}$. in length, thick and deep, and probably weighing from 16 lbs. to i 8 lbs., was moving sluggishly on the bottom of the tank, and was slowly raised to the surface by a landing-net. As its side became visible, its resemblance to a "cooling cast" was even closer than when seen from above. When grasped in the middle of the back, there was just time to realize that it had none of the "lubricity" of the common eel, when the first shock passed up the arm with a "flicker" identical with that which a zig-zag flash of lightning leaves upon the eye, and, as it seemed, with equal speed. A second and third felt like a blow on the "funny-bone," and the hand and arm were involuntarily thrown back with a jerk which flung the water backwards on the pavement and over the keeper who was kindly assisting in the enterprise. This slight mishap recalled a far less agreeable result of a shock inflicted on a previous inquirer, whose recoiling hand had struck the assistant a severe blow in the face. Unwilling to be baffled by a fish less in size than the salmon which form the common stock of a fishmonger's window, the writer once more endeavoured to hold the eel at any cost of personal suffering. But the electric powers were too subtle and pervading to be denied. The first muscular quiver of the fish was resisted; but at the second, the sense of vibration set up became intolerable, and the enforced release was as rapid and uncontrollable as the first. The smaller eel was neither so vigorous nor so 
resentful as its fellow. But though the first and second shocks did not compel the grasp to relax, a third was equally intolerable with that given by the larger fish. The electrical power seems to increase rapidly in the heavier eels. One of $5 \mathrm{ft}$. in length, which appeared to be nearly dead when it arrived at the Gardens, and was therefore handled without ceremony, inflicted a shock which, as the keeper stated, "nearly sent him on his back;" and the same fish, when being carried by hand in a tub up to the rooms of the Royal Society, sent a shock through the water which nearly caused the downfall of fish and bucket alike. This power of projecting its electric discharge, either through the water or by means of any conductor, to the object which it desires to paralyze, may be well observed at the Zoo. The usual way in which the shocks are received is by grasping a copper-rod, which is placed in contact with the fish's back. But. it is when in pursuit of the small fish which form its food that the "range" of the eel's battery is best seen. On the last occasion on which the writer was present at the eel's feeding-hour, eight or ten lively gudgeon were taken from a pail, and placed in the eel's tank. The small fish at once dived to the bottom, as is their habit, and sought refuge in the corners, or at the angle made by the meeting of the base and sides of the stone cistern. Every one of the fish was killed by electric shock before being eaten; but in the case of those in the corners, it was impossible for the fish to bring the 
electric organ, which lies on each side of the lower part of the tail, into direct contact. The eel, therefore, swam past them, like a torpedo-boat which intends to discharge its broadside torpedoes, and as the battery came opposite, the fish gave a slight quiver, which instantaneously produced a violent shock in the gudgeon, and turned it belly upwards. After three had been killed and eaten, the shocks became weaker, and the other gudgeon seemed only partly paralyzed by the first shock, and sometimes recovered and swam away in a crippled condition until benumbed by a second shock. One fish which was "shocked" and left for dead while the eel went in pursuit of more, recovered after a few minutes, and was subsequently pursued, received a direct shock from the eel's side, and was killed. The inference suggested by the writer's own experience of the violence of the shocks inflicted, though with different degrees of intensity, is that the eel controls the power of the electrical discharge at will, just as it controls any other function which has its initiative in muscular action; and that the gudgeons received enough, and no more, than was sufficient to paralyze them, and make them easy victims for the slow-moving eel. 


\section{DEEP-SEA LAMPS.}

The possibility of exhibiting the powers of electrical fishes in the tanks at the Zoo, suggests the question whether, in the progress of marine aquariums, we shall ever see the luminous creatures of the deep seas exhibited alive before air-breathing mortals in this upper world. Virgil's Sybil set the depth of Tartarus at twice the skyward gaze to the summit of Olympus. But the profundity of the ocean abyss is such that in the deep Atlantic Olympus might be imposed upon itself, and Ossa piled above, without rising to break the surface. The imagination almost refuses to grasp the physical conditions in an abyss so profound as the ocean bed off the coast of Porto Rico, wrapped, by a weight of waters five miles deep, in perpetual darkness and everlasting cold, and under a pressure of which figures can convey no practical conception. Even at the average depth of 2,500 fathoms sunlight can never penetrate. The temperature is only a few degrees above freezing-point, the water is without movement, there is no plant-life, and the pressure is two and a half tons on the square inch, or about twenty-five 
times greater than that which drives a railway train. Yet it is now certain that where the fancy painted a survival of the sterile and lifeless plains of an unformed world, or at most the rude survivals of primitive fossils, the bed of the deep sea teems with animal life, and the clinging darkness of its waters is peopled by myriads of fragile and fantastic forms, and lighted into a blaze by the effulgence from their bodies. Hard as it is to conceive the bare existence of life under the conditions of the ocean abyss, the mind pauses in astonishment at the completeness of the triumph by which creatures apparently doomed to live in eternal night are supplied not with mere slimy secretions of luminosity, but with rows of bright and ever-burning lamps, in organs fitted with lenses and reflectors, which shoot their beams sidelong through the circumfluent ocean, or project shafts of light before their eyes to illuminate their path.

The results of recent deep-sea exploration have been summarized by Mr. Sydney J. Hickson, Fellow of Downing College, Cambridge, in a short work on 'The Fauna of the Deep Sea, published in the "Modern Science Series." 1 Though the bulk and specialized character of the reports of separate expeditions organized by the English, French, German, Italian, and Norwegian governments, makes such a task one of no ordinary difficulty, Mr. Hickson has succeeded in his wish to "give in a small compass the more

1 The Fauna of the Deep Sea, by Sydney J. Hickson, M.A., D.Sc. London: Kegan Paul and Co. 
important facts of this great mass of literature in such a form as may interest those who do not possess a specialist's knowledge." The main conclusions are clearly presented with examples and excellent illustrations, in number sufficient to convince without bewildering. On one point we could desire a little more information. There is no suggestion of the means by which creatures differing so little in bodily frame and tissue from the shallow-water species, from which they are apparently derived by migration into the deeps, support the enormous pressure in their present home. Some explanation seems to be required, though an incident in the recent erection of the Forth Bridge seems to suggest that the modification of tissue to endure high pressure may be acquired more rapidly than is supposed. The men employed in the steel shells or caissons sunk to form the foundations of the piers, worked in a pressure of air rather greater than the pressure of the water outside, which would otherwise have penetrated between the rims of the caissons and the ground. On those days on which they were not employed, and came to the surface, they felt such pain in the joints from the expansion of the air, which had been absorbed at high pressure, that they begged to be allowed to go down into the caissons and spend their off hours in the pressure to which they had grown accustomed. This instance of partial migration into conditions of high pressure, seems worthy of a place among the facts of deep-sea exploration. Yet it must remain among the strangest 
features of life in the ocean abyss, that its inhabitants show so little visible change of structure to meet what seems the first and most overwhelming change of physical conditions. The angler-fish and eels, crabs and prawns, star-fish and zoophytes of the shallow waters are represented in the abyss by forms almost similar in structure, though that some difference must exist is shown by the fact that when brought up by the dredge from the depths of the ocean they are killed and distorted by the diminution and disappearance of the vast pressure in which they habitually live. "The fish which live at these enormous depths," writes Mr. Hickson, "are liable to a curious form of accident. If, in chasing their prey, or for any other reason, they rise to a considerable distance above the floor of the ocean, the gases of their swimming-bladder become greatly expanded, and their specific gravity reduced. If the muscles are not strong enough to drive the body downwards, the fish, becoming more and more distended as it goes, is gradually killed on its long and involuntary journey to the surface of the sea. The deep-sea fish, then, are exposed to a danger that no other animals in this world are subject tonamely, that of tumbling upwards."

But however obscure the structure which enables the deep-sea creatures to withstand the pressure of the waters, the means by which they combat the plague of darkness is evident and astounding. It is well known that the number of phosphorescent animals, even in shallow tropical seas, is such that they can 
illuminate not only the waters, but the air, to a considerable distance. Sir Wyville Thompson states, that near the Cape Verde Islands he saw the sea in such a blaze of phosphorescence that, though there was no moon, "it was easy to read the smallest print, sitting at the after-port in the cabin; while the bows shed, on either side, rapidly widening wedges of radiance, so vivid as to throw the sails and riggings into distinct lights and shadows." But, great as is the number of luminous creatures in the shallow waters, the percentage among those dredged from the deeps is greater, though their brilliant glow, when lying upon the decks of the exploring ships, is no guide to the possible intensity of their light in the pressure under which they live. Many of the deepsea species possess light-projecting organs in numbers and perfection unrivalled by the shallow-water forms. Some of the fish have double rows of tiny lamps running the whole length of their bodies, like the rows of port-holes in an ocean steamer's sides. These are supplemented by other sets of less clearly divided light-organs, arranged in clusters and groups of fifty or a hundred. Other deep-sea fishes have bull's-eye lanterns set beneath their eyes, projecting their light "full-a-head." Sections cut through these extraordinary organs show that above the phosphorusburning vessel lies first a layer of "reflectors," and lastly, a lens for concentrating the beams. Perhaps the strangest development of this power of illumination is in an angler-fish, found at a depth of 14,700 
feet. Like the other "anglers," it has a huge mouth armed with long uneven teeth, and a pendent "fishingrod" tentacle which attracts other fish like a bait. In the shallow-water "anglers" this tentacle resembles something edible by fish. In the deep-water species it is fitted with an organ which is supposed to be a phosphorus lamp, and to play the part of a "Will-o'the-Wisp" in attracting little fishes to the angler's jaws.

The phosphorescent power is by no means confined to the fishes proper of the deep sea. Starfish and most of the various forms of zoophytes possess it, though in less perfect organs. One poured out "clouds of a pale-blue, highly luminous substance, which not only illuminated the observer's hands and surrounding objects in the vessel in which it was confined, but finally communicated a luminosity to the water itself;" another threw out light of a brilliant green, coruscating from the centre, now along one arm, now along another. In view of the phosphorescence even of the surface of the sea when full of luminous creatures, it is not rash to conclude that the eternal night of the abyss is in places lighted with sufficient brilliance by its phosphorescent zoophytes and fishes. Where these are few or absent, there must be darkness either partial or complete. Hence we are presented with the perfectly reconcilable contradiction of deep-sea creatures with eyes of high development, and others with no eyes at all; one species possessing eyes with four thousand facets, 
while crabs and prawns are found totally blind, like the fish of subterranean caverns. Those which carry lamps themselves, or live among luminous creatures, not only retain their eyes, but are supplied with organs of abnormal power in order to use to the utmost the phosphorous beams. The presence of bright colouring in the deep-sea forms is also explained in the same way, so far as colour is related to the presence of light. There is little difference in the hues of deep-sea and shallow-water species, except that shades of red are more frequent in the former, possibly because red is the complementary colour of the phosphorescent beams.

It is in the leading facts which make such minor developments possible that the wonder and significance of these discoveries lie,-in the defiance of such physical obstacles as are set to life by enormous pressure, and in the artificial lighting of the abysmal darkness by the invading creatures. Sir Richard Owen once suggested an extension of the limits of terrestrial life, by pointing out that the light of the planet Jupiter was suited to the form of the vertebrate eye. When the mind which has once grasped the physical conditions of the ocean abyss, is confronted with the triumph of living creatures over such surroundings, it no longer lies with it to reject as impossible the surmise that life, which so transcends the limits set by ordinary experience to its scope on earth, may also extend to the planets. 


\section{THE LION HOUSE AT THE ZOO.}

["Hic habitat leones."-Old Map of Central Africa.]

Just fifty years ago, when the best means of keeping wild animals in health and vigour when confined was still matter for experiment, an interesting set of statistics of the length of life of the large felidae in the Gardens was submitted to the Society by Mr. Rees. It appeared from the records of the menagerie that lions, leopards, tigers, and pumas only lived, on an average, for two years in the Gardens, which gave a rate of mortality of about one per month. The value of lions and tigers was then about $\mathscr{E}_{\mathrm{I} 5} \mathrm{O}$ each, and of leopards and pumas $\mathscr{E}_{\mathrm{I} 5}$.

The system which led to this great mortality was one of confinement in small stuffy cages, in a room artificially heated throughout the year, and much was hoped from a complete change of treatment which had just begun.

The new principle was one of "free exposure to the outer air, with no artificial heat whatever," and the range of dens now known as the "Terrace," on 


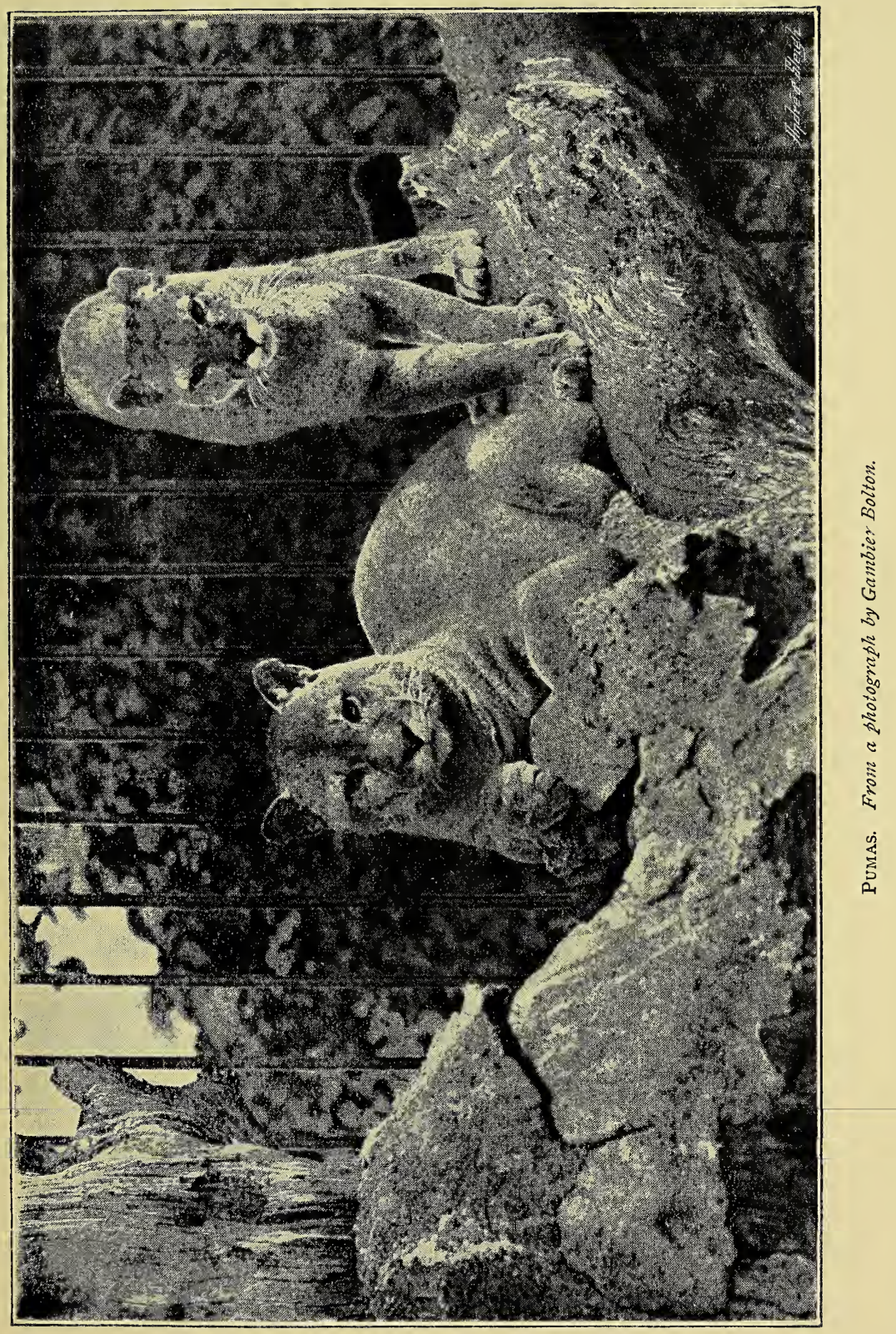



either side of which the bears are kept, was built for the accommodation of the lions and tigers. The cages do not strike us as particularly roomy or comfortable now, but at that time they were looked upon as unusually spacious, and the unfortunate carnivora, which had been boxed up in stuffy rooms and narrow cages, soon felt the benefit of the change. The African leopards, which were emaciated and sickly before their removal, became plump and sleek in a fortnight, and the appetite of all materially increased. The most convincing proof of this gratifying change was that a tigress, feeling hungry in the night, killed a tiger, and a puma did the same, and partly devoured its mate. The Society took the hint, and increased their rations, and for some time the new method of lionculture answered well.

The rough-and-ready expedient of exposing the great cats to all the changes of an English climate had a greater measure of success than might have been expected. One is apt to forget that though the tropics are the main home of the tiger and the leopard, both wander far into the northern mountains, and that the former, if brought originally from Turkestan or China, can stand an English winter as well as the Chinese monkeys. During the year after the removal of the animals to their new house there was not a single death, and the system promised so well that artificial heat was for a time discontinued, both in the Monkey House and the Giraffe House, except that given by open fires. That the health of all the 
animals improved is shown by the list of creatures which lived in the Gardens, including brown and black bears, leopards, and ocelots.

The present Lion House, with its fine outdoor summer palaces, and its indoor winter cages, in a house warmed with hot water, is a combination of the two previous systems, and so far as health goes it seems to leave nothing to be desired. The Zoo of the future will probably contain lion houses of vast size, in which the creatures are allowed to live together in large numbers. This is the system adopted by the largest owner of wild animals in the world, $\mathrm{Mr}$. Carl Hagenbeck, of Hamburg and New York. In his gardens at Hamburg, six lions, two Bengal tigers, and one from Siberia, live harmoniously in society with a polar bear, a Thibetan bear, and a number of leopards. The chance of a battle royal at meal time seems too great to be risked; but Mr. Hagenbeck says, that provided the animals are associated when quite young, and that each addition to the family is a young one, there is no danger. Meantime the space and freedom of the great cages, and the absence of that ennui to which animals are subject when confined separately, or even in pairs, have the best effect on their growth and vivacity. In the Hamburg cage the polar bear will play and romp with the tigers for hours, and most wonderful exhibitions of strength may be seen daily in these wrestling matches between such gigantic and dissimilar creatures.

Mr. Hagenbeck is the Moltke of the wild animal 
trade. His menagerie at Chicago attracted more visitors even than the "gigantic wheel," mainly because the creatures had more liberty and more space than they enjoy in any other "gardens"; and it is probable that he will effect a marked change in the modes of animal exhibitions now in use.

Meantime, whether in summer or winter, the Lion House is perhaps better worth seeing than any branch of the Society's menagerie.

Few public characters are "at home" to visitors during so many hours of the day as its inmates; who might with justice enter a protest against the incivility of the public, which insists on taking the notice that "The lions will be fed at three o'clock," as a pressing invitation to be spectators of their manners at mealtimes. Yet the economy of the Lion House so far differs from the ordinary life of the other inmates of the Zoo that, for an undiscerning public which wants excitement and has no time for observation, there is every inducement to confine its visits to a particular hour. The cattle-sheds, the Antelope House, the Monkey Palace, or the Aviaries, present much the same appearance at any time of the day. The pleasant round of comfort-eating, drinking, playing, or sleeping-goes on without variety or long cessation. But the life of the great carnivora is ordered differently, and with greater exactness. In the morning, in the Lion House, all is quiet. The animals are resting or sleeping, and the only visitors are artists or photographers, whom the lions "oblige" with a sitting at 
a cheaper rate than any professional models in the trade. We wonder in how many characters the old Nubian lion, "Prince," appeared? He has striven with Hercules, carried Una, been vanquished by Samson, and shot by Nimrod. He has roared at Daniel, and eaten martyrs innumerable; and he still lives on canvas to entertain Androcles in his den, or dies, the last of his race, in the desert cavern of some artist's fancy.

"Ars longa, vita brevis," is, perhaps, a saying which would appeal to the hungry lions equally with the artistic visitors to the $Z_{00}$, as feeding-time approaches. At two o'clock p.m., the animals awake, stretch themselves, and yawn, showing the width of their enormous jaws, and rows of gleaming teeth. The public grows interested, and the artists desponding. Even the little lad in knickerbockers, the work on whose easel suggests the story of Michael Angelo's first essay in sculpture, drops his brushes and runs to the steps at the back to watch his sitters in action. Then follows the mauvais quart d'heure before dinner,-in this case unduly protracted. All the beautiful lithe creatures, pacing ceaselessly to and fro, noiseless as ghosts, seem to be performing a kind of "grand chain," which becomes faster and faster as their impatience and hunger increase, As the howling of the wolves in their distant cages is heard by the lions, excitement breaks beyond control, and the roars of the hungry beasts only cease as the truck of food is emptied. As a spectacle, the sight has a certain interest. But 
except for those whose imagination can picture no other side of animal life in daily contact with man, it is, perhaps, the worst moment to select in order to appreciate the real character of those most friendly beasts, the lions and tigers at the Zoo. In the early morning hours, when their "sitting-rooms" have been duly swept and strewn with fresh sawdust, and their toilet -which is always completed in their sleeping-chambers - is finished, the iron doors are opened, and the owners of the different cages come leisurely out to greet the day, each in its humour as the night's sleep or natural temper dictates.

On the last occasion on which the writer waited on the tigers' levee, it was evident that some disagreement had marked the morning hours. The tigress from Hyderabad came out with a rush, and greeted the world with a most forbidding growl. She then stood erect, like a disturbed cat, switching her tail to and fro, and after examining every corner of the cage, summoned her mate with a discontented roar. The tiger then stalked out, and endeavoured to soothe his partner with some commonplace caress, which apparently soothed her ruffled nerves, for after sharpening her claws upon the floor, she lay down, and, rolling over on her back, with paws folded on her breast, and mouth half-open, went most contentedly to sleep. The pair of tiger-cubs in the next cage were still sleeping the long sleep of youth, one making a pillow of the other's shoulder. Tigers, it may be observed, do not sleep like cats, but resemble in all their attitudes 
of repose the luxurious languor of some petted housedog, constantly rolling over on their backs, and sticking up their paws, with heads upon one side, and eyes half-opened. This pair of cubs was presented by the Maharanee of Odeypore in 1892 . Both cubs, when called by the keeper, can be stroked and petted like cats. But no tiger which has yet lived in Regent's Park has been so completely tamed as the fine northern tiger "Warsaw" from Turkestan, which died last winter, after living in the Zoo since 1886 . Taking into account the hardships endured by a wild animal in its transport from the distant steppes of Central Asia, across the Caspian Sea, thence by rail to the Euxine, and finally by ship to England, it is difficult to maintain the belief in the "innate ferocity" of the tiger after making the acquaintance of "Warsaw."

The way in which this tiger found its way to the Zoo is typical of the unexpected means by which the menagerie is supplied with rare animals. Colonel Stafford, who had been engaged on the Afghan Boundary Commission in 1885 , was returning by land through Central Asia, when he found the tiger, in a little cage, waiting at the terminus on the eastern side of the Caspian, and destined for some scientific gentleman at Warsaw. As the northern tiger was almost unknown in England, and there seemed some delay in the arrival of the purchase-money, Colonel Stafford bought it for the Indian Government, who approved of his investment, and presented it to the Zoological Society. To get the tiger by the Russian Central 
Asian railway to the Black Sea, and thence to England, was no easy matter. In the first place, the railway officials objected that tigers were not scheduled in their bill of charges, and unlike the English station-master, who held that cats is dogs, and rabbits is dogs, and parrots is dogs, maintained that tigers were tigers, and ought to be paid for at exceptional rates, including, of course, a bribe to the officials. This view being disputed by the tiger's owner, it remained at the station, where, being not only quite tame, but an adept at small tricks, it became a general favourite. Its great performance was that of raising a basin of water and pouring it over its head; and this accomplishment, displayed before the daughter of the superintendent of the line, ultimately secured the tiger a passage to the sea. At Poti it was shipped for Constantinople, being supplied with a small flock of sheep as food in case the voyage was protracted. The animal remembered and recognized his first purchaser long after it had found a resting-place at the Zoo, though not at so long an interval as that after which the lion in the Tower showed its affection for its old keeper. This lion, which a certain Mr. Archer, employed at the Court of Morocco, "had brought up like a puppy-dog, having it to lie on his bed, until he grew as great as a mastiff, and no dog could be more gentle to those he knew," was sent to the Tower, where, after an interval of seven years, he recognized one John Bull, a servant of his master, who, according to Captain John Smith, "went with divers of his friends to see the lions, not knowing 
that his old friend was there. Yet this rare beast smelt him before he saw him, whining, groaning, and tumbling with such an expression of acquaintance, that, being informed by the keepers how he came, Bull so prevailed that the keepers opened the grate, and Bull went in. But no dog could fawn more on his master than the lion on him, licking his feet and hands, and tumbling to and fro, to the wonder of all the beholders. Bull was quite satisfied with this recognition, and managed to get out of the grate; but when the lion saw his friend gone, no beast, by bellowing, roaring, scratching, and howling, could express more rage and sorrow; neither would he either eat or drink for four whole days afterwards." "Warsaw's" affections were not put to so severe a test; but his forbearance may be judged from the fact that he would allow his paws to be pulled out between the bars, and his toes to be examined, to see whether his nails wanted cutting.

This amiability is very difficult to explain, unless on the ground that the tiger was captured when very young, though many cubs are ferocious when only a few months old. Another northern tiger, from Chind, which came as a half-grown specimen to the Gardens three years ago, was as tame as "Warsaw," though it had suffered much in captivity, and died before attaining its full size. It was starved in China, and never recovered this early ill-usage, its brief life being a succession of illnesses; but its temper was never soured, and it was far more demonstratively affec- 
tionate than any cat. For some months it was kept in invalid quarters at the back of the house, and its loud "purrs" could be heard at the end of the passage the moment its keepers entered. It ran up and down its cage, rubbing against the bars, with its tail standing stiffly up, and delighted to have its head and ears rubbed and patted. Sutton, and the keepers more especially concerned with the Lion House, took all possible care of it, and after nursing it through an illness in which it lost all its fur, they succeeded in bringing it into condition to be shown. But the tiger soon became sick again, and after a long illness, in which it was kept alive mainly by the care and affection of the keepers, it died, much lamented.

Tameness is by no means confined to the northern species of tiger. "Jack," an Indian tiger, which died in the same year as "Warsaw," was quite as friendly to its keepers, and surpassed him in beauty. For some time it shared with the Sokoto lion the place of honour as the finest creature in the Gardens. When it arrived, in $\mathrm{I} 888$, as a five-months-old cub, it was led by a chain and collar like a big dog, and was for some time taken to and from its cage by the keepers with no other precaution, until its reluctance to be shut up when it preferred to walk at large, and the difficulty of "coercing" so large an animal, led to its permanent incarceration. "Jack" was the tiger which, in the experiments with different musical instruments subsequently described, displayed so marked an objection to the sounds of the piccolo. 
In spite of the deaths of the three tigers, of "Duke," the old lion, and of a jaguar and puma, the years I892-I894 have seen an increase in the numbers of the inmates of the Lion House greater than at any period since the return of the Prince of Wales from his Indian visit, and the collection of so many fine young animals gives a good idea of the difference in "points" and form in creatures of the same species. There is as much difference in lions as in horses or in dogs of the same breed, and they are by no means uniformly noble or impressive to look upon. Some are "down at heel," some narrow-chested, others have Roman noses, a very ugly feature in a lion; some, on the other hand, are all that a lion should be.

By far the finest pair in the Gardens are the lion presented to the Queen by the Sultan of Sokoto, and the pale lioness bred in the Amsterdam Zoological Gardens. Those in the "fancy" say, that if the Sokoto lion had a black mane it would be the finest in Europe, except that in the Clifton Zoological Gardens. Its coat and mane are the colour of red gold-dust, its head twice the size of that of the lioness, its eyes a clear brown, and its gaze steady and tranquil. Its body is compact, its limbs straight, and its attitudes unconsciously striking and magnificent. The lioness is a very pale fawn, almost cream colour, and the damask spots of cub-hood were still visible on her legs and feet when she was three years old. In temper she is as savage and ferocious as her partner is gentle. 


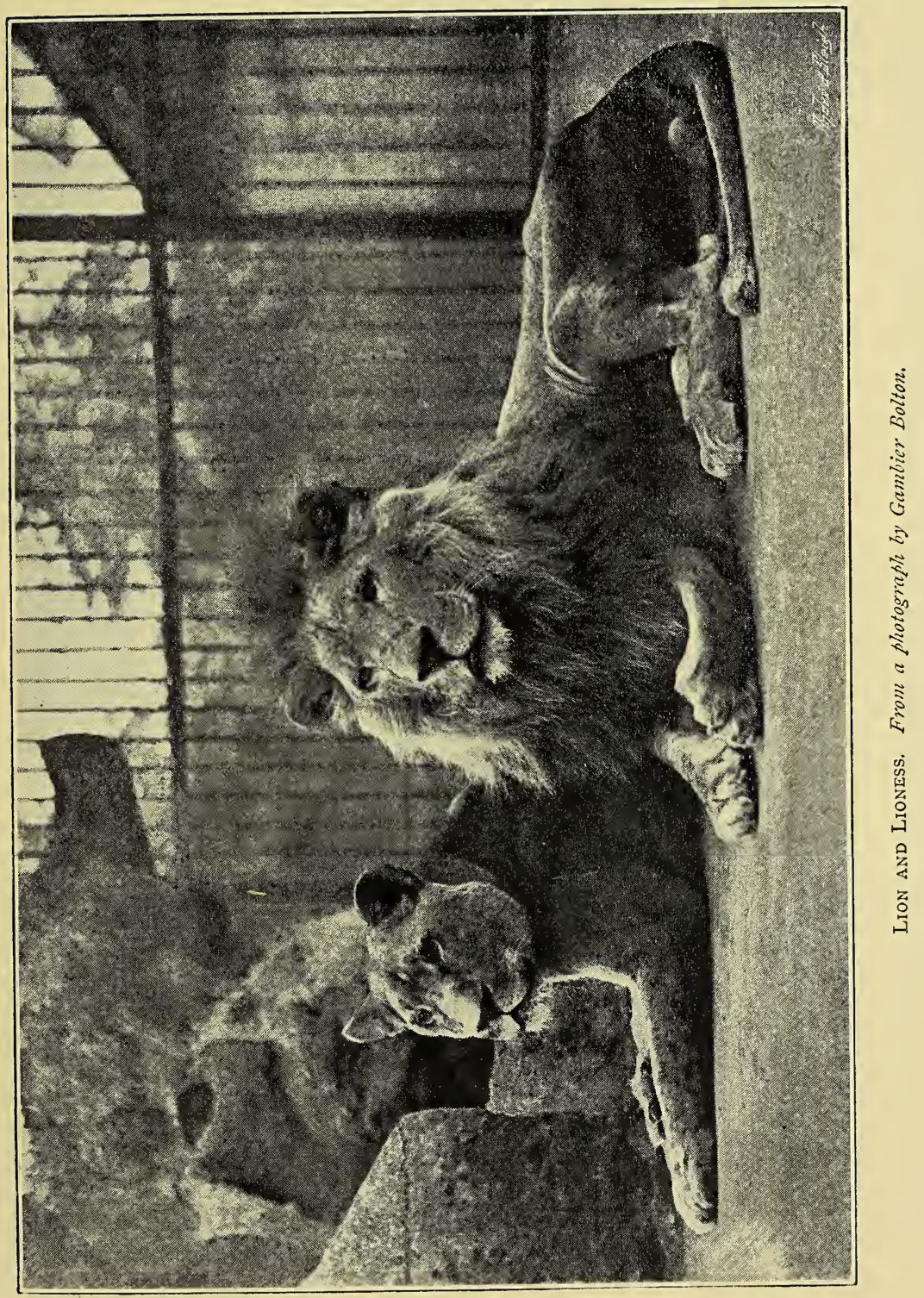



As far as points go she is almost perfect, with a long straight back, round black-tipped ears, short strong legs, square head, flat forehead, rounded, cushioned feet, and a chest like a bull-dog's.

The only other creature which is equally ferocious is a very old tigress, called "Minnie." The writer has seen her "stalk" a keeper, when his back was turned, and there is little doubt that the scene was an exact reproduction of what takes place in an Indian jungle. She crouched down on the floor of the den, her body gradually flattening out until she seemed all head. The jaw was flat on the ground, and the tail also, with only the tip moving, and the profile of the head seemed flattened as well as the body. Thus she remained for a minute or more, the only movement besides that in the tip of the tail being the rush of dust upon the floor, as a blast of growls sent the sawdust flying which strewed the planks. This was followed by the spring, which was of course interrupted by the bars. But the whole performance was an instructive lesson in tiger tactics.

Over-feeding in youth is almost as bad for the future health of a tiger or lion as starvation. In I 893 three very fine tiger cubs, about five months old, arrived as a present to the Princess Henry of Battenberg from an Indian prince. They had been so lavishly fed on mutton during the voyage, that they were immensely fat and heavy when they reached the Gardens. A few months later they all developed weakness in the hind-quarters, and though they may 
in time recover, the effects of over-stimulating food taken too early are very noticeable. ${ }^{1}$

In the last cage of the house, at the eastern end, took place the celebrated fight in November I 879, between a tiger and a tigress, which resulted in the death of the latter. An account of this scene, derived from Sutton the keeper's description of what took place, is almost the last thing written by Frank Buckland, who himself died in the December of the next year. The description of the fight as it appears in the collection of Notes and Jottings from Animal Life, selected and arranged by Buckland shortly before his death, and edited by Mr. G. C. Bompas in 1882 , agrees very closely with the description given verbally by Sutton himself. But the most curious point in Buckland's account is, that he apparently forgot that the tigress died from her wounds, though he himself paid his last visit to the Lion House in order to see the suffering animal. The tigress began the quarrel by sticking one of her claws through the tiger's nostril. The male tiger immediately pulled back his head with a jerk, and the claw cut its way through the nose, causing great pain and bleeding. The only people in the house at this time-Sunday morning-were Sutton the keeper and a Frenchman, and the two tigers at once joined battle with very little chance of interference by outsiders. The male used his feet, and throwing the female down, gave her several heavy blows and scratches, and then, having asserted its power,

$$
1 \text { One has since died. }
$$


gave up the combat. The tigress got up, followed him, and bit him in the thigh. This made the tiger furious. He rushed at the other, and bit her through and through the neck, while the most fearful growls and screams came from both. This set a lion (Duke) and lioness fighting at the opposite end of the house, while the Frenchman, shouting and gesticulating, rushed up and down, and further excited the animals. Sutton quieted the lions, and then managed to drive the tiger off his victim. The moment he let go his hold the blood spouted from the tigress's throat up to the roof, and she fell down apparently dying, while the tiger was driven into one of the sleeping compartments. The tigress was also moved into a room at the back. Buckland in his short account says, that "though of course her nerves were considerably shaken, she was soon all right again." As a matter of fact, she died ten days later, having been unable to swallow food during that time, and being dreadfully exhausted from her wounds. The strangest thing in connection with this encounter and Buckland's note is, that his visit to see the wounded tigress was his own last day in the Lion House. He was anxious to do what he could for the creature, and volunteered a visit, though so ill himself that he had to be pushed into the passage between the dens and the outdoor runs in a bath-chair. But his nerves were so shaken by illness, that when the iron shutter was about to be opened which led into the tigress's sick chamber, he begged that it might be kept closed; and 
though assured that the animal could not move, he would not see it or have the door unclosed. A year later he himself was dead, by no one more regretted than by the keepers of the $\mathrm{Zoo}$.

The paragon of the Lion House at the present moment is the snow leopard. It is a most lovely creature, and deserves all the praises lavished on it. It is exactly like a grey but spotted Angora cat, six feet long from its pink nose to the tip of its bushy tail, and of an exquisite pearly tint, just dashed and spotted with black. Its eyes, liquid and large, with swimming black pupils, are the colour of a greenishgrey aqua-marine, and its expression as gentle as its ways. It was a lady's pet in India, and still remains the same gentle, aristocratic, languid creature that it was when the favourite of the "Mem Sahib's" drawingroom. Its neighbour, the pure black leopard from Singapore, sent to England by the Duke of Newcastle, is a strange contrast in colour and character. It is so ferocious, that when let loose in the cage it sprang at the bars with such force as to bulge the steel netting with which they had been covered, by the mere shock of contact with its head. It sulks day and night, and is no more admirable in appearance than a morose and gigantic black tom-cat. 


\section{DIVING BIRDS AT THE ZOO.}

Submarine boats, according to the naval architects, would be the fastest in the world, if only their crews could work them. This seems a hard saying; but the fact can be proved by theory, and seen at work in nature. On the surface most of the work done goes to form waves. Below, no waves are made, as, for example, when salmon are travelling up a stream. There remains, of course, some resistance to the submerged boat or bird, but so much less than on the surface, that, given the same driving power, the speeds below water are thrice or four times greater than above, the evidence of which proposition may be seen either in Mr. Froude's experimental basin, near Fort Gilkicker at Stokes Bay, or any morning at I 2 o'clock in the glass tank in the Fish House at the Zoo, when the diving birds are fed.

Unlike the submarine boats, all of which are more or less alike, the submarine birds show the most obvious and extreme differences of design, both in body and propelling machinery. Yet they all get their living in exactly the same way, by chasing and 
catching fish in deep water far below the surface. Cormorants, for instance, have been taken in crab-pots set at a depth of $\mathrm{I} 20$ feet; penguins are found miles out at sea, though they generally return to the "rookery" at night; and puffins and guillemots also fish during the whole of the hours of daylight away from the coast, in deep water. The "darters" are inhabitants of American and African lakes. At the present time there is an unusually large collection of all these species in the Zoological Gardens. The most amusing and probably the best performers under water are the small black-footed penguins. These have for neighbours a young puffin, a couple of pairs of guillemots, and a rare and beautiful cormorant, in shape like the English bird, but with a white breast and large sapphire-blue eyes; opposite these live a pair of "darters." Except the puffin, none of these birds in the least resemble the penguins, which, as a glance shows, are strangely altered from the usual bird shape for some particular purpose. The penguin has a large, round, intelligent head, a deep, boat-shaped bill, and short neck. It cannot fly-in the air-it cannot walk, but hops as if its feet were tied together; it cannot even swim. Submarine flight is its only form of motion-it is a winged seal. The darters, on the other hand, have long, snake-like necks, beaks like a wooden spit, heads only large enough to support the bill and to bold a pair of eyes, no brains to speak of, long, narrow, sparsely-feathered wings and tail, and strong webbed feet. As they 
stand, with wings spread out to dry, and the light shining through the pink skin and membranes, their descent from some very early form of bird suggests itself at once, though the anatomists forbid us to jump to the conclusion that the darters are saurianbirds as the penguins are seal-birds.

The submarine flight of the penguin is perhaps the most beautiful form of animal movement known; certainly it is the most beautiful which we can see and admire with our own eyes. The motions of flight in the air, though now analyzed and laid before us in the exquisite drawings of $\mathrm{M}$. Marey, must always remain something which must be taken on faith; transcripts made by other eyes than ours, records of the camera and the sun. The true movements of flight, so made familiar to our brain, may in part be detected afterwards by the naked eye. Yet the speed and direction of birds' flight in air, and the necessary distance between them and ourselves, which every beat makes greater, must always leave it something of a mystery. But the change of medium from air to water gives an added charm to flight. The substitution of aqueous for aërial poise detracts nothing from the wonderful powers of the wing. But it adds two conditions. In the first place, the whole scene is directly cognizable by our senses. All the wonderful phenomena of flight can be watched from a distance of a few feet, or even inches, from the eye. The simile of the caged butterfly does not apply to the diving bird in its tank, which exhibits its powers, pursuing its prey 
up and down in this space of a few feet as well as it could in the open ocean. In the next, the water does for the diving bird what it does for all its true children, be they birds or fish or plants or flowers; it adds a lustre and beauty, a something of "seachange," whose effects not even sunlight can surpass. The plumage of the birds undergoes a transmutation in the "waves' intenser day," which seems to fit them for everlasting flight in the palaces and grottos of the sea-nymphs, across which they fly, bearing bubbles of sunlight from above, scattering them through their chambers like crystal globes of fire. Those who have seen Sir E. Burne Jones' painting of the mermaid, In the Depths of the Sea, will guess the means by which this glimpse of the water world was made possible, and realize in part the effect which the beauties so disclosed produce upon the senses, from the use which the gifted artist made of them in this, one of the few successful efforts made to paint a submarine scene.

The greater part of the end of the Fish House is crossed by a large reservoir, some five feet deep and ten wide, with a glass front. The light strikes upon it from above, and for all purposes of vision the spectator might be standing on the sea-floor, and looking along the vista which is level with his eye. Every movement of the birds can be seen and noted from the moment of their first plunge till their exit up the sloping board which leads to their cages. Like most other animals at the Zoo, these birds are 
only fed once a day, and the appearance of the keeper with his pail of live gudgeon is the signal for sudden and intense excitement in the cages. The penguins wave their little flippers and waddle to the doo: whence they peer eagerly down the wooden steps leading to the pool; the cormorant croaks and sways from side to side, and the darters poise their snaky heads and spread their bat-like wings. At the water's edge the penguins do not launch themselves upon the surface like other water-fowl, but instantly plunge beneath. Once below water an astonishing change takes place. The slow, ungainly bird is transformed into a swift and brilliant creature, beaded with globules of quicksilver where the air clings to the close feathers, and flying through the clear and waveless depths with arrowy speed, and powers of turning far greater than in any known form of aërial flight. The rapid and steady strokes of the wings are exactly similar to those of the air birds, whilst its feet float straight out level with the body, unused for propulsion, or even as rudders, and as little needed in its progress as those of a wild duck on the wing. The twists and turns necessary to follow the active little fish are made wholly by the strokes of one wing and the cessation of movement in the other; and the fish are chased, caught, and swallowed without the slightest relaxation of speed, in a submarine flight which is quite as rapid as that of most birds which take their prey in mid-air. In less than two minutes some thirty gudgeon are caught and swallowed below water, 
the only appearance of the birds on the surface being made by one or two bounds from the depths, when the head and shoulders leap above the surface for a second and then disappear. Any attempt to remain on the surface leads to ludicrous splashing and confusion-for the submarine bird cannot float, it can only fly below the surface. Immediately the meal is finished, both penguins scramble out of the water, and shuffle with round backs and drooping wings back to their cage to dry and digest.

The guillemots and puffins are some of the commonest of English sea-fowl, and the last, with its short thick neck, large beak, and upright attitudes on land, is perhaps the nearest relative to the penguin among British birds, with the exception of the little auk. Like the penguins they fly below water, though, unlike them, they can also fly in the air, the puffin being almost the only English sea-fowl which is a true bird of passage, and yearly leaves the cliffs and islands where it breeds along our coasts, to spend the winter in the Mediterranean. The young puffin at the Zoo refuses to dive for fish at present, and only takes to the water when chased by its keeper. The guillemot is a far more graceful bird. Dark above and white below, with a long, slender, and curved beak, it combines the submarine powers of the penguin with the buoyant gracefulness of a water-hen when floating on the surface. Below water its movements are far more deliberate than those of the penguin. Like the water-hen, it can use its wings for aërial or aquatic 
flight indifferently, but the feet are also used in turning, and the wing-strokes are more sustained, regular, and slower than in the case of the true "seal-birds." As an "all-round performer," the guillemot is perhaps the best in the Zoological Society's collection, and with the whole of the upper plumage, head and neck, converted by a "sea-change" into what appears a clinging mantle of quicksilver, it is certainly the most beautiful in its favourite element. The "air-jacket" which the guillemot carries with it after each dive, and which, gradually vanishing in the water, is renewed after its rise to the surface to breathe or swim, probably plays a useful part in its submarine flights. It lessens the surface friction of the water, and, like the air below the "skimming-dish" boat, which some inventors look upon as the probable means of obtaining the next considerable rise of speed on the surface, is the simplest and most natural of all lubricants between the bird and the water.

The other birds in the cages are perhaps more truly classed as divers than the penguins and their relations. They plunge and swim, using their wings for aërial flight only.

Those who watch the cormorant's diving feats are usually so interested in the fortunes of the chase as the handsome bird dashes after the fish, that not one visitor in twenty observes that, from the mode of its entering the water to its exit, its methods of movement are absolutely different to those of the penguins. The cormorant does not plunge headlong. 
It launches itself on the surface and then "ducks" like a grebe. Its wings are not used as propellers, but trail unresistingly level with its body, and the speed at which it courses through the water is wholly due to the swimming powers of its large and ugly webbed feet. These are set on quite at the end of the body, and work incessantly like a treadle, or the floats of a stern-wheel steamer. Yet the conditions of submarine motion are so favourable, that the speed of the bird below the surface is three or four times greater than that gained by equally rapid movements of the feet when it has risen and is swimming on the top. The lustre of the feathers in the clear water, the cloud of brilliant bubbles which pour from the plumage, like the nebulous train of a comet, as the bird rushes through the water, and the sapphire light of the large blue eye, make the cormorant's fishing one of the prettiest aquatic exercises in the world.

The darters, though resembling the cormorant rather than the penguin in using their feet only for propulsion, are so clearly a survival of some ancient type, with their long snaky necks and pointed mandibles, and meagre membranous wings, that the imagination travels back at once to the steamy forests and swamps, and fish and saurian-haunted waters of some antediluvian epoch. The appearance of these creatures below water is even stranger than when perched on the bank above. Like the cormorant they swim with the feet only, and with the same rapid mechanical alternate movements of each. Like the 
cormorant also they allow their wings to float parallel with the body, and the long black-and-white feathers and tail, loosely set on, and retaining quantities of air in the interstices, are at once transformed by a surface of velvet and quicksilver as the bird descends. But, unlike the cormorant, it keeps its neck drawn back in the form of a flattened $S$ when in pursuit of the fish. Once within striking distance, the sharp bill is shot out as if from a catapult, and the fish is spiked through and carried to the surface. This ascent is made after each single capture. Sometimes the bird has great difficulty in disentangling the pierced fish from the spear-like beak, and its companion adroitly relieves it of the struggling victim and swallows the prize. The brain capacity of these creatures is probably less in proportion to their size than that of any other bird. After years of familiarity with their keeper, they would as soon dart their piercing bills into his eye as into the body of a fish, and are probably the lowest in the scale of intelligence as well as in development of the bird creation. Yet their movements below water are graceful and precise, and their skill in their one accomplishment of fishspearing is unrivalled by human dexterity. 


\section{TAME DIVERS.}

When an ideal home for the diving-birds is constructed at the Zoo, we may hope to see them sitting in the sunlight on the flat rocks they love, and watch the guillemots and razorbills rearing their young, or swimming on the surface with their offspring sitting on their backs as they do off the cliffs of Freshwater and Flamborough Head. These rock-fowl, unlike the gulls and terns, are more easily tamed, and in a sense domesticated, than any other bird except the parrot. But unlike the parrots, they have so little fear of man in a wild state, that is when quite young, but able to fish for themselves at sea, that two or three days in human company are enough to attach them firmly to their new acquaintances. The tameness of the full-grown young razorbills when engaged in fishing in the narrow waters of the lochs on the west coast of Scotland has been more than once mentioned to the writer ; they hardly care to move out of the way of a yacht's boats, when these are rowing to and from the shore or rowing up the lochs. The young full-grown birds would allow the boats almost to row 
over them, and when a hand was stretched out to pick them up they would just dive below the keel, and rise as near on the other side. In the Irish Sea they kept so close to a yacht that the spray from the bow, or the parting waves under the stern, seemed often about to break over them. That this was due to a certain confidence in man is partly shown by the behaviour of a young bird which was found by some members of the same ship's party, swimming by itself in a small lagoon left by the tide off the Norfolk coast. Razorbills are not common near this low shore, and this young bird had probably come in pursuit of a shoal of fish, and been unable to find its companions again. In any case it was quite alone, and in the absence of any of its own kind, made itself one of a bathing party of young people who frequented the part of the beach where it was first seen. It allowed itself to be caught and taken up to the house, where, on the arrival of the elders from a drive, it was found in the stableyard, sitting in the middle of a large preserving-pan which had been turned into a temporary stew-pond for a number of small eels which the children had amused themselves with catching when paddling in the stream the day before. "It has eaten all the fish!" was the first intelligence of the ways of the new arrival; as a fact, there were one or two eels left, at which the razorbill, looking like one who had greatly dined, now and then aimed an apathetic peck. To be carried inland by children, and then, surrounded by a whole family of humans, 
to catch and eat about twenty live eels in a stew-pan, is good evidence of the confidence which these birds have in man. From that day until its lamented death the bird was as much a member of the family as the fox-terrier or the cats. Next day it was carried down to the beach, and placed on the wet sand by the breakers. It waddled down to the water, took a swim round, and came back to the shore. This happened twice or thrice, and as it showed no disposition to return to the sea it was carried back once more to the house. Every day the bird was taken down to the beach and set free, while the whole party bathed from tents set on the shore. It would swim out sometimes as far as a quarter of a mile, until it was a mere black speck on the water. Then, just as it seemed about to leave its friends for good, the black speck turned into a white one as the bird turned its white breast towards the shore. It would swim steadily towards the bathingtent, scramble out of the water, and walk up to the shingle bank on which the party were lying enjoying the sun after their barhe. The razorbill, having conipletely identified itself with the habits of its hosts would do the same, opening its wings and sunning itself beside them. One rather rough day, with a choppy sea, it was carried some way down the shore by a current, and landed at a considerable distance from its usual point; but it succeeded in landing at a place opposite to where some of the party were waiting for it. During these ex- 
cursions it dived and fished in the small lagoons left by the tide, and the provision of a further supply was of course a delightful occupation to the children, to whom the razorbill's unfailing appetite was a valid reason for being on the shore and in the water at all hours. This curious alliance lasted for some nine or ten days, when the bird was choked by its food in a rather odd way. One of the children was holding in one hand a flat-fish, which was about to be cut up into pieces of a size more suited to the size of the razorbill's throat. The bird was sitting on her other hand at the time, and reaching across seized the fish by the head, jerked it from her hand, and swallowed it. But though not choked at the time, it never recovered the effects of its surfeit of flounder, and died greatly lamented on the following day.

The penguin can be tamed almost as easily, or rather are often tame from the first. The keeper of the diving-birds, like many others at the Zoological Gardens, is an East Anglian, coming from one of the most secluded and least aquatic districts of Central Suffolk. But the instinct for the care of animals, from cart-horses down to geese and game-bantams, is innate in the intelligent Suffolk and Norfolk countryman; and Waterman usually has at least one penguin which is almost as companionable as a child. Prince, a rock-hopper penguin from New Zealand, was perhaps the most amusing and interesting of these ainphibious pets. It was the owner of a smart red flannel jacket with yellow facings, which had been presented to it 
by an admirer, and dressed in this the penguin would hop, hop, hop, in the most ludicrous and serious fashion, after its keeper, or make an excursion on to the lawn outside, where the flight of the sparrows seemed a constant source of interest to this wingless bird. Poor Prince died a victim to influenza, and it will be long before his place is taken by a more friendly or amusing creature. 


\section{THE QUEST FOR THE WILD HORSE.}

The sustaining hope of the discoverer of the unknown is seldom wholly vague or visionary. No man, as a rule, breaks into a new world by accident or hap-hazard. New worlds, or lands, or men, or beasts, have lived in the imagination, and been foreshadowed and foretold by a hundred minute and subtle inductions, grouping themselves round the central idea in minds so set on finding what they felt was to be found, that in the end their quest was gained, and they have been able to tell the world that what they felt must exist, did exist, and was found. Even though the nominal object of his search be prosaic and matter-of-fact, the explorer generally cherishes some dear ideal, some side-issue, some pet project of his own in the realm of discovery, which his efforts shall bring to light, and which will realize some reasoned result of his own sagacity and foresight. When Pythias, the first navigator of the Northern seas, was sent on a "commercial mission" by the colonists of Marseilles to find the tin-islands, he performed the practical part of his mission with all good faith and 
diligence; but to him, the man of science, the mathematician and astronomer, the bare discovery of new tribes of barbarians, new islands, and halffrozen seas, could have brought no such nights of triumph as that on which he tracked the Sun to his lair behind the Lapland mountain, and saw the brilliant creature slip again from his cavern, after his brief but necessary repose. Such must have been the triumph of Columbus when he fancied that he identified on the shores of America the plants and streams of India and Cathay; and such, in some sense, the feelings of Prejvalski, the latest traveller to seek the Eastern limits of the Old World through new and untried paths, when he realized his hope of discovering in the deserts of Mongolia the wild camel and the wild horse.

The experiences of this Russian soldier when he had penetrated into the regions behind the plateau of Tibet to the mysterious lake of Koko-Nor, lying I0,000 $\mathrm{ft}$. above the sea, are more in the spirit and setting of the journals of Columbus than any tale of travel of modern times. The lake, blue as a sapphire, lay in a setting of dull salt sand, with an encircling rim of snowy mountains. Outside and beyond the mountains lay on one side the forbidden land of China; on another, Tibet, with its frozen and stereotyped government of a priestly caste; and on the west, the broken tribes of Eastern Turkestan. As he passed towards the great Desert of Gobi, which divides the dwindling population on one side of the 
mountains from the decaying civilization on the other, he found himself almost alone among the primitive animals and birds of the centre of the Old World; and as the old Greeks imagined, and as Darwin found in Patagonia, and voyagers at either Pole, that at the ends of the world Nature was simplified, with fewer and more primitive forms, so, in the "centre of the world," Prejvalski found that in these remote and solitary regions he was face to face with some of the early and original types of those animals which man enslaved and turned to his own uses, at such a distance of time that the original types were believed to have perished for ever. The hope of discovering the "undescended dark original" of some of our domesticated animals, especially of those ancient servants of Eastern mankind, the camel and the horse, seems to have been ever present to the mind of Prejvalski, and to have affected his imagination as the vision of the shining walls of El Dorado did the old adventurers, or the hope of finding the mother-rock of the gold, the gold-seekers of our day. From the sapphire lake of Koko-Nor he pushed towards the North-West across the plain of Tsaidam, a strange, unfinished region, once the bed of a huge lake, a waste of sand, salt-impregnated clay, and marshes, through clouds of mosquitoes and gadflies, towards another lake, called Lob-Nor, lying in an extension of the great Desert of Gobi. He had marked how, as he journeyed across Asia westward, all the elements of Nature grew more simple and severe, and that as the 
more complex landscape resolved itself into waterless mountains, salt lakes, and rude vegetation, so the types of animal life grew constantly more primitive. He had left behind him the semi-wild horses of the Don and Southern Russia, and seen the still wilder ponies of the Mongols, "under the average height, with thick necks, large heads, thick legs, and long, shaggy coats." The camels of the Koko-Nor were smaller and rougher than those further $W^{\top}$ est, and he rejoiced to think that he must now be approaching the original home of the wild camel, and even of the wild horse. "Such a journey," he wrote, "must finally set at rest the question of the existence of wild camels and wild horses; the people have repeatedly told me of both, and described them fully." The wild camels were said to live in North-West Tsaidam, and to have smaller humps and more pointed muzzles than the tame camels, and grey hair. They were hunted for food, and were exceedingly fleet, wary, and suspicious of man. These stories of the Mongols were found to be correct. Several skins of the wild camel were brought to the traveller, and he was at last rewarded by a sight of one of them, though the distance was too great to enable him to shoot it or compare it with the tame animals. Later, however, some have been taken alive, and the existence of the wild camel in the Desert of Gobi may be taken as established. ${ }^{1}$

1 The skins and skeletons of the wild camel are now on view at the Natural History Museum. 
The Mongol accounts of the wild horses, though equally positive, were less satisfactory. They were certain that there did exist wild horses in the same districts as the wild camels; and they were also certain that these were distinct from the horse-like kiang, the wild ass of Eastern Turkestan and Mongolia. The kiangs do, in fact, resemble a Mongol horse in many points. They have the same heavy head, square shoulder, chestnut colour, and short ears; but they differ in having their lower parts almost white, and a true ass's tail. They neigh, but also bray, and, when going at full speed, have the characteristic appearance of an ass with "great ugly head stretched out straight before, and scanty tail straight behind," as Prejvalski says. They are, in fact, probably only a variety of the wild ass of Persia and Western Turkestan. But the Mongol accounts of the wild horse were quite inconsistent with the description of the kiangs. "The wild horses," they said, "were numerous near Lob-Nor, but were so shy that when frightened they continued their flight for days. They were of a uniform bay [? dun] colour, with black tails, and manes sweeping the ground; and were never hunted because they were too difficult of approach." Prejvalski obtained the skin of one of these wild horses; but the evidence so obtained did not bear out the account given by the Mongols, who seem to have fallen into the usual error of imagining that in the "wild horse" they would find the species in a condition of original and primitive 
perfection. Of course nothing could be more contrary to probabilities. "Wild" animals, compared with domesticated descendants of the same species, occupy much the same position as "wild" plants do to their descendants in the garden; and the absence of fine legs and a flowing mane in the Equus Prejvalshii made the place assigned to it as the ancestor of the modern horse all the more probable. Now the news comes that the wild horse of Prejvalski has been seen, hunted, and captured by two Russian travellers, the brothers Grum-Grizimailo, and that four specimens have been brought to the Zoological Gardens of St. Petersburg from their Central Asian home. These creatures are said to correspond in all respects with the skin obtained by Prejvalski, and to represent the ancestors of all our modern horses. From a picture of the animal which appeared in the Graphic, there seems some reason to doubt whether they may not, after all, be only a variety of the kiang, or wild ass of Turkestan. They have the ass's hogmane, and a tail in which the long hairs, though not confined to the tip, do not begin to grow until some inches from the root. Neither has the animal any forelock. On the other hand, the ears are short, not long, as in all the ass tribe, and the square shoulder is not more characteristic of the asses than of all neglected breeds of horses. Moreover, it is a commonplace in natural history, that the primitive characteristics are shown in the young; and the thin tail, short neck, and head set on so as to make an 
angle with the throat instead of a curve, are as characteristic of a young colt as of the Equus Prejvalskii. But, apart from all external differences between the ass and the horse, lies the inexplicable fact that the latter adapts itself to changed conditions in almost all climates, while the former does not. Under human care and selection, the horse varies so rapidly, that we meet with all extremes, from the dray-horse to the Shetland, and all colours from black to white. But the ass in the last five thousand years has varied little. It will not thrive except in hot climates, and centuries of careful breeding have not caused it to change colour further than from grey to white, ${ }^{1}$ and have done little to make it a pleasant animal to ride, or big enough for heavy draught. These facts give a starting-point from which we may judge whether or not the Equus Prejvalskii is of the true stock. Let those recently brought to Russia be made the nucleus of a herd, and the variations of successive generations be noted. Then if they are true horses, they will vary first in colour, then in shape, and human selection ought to be able to guide the varieties towards different types. If, on the other hand, they be asses, they will refuse to vary, and remain true to the type of the steppes of Dsungaria.

Even in our own New Forest, this difference between the horse and the ass is curiously persistent.

1 There are black donkeys, but most appear to be instances of "melanism" rather than of colour gradation. 
In the Southern Forest there are many hundreds of semi-wild donkeys, as well as ponies, which are left to Nature from year to year. The ponies are of every colour known in the annals of horse-breeding, but the shaggy little donkeys are all of a uniform dark stonecolour, which never varies. Looking at the beautiful wild asses from the Desert of Cutch, Southern Africa, and Central Asia, which are exhibited at the Zoo, one is tempted to wonder how it comes that the race in this country has been allowed to degenerate, instead of being retained as a strong and useful auxiliary to our unrivalled breed of horses. 


\section{ÆSTHETICS AT THE ZOO.}

\section{THE ANIMAL SENSE OF BEAUTY.}

THAT sense of beauty to which the gorgeous plumage of the male birds in many species is an obvious and direct appeal, is by no means limited to the knowledge so naïvely shown by resplendent husbands and adoring wives, that fine feathers make fine birds. So common and varied is the pleasure derived from this sense, that in many kinds it extends to the conscious search for and appliance of beautiful objects in the decoration of nests, of pleasure-houses, and the enrichment of collections. This taste for ornament is by no means limited to birds kept in captivity, in which they often learn tricks and habits foreign to their nature, from ennui and idleness. In the freedom of English woods or Papuan jungles, they show the keenest pleasure in the strange or beautiful shapes and colours of flowers, of feathers, of fruits, of gay shells and insects, of woven fabrics, of metal, glass, and gems; and similar tastes shown in captivity are often but the survival and maimed reproduction of their natural love for surrounding themselves with what pleases the eye. It appears in species 
where it might be least expected, and is developed to a point at which it becomes an artistic passion identical in motive and the means taken to gratify it, with the same taste and its expression by civilized man. It is not without reason that the Papuan, who lives naked under a tree, calls the gardener-bird "the master," which can build not only a nest, but a lovely pleasurehouse besides, and adorns this with a hundred beautiful objects to satisfy æsthetic wants which the savage is not yet developed enough to feel or understand.

The gardener-bird has not yet become established at the $\mathrm{Z}_{\mathrm{oo}}$, but the bower-birds build their gallery every spring, and decorate it with such "articles of vertu" as visitors are kind enough to place at their disposal. The bower-birds live in the compartments of the western Aviary nearest to and on the left of the main entrance. Apart from the claims to sympathy which their æsthetic tastes suggest, the birds themselves are singularly handsome, courageous, and active, and thoroughly enjoy the excitement and change of scene which is so distasteful to many creatures confined in a public menagerie. They are strongly-built, compact-looking birds, almost as large as a rook, but in general shape something between a thrush and the Indian mynah. The male in his adult plumage is a splendid purple, while the hen-bird is green and olive, almost as brilliant as the colours of the ground parakeets. They hop from perch to perch with wonderful agility, and whether on the ground or 
in the branches, are seldom still, but always active, inquisitive, and alert.

In the first warm days of early spring they begin to collect materials for the bower. The twigs of a birchbroom are usually given them for the raw material, and these are soon arranged with astonishing skill into two short incurved hedges, the tops being pulled over to make the bower as nearly like a tunnel as the material admits. If they had a larger allowance of brooms no doubt the tunnel would be made longer. As it is, it is only a section of a gallery. When this is complete nothing makes the birds so happy as presents of bright-coloured objects to arrange round the sides of the play-ground. Unfortunately for the birds, the mice, which have no æsthetic perceptions, but are of a practical turn of mind, steal everything soft which is put in the bower, to make nests for their own young. All pieces of coloured paper, rags, and tinsel are carried off in the night, or even in the day, so that the birds can only rely for permanent ornament on things not only bright but hard. But their taste for colour may easily be tested by giving them shreds of paper of different hues. If it be merely a question of colour, not of texture, they usually prefer red, picking out the red strips first and trying the effect in different parts of the gallery. That their power of selection is highly developed may be judged from the following example. The writer was looking at the birds early in January, when they showed signs of a wish to build, and happened to have in his pocket some specimens 
of silk, which had been sent in order to make a selection of a pattern for neckties. The utmost variation from black allowed by the severe taste of London costume being some slight pattern of white, or grey spots, the difference in the "colouring" of these little bits of silk was so slight, as to be hardly appreciable by any but the highly specialized sense of adornment in the masculine mind, consisting as it did of more or less frequent repetitions of little groups of spots or other insignificant pattern. Eight or nine of these were thrown on the floor of the aviary, and the cockbird at once flew out from the recess at the back, and proceeded to pick them up and scrutinize them one by one. Finally, after much consideration, it took to the bower, which was just begun, the piece of silk on which the pattern was closest and most obvious. Their liking for what is bright and shining in texture is even stronger than that for colour. Some ingenious friend, finding that the mice robbed the birds of their papers and silks, presented them with a number of small glass phials filled with coloured shreds, or with tin and brass filings. These were a source of great delight, and when the supply was further increased by a dozen pretty glass solitaire balls, they spent a week in arranging and re-arranging their treasures.

It is obvious that the bower-birds are highly intelligent creatures, but these tastes appear in birds which are quite low in the scale of mental development, even among the hawks, which are among the 
least keen-witted of the birds. The kite, for instance, has a great liking for pretty things, or what it considers such. In two of the rare instances in which the kite's nest has been recently found in this country, the cock-bird had carried home a long, trailing spray of woodbine in flower, and left it by the side of its mate. When kites were common in England, their habit of carrying off to their nests any strange objects which took their fancy was well known. "The white sheet bleaching on the hedge " has as great attractions for them as it had for Autolycus. Shakespeare makes the pedlar refer to this habit. "My traffic is sheets," he says; "when the kite builds, look to lesser linen." But the bird, though as much a "snapper-up of unconsidered trifles" as Autolycus himself, is only a fine-art and bric-à-brac collector in its way, and is perhaps not more unscrupulous in annexing the specimens that take its fancy. In a kite's nest found not long ago in this country, the "collection" was enriched by pieces of newspaper and leaves of "Bradshaw's Railway Guide!"-and on the few estates in England where these birds are still protected, the keepers are said to be quite aware of their mania for collecting linen when laid out to dry, and carrying off socks and bright cotton handkerchiefs to the nest.

The sense of beauty naturally appears, in the rudest and most elementary form, in such uncouth robbers as the kites. In the far cleverer crows, ravens, magpies, and jays, it is a marked and hereditary passion. 
From the Jackdaw of Rheims to the old raven at the Tower of London, who amassed a unique and valuable collection at the bottom of one of the venerable cannon inside the Barbican, there can hardly have existed a tame member of the tribe which has not at times asserted its own right to a share in the enjoyment of what we remember to have seen described in the pompous advertisement of a modern art furnisher, as "those products of the minor arts which contribute to the dignity and refinement of domestic life." They have a wide and catholic sense of feeling for what may contribute to their happiness in this way, and do not always distinguish between what is beautiful and what is merely curious. At the same time, they do often distinguish and keep apart what they collect or steal for food, and their art collections, which are hidden separately, and far more carefully concealed. The writer has seen this in the case of tame jays and jackdaws, and has known it practised by a raven and a magpie. The latter always hid the crusts, and especially the small squares of toast made ready for soup, which he stole or had given him in the kitchen, between the layers of household linen in the dryingroom of a large house in Northumberland. But his "collections" were buried in the straw in a disused outhouse. The loss of several small cups and saucers out of a bright-coloured set belonging to the children led to the discovery of this hoard, as the bird was seen to enter the shed, and was there found pulling away the straw which covered the china. 
So far, we have traced the development of this sense of beauty from the kites, which merely pick up and carry to their nests what they consider to be pretty and interesting, to the crow tribe, which have a separate hiding-place for keeping and enjoying their treasures. The conscious search for and application of ornament to the decoration of the fabric of the nest, even at the risk of its danger and discovery through the gratification of their feeling for beauty, is a further and most remarkable evidence of the pleasure which they derive from that sense; for one of the strongest impulses of the nesting bird is to subordinate the colour and texture of the outside of the nest to the tint of its natural surroundings, and none but a strong and tempting bias to the indulgence of a contrary instinct could compete with their natural solicitude for the safety of their young. Yet two undoubted instances of the addition of ornament by English birds to the outside of a nest have come under the writer's notice, where its use clearly entailed some danger from the enemy. The first was the nest of a chiff-chaff, found in a plantation near Rosamond's Bower, on the Isis, near Godstow. It was a domed nest of the usual kind, made of dry, colourless grass, with an entrance in the side. But on the outside, and round the entrance to the chamber, were stuck several of the brilliant blue feathers of the kingfisher. The position of these bright patches of colour on the outside of the nest is strong evidence that beauty, not utility, was the object of their insertion. The other 
case was the nest of a goldfinch, which was built on a high branch of a sycamore, near the window of a house at Sidmouth in Devonshire. When the fabric of the nest was completed, the birds, or rather one bird, for the other was constantly employed in building, brought long pieces of the blue forget-me-not from the next garden, and so adjusted the sprays that the flowers hung all round the top of the nest. The sacrifice of safety to beauty did not cause any risk from below, as the nest was at a considerable height. from the ground. Unfortunately it attracted the notice of a jackdaw passing overhead, and the black robber plundered the nest of the eggs on which the bird had been sitting for some days. It may be noticed that in both these cases, in each of which there was a large choice of flowers or feathers-for the feathers which lined the chiff-chaff's nest were brought from a farmyard near-the irresistible colour was light-blue. This decorative instinct finds its final and complete expression in the bower-birds, and the still more interesting gardener-bird of New Guinea, both of which construct an "art gallery" for the reception of their treasures, and the better enjoyment of their sense of the beautiful. These bowers are in no sense nests, but "palaces of art" for the days of their honeymoon, and are quite apart from the later cares of the nest or nursery. The best of all are the galleries of the gardener-birds, which Count Rosenberg recently found in New Guinea.

"It was a piece of workmanship more lovely than 
the ingenuity of any animal has been known to construct," writes the discoverer. "It was a temple in miniature, in the midst of a meadow studded with flowers." The bird, which is not much larger than a thrush, chooses a level place round some shrub which has a straight stem about the thickness of a walkingstick. To this central pilaster it fastens the stems of a kind of orchid, and draws them outwards to the ground, like the cords of a bell-tent; but the leaves are left on the stems, and remain fresh for some time. The upper part is then fitted together, and the leaves and moss make a beautiful umbrella-shaped roof. In front of the central building, the birds clear a space about a yard in diameter, which they cover with moss, after removing all stones and weeds. On this moss carpet they arrange flowers and brilliant fruits in great variety, and of the brightest colours to be found. Showy fungi and elegantly coloured insects are distributed about the garden, and inside the tent, and when these lose their freshness, they are thrown away and replaced by others. The tent itself is about thirty-nine inches in diameter and eighteen inches high. The Papuans never disturb these bowers. They call the builder the "Master Bird," or "Tukan Robin," the "Gardener," and say that it is wiser than mankind-and judged by the Papuan standard, this estimate is a true one. In the gallery of one of the bower-birds half a peck of decorations was found. Among these were a large white shell, four hundred shells of a bright-coloured snail, flints and agates, red seed-pods and seeds, and 
the bleached and shining bones of animals. If for shells we read mother-of-pearl; for snail-shells, nautilus cups; for flints and agates, agates and malachite; for seeds, beads; and for bones, ivory, where does the taste for beauty in the bird differ from our own? 


\section{ÆSTHETICS AT THE ZOO.}

SCENTS AND SOUNDS.

OnE of the oddest tales in the "Bestiaries," or stories of Bible animals written by the monks, is the legend of the panther. "The panther," so the homily runs, "is the most beautiful of all beasts. More than this, when it goes abroad it diffuses a marvellous sweet perfume. This odour is so sweet that all the other beasts and birds follow the panther wherever it goes. Wherefore the panther is a type of Virtue." Perhaps the old monks who borrowed and embellished this story had heard and misunderstood the strong love of sweet scents which the panther and its relations, the lions and leopards, often show. The old theory of animal liking for scents denied them any share in such pleasures unless they suggested the presence of their food or prey. But such a reason can hardly be alleged for a lion's liking for lavender-water! The writer, wishing to test for himself the reported fondness of many animals for perfumes, paid a series of visits to the Zoological Gardens, provided with bottles of scent and a packet of cotton-wool, and there tried some 
harmless experiments which apparently gave great satisfaction to many of the inhabitants. Lavenderwater was the favourite scent, and most of the lions and leopards showed unqualified pleasure when the scent was poured on the wool and put into their cages. The first leopard to which it was offered stood over the ball of cotton, shut his eyes, opened his mouth, and screwed up its nose, rather like the picture of the gentleman inhaling "Alkaram" in the advertisement. It then lay down and held it between its paws, rubbed its face over it, and finished by lying down upon it. Another leopard smelt it and sneezed; then caught the wool in its claws, played with it, then lay on its back and rubbed its head and neck orer the scent. It then fetched another leopard which was asleep in the cage, and the two sniffed it for some time together; and the last-comer ended by taking the ball in its teeth, curling its lips well back, and inhaling the delightful perfume with half-shut eyes. The lion and lioness, when their turn came, tried to roll upon it at the same time. The lion then gave the lioness a cuff with his paw, which sent her off to the back of the cage, and having secured it for himself, laid his broad head on the morsel of scented cotton, and purred. These were all old inhabitants of the Gardens, civilized. But at the end of the building was the lovely young Sokoto lion, with the spots of "cubhood" still showing like a pattern in damask on his skin. If he too liked the scent, it could hardly be an acquired taste. His reception of the new impression was 


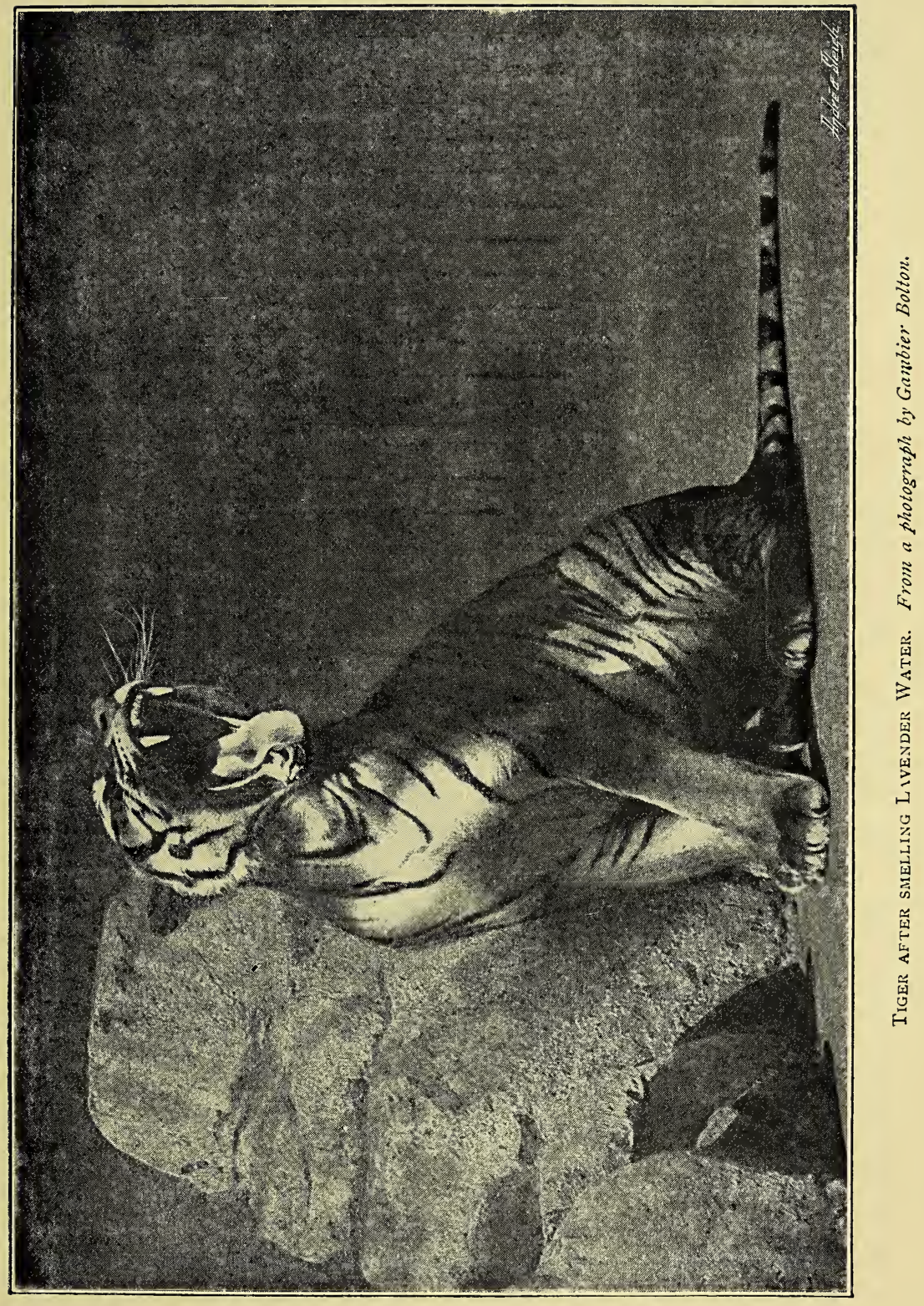



different from that of the others. He lay down inhaling the scent with a dreamy look in his eyes. Then he made faces and yawned, turned his back on the scent, and thought. He then inhaled the perfume again for some time, walked slowly off to his bed, and lay down to sleep.

The smaller cats were in many cases as pleased with the scent as the leopards, the ocelot in particular on one occasion, after inhaling the perfume, ate the small piece of paper on which it was poured. But the liking for lavender-water is by no means confined to the felide. The Cape ratels were delighted with the scent, and the racoon, when the bottle was presented to it corked, with great good sense pulled out the stopper; but this may have been due to curiosity, as it was at once thrown away. Other creatures, on the contrary, either cared nothing for the scent or found it disagreeable. An otter, in particular, gave a snort of disgust, dived into the water, and then ran to its mate, to whom it seemed to convey some of its impressions, for both otters carefully avoided the perfumed wool. No doubt there lies somewhere in our rivers, "under the glassy, cool translucent wave," or on their flower-bordered banks, some odorous herb or water-weed which the otter also loves. That the pleasure felt by so many animals in the odour of "sweet lavender" is due to pure and simple enjoyment of a perfume, made intensely more delightful to them than to ourselves by the wonderful development of their sense of smell, seems clear, not only from the 
fact that so many species share this amiable fondness for the scent, but also because their liking for perfumes is by no means limited to that of lavender. A flask of rose-water will make as many friends among the leopards and their kin as will the former scent, and they also enjoy the sweet odour of pinks and lilacblossom. The heavy scent of lilies and narcissi fails to please, perhaps on account of their strong narcotic qualities. It is not unlikely that the scent of these plants, with which the Furies were said to stupefy their victims, an odour which is often insupportable to men themselves, should be distasteful to their far more sensitive nostrils.

It could hardly be expected that, in the matter of sweet sound, animals, any more than men, should think alike. The scent of the rose gives pleasure from the Himalayas to the Hebrides; but the music that soothes the Highlander is to the Japanese as the howling of cats. Still, as to some men certain sounds are always musical, so to some animals these same sounds give pleasure. The taste finds perhaps its highest expression in those birds which actually learn to whistle the airs which they have heard from men, and its lowest in the snakes and reptiles, which seem to be fascinated by the Indian pipe. The writer has heard more than one parrot whistle part of a tune, and then strike the octave of the last note; and the piping crow at the Zoological Gardens, and a Persian bulbul, which was once an inmate of the same aviary, can whistle a tune perfectly. It is to be expected that 
birds which take such pleasure in each other's songs should be most sensitive to sweet sounds new to them.

But the taste is not confined to birds. The old horses in the regimental riding-schools learn the meaning of the different bugle-calls ; and though it is not possible to say whether they distinguish between different airs, it is well known that they trot or gallop better to some tunes than to others. This may be compared with a curious story told by Playford in his Introduction to Music. "When travelling some years since," he writes, "I met on the road to Royston a herd of about twenty bucks following a bagpipe and a violin: while the music played they went forward; when it ceased they all stood still; and in this manner they were brought out of Yorkshire to Hampton Court." Seals have long been known for their love of sweet sounds. Laing, in his account of a voyage to Spitzbergen, says that when a violin was played on board the vessel, a numerous audience of seals would often assemble and follow the vessel for miles. Sir Walter Scott mentions this taste in the lines,-

"Rude Heiskar's seals, through surges dark, Would oft pursue the minstrel's bark;"

and it is said that when the bell of the church on the island of Hoy rang, the seals within hearing swam to the shore, and remained looking about them as long as it was tolled. In a less prosaic age, the seals of Hoy might have become an established myth of a success- 
ful "deep-sea mission" to the mermaids of the North. It would be interesting to make some musical experiments at the Zoological Gardens; but the first occasion on which the writer attempted this, led to such strong suspicion of his insanity among the visitors, that in the face of a caution addressed by an elderly nurse to her charges, "Don't go near 'im-he ain't right in his 'ead," he had not the courage to continue his researches.

Note.-In a letter to the writer, the late Dr. John Rae, F.R.S., the discoverer of the fate of the Franklin Expedition, urged that he should nevertheless make some trial of the effects of music on the different animals at the Zoo. Dr. Rae spent the days of his boyhood in the Orkney and Shetland Islands, and said that both there and in the regions round the frozen rim of the northern ocean, it was matter of common experience that the seals would follow a boat in which music was played. The following chapters give the interesting result of this suggestion. 


\section{ORPHEUS AT THE ZOO.}

THE FIRST VISIT.

IN making trial, with the aid of a skilled musician, of the effect of sweet sounds on animal ears, we knew that there was good reason to doubt whether Orpheus himself might not fail to charm within the precincts of the Zoo. For if, on the one hand, the creatures so far share the blessings of the golden age that they entertain a liking rather than a fear of man, and have no dread of a possible enemy behind the mask of music, many of them are no strangers to such forms of it as are produced by the harmony of a band which plays there weekly in summer evenings. To those creatures which have lived for years in that part of the Gardens near the band-stand, the sound of music is no new thing; and it was possible that they might be as indifferent to its strains as an organ-grinder's = monkey to the music of the street. On the other hand, there must be many to which, either from living at a distance from the musical centre of the band-stand, or in separate 
buildings, such sounds are new and unusual; and others which are but recent arrivals in the Gardens, fresh from tropical forests, or the wastes and deserts of an unmusical world. In any case, to listen to the distant strains of a brass-band is a different experience from that enjoyed in a chamber recital by your own violin-player, one who can draw from his instrument by sympathetic skill melodious chords, sounds soft and weird, grave and gay, strident or tremulous, harmonious or suddenly discordant, eye watching eye, and quick to change or repeat a note as he marks the varying expression of emotion roused by sound on animal faces, sometimes strangely expressive, or on others in which for minutes the eye alone gives token even of life. It was on some of these last, the snakes and creeping things, that we proposed first to make trial of the powers of sound,-partly because Eastern traditions of snake-charming are some of the oldest in the world; partly because, if they proved unresponsive, this would still leave room to hope that creatures of a higher organization and warmer blood might be more appreciative ; and lastly, the day was dark, with thunder and rain, and Orpheus himself, in his sylvan concerts, might have failed to charm with wetted strings.

Before visiting the cobras and the pythons, we made our way to the Insect House, with some design of making trial of the tarantula spider, our violinist having a theory of his own that spiders had a liking for harmonious sound; partly, too, from a mixed 
feeling that the tarantula, whose bite makes others dance, should itself have a feeling for musical numbers. Apparently the tarantula's powers are objective only, for it remained in its corner sulky and unmoved. But a nest of scorpions was less indifferent. After the piece of bark behind which these venomous creatures were lurking had been gently overturned, and they had settled down to their usual semi-slumbrous state, the violinist played chords, at first gentle and melodious, then rising to a high and sustained series of piercing notes. In a few moments, one after another, the creatures began to move, the mass became violently agitated, and the torpid scorpions awoke into a writhing tangle of legs and claws and stings. When the sounds ceased, they became still; when the loud, shrill notes were played again, they were again agitated. The talking mynah, which lives in the same room, sprang from end to end of its cage with ecstatic hops, and whistled and coughed, and gave evidence that it at least was a critical listener to the rival musician. The pretty dappled Axis deer, which live in a little paddock by the path, were our next audience; and as we passed them on our way to the snakes' house, a few soft chords were played by way of trial. The deer were at once attracted, and drew near the railings, with ears pointed forward. While low, pathetic chords were played, they stood still, panting, but not unpleased. At a sudden discord they sprang back, and shook their heads. Loud, quick music 
followed; but this failed to please, they stood further off, stamped, and shook their heads again, looking excited and defiant. But we had not come to play to the deer that day. The snakes and pythons were our object, the more so as we could play to these without interruption from the interested visitors, whose inconvenient attention our enterprise was beginning to attract.

"Behind the scenes" in the new Reptile House lies a most interesting region; and Orpheus has a prescriptive right of entry to the arcana of the serpentworld. We explained the object of our visit,-

"Cessit immanis mihi blandienti Janitor aulæ!"

and we were most kindly taken to the private side of snake-land at the $Z_{o o}$. There, if we may not "breakfast on basilisks' eggs," as in the land of Cleopatra's asp, we may at least see the creature that does breakfast on basilisks' eggs, the great monitor lizard, which eats the eggs of the crocodile-or of hens at the Zoo, where crocodiles' eggs are scarce. There too we may see young basilisks, or crocodiles, frisking in a homely watering-pot; young rats too, by the score, parti-coloured and piebald, the destined food of serpents, but meantime in high spirits and playfully squeaking. It was the very place for a chamber concert to the cobras, for the thick plateglass before the cages shuts out the sound of the curious crowd in front, while in the back of each 


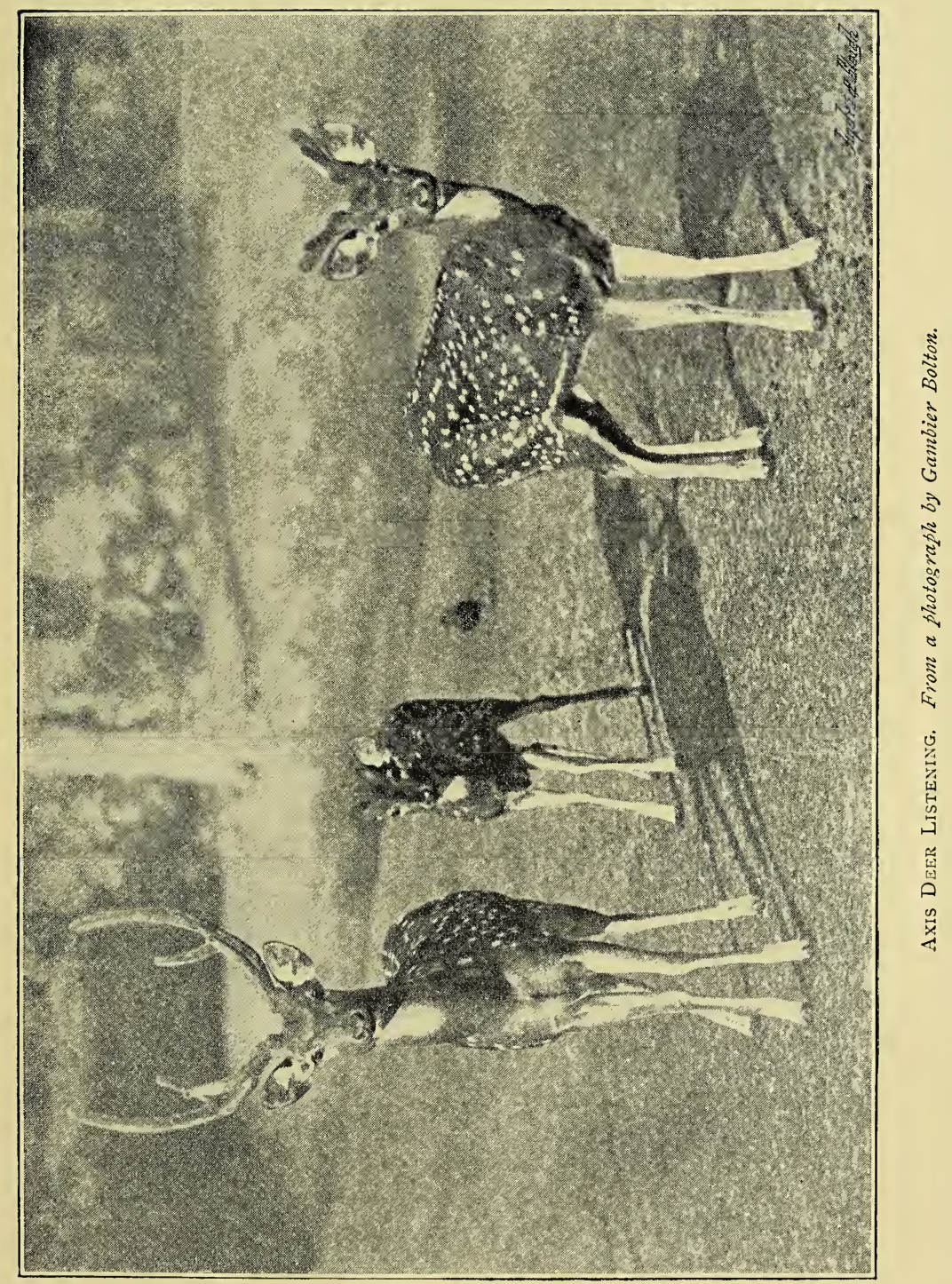



compartment is a small square iron door, like those through which food is passed in model prisons to the inmates of the cells. This door, in the case of the poisonous snakes, is set high above the ground, and is reached by a set of steps which travels on a rail. It is therefore possible to observe the creatures' movements while the player of the music is out of sight below.

The "dweller on the threshold" of the snakes" home is the monitor lizard, an active and formidable saurian some $5 \mathrm{ft}$. in length, whose watchful habits were said to give warning of the approach of the crocodile. It did not belie its reputation for watchfulness, for the instant that it heard the sounds of the violin through its opened door, it raised its head, and stood alert and listening. Then the forked tongue came out and played incessantly round its lips; soft, slow music followed, and the lizard became quite still, except for a gentle swaying of the head from side to side. Two groups of black snakes from the Robben Islands next claimed our attention, and gave some evidence of the way in which the physical conditions of the moment affect the sensibilities of these creatures. In the first cage, they remained absolutely torpid, looking exactly as if carved out in polished ebony. In the next, the heads were raised at once, the forked tongues played, and at a sudden discord each snake's head started violently back. Nor was this quick repulsion caused by any sudden movement of the bow, for the player was invisible. 
In the next cages to these were some smail boas, and Madame Paulus's pythons, with which that lady used to perform in a tank at the Royal Aquarium. The pythons showed no signs of interest, except by a quickened respiration; but a boa was at once attracted by the music. As it worked along the rounded rim of its circular bath in the direction of the sounds, it gave a beautiful exhibition of that snake-movement for which we have no nameneither crawling nor creeping, but gently enveloping portions of the surface on which it lay with its lower scales, and advancing noiselessly and almost imperceptibly. Arrived at the side of the bath nearest to the door, it extended its head with a kind of tremulous motion until it obtained a view of the violin. It remained for some minutes motionless, with its eye fixed upon the instrument, until the music became loud and strident. Then, in sinuous folds, it dropped like some viscous fluid to the ground, and slowly advanced to the door, from which it was gently put back by its keeper.

But the cobra is the snake to which all tradition points as most susceptible to musical sounds, and we prepared to watch its attitude towards the violin with no little excitement and curiosity. The accounts of Indian residents mainly agree in saying that the snake-charmer does influence these serpents by the monotonous notes of his little bagpipes; that as soon as the sound is heard, the snake rises, spreads its hood, and often waves its head from side to side in 
some sort of time to the music; and that, under these conditions, these venomous serpents may be handled with impunity. The last claim of the snake-charmer is perhaps over-bold. 'The snakes appear generally to have their fangs drawn. But in any case, opinion agrees that the sound of the pipes does attract and interest the cobra. Wild cobras are also induced by the pipe-player to come out from the holes in old wells or ruins in which they have taken up their residence, the snake being noosed when its body is sufficiently clear of the hole to enable it to be jerked away by the snake-charmer's partner.

The behaviour of the cobras at the Zoo more than justified the Indian stories. We selected for our serenade a large yellow Indian cobra, which was lying coiled up asleep on the gravel at the bottom of its cage. At the first note of the violin, the snake instantly raised its head, and fixed its bright yellow eye with a set gaze on the little door at the back. The music then gradually became louder, and the snake raised itself in the traditional attitude on its tail, and spread its hood, slowly oscillating from one side to the other as the violin played waltz-time. There was a most strangely "interested" look in the cobra's eye and attitude at this time, and the slightest change in the volume or character of the music was met by an instantaneous change in the movements or poise of the snake. At the tremolo, it puffed its body out. A rattlesnake in the next cage was also listening intently at the same time, 
with its head drawn back, and slowly rising and falling. But it was less apparently sensitive than the cobra. The violin suddenly reproduced the sound of the bagpipes, which greatly excited the snake; and as the "drone" was put on to the tune of "The Keel Row," its hood expanded to its utmost dimensions. Soft minor chords were then played, and a sudden sharp discord struck without warning. The snake flinched whenever this was done, as if it had been struck, and this, it may be worth noting, was subsequently found to be a general effect of discords on most animals of a higher organization. The results of these further experiments were naturally more easy to detect and record than in the case of the snakes; but it may be taken as established, that at the Zoo there are serpents that are not yet deaf to the voice of the charmer, even if he lack the training of Eastern magicians. 


\section{ORPHEUS AT THE ZOO.}

THE SECOND VISIT.

The result of the first experiments made upon animals with musical sounds, was such as to invite a second visit by the violin-player to the inmates of the Zoo. The sun was shining brightly, and most of the animals were just awaking from their morning sleep. Some were not yet awake. The two Polar bears were lying fast asleep in an affectionate embrace, their noses touching, and each with one paw laid on its companion's side, while the other grasped its friend's. Both were dreaming, like dogs on a hearthrug, and gave slight starts and sounds from time to time and movements of their feet and paws. We seated ourselves on the balustrade of the bridge above, and serenaded the bears. The young one awoke at once, and slowly rolled over, stretched itself, and as the music increased in volume, came out into the main cage to listen. The violin was some ten feet above the level on which the bear was standing. In order to get nearer the sound, it stood up on its hind-legs, and listened intently. It 
then retired, and began to walk backwards and forwards, uttering some half-formed sound. But a fresh burst of music from the violin once more brought it to the front, where it stood up, and, spreading its arms wide on either side, pushed its muzzle between the bars. When the musician descended from the balcony and went close to the cage, the bear at once crossed to the place, and sat down to listen, occasionally putting its paws through the bars to try and reach the instrument. It was not until we had ceased to play for some time that the bear left its place against the bars, and sought refreshment in a morning tub. The two grizzly bears, at the first chord struck, assumed at once an air of the most comic and critical attention, each with its head on one side, and its paws clasping the bars. A sudden discord made both bears start back, and the lively tone of "The Keel Row" set them walking up and down the cage. In the Lion House, every head turned to the first sound of the violin; as the strains continued, the largest lion, to whom the music was more particularly addressed, began to wave the black tuft on its tail from side to side; and a lioness, which had been asleep in the inner cage, walked straight out towards the violin, and tried to push the lion from its "front seat." But by this time so much public interest was awakened in our experiment that we were obliged to forego our concert to the lions, and seek an audience less subject to interruption. There is a German tale of a fiddler pursued by wolves who was saved by the accidental breaking 
of a string of his fiddle. The sound of the breaking string frightened the wolves for the moment, and afterwards, the legend adds, he kept them from pulling him from the roof of the hut on which he had taken refuge by playing continuously. The story of the breaking string frightening the wolves, so far agreed with our experience of the effect of sudden and sharp discords on various animals, that it was decided to make the experiment upon the wolves. The result went far to show that the old legend of their fear of music is based on fact. The common European wolf set up its back, and drew back its lips into a fixed and hideous sneer, showing all its teeth to the gums, with its tail between its legs. The Indian wolf showed signs of extreme and abject fear. It trembled violently, its fur was erected, and cowering down till its body almost touched the ground, it retreated to the furthest corner of the cage. When the music was played at the back of the cage, where the musician was invisible, its alarm was in no degree abated. It crept to the door to listen, and then sprang back and cowered against the bars in front of the cage, and so continued in alternate spasms of curiosity and fear. The jackals and some of the wilder foxes were only less alarmed than the wolves. The female jackals ran back to their inner den and hid themselves. The male erected its fur until it appeared as rough as an Esquimaux dog, and crept backwards and forwards, with its lips curled back, opening and shutting its mouth, growling whenever a 
strong discordant note was struck. The scene at this time was extremely amusing. The prairie wolves next door sat down to listen, the African jackals sat on a shelf and watched, and the performance was overlooked from a distance by a nervous but highly interested row of foxes of various sizes and colours, all sitting on the party-walls which divide their cages from the wolves and dingoes. It was like a picture from an illustrated edition of $\mathscr{E}$ sop's Fables. The foxes in the large cages came forward readily to listen to the music, though the usual experiment of striking a discord startled them greatly. But the rough fox from Demerara, in a small cage behind the building, was so violently alarmed that the keeper requested that the music might cease, for fear the creature should "have a fit," to which ailment it appears that foxes and wolves are very subject. As might be expected, the sheep found pleasure in sounds which terrified the wolves. The burrhel, or wild sheep of the Himalayas, all came forward to listen, their ears pointed forward to catch the sounds. Some even stood up, and placing their fore-feet against the palings, stretched their necks in the direction of the music. Our violinist appropriately chose "The Shepherd's Call" in William Tell, and this served to engage their intention more than "The Keel Row" or any more violent airs. Like almost all other creatures, they were startled at a discord. In the row of sheepsheds, the music drew out all the inmates, the Markhor and the Cretan ibex coming forward to 
listen, and walking back to their food when the music stopped. The old Indian wild boar was an unexpected and appreciative convert to the charms of music. It was lying fast asleep in the sun, with its back towards the musician; but at the first chords it rose and faced round towards the player. After listening attentively, with ears forward, the boar began a series of complacent grunts, and advanced to the front of the pen, until disconcerted by a sharp discordant note, which drove it back several feet. The wild swine from Spain and Africa were also much interested in the music. For some unknown reason, the sounds which pleased the boars offended the African elephant. Setting up its huge, flapping ears, it flung up its trunk, snorted and whistled like a steam-engine, driving its head against the rails, and exhibiting every mark of anger and dislike. The Indian bison and the gayal both brought forward their broad ears to listen, and, resting their muzzles against the railings, seemed to enjoy the sounds; a sharp discord caused them to start back, and produced the same effect on the zebras and African wild ass, both of which listened to the harmonious chords with pleasure, and followed the musician from one side of their stall to another. But it was in the Monkey House that the music caused the greatest wonder and excitement. The large apes-two of which will never hear the violin again, for "Sally" and the young ourang-outang have both died since our visit-were more frightened than pleased. "Tim," the silver gibbon, was much 
agitated, opening and shutting his mouth, and waving his long arms about, until two loud discordant notes were played, when he came flying down from his tree, and flung himself against the bars. The young ourang-outang turned his back at once, and made off to the top of his cage, from which not even a banana would tempt him. "Sally" listened gravely, with her hands crossed and a far-off look in her eyes, until a strong crescendo was played, when she made an audible and perfectly articulate remark, though we were unable to record its meaning. Outside the large monkey-house, a large Tcheli monkey was sitting in a cage apart, thoughtfully chewing a stick. At the sound of the violin, it gave a violent start and frowned, which, however, is not a necessary sign of displeasure in monkey physiognomy. When sudden discords were played, it sprang forward and rattled the bars. The Capuchin monkeys, the species selected by Dr. Garnier for his experiments in monkey language, showed the strangest and most amusing excitement. These pretty little creatures have wonderfully expressive and intelligent pink faces, with bright-brown eyes and pink lips, and the play and mobility of their faces and bodies while listening to the music was extraordinarily rapid. The three in the first cage at first rushed up into their box, and then all peeped out chattering and excited. One by one they came down and listened to the music with intense curiosity, shrieking and making faces at a crescendo, shaking the wires at a discord, and putting their heads upside- 
down in efforts of acute criticism at low and musical passages. Every change of note was marked by some alteration of expression in the faces of the excited little monkeys, and a series of discordant notes roused them to a passion of rage. Most of the other monkeys came up to listen; the Malbrook monkey dropped the clay pipe he was making-believe to smoke, and the whitenosed monkey stole a lady's veil and picked it thoughtfully to pieces. But a big baboon recently brought to the Gardens assumed a most comic look of disgust and surprise, and walked off to the utmost limits of its chain.

It is easier to give a record of such experiments than to speak with confidence of the feelings excited in our various listeners. Darwin, while giving many instances of the expression of anger, pain, and fear, gives few of the expression of pleasure, or the milder emotions of curiosity and contentment. It will not, however, be difficult to show that in many cases the animals at the Zoo did exhibit pleasure and curiosity in a very marked degree; while strange to say, in the case of others, anger or fear was shown in all the modes which Darwin has described. With the behaviour of the wolves we may compare his description of the characteristic expression of fear in carnivorous animals, by erecting the hair and uncovering the teeth and trembling. "Cattle and sheep," says the great naturalist, "are remarkable for displaying their emotions in a very slight degree, except that of extreme pain." But in the case of the wild sheep, 
and even of the wild cattle, the pleasure and curiosity aroused by the music was plainly shown, as we have described above, by their instant attention and their approach towards the sounds. At the sudden discords they instantly showed displeasure by stamping the feet and retiring. The African elephant gave unmistakable signs of anger; the wild boar and pigs, of pleasure and curiosity; and among others which shared these amiable emotions, were beyond doubt the zebras, wild asses, Polar and grizzly bears, and the ant-eater. No creature seemed wholly indifferent except the seals, and the sudden start and displeasure at a discord was almost universal, from the snakes to the African elephant. There are many men, perhaps many races of men, who could not detect a discord, and would be indifferent alike to harmony and its opposite. Must we not, then, infer that, owing to some greater sensitiveness of the organ, most animals have a musical ear, and that the stories of Orpheus and his lute have, at any rate, a basis in the facts of animal resthetics? 


\title{
ORPHEUS AT THE ZOO.
}

\author{
THE CHOICE OF INSTRUMENTS.
}

"Last came Joy's ecstatic trial ;

He with viny crown advancing,

First to the lively pipe his hand addrest ;

But soon he saw the brisk awakening viol,

Whose sweet entrancing voice he loved the best."

Is a former trial of the effects of sweet sounds on animals' ears at the Zoo, our Orpheus was so far in character that he played but one instrument; and though the violin did duty for the classic lute, the audience was in many cases as responsive as in the groves of Thessaly, when music still was young. Our object so attained, curiosity went no further, though if a matter-of-fact and scientific age demands " results" as a natural sequence to experiments, however playful, we would sum up the conclusions then reached as follows :-All animals, except the cobras and the wolves, showed pleasure and curiosity when listening to soft and melancholy music; and all exhibited extreme dislike of loud, harsh, discordant sounds. Minor keys in all cases seemed most appreciated, and in 
some animals, such as the mountain sheep, the bears, and the wolves, they produced the strangest resultsin the first two of pleasure, in the last of fear. But though the violin-player is master of many sounds, and can even imitate the drone of the bagpipe, which the cobras so much enjoyed, it still remained to make trial of our hearers with other sounds than those of the tuneful strings. Animals, like the Passions, might have their favourite instrument, if only it could be found, and Orpheus, with his lute, could be matched against the shepherd's pipe, or could watch the emotion of his animal admirers while melancholy "poured through the mellow horn her pensive soul." Respect for the peaceful early hours at the Zoo induced us to forego, for the time, the trial of instruments of brass. But it was thought that the contrasts of the violin, the flute, and the shrill and piping piccolo, might afford some guide to animals' taste in instrumental music, without injury either to their own nerves, or to the comfort of visitors to the Gardens. The hour chosen was the earliest which the rules for securing the animals' comfort allowed; for the tests to be made were far more delicate than those by which we had proved the general susceptibility of animals to musical sound, and demanded the undivided attention of our captive hearers. The general order of our experiments, based upon the supposition that animal nerves are not unlike our own, was so arranged that their attention should be first arrested by a low and gradually-increasing volume of sound, in those 
melodious minor keys which experience showed them to prefer. The piccolo was then to follow, in shrill and high-pitched contrast. And, lastly, the mellow wood-notes of the flute were to soothe away whatever ruffled feelings the less tuneful piccolo had aroused. In case the creatures showed any marked preference for the flute over the violin, then the flute was to take precedence.

There is a curious attraction in watching these halfhuman appeals to animal emotion, and marking the quick look of interest and surprise visible in most of their faces, as the sweet sounds gradually steal on their senses, and the growth of pleasure-or fear-as the creature springs to its feet, and either advances eagerly to listen, or with bristling hair retreats to the farthest corner of the den, until perhaps pleasure or curiosity overcomes their terror at the unusual sounds. Pleasure or dislike are often most strongly shown where least expected, and the result of our last experiment goes to show that the tiger has stronger dislikes, if not stronger preferences, in the musical scale than the most intellectual anthropoid apes.

Our first visit was paid to "Jack," the young red ourang-outang, which, since the death of "Sally," the chimpanzee, claims the highest place in animal organization among the inmates of the $\mathrm{Zoo}$. $\mathrm{He}$ is a six-months-old baby, of extremely grave and deliberate manners, and perhaps the most irresistibly comical creature which has ever been seen in London. $\mathrm{He}$ is extremely well-behaved, not in the least shy, 
and as friendly with strangers as with his keeper. His arms are as strong as those of a man, while his legs and feet seem to be used less for walking than as a subsidiary pair of arms and hands. $\mathrm{He}$ is thus able, when much interested, to hold his face between two hands, and to rest his chin on the third, which gives him an air of pondering reflection beyond any power of human imitation. "He knows there's something up," remarked his keeper, as we entered the house, and the ape came to the bars and sat down to inspect his visitors. As the sounds of the violin began, he suspended himself against the bars, and then, with one hand above his head, dropped the other to his side, and listened with grave attention. As the sound increased in volume, he dropped to the ground, and all the hair on his body stood up with fear. He then crept away on all fours, looking back over his shoulder like a frightened baby; and taking up his piece of carpet, which does duty for a shawl, shook it out, and threw it completely over his head and body, and drew it tight round him. After a short time, as the music continued, he gained courage and put out his head, and at last threw away the cloak and came forward again. By this time his hair was lying flat, and his fear had given place to pleasure. He sat down, and, chewing a straw, sat gravely listening to the music. "He looks just like our manager when a new piece is on," remarked the violinist, as he concluded his share of the serenade. The piccolo. at first frightened the monkey, but he soon held out 
his hand for the instrument, which he was allowed to examine. The flute did not interest him, but the bagpipes - reproduced on the violin - achieved a triumph. He first flattened his nose against the bars, and then, scrambling to the centre of the cage, turned head over heels, and lastly, sitting down, chucked handfuls of straw in the air and over his head, "smiling," as the keeper said, with delight and approval.

The Capuchin monkeys are kept in a large cage next to one containing a number of grey macaques. The little Capuchins were busy eating their breakfast ; but the violin soon attracted an audience. The Capuchins dropped their food and clung to the bars, listening, with their heads on one side, with great attention. The keeper drew our notice to the next cage. There, clinging in rows to the front wires, was a silent assembly of a dozen macaques, all listening intently to the concert which their neighbours were enjoying. At the first sounds of the flute most of these ran away ; and the piccolo excited loud and angry screams from all sides. Clearly in this case the violin was the favourite. We then decided to take the opinion of some of the largest and least vivacious animals, and selected the young African elephant for our next auditor. As this animal had shown the utmost dislike to the violin on a previous occasion, the flute was employed to open the concert, and with complete success. The elephant stood listening with deep attention, one foot raised from the ground, and its 
whole body still-a rare concession to the influence of music from one of the most restless of all animals. So long as the flute continued, it remained motionless and listening. But the change to the piccolo was resented. After the first bar, the elephant twisted round, and stood with its back to the performer, whistling and snorting and stamping its feet. The violin was less disliked, but the signs of disapproval were unmistakable. The deer, as before, were strangely attracted by the violin, and showed equal pleasure in the tones of the flute; the gemul deer, for instance, ran up at once to listen to the latter, their ears and tails being in constant movement at every change of tone or tune. Even the ostrich seemed to enjoy the violin and flute, though it showed marked signs of dislike at the piccolo, writhing its neck and walking uneasily up and down its enclosure. The ibexes were startled at the piccolo, first rushing forward to listen, and then taking refuge on a pile of rocks, from which, however, the softer music of the flute brought them down to listen at the railing. The wild asses and zebras left the hay with which their racks had just been filled; and even the tapir, which lives next door, got up to listen to the violin; while the flute set the Indian wild asses kicking with excitement. But the piccolo had no charms for any of them, and they all returned to their interrupted breakfasts. So far, the piccolo had shown its inability to please in most cases. Of its power to annoy we soon had an amusing proof. The Lion House was almost 
deserted by the few visitors who were in the Gardens, and the opportunity of making trial of the musical preferences of its inmates was too good to be lost. The violin-player approached a sleeping tiger, which was lying on its side with its feet stretched and touching the bars, and played so softly that the opening notes were scarcely audible. As the sound rose, the tiger awoke, and, raising its head without moving its body, looked for some time with fixed attention at the player. It remained for some time in a very fine attitude listening to the music, and then making the curious sound which, in tiger language, does duty for "purring," it lay down again and dozed. The soft music still continued, as we were engaged in watching a cheetah, which showed great uneasiness and fear at the sounds, making sudden starts and bounds, raising the fur on its neck, and waving its tail from side to side like an angry cat. But whatever the cheetah's emotions of dislike, the tiger did not share them, but lay half or wholly asleep, as if the chords which were being played made an agreeable lullaby. Judge, then, of our surprise, when, at the first notes of the piccolo, which succeeded the violin, the tiger sprang to its feet and rushed up and down the cage, shaking its head and ears, and lashing its tail from side to side. As the notes became still louder and more piercing, the tiger bounded across the den, reared on its hind feet, and exhibited the most ludicrous contrast to the calm dignity and repose with which it had listened to the violin. Then came the final and 
most successful experiment. The piccolo was stopped, and a very soft air played upon the flute. The difference in effect was seen at once. The tiger ceased to "rampage," and the leaps subsided to a gentle walk, until the animal came to the bars, and, standing still and quiet once more, listened with pleasure to the music.

No doubt it is possible to draw very different conclusions from experiments of so imperfect a character as those which we have described. But it would probably be fair to infer that, for some cause, the violin and flute, which human taste has marked as among the most pleasing of musical instruments, are those most acceptable to animals under that unknown law which determines this branch of animal æsthetics. 


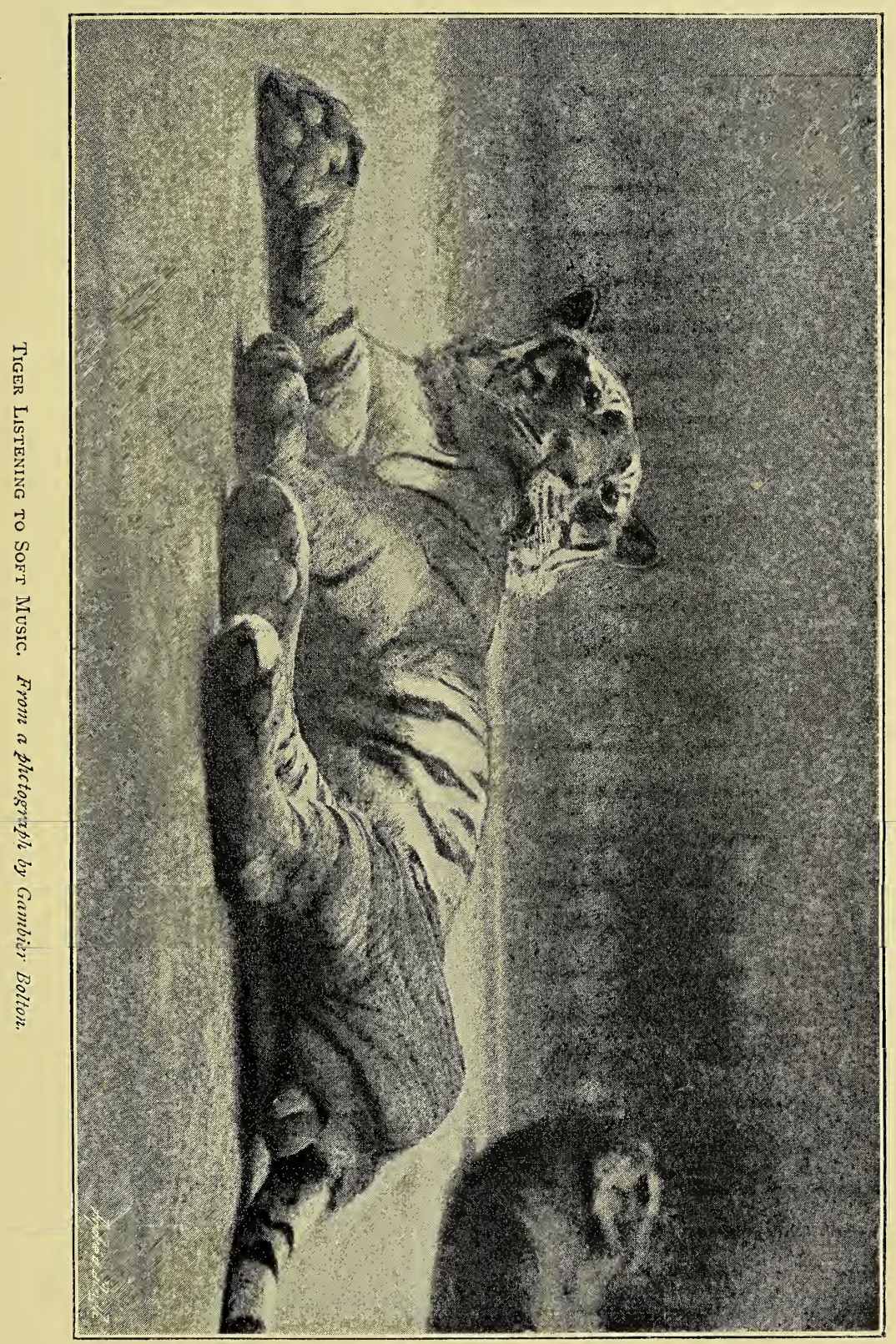





\section{TALKING BIRDS.}

THE parrots and macaws which live in the Parrot House at the $\mathrm{Z}_{\mathrm{Oo}}$ are so numerous and noisy that the keeper has no leisure to teach them to talk. But a parrot which can say a very few words is very quickly imitated by its neighbours, and a new phrase or word travels from cage to cage, should the birds in the immediate neighbourhood of the accomplished talker be of one of the imitative species. Among birds there are progressive and non-progressive races, which are indifferent to "self-improvement," and never try to learn a song of their own, much less to imitate the voices of other birds or of men. But the desire to gain new notes is very much more common than is generally believed, and there are at least twenty kinds of birds which are able to reproduce even the complex forms of articulate human speech. Aristotle mentions an Indian parrot which could talk, and "when it drank wine was somewhat improper," habits and language which it had picked up, no doubt, from Phœnician sailors. But the most accomplished talker of Indian birds is the mynah, a handsome purple-black bird, with 
a short tail, orange legs and beak, and bright yellow ear-flaps, which run round to the back of its head like a collar. It is a bold, lively bird, with a mellow song and whistle of its own. Its power of reproducing human speech is wonderful, and it exhibits the greatest anxiety that the tones should be correct, first repeating them softly to itself, with its head on one side, and then shouting out the words.

In the Insect House at the Zoo there lives a fine old mynah, who was "deposited" in 1883 . While a visitor is examining the Indian moths coming out of their cocoons, he may hear behind him a thoughtful cough, and the "Hulloa!" shouted with startling suddenness. It is the mynah, anxious to be friendly, and to begin a conversation. The Hindoo traders in the bazaars avail themselves of the mynah's services in a curious way. They teach it to pronounce the holy name of Rama; and while the master's thoughts are on earthly gains intent, the bird compounds for the neglect by shouting incessantly the name of the god, and texts in honour of his power. If the poet Ovid's Indian parrot finds its way, as he hoped, to the paradise of birds, and there

\section{"Convertit volucres in sua verba pias,"}

it must surely meet the mynahs also.

Another bird which talks better than most, and whistles better than any, is the piping crow. It is a lively black-and-white bird, as large as a rook, but far more elegant in form. Several specimens inhabit the 
Gardens, but the best is in the western Aviary, where it whistles "Merrily danced the Quaker," in tones like a flute.

The American blue jay, a most brilliant creature, with lines of emerald and turquoise, is an admirable mimic of many sounds, even of the human voice. Wilson writes of one "which had all the tricks and loquacity of a parrot; pilfered all it could conveniently carry off, answered to its name with great sociability when called upon, and could articulate a number of words pretty distinctly." Our English jays can also talk, and magpies, especially if kept in good health and spirits by being allowed partial freedom, soon pick up words. Jackdaws and the American crow can also be made to talk. But in all the crow tribe, except the piping crow, the reproduction of human speech seems to be more a trick of mimicry than an effort to acquire a substitute for song. Parrots, mynahs, and some cockatoos take infinite pains to learn correctly and increase their stock of phrases. But the magpie or jay learns what is easy, and takes no further trouble. Even the raven seldom has many words at command, though,-owing to its deep, resonant voice and imposing size, it attracts more attention than a chattering jay.

The raven is the largest creature, except man, that can "talk," and fancy and superstition have naturally exaggerated its powers. Still the speech of the raven has a depth and solemnity which that of no other bird possesses, and whether in boding utterances, like those attributed to the raven in Barnaby Rudge, or by 
Edgar Allen Poe, or in plain business, like the raven in Guildford Street, which used to say "Ostler, here's a gentleman," when a customer arrived, its powers are generally marked and recorded. A fine bird, belonging to a "statesman" in Northumberland, used to say "Poor old Ralph," or call the collie dog in the exact tones used by its master. "It's my very own voice," its owner used to say, laughing, as the dog came running in from the garden. But the crow tribe, though as clever as some parrots, are not so easily domesticated, and their beaks and tongues are less well suited for the musical sounds of human speech. Most of the parrots, and some cockatoos and macaws, have both the mental and physical gifts necessary to make them excel in talking. Parrots of all classes have fleshy tongues, moistened with saliva, and the arched beak provides a substitute for our palate and teeth. They have also wide nostrils, and their natural voices are loud enough and strong enough to equal the volume of human speech. In disposition they are highly imitative. Cockatoos are almost like monkeys in mimicking men. For instance, if you bow to them, they will make elaborate bows. If you put your head on one side, they will often do so too. But with many parrots the desire to learn new sounds is not, we think, a mere trick of mimicry, but the desire to possess a song-an accomplishment with which to please, identical in kind with the motive which prompts the young of singing-birds to learn their parents' notes, or, in the case of the canary, to learn and improve upon a 
song, not their own, which they have transmitted to their posterity.

The following account of the development of the talking power in a young parrot of which we have seen much lately, is, we submit, a strong confirmation of this view. Our informant is a lady whose sympathies are by no means limited to parrots, as the context will show, and her observations are wholly reliable. "We bought 'Barry," " she writes, "when he was quite young before his feathers were fully grown; and we had him about a year before he began to talk. Then he began to make very odd noises, as if he were trying to say words, but could not quite do it. Now he constantly learns new words and sentences, and early in the morning I hear him practising them over to himself, exactly as our babies used to do in the early morning hours in bed. If he improves as much in the next ten years as he has in the last, he should be able to recite a poem if we teach him." There is no reason why a parrot should not continue to increase his stock of phrases as he grows older, if the supposition that he looks upon it as an accomplishment for which he is in some way the better is correct. The butcher-bird, for instance, and the sedge-warbler do not rest satisfied with learning their own notes, but often learn and reproduce the notes of other birds in great perfection. The mockingbird, which, like the sedge-warbler, has a fine song of its own, does the same. But the parrot has an advantage in being very long-lived and constantly in human company. The young parrot mentioned 
before gave an excellent instance of the association in its mind of words with things. Before it could talk, it was friendly with a kitten which used to enter its cage. This kitten was sent away, and for a year there was not another in the house. Then a grey Persian kitten was bought, and when introduced to the parrot was at once addressed as "Kitty," a word he had hardly heard since the departure of the other. The correctness of parrots' imitation, the result, no doubt, of their careful practice, is remarkable. A lady of the Dutch Court, visiting the palace in the wood at the Hague soon after the death of the late Queen of Holland, was startled by hearing the Queen's voice exactly reproduced. It was a white cockatoo that had been a great pet of hers, which was in a corner of the room.

Parrots have no exclusive liking for the English language. They learn German, French, and Dutch quite easily. Another parrot at the Hague went through part of the Lord's Prayer in Dutch at an afternoon party, with other fragments of its mistress's devotions, which it had heard when in her room. All small white and sulphur cockatoos seem to say, "Küpper crou" when they want their heads scratched. We have translated it, "Scratch a poll;" but it is probably pure parrot language. Go up to any cockatoo and say this to him, at the same time holding the hand well above his head, and he will probably answer, and gradually lower his head and crest to allow you to gently ruffle the feathers the wrong way. 
Macaws do not seem to understand cockatoo language; but the grey parrots often use much the same sound. It seems to be a call-note expressing their willingness to make friends and be petted.

"Is the talking of birds due to mental or physical causes ?" is a question often asked. In the first place, no doubt, it is due to the disposition of the bird. Some parrots and cockatoos never learn to talk, though their organs of speech differ in no way from those of others that do. They seem to be without the imitative bias, like the hawks which have curved beaks and thick tongues, but are equally silent. But where the disposition to mimic is present, physical causes limit or widen the bird's powers. Parrots and the crow tribe are both imitative, but the parrots' beaks and tongues are more suited for imitating human speech, just as the raven, with his high-arched beak and big throat excels the jay. Other birds with still less suitable organs, such as the sedge-warbler, though excellent mimics, cannot reproduce human speech at all. There seems no reason why parrots, if they would breed in confinement, should not teach their accomplishments to their young ones, as the canaries have done theirs. Perhaps in time the experiment may be made. 


\section{ELEPHANT LIFE IN ENGLAND}

THE strangely artificial revival of elephant life in the countries north of the Mediterranean, and in districts where the bones of the fossil species show that they once lived and flourished naturally, is yearly more remarkable. The European elephant herd in the present year numbers one hundred and thirteen, or about thirty less than the annual catch in the keddals of the Indian Government. Their health seems quite independent of climate, to judge from the countries in, which they are kept, often with very rough provision against the chances and changes of weather. Russia owns eighteen, Sweden and Norway four, France and Belgium ten each, seven of which are in the great travelling menagerie of the Lockharts, which migrates to and fro across the Franco-Belgian frontier; Germany has thirty-four, and England about the same number; Holland has eight, and Italy two.

The British stock is at present supplied almost entirely from Burmah. There only in the East elephants are bred in a half-wild state and not caught 
in the keddahs. They are brought over to Europe when quite young, and are now so cheap that any one who pleases may become the owner of a sober, wellbehaved little elephant from four to five feet high, delivered at the docks, for from $\mathscr{E}_{\text {IO5 }}$ to $\mathscr{E}_{\text {I } 20}$, or not more than the average price paid for firstclass shire-horses. Their subsequent development depends mainly upon their daily treatment. In those which spend their lives at ease in the elephant palaces at the Zoological Gardens the rate of growth is surprising, and they soon develop into magnificent animals, not surpassed in size by the finest creatures in the stables of Indian rajahs. The pair of Indian elephants now in the Gardens are already nine feet and ten feet high at the shoulder respectively, though when they reached the Gardens in 1876 they were hardly bigger than a Shetland pony. But the greater number of English elephants spend their time as hard-working members of the large circuses and travelling menageries, and lead a wandering, homeless life, in curious contrast to the comfort which surrounds the fortunate inmates of the gardens of learned societies. Their deliberate movements mask a wakeful self-possession which hardly ever deserts them, and whether marching by the cornfields on the open downs, or through the streets of a manufacturing town, the elephant never misses a chance of levying contributions of food on the road. "Where didst thou teach thy elephant that trick?" says Petersen Sahib, in Mr. Rudyard Kipling's charming 
tale of the elephant dance, when the animal holds the mahout's son aloft in its trunk. "Was it to help thee to steal green corn from the roof when the ears are put out to dry?" "Not green corn, Protector of the Poor-melons," says little Toomai.

In England the elephant is not an accomplice, but helps himself freely in the back streets of the towns, up which he is usually taken, to avoid difficulties with the urban police. He has ever a sharp eye for an open window or door, and many a batch of new loaves smoking on the dresser or bunch of vegetables intended for the mid-day dinner, is extracted through the window, before the good woman, who is admiring the procession at the door, has time to rush back to the rescue. At Sanger's repository last year a fine gilded car came back for repairs. The body of the car had been filled with loaves of bread on Saturday night and then locked up. An elephant smelt the bread, and not being able to open the lock, turned the whole car over to see if it would open in that way, to the serious damage of the ornamental upper works. The clever picture of the "Disputed Toll," by Charlton Adams, in which an elephant is painted breaking open a turnpike-gate, records an amusing incident of elephant travel which occurred many years ago outside the pretty little town of Sidmouth in South Devon. Van Ambrugh's show was expected, and the turnpike keeper locked the gate and demanded toll, not only for the cars but for the animals. The elephant was leading the way, and after much 
fruitless argument, its keeper, slipping through the turnstile for foot-passengers, said to the elephant, "Come along, Fido," and the animal at once lifted the gate off its hinges and walked through. Cool and sagacious on the march, they seem also thoroughly to enjoy the tinsel and trappings, the music of the brass band, the lights, noise, and crowd of an evening show. Perhaps there is something in this which recalls to them memories of the "gorgeous East." Take for instance the annual "World's Fair" at the Agricultural Hall, which a Hindoo would describe as a very fine tumasha, and in which no one but an Oriental, a British working-man, or an elephant, could keep his brains clear for half-an-hour. Two large steam "round-abouts" at either end of the hall, grinding a different tune with an engine of ten-horse power, form only a portion of the bewildering attractions of this Palace of Delight. Opposite each of these machines, at the time of the writer's last visit, was stalled a small Indian elephant, cool, collected, and sagacious, his business mind wholly intent on raising contributions from the public. One occupied a compartment in the centre of what was magnificently described as the "Mammoth Wild Animal Congregation." He was a very little mammoth, not five feet high, black and bristly, supported on one side by a Persian goat and a kangaroo, and on the other by a couple of llamas. In front stood a stall of cakes, and to every visitor who came past the elephant pointed out the biscuit pile, his trunk main- 
taining a line true as the needle to the Pole, while his head and eye followed the movements of the passer-by. When quite neglected and alone, he tried to attract attention by dancing a kind of double-shuffle to the tune of the "round-about."

Some one rentured to give a biscuit to the unfortunate goat, its neighbour. The elephant dexterously twisted it from between the nibbling lips of the goat, and at once mounted guard to prevent any such diversion of its dues again. With ears cocked and eye alert, he held his trunk stretched out a few inches above the goat's head, taking it away for a moment to receive offerings tendered elsewhere, but switching it back to the suspected quarter the moment the dainty was swallowed.

Elephants suffer from nervousness, and occasionally from unreasoning panic, in England, just as they do in India. A windmill has been known to cause them to jib like a horse, and a large and very tame female Indian elephant at the Zoological Gardens actually died of fright, caused by a thunderstorm in the summer of 1855 . She was out at exercise, when a violent and reverberant peal of thunder caused her to break away from her keeper. When caught she was found to be in a pitiable state of terror, shaking and trembling with violent spasmodic twitchings of the whole body. When led back to her stable she continued to show unmistakable symptoms of shock and collapse. In a short time she lay down, and after a few days died, in spite of the anxious 
and skilled attention which she received from the first.

Minor instances of panic are not uncommon, but it is not often that the English-trained animal loses his head so as to be a source of danger to the public, as so frequently happens in India. This is partly because they seldom travel alone. In Mr. Sanger's menagerie, for instance, the elephants are led when on the march by an old chestnut thoroughbred, known as the "jumping horse," from his feat of clearing six five-barred gates in succession. It was when out at exercise without its usual companion that one of these elephants bolted at Highbury last September, and spent an afternoon in rambling about the suburbs of North London. The damage done by ti:e animal was greatly exaggerated, so far as the writer could judge after a visit to the scene of its exploits. The elephant was drinking from a water-trough just opposite Finsbury Park, when it took fright at the sudden ringing of a tram-car bell. Pursued by boys and policemen, it ran through the Park and down a street near the lower entrance. Seeing a large wooden gate, like that which leads to its own yard at Tottenham, it burst it open, and found itself in a labyrinth of small sheds and wooden stables at the back of some shops. Threading its way through these with wonderful agility, it ultimately arrived in a cul de sac in the yard at the back of a fishmonger's shop. Having thrown off its pursuers by this manœuvre, the elephant proceeded to make itself as much at 
home as circumstances permitted. It first kicked into quiet a collie dog which had resented its intrusion. Next it picked up its kennel and pitched it over the garden wall. Then cautiously approaching the kitchen door, it looked in to see if any provisions were lying within reach. Meantime the fishmonger, who was taking a nap on his sofa, was apprised that there was an elephant in his back-yard. Trespass, whether by man or beast, is a thing no British householder can put up with; so the fishmonger took down his whip and went to turn it "off his premises." "Jim" was at that moment looking in at the door, and elephant and fishmonger met on the threshold. Victory lay with the latter, but only to a limited extent. For the elephant, still bent on finding provender, broke in the door of the stable in which the tradesman kept his pony. 'The door was only six and a half feet high, and the elephant more than eight. But it stepped in, and being familiar with the economy of a stable, looked for the corn-bin. This found, it emptied the whole of the contents on the floor, and soon ate up a bushel of oats. This was not to be borne; so the plucky fishmonger determined to "catch" the robber when it emerged from the stable. This it did rather sooner than it had intended, as the pony, frightened at its strange visitor, avenged the collie by kicking the elephant's ribs. Outside, the indignant fishmonger and his man had barred the passage by drawing a light van across it, and, armed with whips, mounted guard on the other side of the 
barricade. Jim on his part took a long drink out of a small slate water-tank which stood near, and having refreshed the inner elephant with food and drink, surveyed the situation at his leisure. Seeing no other way out of the yard than that by which he had entered, he walked up, and with his head upset the van, and brushing past the garrison and through the crowd outside the gates, resumed his rambles in the streets. When captured, it was long past seven o'clock, and the animal was then well beyond the river Lea. No one was hurt by the elephant, and beyond the wanton destruction of a small shed belonging to a fishmonger, which it mischievously broke into pieces the size of barrel staves, and an unfortunate rush through five garden walls in a rather awkward place in Highbury Terrace, it did little harm to property. Next day it was seen by the writer, apparently none the worse for its adventures, though a violent scolding administered by the keeper's wife caused it obvious uneasiness. It could hardly swallow the hay which it was eating, but taking it from its mouth, rubbed its knees with it, turning its head away, and exhibiting signs of the utmost penitence and confusion.

African elephants are now very scarce in this country. This is due partly to the total blockade by the Dervish power at Khartoum of the ancient traderoute down the river. At present there are only seven left in Europe; of these one is in the London Zoological Gardens, one at Manchester, and one in 
Wombwell's travelling menagerie. But except to complete the collections of learned societies, the African is far less in demand than formerly. The elephant trade exists mainly to supply performing animals for the circuses, and the African is not popular with circus owners, or with their keepers or trailiers. This is strange, because it was in the Roman circus that the African elephant first became a popular favourite in Europe. Though the first war-elephants captured by the legions were baited to death in the arena, the later arrivals appealed just as much to the good nature of the populus Romanus as do their descendants to the British public. This fact suggests one of the few humorous remarks which can safely be credited to a Roman; and in keeping with the rarity of the event the joke was made by almost the greatest of all Romans, Caius Octavius Augustus, Emperor, Proconsul, Prince of the Senate, and Pontifex Maximus. One of the humbler Quirites, anxious to present a petition, was so fortunate as to escape the eye of the lictors and to catch that of the Emperor, who graciously stretched out his hand for the document which he saw lurking beneath the folds of the citizen's gown. Flustered at the sudden chance of royal protection, he pushed his scroll towards the outstretched hand, then shrunk back before the thought of almost personal contact with the human embodiment of power. "Come, man," said Augustus, "do you think you are giving a penny to the elephant:" "Putasne te assem elephanto dare?" 
To-day, though the public are ready to make the biggest elephant their greatest favourite, as in the case of the African "Jumbo," the keepers and trainers have little to say in favour of his kindred. Their opinion seems almost as unanimous as it is hostile. At the Zoo it is said that the Africans are "stupid," and therefore dangerous. For example, supposing an Indian elephant to be backing towards the wall, and so in danger of crushing its attendants, a push or a slap on its huge thigh will instantly be understood as a hint to move forwards, or to stop. The less careful African would probably take no notice of the warning, and the man must either slip on one side or be crushed. The trainer alleges that they have bad memories. This makes them uncertain performers in the ring. They will learn a few tricks without difficulty; but when called upon to show off in public, they are extremely likely to refuse their parts, and either to stand still, or bolt to their stable. There seems also to be a general feeling among circus attendants that they are unsafe. The fine young African elephant now at the Zoological Gardens has given far more trouble to its keepers than the two large Indian specimens during the far longer period of their sojourn in Regent's Park. When quite a baby its obstinacy was as marked as their docility. The Indian pair would walk round the grounds with their keeper between them, the man placing a hand on each of their backs, and the two solemn little fellows walking in step on either side. The African 
would not even take the bath which most elephants look upon as one of their greatest treats in hot weather. He roared, and kicked, and made such a determined resistance that it was necessary to rig up a block and tackle, and haul him into the water. When there he sulked, and seemed prepared to undergo the fate of drowning rather than the humiliation of obedience. The recollection that you may bring a horse to the water but cannot make him drink, hardly expresses the feelings of his keepers when they realized that the tackle which is sufficient to haul an elephant into the water may be unsuited for hauling him out. Ultimately the Chinaman's recipe for driving a pig-"If you no can pushee, no pullee, then try plenty stick," was adopted with success. The African elephant's "uncertainty" has one redeeming feature. It may shy or jib on one day, and get the better of its keeper for an hour or more, but he does not necessarily therefore lose prestige in the eyes of the animal, and can assert his authority next day unimpaired. An Indian elephant, if once the master in a deliberate act of disobedience, loses from that moment all respect for the man whom it has worsted. Inferiority in "parlour tricks," and in comparative docility, does not excuse the strange neglect which the native species receives as a beast of burden suited for the work of African pioneering. Dr. Sclater, writing from the offices of the Zoological Society in Hanover Square, says that there have been African elephants in the Gardens of 
the Society for nearly twenty years, and that in his opinion they are quite as intelligent as those of the Indian species, though perhaps not quite so docile. He suggests that a keddah of Indian elephants and their attendants should be transported to the East African coast, and that the Indian elephants should be used to capture and tame their African brethren. General Gordon, shortly before the disaster at Khartoum, wrote to Dr. Sclater advocating the employment of the elephant in Africa, and making inquiries as to its possibility. The size which the African elephant will attain under favourable conditions in this country is well illustrated by the case of "Jumbo." When this elephant came to the Gardens he was about four feet high and weighed 700 lbs. At first he was troublesome, but after a short time became perfectly manageable, and grew very rapidly. This was attributed by Mr. Bartlett, in his remarks on a paper read before the Society of Arts in I884, by Colonel Sanderson, to good food, and a daily bath in hot weather. In sixteen years he grew from four feet to eleven feet in height. By that time he was probably twenty-three years old. An elephant does not reach its prime till thirty-five, and Jumbo increased another ton after a year at Barnum's; he was therefore probably not full grown at the time of his lamented death.

The reasons for his sale were not very clearly stated at the time of his transfer. The cause of sale, in the case of any animal, is never a point on which 
the vendor is anxious to dwell. "Sold for no fault, but solely because the owner is giving up hunting," is the favourite formula at Tattersall's; and an elephant which is leaving a zoological garden to appear in a monster circus might be supposed to be disqualified for service in the latter, if it possessed any vice which made it an undesirable inmate of the former. The inference is more apparent than real; for the harder work and exercise at Barnum's could hardly fail to make a change in the impressionable elephant temperament. But a pleasing mystery surrounded the "deal." The shrewd sense of Barnum himself nursed the growing excitement on both sides of the Atlantic with a genial dexterity which will ever be considered a masterpieee of management among the illustrious exhibitors of the future. The Society, on their side, kept their own counsel, and the sale of the big elephant was briefly alluded to in the report as "made for satisfactory reasons given by the responsible executive." Neither did the price received figure as a separate item in the receipts. But as the amount credited to "Garden sales" exceeded that of the previous year by about $\mathscr{E}_{\mathrm{I}} 800$, we may assume that the sum paid by Mr. Barnum was well within that limit. A good authority informs the writer that the net payment was $£_{\text {Iooo. Mean- }}$ time the "Jumbo boom" was immensely profitable to the Society's revenue. The fees paid for admission to the Gardens rose by $\mathscr{L}_{5500}$ in the year, an increase which the Secretary's report attributes to the 
"great interest taken by the public in the removal of a favourite animal." The splendid new Reptile House, with its unrivalled facilities for observing the habits of the snakes, lizards, and alligators, was the result of this most welcome windfall. It was in fact the legacy of the African elephant to the Zoo.

The facts as to Jumbo's state of mind were afterwards clearly given by Mr. Bartlett. During the last years of his life in the Gardens he became at times very excited, and terrified every one who came near him except his keeper Scott, who had extraordinary control over him. "Scott," added Mr. Bartlett, "was a very curious man himself, and it was with the greatest difficulty that he could be persuaded to allow another man to assist him in the management of the huge animal. It was feared that if Scott fell ill, or were injured by the elephant, he would be entirely unmanageable, for no other man dared go near him in his house, though when out at exercise he was perfectly quiet. At night, however, he would tear about and almost shake the house down, and became such a source of trouble that the Council decided to part with him."

$\mathrm{He}$ was quite tractable in Barnum's show, and became the father of two little elephants. Scott went with him, and after his death in a collision with a locomotive, was offered the charge of a large stud of elephants which was shown afterwards at Olympia. But his sturdy independence rebelled against the wearing of "costume," which Barnum's feeling for 
the proprieties of the arena enjoined. Faithful to his old charge he mounted guard over the stuffed Jumbo, and preserved his hide from the knives of relic-hunting visitors.

In conclusion we may contrast the knowledge and skill shown in the management of Jumbo at a critical time, with the fate of an elephant which exhibited much the same symptoms, in the Liverpool Zoological Gardens, in 1848 , before the present race of English elephant-keepers had been trained to their work. This elephant, like Jumbo, was said to be the finest in Europe. It cost $£ 800$ eleven years before its death, and was said to be then worth $f_{\text {I }}$ ooo. It had already killed one keeper, accidentally, as it was thought, but not long afterwards it struck down and crushed a second. Such was the panic of the owners, that two six-pounder cannon were bought from the Albert Docks, and set loaded opposite to the elephant's house, in case it should succeed in escaping. As it remained quiet, two ounces of prussic acid and twenty-five grains of aconite were given to it in its food. As the poison did not seem to take effect, thirty men from the 5 2nd Regiment were ordered to shoot it. The first fifteen delivered their fire, and as the creature did not fall the next squad discharged their muskets, and the elephant sank dead with thirty bullets in his body, together with enough poison to kill a ship's company.

It may fairly be claimed that we have made some progress in the management of the elephant in 
England, since the days when the owner of such a valuable animal was not only incapable of keeping it with safety, but ignorant of the means to kill it humanely. The average duration of their life in this country is now probably well over fifty years; and though this does not contrast favourably with the eighty years of the Indian studs, there is every prospect that it will increase. The office of mahout promises to become almost as hereditary here as in India; and while traditions of elephant management are handed down from one generation of keepers to another, so it is noticed that the new and acquired habits practised by the more experienced and sagacious animals are observed and copied by the young arrivals. The elephant is being slowly Europeanized. 


\section{WANTED-A NEW MEAT.}

THE lack of variety in those meats which, whether flesh or fowl, must always form the ground-work and basis of an English bill-of-fare, is a want keenly felt, but most difficult to remedy. To judge from the list of fresh food which the improved transport of the last few years has made available for the London dinnertable, a natural inference would be that, so far as novelty has been studied, we had made provision, not for man as humanized by Schools of Cookery, but for a race of fruit-eating apes. We have a dozen new fruits, shaddocks, limes, custard-apples, bananas, pines, Italian figs, pomegranates, lichees, ground-nuts, gourds, watermelons, and avocado pears. But among the thousands of tons of foreign game imported yearly, there is hardly a beast or bird which may not be had in better quality and condition at home, except the prairie-bird and the quail; for those canvas-backed ducks which escape the keen search of the New York dealers and find their way across the Atlantic, alight only on the tables of City Companies and millionaires, like the caladrus of old, that appeared only at the deaths of 
kings. Yet there are probably twenty people in this country who have eaten canvas-backed duck for one who has ever tasted swan, or rather cygnet, the finest water-fowl for the table alike in size and flavour, a bird easy to rear, most prolific, rivalling even the breast of a teal, without the fatal drawback of that excellent little bird, that no one has ever been able to get enough of it. Even now, though so neglected by the world, swans may be had from the Norwich Swan-Pit for $\mathscr{E}_{2}$ each. They weigh some sixteen pounds, and with them is forwarded an ancient recipe for cooking them- "done into rhyme by a Person of Quality."

Another "fowl" which was once reserved for the tables of kings, and is now hardly thought good enough for aldermen, is the peacock. What roast swan is to roast goose, such is roast peacock to roast turkey. Many owners of country houses who keep peacocks and let them run wild and nest in their woods and shrubberies, take little trouble either to fatten or cook the pea-chicks. If they did, they would perhaps take more pains to rear these birds for the table. The meat is very white, and of exceedingly fine and close grain, and has the true game-flavour, with none of the stringiness of the common turkey. The American wild turkey is, however, an even finer bird for the table than the peacock. Those which appear in the poulterers' shops of London generally arrive in such bad condition from careless packing and refrigerating, that they are inferior to the domestic bird. But when allowed to run wild and nest in 
English woods, as is done on some estates, on its merits, and apart from any tricks of cookery, it is perhaps the very best land-bird that is available for food. The game-flavour is not too pronounced, but gives a character to the whole which is altogether absent in the tame black turkeys of the farmyard.

But flesh, and not fowl, is what is mainly desired to widen the possibilities of the dinner-table. Fatted swans, or peacocks, or American turkeys might be increased and multiplied without affording more than an occasional relief to the monotony of the menu and the brain-searching of housekeepers. What is wanted is some new and large animal, whose flesh has a character of its own which would readily distinguish it from beef or mutton, and an excellence which shall make it independent of any special treatment in cooking,-something which shall combine the game-flavour with the substantial solidity of a leg of mutton. An increase in the quantity of venison reared in this country naturally suggests itself; and it is not impossible that, in neglecting the produce of our deer-parks, we are hardly less careless than in losing sight of the culinary possibilities of the swannery. Good doe-venison may be bought in the neighbourhood of some large parks at a much lower price than mutton; and the quantity of first-class venison which finds its way to London is surprisingly little, considering the number of parks and private herds in the country. It is objected that deer can never pay to fat for food, because the annual growth of their horns reduces them so much in 
condition as for a time to make the venison worthless. But this applies only to the bucks; stags might be kept like bullocks, and doe-venison might still be remunerative. As early as I740, an enterprising Jersey squire, of the name of Chevallier, who had succeeded to an estate in Suffolk-whose descendants still constantly sit in Parliament-had formed a small park for fattening deer and sending them up to London. His accounts of the cost and profits of the enterprise are still preserved, and he abandoned the scheme, not from difficulties encountered in fattening or selling the deer, but because of the uncertainty of carriage to London. Venison, even when reared under the present unscientific method, or rather want of method, varies greatly in quality, that from certain parks being much superior to that grown on less suitable pasture; and it is not too much to hope that, if bred and fattened solely for the table, venison would be in demand as something more than an occasional luxury.

But swan, peacock, and venison are, after all, only revivals of the old bill-of-fare which was available in the households of Old Enyland. To find a new meat, we must take stock of the world's resources of animal food, and inquire, after due survey, if there does not still exist some neglected quadruped which will furnish what we seek. Roughly speaking, our main supply of animal food is drawn either from the rodents, the ruminants, or the pachyderms,-represented by the rabbit, the ox or sheep, and the pig. To vary the supply at our disposal, we shall probably not 
be able to go beyond these limits; for the general experience of civilized man has already pronounced judgment on the question, and science supports the verdict. It is no good to eat a wolf; for the wolf has already got the benefit of eating the lamb, and left no surplus for us. Of the three great tribes, the rodents may be dismissed from our search; for those that are not already used as food are either too small to be useful, as the lemming or the guinea-pig, or too repulsive in appearance, like the capybara, or in habits, like the rat. Of the pachyderms, we find only one which is domesticated for food-the dear, familiar Berkshire or Yorkshire piggie. The larger pachyderms are too big; the smaller, like the peccary, too savage; the wart-hog and other African varieties too repulsive. Clearly, then, we must have resource to the list of ruminants if we are to find one to add to the British bill-of-fare. At first, the choice seems wide enough. It embraces all the deer-tribe, the wild sheep and antelopes, goats and ibexes, which are numerous; but they all possess a rank and disagreeable flavour, which must prevent their coming into the list of firstclass food. The possibility of extending the supply of venison we have already considered. The wild sheep would probably differ so little in flavour from mutton as to make it hardly worth while to domesticate them, though those of the Himalaya will breed freely in confinement. The antelopes and wild oxen, therefore, alone remain, and it is among their number that the animal wanted must be found, if it is to be found at 
all. If the accounts of African hunters are reliable, the venison obtained from the larger kinds of antelope found in South and Central Africa is really excellent, that of the koodoo, the oryx, and the eland being the best. Perhaps the highest modern authority on the subject is the opinion of Lord Randolph Churchill. Those who read of and sympathized with his account of his sufferings under the cuisine of the Cape steamers, must have marked with a feeling of relief, that in his letters to the Daily Graphic he confessed to having made an excellent supper on stewed roan antelope. His verdict on the eland has not been given, but its flesh is said to surpass that of all other antelopes by as much as Welsh mutton surpasses Lincolnshire "teg." Ten educated palates have pronounced it "peculiarly excellent, having in addition the valuable property of being tender immediately after the animal is killed, which makes it much appreciated in Central Africa, where the meat is usually tough and dry."

In addition to the quality of the meat, the eland has the additional recommendation of large size. A full-grown eland is as large as a two-year-old shorthorn, and has far more the appearance of a high-bred Indian bullock than of an antelope. Its horns are short and straight, pointing backwards, and it has a dewlap like an ox. It can live on the hardest fare, and soon grows fat on good pasture. Best of all, it becomes quite tame, and is easily acclimatized.

When Lord Derby, the President of the Zoological 
Society, died in $185 \mathrm{I}$, he directed that his herd of five elands at Knowsley should be given to the Society for use in their menagerie. They multiplied fast, and six fawns were produced between $185 \mathrm{I}$ and 1855 , and it was found that at two years old they stood thirteen hands at the shoulder. The protection necessary was not more than that usual in fattening fine cattle, and the Society resolved to sell their fawns for the experiment of acclimatization in English parks. Lord Hill bought a young male and two females for his large park at Hawkstone; but according to Whitaker's Deer-Parks of England, none of these survive. The Marquis of Breadalbane also bought three. In I86I, twenty-one calves had been born in the Zoological Gardens since Lord Derby's gift ten years before, and there is still the nucleus of a herd of their descendants at the Zoo, though their size and stamina is diminished by inter-breeding. It does not appear that eland breeding is now followed with much enthusiasm by the owners of large parks and chases, partly, no doubt, because the "shorthorn mania" was for a time such an absorbing pursuit among country gentlemen as to leave no thoughts for any other experiments.

It seems a waste of the resources of nature to allow these fine animals to be exterminated, as they soon will be, in our new African empire. The argument, that because South African negroes have not tamed them, we should not attempt to do it, is of little force. The African keeps cows to give milk; meat was supplied in inexhaustible quantities by the wild 
antelopes and other game, and with far less trouble than domesticated animals give, until the white man with guns destroyed them. We are too apt to forget that England owes the best of her trees, vegetables, and animals to other countries. All are now so good that we are prone to believe that neither can be added to or improved. Perhaps Admiral Rous was right when he declared that it made him "simply sick" when an Arab cross was proposed for our English thoroughbreds. But why should we not save the eland, the harness antelope, and the koodoo, and other large African species from extermination? America has almost allowed the bison to perish. Shall we not take warning, and preserve for our own use the splendid African antelopes, which, within the memory of man, were a thousand times more numerous than they are to-day: 


\section{AN EXPERIMENT IN ANI.MAL PRESERVATION.}

WHEN the founders of our Zoological Gardens formed plans for acclimatizing foreign animals in England, they could scarcely have imagined that the Gardens might form almost the last preserve of animals then living in enormous numbers in America. Yet it is not beyond the limits of possibility, that our Zoological Gardens may within a few years contain the last living specimens of the American bison. It is said that thirty of the surviving herd in Yellowstone Park were recently killed by poachers for the sake of their hides and horns, and the chances of their survival in the United States are thus further diminished. If they do not disappear altogether, it will be in a great degree due to an experiment in the preservation of wild animals and natural scenery, undertaken by a wealthy American, Mr. Austin Corbin.

The story of the enterprise, so far as it has yet appeared, is given in a connected form in the last report of the Smithsonian Institution of Washington. 
Mr. Corbin is a "railway king," who owned a property on Long Island. There he amused himself by keeping a few deer at his home-farm, not in a park, but much as antelopes, elands, and bison are kept in the Queen's stock-yard with the domestic cattle at Windsor. This was in 1886 . Six years later Mr. Corbin conceived and carried out an idea for extending his deer-farm on a scale which a comparison with some of the forest areas most familiar to Englishmen, scarcely enables us to grasp. He bought twenty-two thousand acres in a compact block, and to these he subsequently added an adjacent territory of eight thousand acres more, and reserved them as a sanctuary for all such of the large game of North America - with the exception of bears, pumas, wolves, and foxes-as could be obtained to stock the ground. The area so reserved is larger by a quarter than the twenty-two thousand acres of the Forest of Dean. Windsor Forest contains barely fourteen thousand acres, and the New Forest alone of the ancient gamepreserves of the Crown exceeds it in dimensions. But all these are forests in the proper sense, not enclosed parks, the animals of which are fenced in and protected. The Corbin preserve is a true park, surrounded with a fence high enough to confine a wapiti, and strong enough to resist the charge of a bull bison, and entered by nine gates, each under the supervision of a resident warder. Contrasted with an English park, it differs alike in dimensions and general purpose. Here the object of the enclosure is to 
surround the mansion with a wild domain in which deer may run wild within certain limits, and trees reach their finest proportions without formality. The park and its contents are really subordinate to the daily pleasure and convenience of the resident owner, though in some cases, notably that of Warwick Castle, small and ancient deer-parks exist at a distance from the mansion, and form preserves much in the spirit of Mr. Corbin's forest. But this enclosure of thirty-five square miles in a ring-fence must be without a rival either in modern or ancient history, though perhaps the "paradises" of the Persian satraps, "filled with all kinds of wild beasts and trees," watered by numerous streams and enclosed by walls-parks like that in which Xenophon and the Greek captains were led to expect that the army of the great king was lying in wait to destroy themmay have approached it in size.

The modern "paradise" lies in New Hampshire, almost the northernmost of the old States, on the Atlantic slope, between Vermont and Maine, and incloses a portion of the "White Mountains" and hill-lands, running northwards from the Alleghanies to the banks of the St. Lawrence, east of Montreal. It is a temperate and well-wooded region, and water is abundant. The park itself contains two large pools of twenty and thirty acres, and nearly two miles of streams, with timber of all sizes, and good pastureland. Bison, beaver, and deer should all find favourable conditions in such a spot. The work of stocking 
the park was doubtless made easy by the owner's indifference to expense; $£ 80,000$ were laid out on the purchase of the land and the costly fencing alone; but $\mathrm{Mr}$. Corbin was fortunate in being able to obtain twenty-five bison from the few survivors of the wild herds to start his "buffalo ranch." Those bred in the paddocks of England during the last fifteen years have steadily deteriorated in size and stamina, the cows growing yearly more "weedy" and less prolific; but there must be some source, not generally known, from which they can still be bought, though at a high price. Cross, the Liverpool dealer, is said to have sold ten cows two years ago, and those in Mr. Corbin's preserve show a disposition to increase and multiply. The history of the Chillingham and Chartley wild cattle, which, though inbred for generations, remain vigorous and prolific when allowed to live their natural life in parks not a tenth of the area of that in which the bison now roam, gives good ground for hoping that the existence of the bison may now be prolonged for such time as American sentiment may think fit to preserve them. Besides the bison, the original stock in the Corbin Park includes sixty wapiti deer, or "elk," as they are called throughout North America; seventy deer, probably the black-tailed deer of the Rocky Mountains; six cariboo, the American reindeer; six of the rare prong-horned antelopes; twelve moose, or elk proper; eighteen wild boars, and by this time, it is hoped, a colony of beavers. Of these, the moose, the ante- 
lope, and the beaver must soon be extinct species, unless protected by some such means as $\mathrm{Mr}$. Corbin has chosen to preserve them. The cariboo seems to have migrated beyond the extreme margin of human habitation. Though rapidly disappearing in the North-West, immense herds were seen last summer by explorers in the almost unknown "barren lands," fringing the Arctic Sea, and the mouths of the Coppermine and Fish rivers. The hunters employed in the capture of the various deer were fortunate enough to discover a "moose yard" in the deep snows of northern Canada, in which three hundred animals were collected on the area which they had stamped down and made safe for movement amidst the snow. Six of these were found isolated from the herd, and adroitly frightened into the deep snow, in which they were easily captured, the weight of the animals breaking through the crust of ice above, and leaving them helpless. These were sent with others a distance of two thousand miles by train in four days; but neither they nor any of the deer would feed while in the train, and several of them died either in transit or after their arrival. Twenty deer were also killed in a railway collision. But more than two hundred animals were before long collected in what is to be their permanent home, and the wapiti alone have already doubled in number.

The limits to be set to the increase of each species, should the experiment prove successful in all or most cases, will no doubt be matter for careful inquiry. 
Large as the area is at their disposal, the space required by wild animals is far larger than that which suffices for domestic creatures. The three acres of good land which is supposed to suffice for the poor man's cow, expands to twenty-five acres of the best deer-forest as the yearly keep of a single stag; and, setting the increased size of bison, moose, and wapiti against the better pasturage of the New Hampshire hills, it is probable that the proportion of game to acreage in Corbin Park cannot safely be increased beyond the limits which experience shows to be necessary in the forest of Blair Athole. Two of the species, the moose and the beaver, live entirely on the branches of trees. The beavers are far more destructive than the moose, and will soon level all the timber near the streams. A single family in the Island of Bute cut down one hundred and eightyseven large trees in ten years, and it is not likely that they will be less industrious in what was once their native home. Twenty thousand hawthorn-trees have been imported from England to be planted, not as a vast and beautiful feature in the landscape of the park, an experiment well worthy of the author of the enterprise, but as a hedge to take the place of the wire fencing which now surrounds the enclosure. The beavers will soon convey the thorn-trees to their "lodges," and make an easy road for the escape of the rest of the colony.

Nothing is said of the removal of human occupiers from this area, though it seems improbable that such 
favourable soil should be void of inhabitants, even if the exhaustion of the land in the old States, and the movements of the inhabitants westward, has been as rapid as recent observers would have us believe. New Hampshire is a small state; yet we hear no protests against the exclusion of population from an area one-third of that of the New Forest. On the contrary, the project seems welcomed as suggesting a new employment for millionaires. Preservation of every kind is costly, and, as a rule, makes no return in a case in which sentiment, and not prudence, suggests it. When States intervene, it is generally too late, and there is always a suspicion that the rights of the poor may in some way be interfered with, just as in the case of preservation by ancient landowners, whether of game or trees, or streams or mountains. But though Mr. Corbin's enterprise provokes no suspicion, and seems to have gratified American sentiment, he is evidently aware that time and continuity are essential for its success. The association of his son with the fortunes of the park gives a guarantee of permanence not perhaps equal to the traditions that have maintained Chillingham and Chartley, but sufficient to insure a fair trial for the experiment. 


\section{“JAMRACH'S."}

"JAMrach's," the ancient and original centre of the wild-beast trade in London, lies in what is now called St. George Street, but was until late years known as Ratcliffe Highway, not many minutes' walk beyond the Tower. It existed when the King's lions were kept in the Tower itself, and was established thirty years before Sir Stamford Raffles conceived the notion of the Zoological Society. The shop itself is almost the oldest building in the street, far older than the docks and their lofty warehouses opposite, and dating back as far as some of the later work in the Tower itself. The main bulk of the traffic from the docks which line the river for miles below rolls past its doors, which open to receive the ship-captains' ventures of birds and wild beasts, armour and "curios," idols and fetishes, mummy and Dyak skulls, weapons and snake-skins, and the odd zoological bric-à-brac which are part of the minor stock-in-trade of the "naturalist" salesman. The front of the shop in which these are displayed looks like an old picture. Time and varnish, with the dust 
of the docks, have given a rich mellow colour both to frame and contents, in curious contrast to the brilliant hues of the parrots and lories which fill the cages in the adjacent window. In the little office at the back the steady traffic in wild beasts has gone on for a hundred years, between the Jamrachs and the ship-captains in the first instance, and later with the buyers employed by Zoological Gardens and menageries. Frank Buckland, Van Ambrugh, and Mr. Bartlett, and most of the great circus and menagerie proprietors, have sat in the old Windsor chairs, and discussed the merits of new purchases, or schemes for the capture of rare and valuable animals.

Few even of the most ancient business houses of that most picturesque and characteristic part of London, the City, and the eastern wards which cluster round the Tower, have retained their old form so entirely as this. Some of the old back parlours and lobbies are still provided with the racks of blunderbusses and bayonets, which the traditions of the Gordon Riots suggested as a terror to daylight robbers, and a guarantee of security to timid depositors. Others keep upon their walls the charters and firmans granted to adventurous merchants by sultans and chieftains whose territories are now well-regulated provinces of the British Empire. But the trade of Jamrach's has this peculiarity, that it always deals in commodities which as a rule disappear before advancing civilization, and must be drawn from 
beyond the ever-encroaching limits of common commerce; from the regions where the half-armed savage still robs the cubs of the Gætulian lioness, and barters his barbaric spoils for the wares of the civilized West. So in the old room at Jamrach's, the barbaric settings have gathered almost without intention round the spot which the nexus of commerce links with the rough outside edge of the white man's world, and the ciusty shields and assegais, the bolas and bows, the matchlock and two-handed swords of the rhinoceros-hunting Arabs, are mingled with sharks' and crocodiles' skulls, scalps and tomahawks, wampum and Indian relics, and whatever in the unnumbered lumber of the world of savage sport and warfare corresponds to the tamer accessories of the "gun-room" in our English country houses. The place of the favourite dog before the fire, to continue the simile, is of course taken by some foreign pet which is the favourite of the moment. At the time of the writer's first visit to this naturalist's sanctum the goddess of the hearth was a lovely little Japanese pug puppy. The little creature was covered with the long silky black and white hair which in the Japanese pug, like the Japanese bantam, takes the place of the shorter and less elegant covering of the Western breed. It was carefully clothed in a neatly-fitting flannel jacket, and apparently had all the fondness for English habits which distinguishes the cultivated classes of modern Japan. It sat up and begged, and wagged its tail like an educated little 
British dog, and carefully measuring the appreciation and temper of its visitor, suddenly dropped ceremony and bounded into his lap. There, after an apologetic wriggle, it curled itself up, and its master discussed the present and future of the animal trade.

A great revival in this ancient industry has recently taken place, and at the time of the writer's visit Carl Hagenbeck, the largest owner of wild beasts in the world, and exhibitor of the model Zoological Gardens at the World's Fair, was making a rapid inspection of the stock of animals on view, in order to make purchases for his new gardens in New York. In most forms of live-stock buying, the necessary acquaintance with the points of two or three species is sufficiently difficult to master. In the present case it was necessary not only to judge the merits of the animal, but to identify the species with certainty. But once among the stalls and cages, the "deals" for a dozen different species were made in less time and with less discussion than a Berkshire farmer would feel due to the merits of a litter of pigs. The "stables," as the wild-beast store is called, lie away from the shop and the main street, up a narrow court, like those which run back from the north of Fleet Street. Up this passage every animal must be either driven or carried before it can be deposited in safe quarters in the store, and though its length and want of breadth lend themselves to blocking the escape of any creature which might succeed in breaking out, it must offer considerable difficulties to the transit of a large iron 


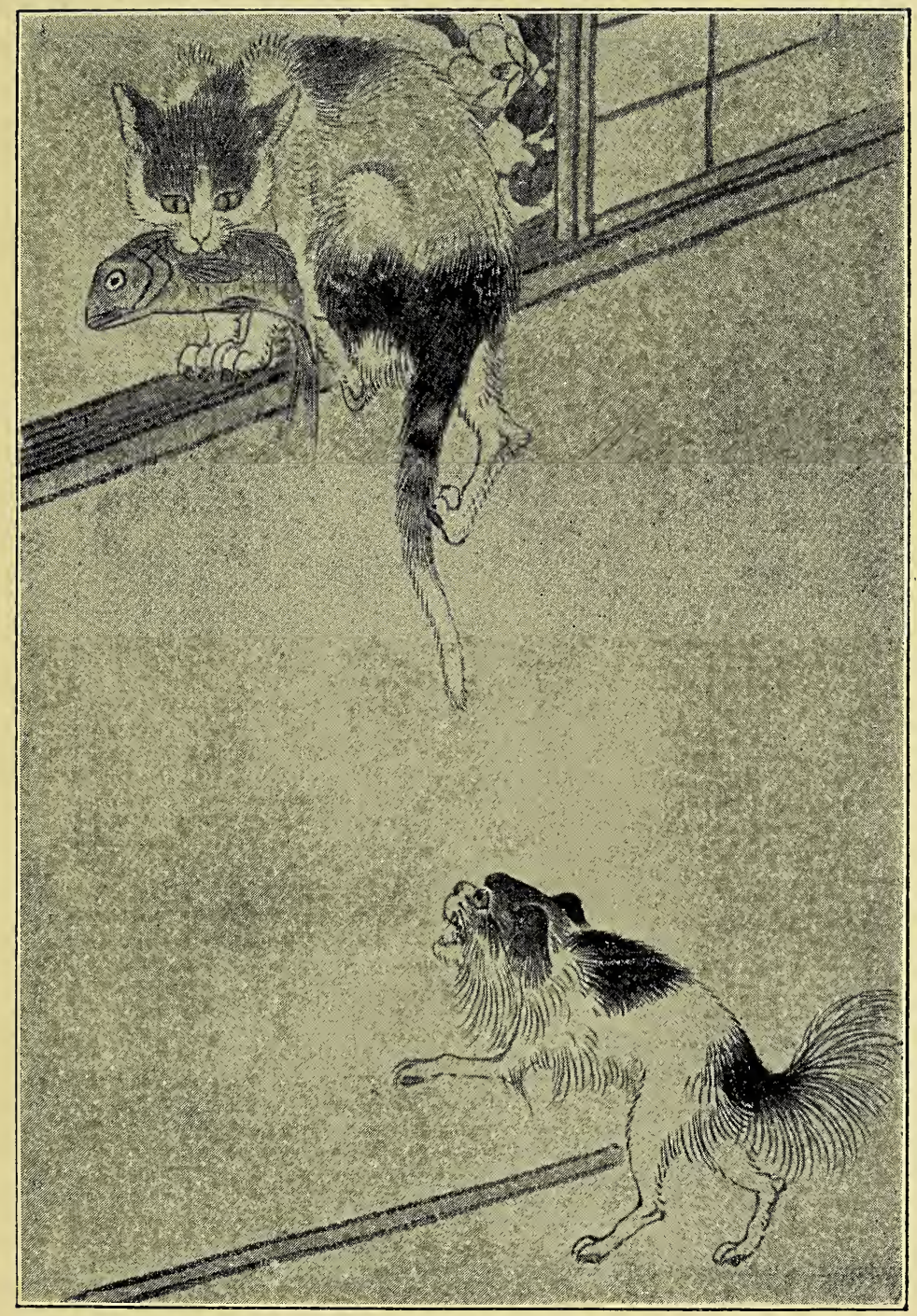

JAPANESE DUg AND CAT. From a Japanese Drawing. 

cage, or of a refractory camel or elephant. The lower storey of the "stables" resembles a large, well-warmed London cow-house, with antelopes, deer, or kangaroos tethered to the walls and mangers, or stalled in looseboxes, instead of Alderneys and shorthorns. An immense aoudad, ${ }^{1}$ with wild yellow eyes, horns curving in an almost complete circle, and a thick shaggy beard continued into a fringe down its chest, and sweeping the ground between its feet, occupied the first loosebox. Most of the other pens were vacant, as a large shipment had left that day for the United States.

A steep flight of steps leads to the second and third storeys, in which the animals are stored, not for exhibition, but just as they have come from the ships in the docks close by. There are no fixed rows of cages for the carnivora, or wooden pens for the large birds and harmless quadrupeds, because the former are delivered in their sea-cages, and the latter have grown used to confinement, and are either tethered or confined by wattle hurdles in corners or against the walls. The gallery is warm and dark, an important element in the comfort of the nervous, night-feeding animals, and of the more savage felida, lighted only by one or two gas-jets, and redolent of sweet-scented cloverhay. The floor is encumbered with boxes of various dimensions, with all kinds of inmates, from squirrels and civet cats to pumas and panthers. The small size of the box or cage in which a large leopard or panther will live in fairly good health for several

1 The Barbary sheep. 
weeks makes their transport an easy matter. They curl up like a cat in a basket, and if kept quiet and in the dark, do not greatly suffer in condition. The semi-darkness, and the position of the boxes on the floor, make it difficult to see the full beauty of the prisoners within. Nor is it desirable to approach the roughly-constructed cages too closely. The animals at Jamrach's are not the half-domesticated creatures of the Lion House at the Zoo, but the wild and savage denizens of tropical jungles, captured but not yet cowed, or even reconciled to the proximity of man. As parts of the fronts as well as the sides and backs of the cages are boarded over, the visitor naturally seeks a view from a point somewhat close to the bars-an approach which is at once converted into a sudden movement in retreat, as the animal inside appears to explode. A crash of claws upon the bars, a sharp, throat-splitting blast of growls, and a glimpse of white teeth and yellow-green eyes in the darkness, is the instantaneous expression of the panther's dislike to intrusion. If the shutters are removed, and the light admitted, the beautiful creature shrinks slowly backward and downward, its soft and elastic body slowly contracting and flattening with the fluid suppleness of a python's folds. A pretty pair of young African cheetahs in another box spat and bared their teeth with a show of high resentment which would not have discredited wild beasts of a far larger growth, and maintained a bickering sputter of repugnance and hostility till the offending gaze 
was withdrawn. Two large and richly-coloured Patagonian pumas, a pair of leopards, and several striped hyenas, and small jungle and civet cats occupied the same gallery. Of these, the pumas were perfectly tame, as safe to caress and as willing to be petted as a cat. They do not even catch the infection of ill-temper from other animals; and the writer observed a puma arching its back and rubbing its face against an attendant's hand, quite unmoved by the hostile growls of the panther, its neighbour. These pumas had probably been domesticated for some time, and a certain proportion of the fiercer animals which arrive at the docks must have been in captivity for some time previous to shipment. Men who habitually deal with wild animals are quick to see the difference between the savage and the half-tamed beast. Van Ambrugh, the celebrated liontamer, is said to have called at Jamrach's to purchase a leopard. He soon selected one from the boxes, and when asked how he would like it to be sent, produced a steel chain and collar from the pocket of his greatcoat. He then opened the box, dragged the leopard out, put on the collar, and hauled it down the passage and into a four-wheeled cab, in which he drove off to Astley's with his purchase. The strange medley of animal forms in the upper chambers, the gleam of green and yellow eyes in their dusky recesses, and the juxtaposition of creatures whose natural instinct is inveterately hostile, with others which are their common prey, give to the 
chance menagerie at Jamrach's a character quite distinct from any exhibited collection. The creatures are there for sale, not for show, and meantime are kept as quiet and as close together as due attention to health permits. The panthers' room was shared by an African black-buck from the Cape, a blacktailed jackal, various kangaroos and wallabies, and a pair of demoiselle cranes. On another storey were a happy family of monkeys, lemurs, and Chinese dogs, a pair of cassowaries, a viscacha, foxes large and small, "native companion" cranes, a brown Tasmanian opossum, coatimundis, a beautifully-marked civet cat, and two small Siamese porcupines. This list, though apparently no bad nucleus for a Zoological Garden, is only a fraction of the number which is usually stored in the depôt by the docks. There is a sudden and unprecedented increase in the demand for wild animals at present, not only for the Continent, but for the United States. The stocks in most of the European Zoological Gardens have decreased of late - a shrinkage partly caused by the closure of the Soudan by the Dervishes. In America the popularity of the great menagerie at the World's Fair has created a sudden demand for wild animals of all kinds. Circuses and private menageries are competing with the Zoological Gardens and scientific societies for rare and interesting animals, and the demand for America is far greater than for the continent of Europe. After five or six years of neglect, there is such a "boom" in the wild-beast trade as is hardly 
remembered. Until the expeditions which Hagenbeck and others have despatched into Central Africa, via Berbera, and into Borneo and the West Coast of Africa, return, there is little to fall back upon but the average supply which arrives without system and in chance ships. A single purchase by an agent from the Philadelphia Zoological Gardens included a leopard, a hyena, a pair of cheetahs, a Bornean bear, antelopes, emus, and other birds. Other Zoological Gardens are being laid out and built in New York and the cities of the West; but it may be doubted whether, even from Jamrach's, the inhabitants will readily be found to occupy them.

The frailness of the cages in which many of the animals arrive from their sea voyage is matter for some surprise. They are nearly always wooden boxes hardly stronger than a sound packing-case, with a front of strong iron rails. The secret of their safe carriage lies in their own stupidity. Like a lobster in a pot, they always endeavour to escape from the front, springing towards the light, and it is precisely at this point that the strongest part of the case, the iron bars, blocks the way. When the last black leopard arrived at the Zoo, as a present from the Duke of Newcastle, who had purchased it at Singapore when on a tour round the world, it was soon shifted from its travelling cage into the fine new den it was to occupy in the Lion House. As it was known to be a violent and savage creature, an inner lining of steel netting about eight inches across the mesh had been fixed inside the 
vertical bars. 'The leopard on being turned into the den at once made a violent spring towards the light, and pitching head-foremost against the netting screen, bulged it out to the exact contour of its face. It never seems to occur to these creatures that they could easily gnaw their way through the wooden sides of their temporary prisons and escape, like the hyena which recently maintained itself for a week in the hold of a large cargo steamer, and was kept in a good temper by joints of prime New Zealand mutton, until on the unloading of the vessel the hyena was captured in the congenial cavern in which it had taken up its residence.

The well-known escape of the tiger which the elder Mr. Jamrach recaptured in the street, was partly due to the weakness of a cage. An Indian tiger had been brought up from the docks, and was about to be transferred to a larger den in the "stables." This animal showed more judgment than most of its kind, for it used its back in the fashion of a lever, and burst the rear of the cage. It then trotted down the narrow passage, and into the main street, then known by its old name of Ratcliffe Highway. The only person who waited its approach was a little boy of eight years old, who had put out his hand to touch it. The tiger patted him with his paw, and of course the child fell on the pavement, though the blow was so gently given that the child was stunned but not injured. The tiger then picked him up by the loose part of his jacket, and was trotting off with him, 
exactly like a cat carrying a mouse, when Mr. Jamrach the elder came running up in pursuit. He at once sprang on the tiger's back, and grasping its throat with both hands drove his thumbs into the soft part below the jaw. The tiger dropped the child, and Mr. Jamrach literally "drove it home" like some domestic animal, only with a crowbar instead of a stick.

The courage and readiness of Mr. Jamrach's attack can hardly be over-estimated. The creature was an absolutely new arrival, as to whose temper nothing but the worst could be imagined after so prompt an escape and the attack on the child. The native coolness and indifference to human powers of resistance of the tiger could hardly be better illustrated than by the unabashed impudence with which this tiger, after months of captivity by human beings, after being fed, moved hither and thither, lowered into ships and hoisted on to quays, by men whom it was powerless to injure, picked up the first nice little boy it met after two minutes of freedom, and trotted off to make a meal of him in a city of four millions of people.

Mr. Jamrach has been good enough to give the writer details of another and less well-known tiger escape, which took place on the North-Western Railway near Weedon Station about fifteen years ago. The tiger was being sent to a dealer in Liverpool, and was in a cage fastened to the bottom of an open truck. The cage was amply strong, but another 
train, loaded with huge iron girders that had been improperly packed, and projected from the sides of the trucks, passed that in which the tiger was travelling, and one of the girders struck the cage and smashed it to pieces. The tiger was unhurt, but the cage fell to pieces round it, and left it sitting on the truck like a pigeon when the "trap" is pulled. The tiger at once bounded off, and by a strange chance alighted almost in the middle of a flock of sheep. It knocked down half-a-dozen, and after making a meal off one of these, trotted off up the line. "The news soon spread," writes Mr. Jamrach, "and caused the greatest consternation everywhere. Fortunately a troop of soldiers happened to be quartered at Weedon, and these were called out and packed away in a railway train, which followed up the tiger at a slow rate, and out of the railway carriage the soldiers potted away at the tiger until they killed him. My father always considered he had a good claim against the Railway Company for damages, but did not follow it up, and consequently was a heavy loser."

The most troublesome arrival to recapture which ever escaped from the "stables" in London was a large baboon. It contrived to get clear of its cage over-night, and opened the window of the room in which it was confined. Thence it leapt on to the roof of a house opposite; "crawling over the tiles," says a writer to whom Mr. Jamrach told the story, " it ensconced itself among the chimneys, pleased with the warmth, and chattered defiance at its pursuers. 
Then a grand commotion ensued among the neighbours. Letters and messages of horror and entreaty poured in to Mr. Jamrach; he was even threatened with legal proceedings. All sorts of methods were tried to catch the fugitive; but an ape's feet are more at home on narrow ledges and steep inclines than feet cased in boot-leather. For days the baboon kept his liberty, consoling himself for the chilliness of the nights by abundant frolics during the day. Little wonder if the children were afraid to go to bed at the top of the house, or if the servant-girls looked up nervously from their toilets at any sound on the tiles outside, fearing to see the face of that 'odious creature' glaring in through the glass pane. There could be no rest till he was caught and caged. Eventually he was enticed into a room through an open window, and a blanket having been thrown over him, he was caught and carried home in triumph."

The panic caused by a big monkey at large is almost equal to that which follows the escape of some really dangerous beast. Only in the present year a large mandrill owned by a lady was pursued and shot without mercy in Essex, as a precaution against "its well-known ferocity."

"The most interesting side of our profession," says Mr. Jamrach, " is the possible arrival of new creatures, animals never seen alive in Europe, or new to our experience." The chance of such an event is never quite absent. Even in 1894 he received a strange deer from Japan. He sent this at once to Professor 
Milne Edwards at the Jardin des Plantes of Paris, who pronounced it to be a new species.

The prices of rare animals, often differing little in general appearance from common species, are high enough at present to make the wild-beast trade a lucrative business. But it would be a mistake to suppose that the pursuit of this profession, or even the business of owning and exhibiting wild beasts, is solely a matter of sale and barter, or mere moneymaking. In all connected with the sale or management of wild animals with whom the writer is acquainted, there is a genuine naturalist's appreciation in the creatures they deal in, often existing side by side with something of that pride in maintaining animals in good condition which they share in common with the whole race of breeders of prize cattle, race-horse trainers, masters of hounds and huntsmen, down to the labourers with their pigs. From the highest to the lowest, they seem to know most of what is going on, not only in the different menageries of England, but also on the continents. The masters and owners will meet one another often in the course of business, and the men pay cross visits to rival establishments, and discuss the latest additions or losses. We seldom fail to see at a circus or exhibition of performing animals the well-known faces of some of the keepers at the $\mathrm{Zoo}_{\mathrm{oo}}$ and when going round the houses at the Gardens, the best-known owners of circuses, the lion-tamers or elephant-trainers of the ring, may often be seen musing in front of the 
cages and taking stock of their inmates. A Suffolk villager in London nearly always chooses the meatmarket at Smithfield as the first place in which to spend a happy day; and a wild-beast keeper goes naturally for change of scene to another wild-beast menagerie. 


\section{EXPRESSION IN THE ANIMAL EYE.}

THE wonderful compound eyes of insects recently formed the subject of a paper read by Lord Rayleigh before the Royal Society, recording observations of minute accuracy and ingenious measurement by $\mathrm{Mr}$. A. Mallock. The general conclusions formed as to the actual power of these complex organs rather raises than lessens the claim to efficiency of the simpler vertebrate eye. The compound eye pieces together the separate impressions of the object seen, and should any of the facets be out of order, a blank must be left in the corresponding part of the picture. The only advantage which is claimed for insect-sight is that at the shortest distances the object seen is still in focus, which partly accounts for the "shortsighted" manner in which most insects seem to examine any object in which they are particularly interested. Seen under a powerful microscope, and measured by the delicate instruments so skilfully employed by Mr. Mallock, these insect eyes are marvels of geometrical symmetry. But they are merely organs of sight, not of expression. They are 
beautiful with the beauty of cut gems, and as devoid as a brilliant of any power of expression of character or emotion.

A very brief visit to the stalls and cages of the Zoo, shows that the importance of the eye in the physiognomy of the higher animals is even greater than in the human face; for in the greater number of even the best animal types, the play of feature is so limited, that expression is conveyed mainly by the eye, to which the movable ear plays an important and connected but always subsidiary part. By what seems almost a paradox, many human eyes, which produced a first impression of beauty, but are soon discovered to be singularly lacking in expression, are afterwards felt to have a strong resemblance to the eyes of certain animals, - of deer, for instance, or of birds; yet in the very animal which suggests the resemblance, the eye often possesses great intrinsic beauty, which is increased and dignified by a peculiar fitness for the face in which it appears. It is in keeping with the limits of animal expression that the actual size of the eye should bear a greater proportion to the area of the face than it does in man; and it will be found that the general estimate of animal beauty varies in the main with the size of the eye; the giraffe, whose immense orbs exceed those of any other animal in size, perfection of shape, convexity, lustre, depth of colour, and length of eyelash, being perhaps the most general favourite in the rivalry of beauty, and the almost eyeless moles 
and manatees those which stand lowest as judged by the presence or absence of expression, without the accession of hideous deformity.

The analysis of beauty must always be approached with diffidence. There is always the danger that, like the crystal drop, it may, on the displacement of a single component part, rebuke the impertinent inquirer by the shivering and resolution of the perfect whole into fragments which baffle reconstruction and defy recognition. Common opinion, the fairest arbiter in a matter of such general interest, is probably agreed, that in the human eye, colour does not control our estimate of beauty. "Black eyes or blue eyes, hazel or grey," as the song says, are equally admired in the proper setting. But in the eyes of all other creatures colour does make a marked difference in the impression which they convey to us, though the reason for this difference is obscure. Light-coloured eyes of any shade seem to detract strangely from the depth and significance of animal expression. The usual tint in these light-coloured eyes of animals is a bright golden yellow. Creatures of very similar form and almost identical shape of head and face, appeal, or fail to appeal, to us by the expression of their eye largely on account of this slight difference, though the probable range of emotion and scope of intelligence in the one can hardly be believed to differ greatly from the same powers in the other. The yellow eyes of the sheep and the goat have probably never been the subject 
of a word of commendation, while poets and painters have never tired of celebrating the dark eyes of their cousins, the roebuck and the gazelle.

In birds the contrast is even more marked. As a rule, the eyes of the hawks are light-yellow, bright, and piercing, with wonderful powers of vision. The true falcons, which do not surpass the hawks either in size or courage, have black eyes, which lend a nobility and dignity to the expression of the bird which the goshawk, with all its pride of carriage, never attains. There is something infinitely roguish and mischievous in the light-blue eye of the jackdaw, which would be pure ruin to the character of its grave cousin "parson" rook, if, by some unkind freak of nature, one were born with such disfigurement; indeed, it may be doubted if the colony would not pronounce sentence of execution at once upon such a discredit to the tribe. There seems good reason to believe that this feature, often the only obvious mark which distinguishes young nestlings of one species from those of another, is that which leads to the detection and prompt destruction by birds of the newly-hatched young, from alien eggs which have been placed for experiment in their nests. There is, however, one middle shade found in birds' eyes which is singularly beautiful, the so-called "gravel-coloured" eye of certain breeds of pigeon. This is really a brilliant shade of tawny-red, and though unshaded by lashes, and set in the centre of the bare "cere," gives to the birds a bold and intelligent appearance in com- 
plete contrast to the vapid effect of red eyes in most animal faces. We believe that the countenance of a pink-eyed albino guinea-pig is as nearly devoid of expression as it is possible for the face of a quadruped to be; and whenever the pink eye accompanies albinism there is an obvious loss of interest in the face, though the eye, considered as an object apart, may have the depth and lustre of a smooth garnet. Where albinism develops blue eyes, as in white cats, and sometimes in white horses, the loss of expression is less; but even in the horse, the blue eye, ringed with pinkish-white, is too like that of fish to suggest a tenth part of the intelligence and power of emotion latent in the face of the dark-eyed Arabian. Even dogs with light eyes have less of the appearance of truth and trustfulness than others, though the pale eye is seen in some of the most ancient and valuable breeds, such as the lemon-and-white Clumber spaniel. In the case of the dog; the human preference for the dark over the light eye is perhaps explained by the affinity which the last has with that of the wolf and the common fox. The cunning, shifty look which the last animal possesses, is largely due not only to the yellow colour, but also to the shape and mechanism of the vulpine eyes. They are set close together, and the inner corners run down almost parallel to the muzzle. In addition, the pupil of the fox's eye expands and contracts like that of a cat. ${ }^{1}$ By day the eye is a mere yellow orb, with a

1 The miniature Asiatic foxes which are often shown in numbers 
narrow line of black in the centre. The reason that the stuffed foxes' heads to be seen in so many country houses bear the amiable and most un-foxy expression which they do, is that the "artist" who stuffs them, sticks in nice brown glass eyes with black pupils, which he takes from the compartment labelled "dogs" in the curious box in which glass eyes for all creatures, from tom-tits to stags, are kept duly sorted for use. Cats' eyes are by no means devoid of a pleasing expression, except in strong light; but among them the dark-grey iris of the Angora and some of the "blue" cats give a look of repose and serenity which the brassy orbs of the yellow-eyed varieties never possess. A larger and more striking example of the same difference is found in contrast of the yellow eyes of the black leopard at the Zoo, one of the most unpleasant-looking of the big felidce, and the dark, convex eyes of the ocelot. But the most striking instance of the immense difference between the effect of the light eye and the dark, is seen in the case of a new species of eagle-owl which has just been brought to the Zoo from Mashonaland. The great brown eagle-owl of Northern Europe, with its huge, round, yellow-and-black eyes with which it sternly stares the visitor out of countenance, has a fierce, wide-awake, resentful expression exactly in keeping with its character. The "milky eagle-owl," a splendid bird, with plumage barred with wavy lines

at the Zoo seem less affected by bright sunlight than the English species. 
of grey from crest to talons, has oval eyes of the deepest black, soft and lustrous, and shaded with eyelids and lashes. The result is a change of expression to something quite unlike the face of any bird, and more human than that of most beasts. It is certainly the finest bird-eye yet discovered.

The eyes of Homer's goddesses must not be judged too literally by the animal model in the standing epithets by which he loves to describe them.

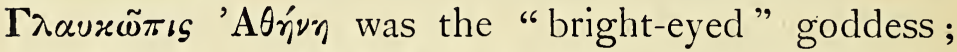
and the owl probably had its Greek name from the brightness of its eyes. So Hera was ox-eyed-that is, with round dark eyes-fine to look at, but if we may judge from her character, perhaps equally without expression, with those of the animal which they resembled. Helen, when restored to Menelaus, and playing the part of hostess to Ulysses, artlessly apologizes for the trouble which the Greeks had incurred on her account, -

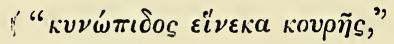

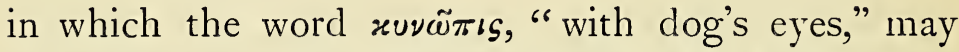
be taken to mean what would now be described as "rather a forward young person." Yet in the recognition of Ulysses by the old dog Argus, there is a feeling for the pathos of animal expression which finds adequate interpretation in the beautiful picture in which Mr. Briton Riviere has depicted the longing look of recognition in the eyes of the dog, and of pity in those of the hero, who sees in the first the 
sole signal of welcome to his island home. The charm of this picture lies in the truth that in the eyes of the dog and in the eyes of the King the same emotion is actually present, and exhibited naturally and spontaneously by the organ of sight, without transgressing the limits of expression in the animal, which one of the greatest animal-painters not unfrequently ventured to do, by transferring to it modifications of feature only possible in the human eye. The expression which is associated with the most beautiful of animal eyes, those of the horse, the stag, and the eagle, is so dependent upon particular differences of shade and setting, in creatures whose emotions and intelligence cannot greatly differ in degree,- that its common interpretation must be due rather to analogy than to any appreciation of its meaning. 


\section{LONDON BEARS.}

"Never make a pet of a bear," is the advice given by the experienced "bear-ward" at the Zoo. But though his conclusions are the result of longer and closer experience of the animals than is possessed by any one person in Europe, there is something so attractive in the apparent simplicity and bonhomie of the comfortable, warmly-clad, deliberate ursine race which appeals irresistibly to animal-loving Englishmen. Ever since the early middle ages the performing bear has been a farourite; and to this day there is in Turkey and Bulgaria a wandering race of gipsies who are known by the common name of "bear-tamers," from their traditional occupation of catching the young cubs in the forests of the Carpathians, and leading them through the villages as performers in all the feasts, whether Christian or Mussulman, of the ancient land of Thrace.

The tame bear, which for the greater part of $\mathrm{r} 8 \mathrm{~g} \mathrm{I}$ and 1892 was exhibited in the London streets, and ultimately had an audience from her Majesty at $\mathrm{W}$ indsor Castle, was also a familiar acquaintance of 
most of the London police magistrates. Its popularity was such, that whenever exhibited it instantly became the centre of a crowd, which increased until the police constable on duty felt it incompatible with his position not to take it into custody. Then came the scene in the dock next morning, and the "dismissal with a caution" as a sequence. Meantime the bear had usually held a reception in the police-station the night before; and so much did its endearing ways win the hearts of the "force," that on one occasion the constable who had run it in made a collection for its benefit the moment the case was dismissed.

This was a small Pyrenean bear, about three years old, with a rough coat the colour of a dusty cocoa-nut fibre door-mat, and though it had a strong steel muzzle of apparently needless severity fixed round the base of its nose, the genial Provençal who owned it, and whose bed it usually shared at night in the quarters of the foreign artists in street music and icecreams in which he dwelt when not employed in exhibiting his pet before royalty, or elsewhere, declared that it was a "brare bête, doux comme un enfant, et doué de traits de charactère tout à fait remarquables." The behaviour of the street urchins to the brave bête was perhaps a reminiscence of the days when bearbaiting was looked upon as an exhibition calculated to maintain the pugnacious character of the true-bred Englishman; for, once assured that it would not hurt them, they stamped on its toes as occasion offered, until the bear rose on its hind legs and assumed an 
attitude of defence, which drove the malicious tribe to a safe distance. "Pauvre bête, il a peurr," said his owner; and it was evident not only that the bear was afraid of the brutal children of the street, but that it looked to the "grown-ups" for protection.

Probably the most easily tamed of the tribe are the small Malayan bears, five of which are at present in the collection of the Zoological Society. These are true honey-eating bears, provided with long elastic tongues, and covered with short close fur of the most beautiful dark and glossy brown, of the tint to which seal-skins are dyed. The largest is a perfect beauty in the eyes of bear connoisseurs, sleek and glossy, its coat fitting it like a well-made suit of felt, and when walking upright, as it prefers to do when about to be fed, it is "just like a person," as we once heard a small girl remark. It has a cream-coloured face, and a beautiful orange "bib." The oldest of the family has been twenty years in the Gardens, and is so stiff and decrepid, that when on the ground it moves like a rheumatic old man. But it can still climb, and will exhibit most amusing feats upon the bars in return for a lump of sugar. Sugar is the greatest luxury which can be given to these "sweet-toothed" animals except honey, and their rations of this are carefully regulated, as it does not agree with their constitutions when in confinement. When a lump of sugar is shown to the old bear it climbs the bars with great deliberation, and then holding on by all four feet waits for the visitor to go through his part of the perform- 
ance. Unless this is carried out according to rule, the bear descends and sits on the floor, waiting until it gets the sugar thrown to it without further trouble. But if the lump is slowly waved round in circles from right to left-the opposite direction is not considered fair, and the animal "won't play" if it is persisted in-the bear also turns "coach wheels" slowly on the bars. His old elbows stick out and his paws turn in, but he still feels equal to almost any number of turns if the visitor is exacting. When rewarded with the sugar the bear "makes it last," like a nasty little boy with a sugar-plum, only far more ingeniously. "That was a white sugar-plum I gave you," says the horrible child in Mr. Du Maurier's picture- " it was pink once." The bear is not really nasty, but it has discovered an ingenious process by which loaf-sugar can be converted into honey. It first wets its fore-paws, and then cracks the sugar into two pieces, and puts one on to each paw. It then rubs the bits on with its nose, and next picking each up again cracks it, and lays two well-moistened pieces on to each paw, as before. It then licks these off again, and if any is left again deposits them on the backs of its well-moistened sticky knuckles. Finally it licks them quite clean, and turns slowly head over heals, as an acknowledgment of the treat.

A regiment of Life Guards recently owned a large brown bear, which ultimately found a home in the $Z_{0 o}$ after giving proof of the wisdom of the keeper's opinion. It was a pet of the regiment, and was taken from Knightsbridge to Windsor, and later to the 
Albany Street barracks, where it was kept chained up like a big dog, and treated with all the consideration due to a non-combatant member of the corps. A boy who was rather a favourite with the men, and used to run errands, and make himself useful about the barracks, took a fancy to the bear, and was employed to bring it its daily rations. One day, when the animal was asleep, the boy woke it by pulling the chain, at the same time laying the food before it. The experience of all those employed in the care of animals, whether wild or domesticated, forbids any approach without speaking to the creature first. In this case the bear, sulky at being wakened, and tethered only by a very long chain, seized the lad, and bit and clawed him so seriously that he was for some time an inmate of the Middlesex Hospital. The bear was "dismissed from the service," and condemned to solitary confinement in a cage in the terrace in the Gardens. The ungrateful behaviour of the Guards' bear must not be taken as a reflection on military treatment of wild animals, for an almost similar instance of the innate surliness of its species occurred many years ago in the establishment of one of those retired East India civilians whose Oriental habits were such a puzzle to the country squires, in the country seats in which the retired "Nabobs" often chose to spend their latter days. The gentleman in question had bought an estate in Devonshire; but it was his pleasure always to be waited upon by a "black man" at dinner, and in the later parts of the evening to 
sit at table with a pair of black bears, each adorned with a silver collar, seated in a large arm-chair on either side of him. An old Devonshire woman, who had been a servant in his family, took the bears under her charge, and fed them daily, until one of them bit three of the fingers off her hand. This was too much even for her master's partiality for his pets, and the bears were slaughtered, and their bodies duly boiled down into "bears' grease," under the superintendence of their former owner and the attached domestic, who, though approving of the measure, like John Gilpin's wife, "had still a frugal mind," and felt that the unexpected supply of an expensive cosmetic should not be wasted.

The Polar bears are perhaps, with the exception of the elephants and other great pachyderms, the longest lived of animals when in captivity. In 1880 the first of the Polar bears died, after spending thirty-four years in Regent's Park, and the eldest of the pair now in the collection has already spent twenty-six years in the Zoo. This is a splendid animal; at a rough guess it must weigh nearly a ton, and no carnivorous creature approaches it in size and strength. When we recollect that its common prey is the walrus, a sea beast nearly as large as a rhinoceros, seldom moving far from the edge of the ice-floes, and able by mere weight to drag both itself and its enemy into the sea, and to fight for life in its native element, the strength and armament of teeth and claws necessary to destroy it must be greater even than those of the lion, which, 
with all its weight of bone and muscle, seldom attacks even so large an animal as a buffalo, unless crippled by wounds.

The old Polar bear is now heavy with age and indolence; but the young female exhibits an activity and "lissomness," whether on land or in the water, which shows how swift, dexterous, and terrible a foe to animal life the Polar bear must be. Confinement and maturity have not in the least abated its vigour, and it seems to enjoy life more than any creature in the Zoo. Fresh water is let into their bath three times in the week, and as soon as the bottom is covered the young bear rolls in and "cuts capers," to use the keeper's phrase. "She teased the old one till he got up to have a look, and then shoved him in," he informed us on a recent visit; and though he seldom enters the bath now, he quite enjoyed it when once under-water. When in the bath by herself the female bear is in a state of pure physical enjoyment delightful to watch. She always prefers to take a "header," but not after the orthodox fashion, for as her nose touches the bottom she turns a somersault slowly, and then floats to the surface on her back. After several rolls in the water she begins to play. Taking hold of her hind-paws with her fore-feet, she makes a huge ball of her body, and turns round and over with a curiously buoyant, easy movement, occasionally putting her head out to take breath and look at the spectators. Then she clambers out, shakes herself, and gallops round the edge of the 
bath. In spite of her bulk, this bear is really as actire as a cat, and can go at speed round the narrow circle without pausing or missing a step. The next object of the bear is to find something to play with in the water. Anything will do, but if nothing else is handy, she usually produces a nasty bit of stale fish which she seems to keep hidden in some handy place, and dives for it, coming to the surface with the fish balanced on her nose, or on all four paws. If the water is still running in she will lie under the spout, and let it run through her mouth. But the most amusing game in which the writer has seen her occupied was played with a large round stone. After knocking it into the water, and jumping in to fish it out, she took it in her mouth, and endeavoured to push it into the hole in the pipe through which the water was running. This was a difficult matter, for the stone was as large as a tennis-ball, and the pipe was not much wider. Several times the stone dropped out, though the bear held it delicately between her lips, and pushed it out with her tongue. At last she sat up, and holding the stone between her fore-paws, put it up to the pipe and pushed it in with her nose. This was a great triumph, and she retired and contemplated the result with much satisfaction. Later, being apparently tired of this achievement, she threw water at it with her head, and failing to wash it down, picked it out with her claws, and went on diving for it in the bath.

Bears do not often have families in the Zoo. They 
are bad mothers in confinement, though when wild they are most devoted to their pretty little cubs. It must be admitted that they are almost the least well-housed of any creatures in the Gardens, as their dens, though dry, are cold and small. The most remarkable cubs ever born in the Gardens were a cross between the Polar and American black bear, born in 1853 . In the spring of 1894 , one of the she-bears in the pit gave birth to a litter of two, but one of these was killed by the male bear, and the other fatally injured.

Their place was, however, more than filled by a pair of tiny cubs which arrived at the Gardens on Easter Monday, a gift from Mr. Arnold Pike. They are of the grey Syrian breed, which is found from the Lebanon, across the high lands of Asia Minor, as far as the Caucasus, in which mountains these cubs were found when only a few days' old. Though in a sense they are distant relations of the bears that ate the bad children who mocked the prophet Elisha, these little fellows were extremely tame and friendly. They were about the size of a large Skye terrier when they arrived, with sawdust-coloured heads, white collars, brown bodies, and sharp noses. They fed heartily on bread-and-milk and treacle, and their little stomachs stuck out roundly in evidence of their appreciation of their diet.

They were extremely sociable, and never quite happy unless people were near them or within sight. When they had human company they sat up, 
stretching their claws through the bars, in order to take hold of and suck the fingers of any one who would permit it. If not they sucked their own, keeping up a continual humming noise all the time. If left alone this became a loud, sustained complaint, like the noise of a litter of hungry puppies.

Bears are far more difficult to rear than would be thought in the case of such rough, hardy creatures. They are liable even after the first six months to cramp and paralysis of the hind-quarters, which gradually increase until the animal dies.

In winter-time all the bears are worth a visit. The black Himalayan bear, with its white front, the brown Russian and American species, with their magnificent soft fur, and most beautiful of all, the full-grown Syrian bear, with coat of cinnamon-grey, carrying a bloom like that on some soft fruit, are then in perfect condition. The two grizzly bears are interesting mainly on account of their rarity, and the possibility that they may live to develop the huge proportions which American hunters are unanimous in ascribing to the monsters of the Rocky Mountains. But even in full growth, it is much to be doubted whether the grizzly ever reaches the size even of the smaller Polar bear now in the Gardens. 


\section{YOUNG ANIMALS AT THE ZOO.}

ARTEMis, protectress of all young wild-beasts, should be honoured with a statue at the $Z_{o o}$; for the cages are yearly filled by the graceful young of wild creatures native to every quarter of the globe. The greater number are born in the menagerie, honest little British lions and the rest, of the true Cockney breed. Others come from the Gardens on the Continent, notably from Amsterdam, where, for some reason, the wildbeast farm thrives amazingly; and others, mainly the whelps of the fierce carnivora, are the gifts of Indian rajahs or of African sultans to the Empress of India, or captured by English sportsmen in their distant forays among the beasts of prey. By mere coincidence, the Lion House has lately been almost restocked by gifts which have been part of the tribute from the East to the West since the days of Roman Proconsuls. Five of the new arrivals were cubs, all of rare beauty of form and colouring, and in the finest health and condition. 'Three young tigers presented to the Princess Henry of Battenberg by the Nawab Sir Asmanjah had reached the Gardens only twenty- 


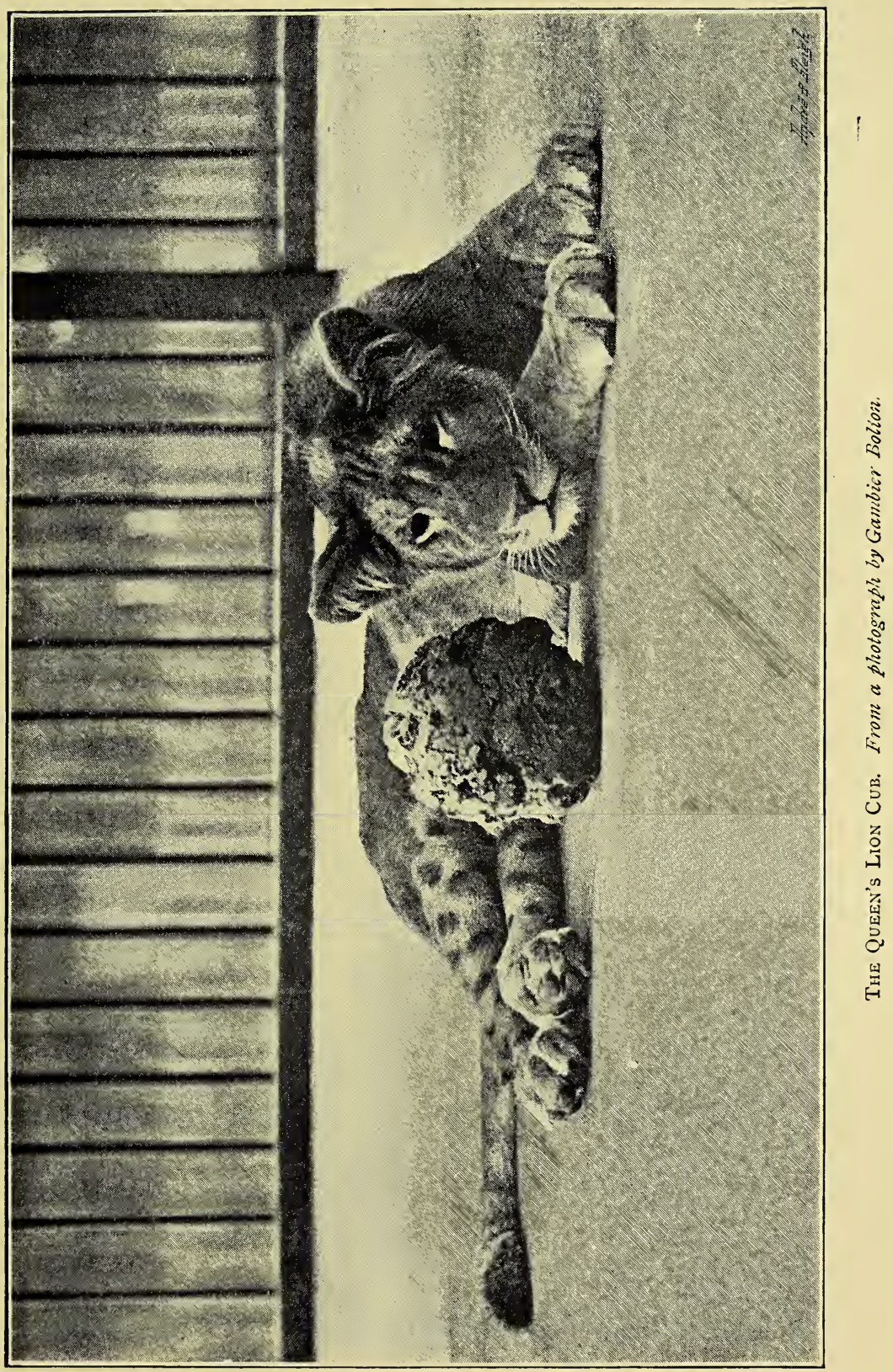



four hours before the writer paid them a visit, and were in a state of royal indignation at their change of quarters from the ship, to which they had become temporarily reconciled. One only would enter the front cage of the den, where it lay on its back with its paws bent inwards, growling to itself, occasionally turning over, laying its ears back on its head, and flattening its nose against the back of its wrist, like a sulky child. Two other half-grown cubs were in that interesting region known as the "passage," which runs between the winter cages and the fine outdoor palaces behind. The details of the daily management of from twenty to thirty lions, tigers, leopards, jaguars, and pumas can be comprehended at a glance from this central position. The ground-floor of the cages in the house, and of the playgrounds on the opposite side, is about four feet higher than the floor of the passage. The sleeping compartment of each cage has an iron sliding shutter, always kept locked, which gives on the passage. A corresponding shutter leads to the playground. A travelling bridge, running on rails, and barred on each side with iron rods, is the means of transit from the cages to these outer runs. When an animal is to be transferred from one to the other, the bridge is run up, the shutters are raised, and the lion or tiger, after sniffing and hesitating like a cat entering a room, walks through the bridge-cage, and takes possession of its apartments. Two of the young tigers were in the sleeping-den; the other chose to remain in the bridge-cage, where it lay, crouched and 
sulking, on the floor. Though not more than halfgrown, they are more massive in shape, richer in colour and marking, than any full-grown tiger in the Zoo. The record of their capture is more complete than is usual in the case of animals presented by native princes. They are part of a litter of five taken at Charglain, about fifty miles from Hyderabad. The Nawab himself shot the tigress, and had alighted from his howdah to measure it, when an alarm was raised by the beaters that another tiger had been seen creeping in the jungle. On the beat being resumed the five cubs, then about a fortnight old, were caught, each being about the size of a full-grown cat. For the first week a she-goat acted as foster-mother, but they were afterwards brought up by hand with cows'-milk from a feeding-bottle. For food on the voyage to England they were provided with a flock of sheep, and so well were they fed, that they arrived at the Gardens with half a sheep still uneaten in the cage. ${ }^{1}$ The two lion cubs caught by Lord Delamere in Somaliland were hardly of age to leave the nursery, though the difference of temper which is so commonly observed among lions was already marked. One, a beautifully mealy-tinted little lioness, with a thick rough coat like a St. Bernard puppy, and dark-brown eyes, ran out to play with a handkerchief, and could be petted like a kitten. The other was a morose little savage, lying at the back of the cage, and growling at

1 The tigers were, in fact, over-fed. They were too heavy for their legs, their hind-quarters grew weak, and one has died. 
every passer-by. They are fed on mutton powdered with bone-dust, and promise to rival in beauty even the slim and elegant young lioness presented by the Sultan of Zanzibar.

Three litters of wild swine were born in the Gardens during the first eight months of 1893 - two early in the spring, and one, of four beautiful piglings, late in the summer. Young wild boars are far prettier than might be expected from the rather forbidding appearance of their parents. Their bodies are slim and elegant, their snouts fine, their ears short, and their legs and feet almost as finely-shaped as those of a young antelope. Their colour is a bright fawn or a rich tan, with longitudinal stripes like those on a tabby kitten; and in place of the thick bristles of the older pigs, their bodies are covered with a long and thick coat of rough hair. Family life in the wild boars' quarters is harmonious and amusing. For the first month the little orange-striped pigs depend on their mother for food, and take no notice either of visitors or of each other. Each roams about by itself in the most independent fashion, or drops down to sleep on its stomach, with its legs stretched straight out before and behind, like a kneeling elephant in miniature. Later, when they have to be satisfied with the food provided in the troughs, they become the most amusing and importunate beggars in the Zoo, the old sow and boar setting the example, well supported by the little pigs. The whole family stand upright on their hind-legs in a row, like heraldic pigs supporting a 
coat-of-arms, with their fore-feet against the rails, and squeak, grunt, and even climb the wire-netting for contributions. Even if the floor is littered with delicious hog-wash, they prefer to plead in formâ pauperis, and the yearning to reach just one inch farther than their brothers seems to give an impulse to the growth of their snouts, which soon grow long, flexible, and narrow, like those of the parentswine. The ancient breed of wild swine which haunted the great Caledonian forest may claim to have been re-established, for some of these are the third generation in descent from ancestors bred in Scotland.

But the youngest member of perhaps the oldest family in the British Islands was the white calf, the lineal descendant of the wild white cattle of ancient Britain. The bull, cow, and calf formed one of the happiest family groups in the Gardens, and should be studied by any one desirous of appreciating the natural beauty of these cattle, one of which, a wild steer from Chillingham, took a first prize when judged on its merits among the finest domestic breeds of England. The bull at the Zoo belongs to the Chartley herd, which has been in the possession of Lord Ferrers' family for nearly a thousand years, has a short muzzle, broad forehead, and crescent horns with a downward reversed curve. Its silky coat is pure white, its eyes the deepest jet-black, shaded by long white eyelashes. The tips of the ears and of the horns are black, and just above the hoof are black and white speckles, like the "flea-bites" on a Laverack 
setter's coat. The cow, like the bull, is white, with black points, but the horns curve upwards. Between the two stands the little bull-calf, a perfect miniature of its father, except that the horns are only budding. It has the same black muzzle and ear-tips; even its tongue is black, and the black and lustrous eye is shaded by thick, straight white lashes, like rims of hoarfrost. Deer and antelopes breed freely at the Zoo. The eland calf has a short body, more like that of a young colt, with long legs, and the hump upon the back undeveloped. All the elands are in fine condition, and might be propagated to stock our English parks; but as an ornament they cannot compare with the indigenous wild cattle of the Chillingham or Chartley herds. Both the wild ass and the zebra had young ones. The young wild ass was a pretty, playful creature, with a coat like grey velvet; but the infant zebra was perhaps the greater favourite with the visitors to the Zoo. It exactly resembled its mother in colour, and in the distinctness and arrangement of the stripes, but it was far lighter and finer in its proportions. With a luxurious instinct for comfort, the little creature usually lay asleep upon the light-green hay which the mother pulls from the rack above-a background which contrasted admirably with its rich sepia and creamcoloured stripes.

But the pride and flower of all the youth of the Zoo is the young hippopotamus. As it lies on its side, with eyes half closed, its square nose like the end of a bolster tilted upwards, its little fat legs stuck out straight at 
right angles to its body, and its toes turned up like a duck's, it looks like a gigantic new-born rabbit. It has a pale, petunia-coloured stomach, and the same artistic shade adorns the soles of its feet. It has a double chin, and its eyes, like a bull-calf's, are set on pedestals, and close gently as it goes to sleep with a bland, enormous smile. It cost $£_{5}$ oo when quite small, and, to quote the opinion of an eminent grazier, who was looking it over with a professional eye, it still looks like "growing into money." There are connoisseurs in hippopotamus-breeding who think it almost too beautiful to live. We had hoped to find a prairie-dog family, as several of the smaller rodents had produced young ones; but though several of the solemn little fellows were sitting bolt upright, cramming straw into their mouths with both hands as fast as they could, like a conjuror swallowing tape, there were no little prairie dogs. The kangaroos and wallabies, on the other hand, had several "joeys"; and nothing could well be stranger than this dual existence of mother and young, in which, contrary to all precedents, the young is carried by its parent, though it is quite independent of its milk. Thus an old kangaroo or wallaby will put its head down to drink, while the young wallaby, wide awake and independent in the pouch, picks up a piece of cabbage, and, holding it in its hands, eats it like a boy eating an apple and looking out of a window. The long, sharp claws of the hind-legs are doubled forward when in the pouch, and project like a couple of pens on either side 
of the young one's ears, while the tip of its tail also hangs out just under its chin. In a cage in the small mammals' house there were a number of young weasels, which were, without exception, the brightest and most active creatures in the Gardens. They were absolutely without fear of man,--bold, impudent, and astonishingly agile. They had converted the hay at the bottom of their cage into the likeness of a hedgebottom, with numerous tunnels, galleries, and holes, and in these they would play by the hour. It was always the same game, catching and killing, and the fury with which they would roll over and over until one had the other by the throat, and pretended to kill it, was most excellent counterfeit. The difficulty was to tell the number of the weasels. There were only four, but there seemed to be as many more. They were here, there, and everywhere, and scarcely had the tail of one disappeared at one hole, than its sharp, bright eyes were peering from another at the opposite side of the cage. They could run either backwards or forwards in the holes, and no mouse, rat, or rabbit would stand a chance against these untiring and agile little enemies.

It is difficult to say why there are no young wolves at the Zoo. According to Tschudi, the naturalist of the Alps, they are pretty little creatures, born blind, covered with reddish-white down, and sprawl in a heap like puppies. The little dingoes, of which a litter were born early in the year 1893 , much resemble this description, and, like the wolf cubs, are 
born blind. They are sold, and fetch $\mathscr{E}_{\mathrm{I}}$ each. Esquimaux puppies, which are often born at the Zoo, are amusing little creatures, ready to eat boiled tripe from a dish until their little stomachs resemble a cricket-ball, an instance of heredity no doubt transmitted by generations of half-starved ancestors. Young marmosets and gerbilles, Angora goats, ibexes, mountain sheep and wapiti deer, gazelles and opossums, with a brood of young puff-adders, young seagulls, and wild geese, hardly complete the list of the year's increase at the Zoo.

In I894 the black-headed gulls reared several broods in the Gardens, but all the other water-fowl in the large aviary failed to rear their young, though the ibises nested, and seemed about to lay.

The water-animals, unlike the water-birds, seldom breed at the Zoo. Probably the little ponds and pools in which otters, beavers, and seals are kept are not large enough to give them that quiet and repose which conduces to family life. But otters, true Devonshire otters, did once have a litter at the Zoo, and the head-keeper, Mr. James Hunt, who was greatly interested in their welfare, gave the following pretty description of their habits. ${ }^{1}$

"The female otter was presented to the Society by Lady Rolle on February 4, I840, being apparently at that time about three months old. In 1846 a large male was presented to the Society by the Rev. P. M. Brunwin, of Braintree, Essex. Its weight

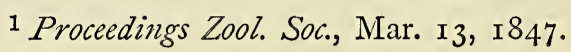


when first taken was $2 \mathrm{I}$ lbs.; but it was not half that weight when presented to the Society, having wasted much in confinement in a cellar. About a month after his arrival there was continual chattering between him and the female at night, which lasted for four or five nights, but they did not appear to be quarrelling. On August 13, the keeper who has charge of them went to give them a fresh bed, which he does once a week. While pulling out the old bed he saw two young ones, apparently about five or six days old, and about the size of a full-grown rat; he immediately put back the bed, with the young ones in it, and left them.

"On the twenty-first the mother removed them to the second sleeping-den; her object appeared to be to let them have a dry bed. On the 9 th of September they were first seen out of the house; they did not go into the water, but crawled about, and appeared very feeble.

"On September 26 they were first seen to eat fish, and follow the mother into the water. They did not dive like the mother, but went in like a dog, with their head above water, and it was not till the middle of October that they were observed to plunge into the water like the old ones. When the water was let out of the pond for the purpose of cleaning it they were shut up, but got out, and into the pond when it was half full of water. The young ones were not able to get out without help, and for some minutes the mother appeared very anxious, and made several attempts to reach them from the side of the 
pond where she was standing, but without success, as they were not within reach.

"She then plunged into the water to them, and began to play with one of them for a short time, and put her head close to its ears, as if to make it understand what she meant; the next moment she made a spring out of the pond, with the young one holding on to the fur at the root of the tail by its teeth; this she did several times during a quarter of an hour, as the young ones kept going into the water as fast as she got them out. Sometimes the young held on by the fur of her sides, sometimes by that at the tail. As soon as there was sufficient water for her to reach them from the side of the pond, she took hold of them near the ears with her mouth, and drew them out, and led them round the pond close to the fence, and kept chattering to them, as if telling them not to go into the pond again."

A litter of young racoons were born in the spring of I 894. Unfortunately they all died, just as it was hoped that they had passed the most dangerous time of infancy. On the other hand, the little Caucasian bear cubs, which arrived at Easter, throve amazingly, and in three months grew to the size of a retriever dog, though they had not abandoned the youthful habit of sucking the paws and "humming," to signify that they wanted to be fed. But the great and notable birth of the year, almost contemporaneous with that of the infant prince, and worthy to be noted as a prodigium, if the keeping of Sibylline books were 


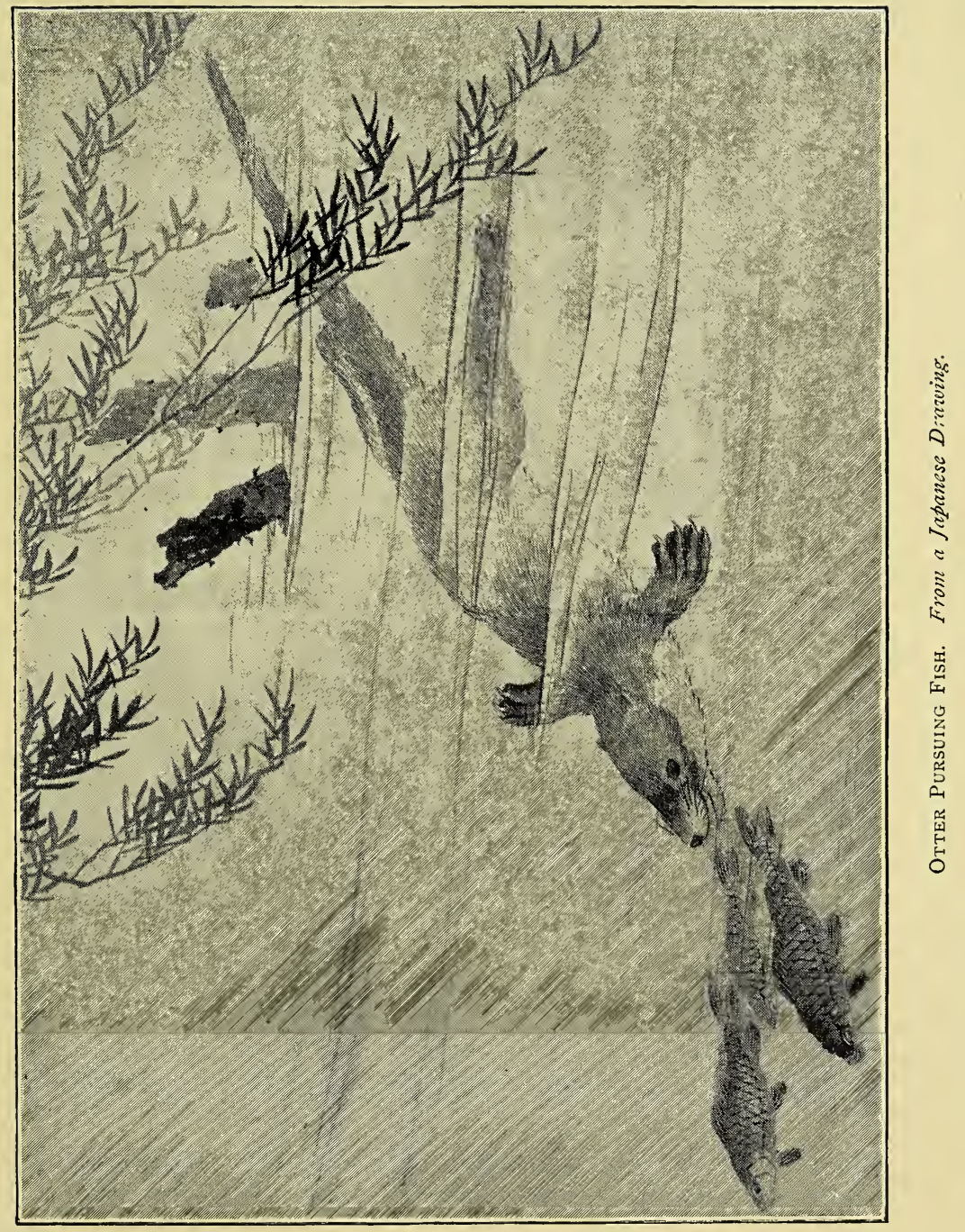



part of the English Constitution, was the arrival of a young "gnu." It was even uglier than its mother, whose compound features of a horse's body, a bull's horns, and a goat's beard combine to make her one of the strangest beasts existing. The infant was exactly like its mamma, minus the horns, but plus a high nose, and a curly beard, which makes it in profile rather like a portrait of Sennacherib or Shalmanezar. Another most beautiful calf of the wild cattle, a cross between the Chartley bull and the white cow from the Bangor herd, is as pretty and pleasing as the gnu calf is ugly. But in each case the mother is vastly proud of its infant, and they are probably the best judges of what their offspring should be. 


\section{ANIMAL COLOURING.}

The conclusions of naturalists as to the laws which govern the colouring of animals must, it seems, be modified. There is no reason, however, to fear any loss of interest in one of the prettiest and most attractive sides of natural history. The collection and comparison of the wonderful analogies in colour between animals and their environment, and between one animal and another, will still be guided by the leading principles which Bates and $\mathrm{W}$ allace detected; and the delight and surprise with which the nonscientific world welcomed these discoveries need neither be regretted nor diminished. But without wishing to grudge one iota of the praise awarded to explanations, the dexterity and aptness of which would alone entitle them to admiration, it is still possible to doubt whether some of the minor hypotheses framed to account for facts which seemed to stand outside the explanation of colour mimicry by the general law of the survival of the fittest, are not almost too ingenious. The fascination of the subject is so great that it seems to develop an over-keenness 
of scientific insight. The facts of resemblance themselves are so wonderful, and the contrast between the colours of the sexes in birds so startling, that the temptation to make a great principle like that of natural selection fit the exact requirements of each case, and to explain the complexity of Nature in a sentence, is almost irresistible. It is quite possible that the principle of natural selection, which gives a perfect explanation of the wonderful phenomena of "protective mimicry," may also be the master-key to the remaining problems of animal hues. The chief difficulties which remain, after accounting for protective coloration, are, first, the extraordinary differences between the tints and plumage of male and female in many birds; and, secondly, the conspicuous colours of certain creatures by which the attention of their enemies must necessarily be attracted. The first of these obvious difficulties has been explained by what is called "sexual selection," which is an auxiliary to the general law of natural selection. The female pheasants, or birds of paradise, or pigeons, as the case may be, by an enduring good taste in choosing for their mates those with the brightest plumage and finest wattles and spurs, have played their part in the general scheme of erolution so well, that their progeny have in time developed all the beauties which they now possess. That theory is obviously quite consistent with the general law. It accounts logically in part, if not entirely, for the perilous beauties of the stronger sex. But there are creatures in gorgeous 
attire for which "sexual selection" could give no justification-caterpillars, for instance, which run additional risks by their conspicuous hues. "That," said the naturalist, "is in order to advertise their inedible qualities!" “They require," writes $\mathrm{Mr}$. Wallace, "some signal, or danger flag, which shall serve as a warning to would-be enemies not to attack them, and they have usually obtained this in the form of conspicuous or brilliant coloration, very distinct from the protective tints of the defenceless animals allied to them." There is one obvious objection to this explanation. It is really too clever. It fits the case so perfectly that, in the absence of further experiment and observation, one is reluctantly obliged to pause before yielding entirely to such a brilliant surmise, and to welcome the note of warning which Mr. Beddard, the Prosector of the Zoological Society, utters in his admirable work on "Animal Coloration." " It is evident, from the space given to the two points of "Sexual Selection" and "Warning Colours" in this work, which aims only at furnishing a general notion of the facts and theories relating to animal coloration, that room exists for doubt as to the value to be attached to either theory. The contribution which Mr. Beddard makes towards solving the difficulty is threefold. He presents as alternatives to the theories of sexual selection and warning coloration,

1 Animal Coloration, by F. E. Beddard, M.A., Prosector to the Zoological Society of London. Swan, Sonnenschein, and Co., London. Macmillan and Co., New York. 
the ingenious speculations of Mr. Stoltzman and Dr. Eisig, neither of which have yet found their way into works of a popular character; and he gives an account of numerous and careful experiments made at the Zoo, with insects of brilliant colouring and reputed evil flavour, as food for birds and reptiles. No care or pains was omitted to get at the truth of these supposed instances of warning colouring. No augurs, with the purest motives to guide their interpretation of the omens, ever watched the feeding of the sacred chickens in the Capitol with a more ardent desire to mark the real appetite of the prophetic fowls, than did Mr. Beddard and his predecessors, in observing the practical results of "warning coloration" when making trial of the birds at the Zoo. But the list of experiments does not give any clear line of refusal or acceptance between the "protectively coloured" insects and their more sober relations, and Mr. Beddard's conclusion is that "the experiments which have been made might be taken to prove anything." That is, so far, disappointing. But it is probable that with time and patience a body of evidence will be accumulated which will throw more light on the vexed question of the palatability of these gaudy insects or reptiles. Meantime, the discoveries of Dr. Eisig, to which Mr. Beddard introduces us, throw light on the question from a different point of view. If his surmises are confirmed, the fact will be additional evidence in favour of that minute and laborious specialization which so often 
goes without reward. His researches were deroted to the history of a small group of sea-worms. One of these he found living parasitically upon a marine sponge in the Bay of Naples. The sponge was of a yellow colour, caused by the presence of small particles of colouring-matter. The worm was of the same colour, with bright orange spots, and the pigment which coloured the sponge was found to be the same which coloured the worm, having been simply transferred from the tissues of the sponge to the skin of the worm, after going through part of the alimentary canal. Dr. Eisig is of opinion that the "pigment" so transferred from the alimentary canal to the skin is itself the cause of the creature being distasteful, which suggests the conclusion that the brilliant colour-that is, the secretion of a quantity of colouring-matterhas itself caused the inedibility of species, rather than that the inedibility has made necessary the production of bright colour as an advertisement. "This explanation," Mr. Beddard remarks, " is not entirely contrary to the views of Wallace, Poulton, and others; for we may still suppose that the bright colours are actually 'warning' colours, although they have not been evolved for this purpose." But the weakness, as well as the attraction, of the unmodified theory really lies in the supposition of the creation in the creature of colour, for the express purpose of advertisement. The modest conjecture of Dr. Eisig transfers the explanation to safer ground.

The mode by which, in the simple organisms which 
he observed, the colour was transferred from the food to the feeder, also suggests the existence of some simple and natural relation between the tints in the skin, or hair, and external conditions of food and temperature, to account for the strange changes of colour to suit outside conditions in animals exposed to the rigours of a northern winter. The mountain hare of Ireland does not always change its colour to white in winter, though in the colder climate of Scotland and Norway the change is the rule. So the Arctic fox seems always to be "bleached" in the extreme north, though often retaining its darker dress throughout the year when further south. Yet exactly the same effects are found in connection with want of food as with want of warmth. The rats in a large iron ship which was recently wrecked off the coast of Northumberland, ${ }^{1}$ and remained stranded for many weeks without connection with the shore, turned quite white-a change due apparently to starvation.

In strong contrast with the modifications of the part played by evolution in animal colouring, suggested by Dr. Eisig, is the alternative which Mr. Stoltzmann proposes to the theory of sexual selection. It is not a change which will flatter the masculine imagination. Contrasted with the view which accounted for the predominance of male strength, and in some cases of masculine beauty, over the weaker

1 Near Blyth. When some shipwrights visited the vessel to remove rigging and fittings, the starving rats swarmed round them, and ate the food which they had brought for their dinners. 
sex by a long course of discerning feminine selection, it has an unconscious irony. Going quite outside the merits of the male sex per se, Mr. Stoltzmann weighs its worth in view of the survival of a species. So considered, an excess of males is an evil, which the law of natural selection is under obligations to remedy. ${ }^{1} \quad$ The tendency of Nature is to produce a superabundance of males, observations on the origin of sex having shown that the percentage of male birds among birds is greater than that of females. Further inquiries into the influence of nutrition on sex go to show that badly-nourished eggs produce males, while well-nourished eggs produce females; and scarcity of food is a more common condition than its abundance. The fine feathers which "make fine birds" have therefore been given to the males with a view to exposing them to the attacks of their enemies, and so reducing their numbers, always-be it observed-in accordance with the law of the survival of the fittest, but by a curiously different line of argument from that which lent its weight to the theory of sexual selection. Probably neither the one nor the other should stand alone; nor is this result to be feared. Bigotry seems almost unknown to the spirit of the natural history research of to-day; the only danger of the open mind of its followers is in the constructive ingenuity of theory which it seems to foster.

1 The bad result of an excess of males is perhaps best ascertained in the case of grouse moors. See Mr. A. Stuart Wortley's remarks upon this in The Grouse (Fur and Feathers Series, Longmans, Green \& Co.). 


\section{WILD-CATS AT THE ZOO.}

THE reservation of one-tenth of the area of Scotland for deer-forests has probably arrested the extermination of three, if not of four, of the largest and rarest of our birds and beasts of prey for at least a century. The great increase in the numbers of the golden eagle, and the migration of the ospreys from the lakes to the forests, are among the results of the protection so afforded. It was reasonable to expect that the wild-cat would also benefit by the policy, now generally in favour with owners of forests, of encouraging animals of prey to keep down the grouse and hares. The arrival at the Zoological Gardens of two genuine Scotch wild-cats, trapped during last year on the same estate in Inverness-shire, is evidence that even there the rarest and wildest of all British quadrupeds are recovering from the persecution of half a century of grouse and black-cock preserving. Both were caught in steel traps, and each had lost part of a fore-foot; but with the wonderful vitality of all cats, they so far recovered from their injuries that, on being confronted with each other, they at once 
joined battle, like the Border rider at Chery Chase, who-

"When his legs were smitten off,

Did fight upon his stumps."

These bold and courageous beasts, fresh from the remnants of the Caledonian Forest, have not diminished either in size or courage since the wild-cat was described by John Bossewell in I 597 :- " He is slye and wittie, and seeth so sharply that he overcometh the darkness of night by the shyninge light of his eyen. In shape of body he is like unto a leopard "- [this is not the case, however] — " and hathe a great mouth. He doth delight that he enjoyeth his liberty; and in his youth he is swift, plyante, and merye. $\mathrm{He}$ maketh a rueful noise and a gasteful when he profereth to fight with another." The growling of the wild-cats is "gasteful" indeed, not only when they proffer to fight with another, but whenever a friendly visitor proffers to look at them. That owned by Lord Lilford, which has been in the $\mathrm{Z}_{\text {oological }}$ Gardens for some time, when exhibited at the cat show at the Westminster Aquarium, performed the singular and creditable feat in wild-cat annals of growling without ceasing for two whole days, varied only by explosions of hisses and spitting. This cat is somewhat lighter, and has fewer dark markings than the Scotch wild-cats; the ground hue of the fur is pepper-colour, its eyes pale-green, its nose very small -not a usual feature in wild-cats-and covered with fur, its face round and bushy, and its expression 
infinitely surly. The only stripes distinctly marked are two on either side of the head.

Though the list of so-called wild-cats includes nearly twenty species, there is only one, besides the animal we have described, which seems to compete with it as the possible undescended great original of the "bundle of concepts" which civilized man has in his mind when, with reference to all the varieties of the domestic animal, he uses the abstract term "cat." This is the "chaus," or jungle-cat, which bears somewhat the same geographical and tribal relation to a Scotch or Russian wild-cat as a Pathan tribesman to a Highlander. The Scotch wild-cat is found with very little variation throughout Northern and Central Europe, across the steppes of Northern Asia, as far as the southern limits of the Nepaul Hills. At a height of some $8000 \mathrm{ft}$. his place is taken by another cat, equally bold, and far less retiring and solitary, the "chaus," which is common not only in India, but at the roots of the Caucasus, and throughout Northern Africa and Upper Egypt. A splendid specimen of this Oriental cousin of our wild-cats occupies a cage in the same house at the Zoo, under the somewhat misleading name of the "Egyptian cat." Nothing could well be more different from the paintings of the sleek tabbies of ancient Egypt, the sacred animals of the goddess Bast, petted by priests, and taught to catch wild-fowl for their masters in the reedy banks of the Nile, than this rough, round, broad-headed, bushywhiskered, "upstanding" savage, who has held his 
own till the present day in the swamps of Asia and Africa, and in the immediate neighbourhood of every Indian country village or tank, just as the European wild-cat did in England till the days of the Tudors. The late General Douglas Hamilton, in his journals of sport in Southern India, tells a story of the courage of this Indian wild-cat, which matches exactly the experience of Charles St. John in Sutherlandshire. St. John's terriers had brought a wild-cat to bay under a rock, and when he approached, the animal sprang straight at his face, and was only stopped by a blow from a stick which he had cut before coming up to aid the dogs. General Hamilton says of the chaus"One of these animals came into our cantonment evidently on the prowl for fowls, or anything it could pick up; so we collected all the dogs we could, and had a hunt. We came to a long check, the dogs being quite at fault. After looking for some time, I spied the cat squatting in a hedge, and called for the dogs. When they came I knelt down and began clapping my hands and cheering them on; the cat suddenly made a clean spring at my face; I had just time to catch it as one would a cricket-ball, and giving its ribs a strong squeeze, I threw it to the dogs, not, however, before it had made its teeth meet in my arm, just above my wrist. For some weeks I had to carry my arm in a sling, and I shall carry the marks of the bite to my grave." The chaus is a far finer animal even than the European wild-cat. It is larger and more powerful, though its proportions 
and movements are almost the same. In colour it is a fine tawny-grey, with long bushy hair, a ruff round its face, yellow cheeks shading into white, a long, very broad nose, long ears slightly tufted, yellow eyes, and bars on its tail. There are also two dark bars on the inside of the arm, above the elbow; when laying its ears back, spitting and uttering growls like distant thunder, it is the "very moral" of a big, ill-tempered domestic tom-cat, which poaches all day, fights all night, and sleeps by choice in the coal-cellar. Apart from their general resemblance to the tame cat, both the chaus and the Scotch cat in their moments of repose exactly resemble the domestic species. They never "pace" their cages-a habit which distinguishes all leopards and tigers, and all the tiger-cats when young. They sleep all day, if possible, either curled up on their backs with their noses upwards, like a tame cat in a sunny window; or with their backs drawn up and their fore-paws tucked neatly under their chests. When feeding, they do not lie down like the leopards, but crouch over their food, with their jaws almost upon the ground, and their backs somewhat arched, like a tame cat with a mouse. Anatomists state that the European wild-cat differs from the tame animal in the dimensions of that part of its interior which is in such request for violinstrings. If this objection is fatal to the claim of the former to be the ancestor of our cats, we should be inclined to find its direct ancestor in the chausa view which need not conflict with the conclusions 
of M. Champfleury, who considers that the Egyptian cat was acclimatized in Egypt at the same time as the horse, in 1668 в.c.

All the other wild "cats" are either tiger-cats, leopard-cats, or puma-cats, names in which the last half of the compound should, we think, be read rather as a "diminutive" than as an index to race. In them the habits and appearance of the larger rather than the smaller animal appear to the writer to bear the greater proportion in the affinities of the whole. From first impressions, the Bengal tiger-cat, for example, appears to be a variety of the domestic cat with the coat and colouring of a leopard, or rather of a cheetah. Its attitudes, or rather those of the fullgrown specimen in the Society's collection, are those of a tired house-cat. It sleeps in the same positions, and like the true cats never "paces" for exercise. But a young one of the same species, shown this year at the Westminster Aquarium, untamed, preserved all the lion-like features strongly developed, just as the young of lions and pumas preserve the spots which disappear at maturity. The movements of this little creature and its general proportions were almost exactly those of a quarter-grown lion. It had the square head, the flat massive jaws, and the same restless, eager, pacing movements from side to side of its cage, and feet always ready to claw or strike. The colouring and texture of the skin in the full-grown animal are wholly unlike any variety of domestic cat known to the "fancy." Its colour is tawny, its coat short 
and close, its eyes yellow with a black centre. The face of the adult is narrow like that of a female housecat; but the six parallel lines, two on either side, and two in the centre of the head, break into spots upon the back. Its tail, which is long and thick, is spotted, not ringed, and it has spotted, leopard-like legs.

The collection of these beautiful smaller felidee in the Zoological Gardens is less complete than that of any other tribe exhibited. Even the "clouded tiger," the most perfect in colouring of all the spotted kinds, has disappeared from the collection, though some years ago there were two fine specimens in the Cat House. The "clouded tiger" is marked with almost rectangular ornaments of clouded black on a ground of rich buff. It is the largest of all the "tiger-cats," and has a very long, thick, silky tail, ringed with black. This animal has a special claim to be an inmate of the Zoo, for it was first discovered and brought to this country by Sir Stamford Raffles, the moving spirit in the establishment of the Zoological Society. They were no less good than beautiful, and the following description of their behaviour from the pen of Sir Stamford Raffles himself should be contrasted with the ancient and inbred malignity of the true wild "cat."

"Both my specimens," he wrote, "were remarkable for good-temper and playfulness; no domestic kitten could be more so. They were always courting intercourse with persons passing by, and in the expression of the countenance, which was always open and smiling, 
showed the greatest delight when noticed, throwing themselves on their backs, and delighting in being tickled and rubbed. On board the ship there was a small Musi dog, who used to play round the cage with one of these animals, and it was amusing to see the playfulness and tenderness with which the latter came in contact with its inferior-sized companion. When fed with a fowl that had died, he seized the prey, and after sucking the blood and tearing it a little, he amused himself for hours in throwing it about, and jumping after it, in the manner that a cat plays with a mouse before it is quite dead. He never seemed to look on men or children as prey, but as companions. The natives assert that when wild they live principally on poultry, birds, and the smaller kind of deer. They are not found in numbers, and may be considered rather a rare animal, even in the southern part of Sumatra. Both specimens constantly amused themselves by jumping and clinging to the top of their cage, and throwing a somersault, and twisting themselves round in the manner of a squirrel when confined, the tail being extended, and showing to great advantage when so expanded."

It is obvious that so active and beautiful an animal could not be seen with advantage, or kept in good health in the cramped little cages of the present Cat House. But the Society still possess a good specimen of the finest of the "self-coloured" puma-cats,- - the golden cat of Sumatra, an island in which every ornamental species, whether bird or beast, seems endowed 
with a double gift of beauty. In colouring it is unique, and its proportions are as elegant as its tints. The fur on the back is the colour of the red variety of gold-stone, with the texture of thick-piled velvet. This warm and luminous hue pales into white on the belly, and runs up the chest, ending on the chin, which is square and almost bearded, giving a tigerish expression to the head. On the mask of the face the reddy golden fur is striped with wavy lines of orange and white. The eyes are strangely large, dark, clouded, beryl-brown globes, with smoky-yellow topaz lights, and shine like round translucent gems set in a velvet case. This mass of orange-tawny, gold, and topaz, is set off by the pale rose-pink of the nose and lips, and the not unfrequent exhibition of rows of ivory teeth. The whole body is elegant and symmetrical, and the colouring so exactly balanced, that the warm white of the lower parts which ends in front at the point of the chin, extends with the same precision along the lower part of the tail even to the tip, as if the golden cat were fresh from a swim across a lake of cream. Among the lacunce in this part of the collection the marbled tiger-cat, the viverrine cat, the Pampas-cat, the Margay, the Eyra cat, the jaguarondi, and the leopard-cat of Bengal may be mentioned. Most of these have been seen at the Zoo at one time or another, and Mr. Bartlett found the "Eyra cat" a most affectionate and amusing pet. It is an American wild-cat, but far longer and lither in shape than others of the true cats, resembling a genet in shape. It is 
a tree-climbing species, as active on the branches as a squirrel.

On the other hand, there are a pair of ocelots which, in the absence of the clouded tiger, may be taken as representing almost the highest development of ornament among four-footed animals. One of the pair comes from Southern and the other from Central America. No two ocelots are marked exactly alike, but the general tone and shading is sufficiently alike to compare them generally with other species. The Argus pheasant alone seems to afford a parallel to the beauties of the ocelot's fur, especially in the development of the wonderful "ocelli," which, though never reaching in the beast the perfect cup and ball ornament seen on the wings of the bird, can be traced in all its earlier stages of spots and wavy lines, as far as the irregular shell-shaped ring and dot on the feet, sides, and back, just as in the subsidiary ornament of the Argus pheasant's feathers. Most of the ground tint of the fur is a pearly smoke-colour, on which the spots develop from mere dots upon the legs, and speckles on the feet and toes to large egg-shaped ocelli on the flanks. There are also two beautiful pearl-coloured spots at the back of each ear, like those which form the common ornaments of the wings of many moths. As in the golden cat, the very large convex translucent eye and the pink nose make the face of the ocelot a wonderful combination of contrasts in colour and texture. Apparently they are tame and friendly, though the conditions of their life 
at the Zoo are hardly such as tend to promote goodtemper.

The remaining occupants of the Cat House are mostly lynxes, or half-lynxes, like the servals and caracals, or civets and genets. There is a fine collection of the last pretty little creatures, which are far more like ichneumons and mongooses than any form of cat. The most interesting fact about these thoroughly Oriental-looking beasts is that one is actually found in the Alps, where one could almost as soon expect to discover a cobra or a crocodile. They are beautifully marked and spotted with black and dark brown or smoky-grey, and are as restless as a mongoose or a coati. 


\section{THE SPEECH OF MONKEYS.}

Mr. Garner's claim to have gained a clue to a form of language understood by monkeys for a short time excited more interest than any subject of natural history in recent years. It was based on such ingenious experiments, including the practical use of such an invention as the phonograph, and was based on methods so pleasing to the scientific mind, that there seemed more than a probability that he was on the verge of a great discovery. On the other hand, men like the keepers of the monkeys in the Zoological Gardens, who have a special and practical knowledge of the subject, refused for a moment to entertain the idea, either that there was a universal "Simian tongue," or even one which was common to more than the members of a single class. In his book on the "Speech of Monkeys," ${ }^{1}$ he gives in a complete form the result of the ingenious inquiries, the first instalment of which roused such curiosity when published in the New Review. Every one who read the story of the clever

1 The Speech of Monkeys, by R. Garner. London: Heinemann. 


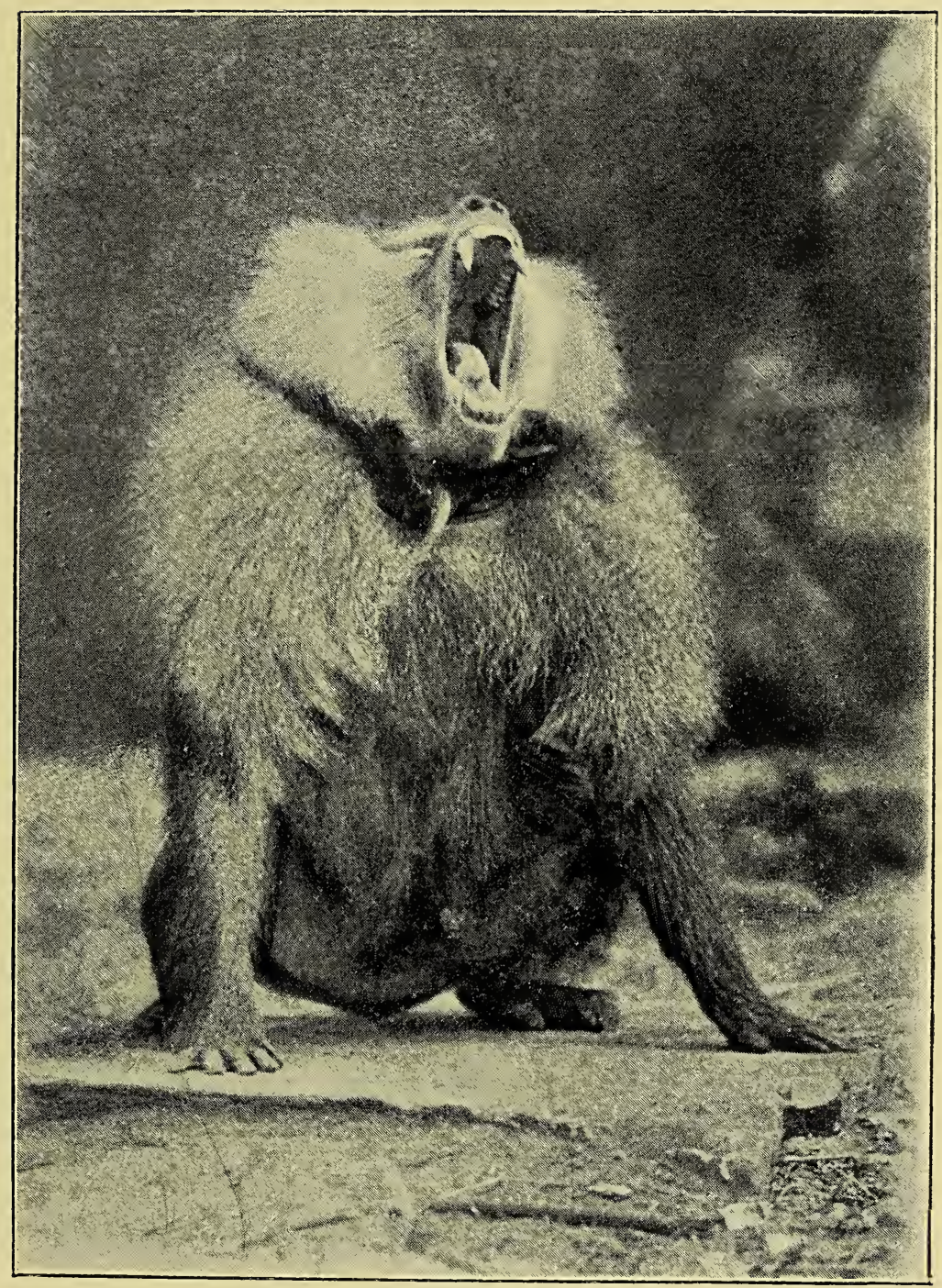

Arabian Baboon. From a photograph by Gambier Bolton. 

experiments made by the aid of the phonograph, which caught, and reproduced when required, the characteristic tones of monkey chatter, will be anxious to learn whether the increase in the numbers and variety of the experiments recorded strengthened or weakened the conclusions which $\mathrm{Mr}$. Garner first formed. With one important modification, he is still confident that he has obtained evidence, not only of the existence of a form of speech current between monkeys, but of the meaning and modifications of some of the sounds in use. The exception is one which would occur to most minds on reading the evidence, if not from natural probability. He no longer claims for monkeys any one speech common to all races, a universal "Simian tongue," which if it existed would argue a greater uniformity among the diversities of monkey structure than exists among the uniformity of human physique. The experiments on which Mr. Garner based his conclusion, that there is a common "Simian tongue," was no doubt difficult to explain on any other supposition, for having obtained on his phonograph a record of the sounds made by two chimpanzees, he found that a note which he translated to mean "milk," but which he subsequently took to stand for "food" in general, was used by the Capuchin monkey in apparently the same sense. He now believes that the sounds are only understood by members of the same species. This admission agrees with the views of the keepers, who maintain that the cries and exclamations of different species of monkey, when expressing the 
ordinary emotions of fear or pleasure, offer no sort of resemblance, and scout the notion of a common "Simian tongue."

The fact of the interpretation of the chimpanzee's note by the Capuchin, can perhaps be explained without throwing doubt upon the whole theory. Monkeys in captivity do learn occasionally the notes of another species, not as mere mimics, but with the meaning which the other naturally attaches to the sounds.

"The most remarkable case," writes Mr. Garner, "which has come under my notice, is one in which a young white-faced monkey has acquired the sound which means 'food' in the Capuchin tongue. This event occurred under my own eyes, attended by such conditions as showed that the monkey had a motive for learning the sound. In the room in which the monkeys were kept by a dealer in Washington, there was a cage which contained a young white-faced cebus, of more than average intelligence. He was a quiet, sedate, and thoughtful little monkey, whose grey hair and beard gave him quite a venerable aspect, and for this reason I called him 'Darwin.' From some cause unknown to me, he was afraid of me, and I showed him but little attention. On the same shelf, and in an adjacent cage, lived the little Capuchin 'Puck.' For some weeks I visited 'Puck' almost daily, and in response to his sound for food, I always supplied him with nuts or bananas. I never gave him any of these things to eat unless he would ask for them in his own speech. On one of my visits, my attention was 
attracted by little 'Darwin,' who was uttering a strange sound, which I had never before heard one of his species use. I did not recognize the sound at first, but very soon discovered that it was intended to imitate the sound of the Capuchin, in response to which I always gave 'Puck' a nice morsel of food. After this I always gave him some in acknowledgment of his efforts, and I observed from day to day that he improved in making this sound, until at last it could scarcely be distinguished from that made by the Capuchin."

This may explain the mistake as to the "Simian tongue." Professor Garner also wishes to get rid of the notion that monkeys can carry on a connected conversation. "Their speech is usually limited to a single sound or remark, which is replied to in the same manner." What Mr. Garner now claims for monkeys' speech is, that it is voluntary, deliberate, and articulate; that the sounds are always addressed to some certain individual with the evident purpose of having them understood, and that they wait for, and expect an answer, and if they do not receive one, frequently repeat the sounds, which they do not utter when alone. He further finds that they understand the sounds made by other monkeys of their own kind, and usually respond to them with a like sound, and that the sound is interpreted to mean the same thing, and obeyed in the same manner by different monkeys of the same species. The words which we have placed in italics are, of course, the most important part of the conclusion. 
But much, if not the whole value which they bear, must depend not only on the certainty that "their sounds convey a fixed idea on a given subject from one mind to another," but also on the assurance that these sounds are sufficiently numerous and definite in meaning not to come under the same head as mere exclamations of alarm, or pleasure, which form part of the usual utterance of so many animals. A cat, for instance, shows pleasure by sound,--that is, by purring; displeasure or fear by sound, - that is, by growling and spitting; and desire by sound,--that is, by mewing; and if all that Professor Garner had to show was that monkeys had something equivalent, or rather more than equivalent, to a cat's purring, growling, or mewing, there would be nothing very remarkable in the fact, though the extreme ingenuity and patient attention which he has exhibited in making his experiments must always lend these a subordinate and secondary interest of their own. But he rightly excludes mere sounds of emotion from the faculty of "speech," such as he claims for monkeys. "Speech," he says, "is that form of materialized thought which is confined to oral sounds, when they are designed to convey a definite idea from mind to mind;" and "sounds which only express emotion are not speech." It is, therefore, not sufficient for Professor Garner to show that the sounds which he has so carefully observed and noted are understood by his monkeys, he has also to show that they are distinct from mere expressions of emotion. The fuller experi- 
ments, from which he now writes, do not tend to clear away this difficulty.

The Capuchins, which are alike the most voluble and the cleverest of the smaller monkeys, have a sound which Professor Garner first translated as "food," but to which he subsequently found he must attach a wider meaning. He now thinks that when modulated in one way the sound means a certain kind of food, and when modulated in another, it means "give," or "give me that." By repeating it to a Capuchin, he often induced it to hand over a part of its food, or some plaything. But it would be possible to infer from this that the sound was a mere expression of desire, and not really different from the mewing of a cat when it wants its kittens returned, or a door opened. The word for "drink" he still considers to be distinct from that expressing "food," and fixed alike in form and meaning. The sound which he took to mean "weather," because uttered by a sick monkey when a storm burst, has now resolved itself into a general expression of discontent. The alarm sound is dual, one form, "e-c-g-k," expressing fear, another, "c-h-i," merely calling attention. But some animals, such as the elephant, have more than one "warning sound," and warning sounds in themselves do not constitute "speech"; nor does the fact that the Professor has been able to reproduce and get replies to the "food sound" of the rhesus and cebus monkeys prove more than that he has been a clever and careful observer of a particular exclamation. He thinks, 
however, that there is a sound meaning "monkey," because this is uttered when one meets another, or is shown its image in a mirror after solitary confinement; and he finds that the shake of the head, by which monkeys, like men, signify "no," is also accompanied by a clucking sound, which he takes for a negation. But even if the results of his later experiments are less fruitful than might have been anticipated, Professor Garner has still good reasons for hope. The phonograph, which alone made it possible to conduct his inquiry with scientific accuracy, promises to give aid in a new and unexpected quarter. The same invention which has rendered possible a permanent record of sound, and its reproduction at will, also facilitates its analysis or synthesis. One of the main difficulties for the human ear in dealing with monkey speech, is its extreme rapidity, and the possibility of modulations existing which are to us inaudible, but are perfectly distinct to the acute Simian perception. By recording the monkey notes on the drum, and then spinning the machine at a slow rate, the sounds are analyzed, and modulations detected, and in a way hitherto impossible. Much is hoped from such analysis of the main "words" of monkey speech, which seem now to have different meanings, though the vocal difference is indistinguishable. Professor Garner pins his faith to the obvious fact that monkeys, like men, have tongues, teeth, lips, and all the organs of speech; that they use the organs, and that there is at least a probability that a distinction is attached by them to 
many sounds in which no difference is detected by our ears. He deserves every success in his new experiments, though the effect of the latest has been to diminish rather than to increase the range of the monkey vocabulary.

The later experiments with the larger anthropoid apes, from whose deliberate utterances better results might be expected than from the volatile chatter of the small monkeys, do not seem to have given much additional information. Mr. Garner's expedition to Western Africa, in the hope of inducing wild monkeys to answer the sounds which he had succeeded in learning from the tame ones, ended as such an enterprise might have been expected to end-in failure. Perhaps the whole inquiry may lead to the conclusion that we know no more now of monkey speech than we did before. But in any case it was a hopeful and ingenious experiment, and without boldness and enterprise fresh knowledge comes slowly. 


\section{RARE AND BEAUTIFUL MONKEYS.}

Among the hundred inmates of the Monkey Palace at the Zoo, more than half the species shown may claim a place among the more elegant animal forms; and an acquaintance with the smaller and squirrellike members of the tribe which abound in the forests of Central and Southern America, and which, in spite of their delicate constitutions, are generally represented in greater or less numbers in the Society's collection, shows that in at least three elements of beauty, the delicate modelling of the hands, the brightness and vivacity of the eye, and in the colour of the fur, they hold their own with the prettiest and most attractive of the four-footed animals of the four continents. The repulsion with which all monkeys are now commonly regarded, is a curious instance of the change of association with animal types. It is mainly modern sentiment that has identified the monkey with the idea of repulsive ugliness, and if the great anthropoid apes, with their disgusting "affinities," had never been discovered, the monkey tribe might have retained the place which they held in the 


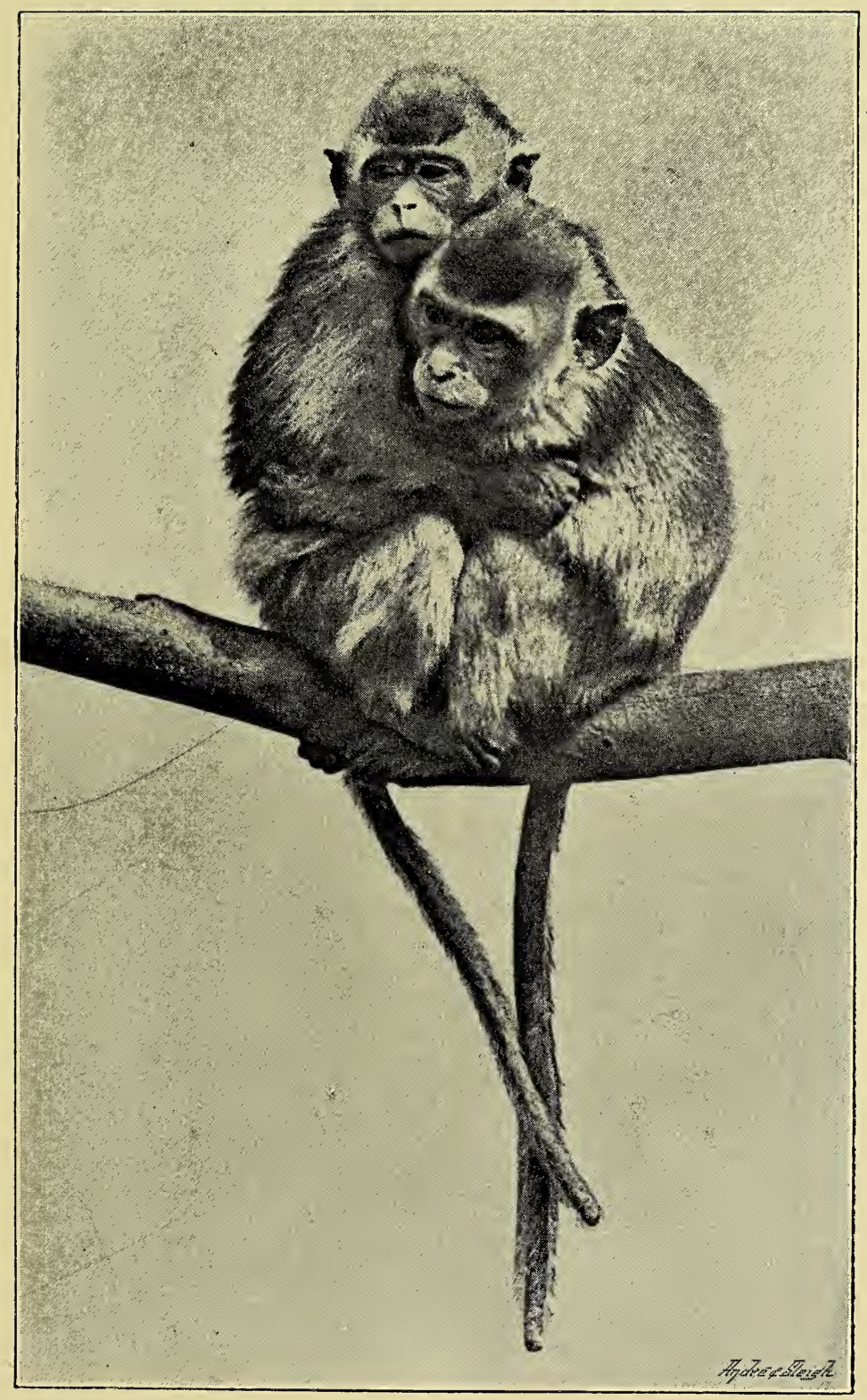

MaCaQue Monkeys. From a photograph by Gambier Bolton. 

imagination of old Cosimo Tura, "the rugged and angular but illustrious painter" of the fifteenth century, who filled the backgrounds of his stately pictures of pageants and processions, and his illuminations in the choir-books of Ferrara, with groups of the fantastic and decorative monkeys which he had seen kept as pets in the precincts of the ducal palace.

Like the lemurs and lories, with which they are not remotely related, the most elegant little monkeys are natives of the great tropical forest; but the rarest and most interesting of the tribe are so delicate that their brief lives are passed almost unnoticed at the Zoo, where most of them, as they arrive from time to time in the Gardens, are kept secluded in an inner chamber. Those from the woods of Guiana and Brazil are at once the most beautiful in form and the richest in colouring. Like all the monkeys of the New World, they have round heads and broad noses, of the order known as the "cogitative nose" in the classification by which an ingenious physiognomist recently determined the place of that organ as an index to character. There is, however, little else in the countenances of these vivacious little creatures which suggests a reflective mind; though the separation of the nostrils by a wide breadth of cartilage is the character-mark which distinguishes the monkeys of the New World from those of the Old, and rescues the face of each and all of them from the cast of vicious inanity which disfigures so many of the latter. Whatever human features they possess are neither 
exaggerated nor degraded; and the intelligence which this resemblance lends to their expression is fully borne out by their behaviour as observed by Humboldt and others, who have recorded their character in confinement. It is on record from more than one reliable source, that these South American monkeys, we believe alone among animals, can recognize the meaning of a picture. Audubon showed one the portraits of a cat and of a wasp, at both of which the monkey was much frightened, whereas on seeing the painted picture of a grasshopper and a beetle, its natural food, it " precipitated itself towards the picture, as if to seize the object there represented."

The beauty of the fur is perhaps the most marked feature of these South American monkeys. One, the squirrel-monkey of Guiana, possesses the most brilliant colouring of any mammalian creature great or small. When lying along a branch, it might be taken for some slender, golden-hued squirrel, did not its round head and baby-like face at once claim a place for it among the monkey tribes. Its arms looks as though they had been dipped in gamboge-yellow dye up to the elbows. Above, the fur shades off into rich hues of greenish-olive, with alternating lengths of short and long hairs, of gold, green, and black, which cover the arched squirrel-like back. Its eyes are a brilliant black, but the cheeks are pink, and the hands fleshcoloured, like those of a very young child. This is a most vivacious little creature, quick and active in its 
movements, and extremely short-tempered. If it is not fed when it stretches out its imperious little hand, it flies into a passion at once, making ugly faces, shaking the bars of its cage, and uttering shrill batlike cries; for the squirrel-monkey is by no means the silky little pet which it appears, but a bold, carnivorous little creature, though its prey is only butterflies and the insects of the Guiana forest. Another pretty and extremely rare Central American monkey, lived for some time at the Zoo during the summer of I 893. This was the Negro Tamarin, also a Guiana species, which had not been seen in London for twenty years. Two of these were still alive when the writer visited them in their private apartments at the Zoo. Seated on a small strip of Turkey carpet, they looked like statuettes of the negro chieftains whose portraits adorn the works of travellers in Central Africa. Each was about seven inches high, with head, limbs, and body in perfect proportion. Their faces, hands, and feet were highly polished ebony-black, with black bead-like eyes, and black nails, or rather claws; for the Tamarins, like the squirrelmonkey and the marmosets, are insect-feeders. The fur is close and silky, and covers all the body except the face, ears, and hands. The back is "shot" and mottled with wavy bars of orange, an ornament which seems peculiar to the monkeys of tropical America. Unlike the rest of its near relations, the little " negro" has one thoroughly monkey feature, large, sharppointed ears, too like the impish forms of Fuseli to 
allow it to rank amongst the first in the scale of monkey beauty.

The pre-eminence in this respect belongs without question to the marmosets. Two of these are by this time sufficiently acclimatized to be placed in a separate cage in the large room of the Monkey House, where they live in great contentment with another little tropical rarity, the Pinche monkey from Guiana. Except on very hot days, they prefer to spend thineir time curled up in a nest of hay, made in a small box at the top of the cage. When the keeper calls them, there is an answering cry from the inmate, and in a few seconds the sounds in the box are like those from a nest of active little twittering birds. Presently three bright little heads and a row of six miniature hands appear at the door, so rapidly put out and withdrawn that it is impossible to say to which of the inmates they belong. Then, after much conversation, apparently directed to the question of which is to get out of bed first, one marmoset descends a few inches of the stick which serves as a ladder to the sleeping-box, eagerly pushed from behind by the others, who are anxious to go shares in the food offered below, but unwilling to fetch it. When once out of the nest, the beauty of the marmoset's colouring, as well as of its face and limbs, is at once apparent. The fur is more like the plumage of birds or moths than the hair of any four-footed animal, loose and feathery, and mottled with tortoiseshell on black, like the ornament seen in some of the 
rarer Oriental pheasants; this mottling is exchanged for bars on the tail, and runs up between the shoulders to the neck. The beautiful little pink faces of these black marmosets, set with bright, jewel-like brown eyes, are fringed over the eyebrows and above the ears with white fan-like sprays. Their movements, like their voices and their fur, resemble those of birds rather than of monkeys, a resemblance which their insect-feeding habits indirectly promote. The king of the tribe, the lion marmoset, covered with golden-yellow fur, with a mane-like cloak across its shoulders, is not among the present inmates of the Zoo; but some years ago a pair of black-eared marmosets produced a family, whose welfare was the engrossing care of the keeper. These tiny creatures were scarcely so large as a mouse, with shorter and lighter fur than their parents, but of exquisite proportions, their baby hands being, it is said, one of the most beautiful instances of minute proportion ever seen in young animals. For three weeks the marmoset mother nursed her babies, until after one exceptionally cold night, father, mother, and infants were all found dead.

As a rule it is fog, not cold, which is fatal to the monkeys at the Zoo. In the past year, which was exceptionally sunny and free from fog, though with many weeks of low temperature, scarcely any rare monkeys died. In the season which preceded it the fogs killed sixty. But the marmosets are an exception to the rule. They can no more endure 
cold than a tropical butterfly, and a fall of a few degrees of temperature on a winter night chills the last sparks of life in their tender little bodies. The Pinche monkey fully deserves its place in the marmoset cage. Except in face it might pass for one of the latter, for its body has the same bird-like plumage, barred with yellow and black, and it warbles a little song like some tropical wren. But its head and neck are plumed with white, like the war-dress of some Indian chief, and its black face and high features make the resemblance more amusing and complete.

Of all the American monkeys the Capuchins seem the most hardy and long-lived species. They occupy a portion of the large central cage at the $Z_{o o}$, being well able to take care of themselves both in human and monkey society. The last addition to the family is a brown Capuchin, a bright, intelligent, roundheaded, round-eyed little monkey, with a long thick tail, and a coat of rich brown fur. Though perfectly fearless when with grown men, pulling them towards it with all the strength of its little arms, this Capuchin has a vehement and aggressive dislike of boys. The instant one approaches the cage it warns him to keep his distance with menacing and imperious gestures, and if a face comes too near the bars, slips its arms through and slaps the odious countenance with the utmost fury and aversion. The monkey appreciation of degrees in human development is as alert and vigilant as the limits which human instinct sets between themselves and the latest prodigy of infant humanity. 


\section{THE LARGER MONKEYS.}

Though most of the best specimens of monkey beauty belong to the New World, the richness and variety of the colouring of one or two of the African species is not surpassed by that of any American species. Yet the ornamental value of their skins is little known, even among those professionally engaged in the fur trade. In the catalogues of the great sales at Sir Charles Lampson's in College Street, there is always a column headed "various," to which the visitor, tired with the enumeration of the regular commercial skins by the hundred thousand, always turns with a sense of curiosity. Most of these are "dressed" skins, of exceptional rarity and beauty, sold separately, and not in "lots," like the pelts of musquash, beaver, and bear, and exhibited in a room by themselves instead of by sample. At the last of these great sales which the writer attended, the collection in the room set apart for this purpose was exceptionally interesting, and the buyer of one of the great wholesale fur dealers marked several of the lots for purchase. A row of fourteen skins of the northern 
(Manchurian) tiger, with long, deep fur and magnificent markings of rich tawny and white, was perhaps the most striking feature in the room. But dozens of leopard and lynx hides, Chinese coats of Thibetan lamb, fleece inwards, ocelot, tiger-cat, and even pythons' skins, made up a richly-coloured and curious collection. Turning over a pile of small unnamed skins lying on a trestle table, the buyer discovered a set of monkey hides of a species quite unknown to him. The prevailing colour was a beautiful iron-grey, and in the centre of each skin was an oval scutcheon of the richest chestnut brown. These were at once marked for purchase, and next day the writer identified the species to which the skins belong by a visit to the Zoo. They were those of the Diana monkey of West Africa, a creature which, though of a thorough monkey type, has almost the colouring of some of the most ornamental wild ducks. Its face is black, with a white crescent on the forehead, and a long white beard, and a white throat and shoulders. The rest of the body and fore-legs is mainly of a tint of irongrey, speckled all over with a "pepper and salt" arrangement of dots. In the centre of the back is the deep chestnut patch which has such a curious effect in the dressed skin, and the lower parts are a brilliant pale yellow. The Diana monkey now in the Gardens is an extremely friendly creature, and spends much time in stroking and arranging its beautiful fur. One kept in confinement is said to have always drawn its beard aside with the hand to prevent its 
being soiled when drinking. The "moustache" monkey, though not so brightly coloured as the Diana, is in many respects a most beautiful creature. It is a medium-sized monkey, five or six times larger than the tiny squirrel monkey of Guiana, but the scheme and method of its colouring is much the same, with the substitution of "powder blue" for gamboge. In most of the "self-coloured" monkeys the whole body seems permeated with some particular colouring matter, black, blue, yellow, or green, as the case may be, just as human beings who have been dosed with nitrate of silver acquire a violet tinge. The colour is brightest in the skin, especially on the face and hands, but extends all over the body, shows between the roots of the soft fur, and seems to climb the hair and colour the "stalk," just as the green liquid in which a white carnation is placed ascends into the flower and tinges it with an unnatural dye. In the "moustache" monkey the face and lips are a beautiful "powder" blue, the eyes bluish smoke colour, the inside of the ears as blue as a hyacinth, and the skin which shows between the soft hair on the arms, legs, and chest a paler turquoise shade, which makes the greyish fur of the lower parts a chinchilla colour. The fur on the back is of yellcw and black mixed, shading into the grey of the abdomen by gradual changes.

The inmates of the main cages in the centre of the house, with the exception of the Capuchins, are nearly all Old World species, and exhibit much that is 
strange and interesting, and a good deal that is repulsive in monkey characteristics. Though the cages seemed first to contain a chance medley of all sorts, the monkeys are really distributed with due regard to affinities of continent and species; and a "synoptic" view of the various tribes behind the bars shows better than any book the manner in which certain monkey types, like particular races of mankind, have either advanced or receded over great tracts of continent.

The sole European monkey has retreated literally to the last stone of the continent, and only lives on the great cliff of the Rock of Gibraltar, in the vertical face of which it still maintains itself, midway between sea and sky. On the cliffs of the opposite coast they are more plentiful, and its name of "Barbary Ape" is more appropriate than any European title. That at the Zoo is a female, a large, heavy, round-backed monkey, with olive-tinted fur, a dull, morose face, and a by no means pleasant temper. Like most large monkeys, it is a far heavier, stronger, and more active creature than it appears to be when sitting bunched up on the floor. The big monkeys, not only the baboons, but creatures like the large macaques and the Chinese and Japanese monkeys, have the power of leaping suddenly in almost any direction without any previous contraction of the limbs or body. They may be sitting in the most listless and apparently dejected attitude, and yet in a moment fling themselves upon an enemy, inflict a 


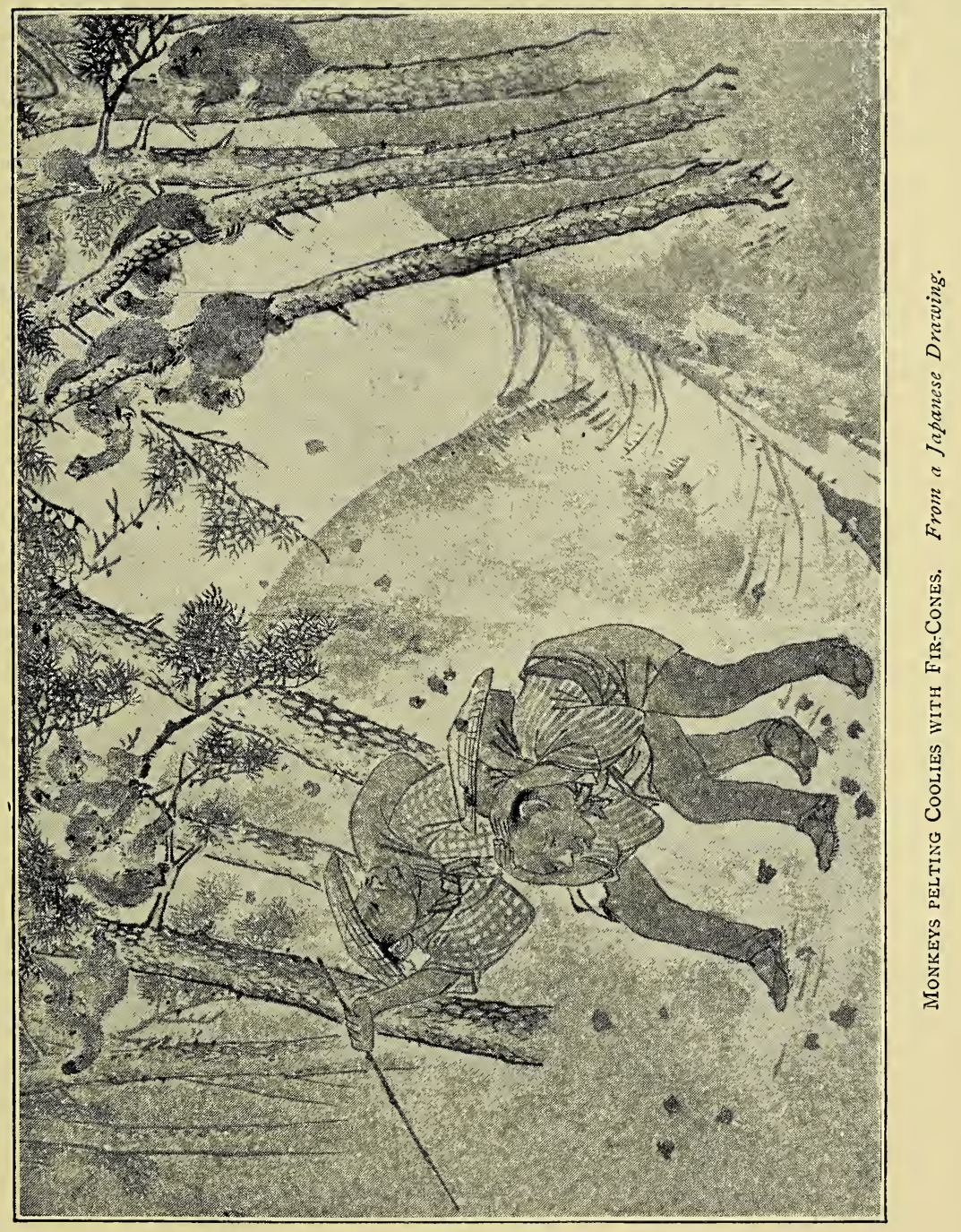



frightful bite, and be away before he has time for defence or retaliation. The large Chinese Tcheli monkey outside the house will usually give an example of this form of monkey tactics. It is a longlegged, short-bodied, powerful creature, extremely heavy and contemplative in manner, and, it must be owned, an ugly, unpleasant-looking brute, though it is both loyal and attached to its keeper. If a visitor pretends to strike the keeper, or use any rough gesture to him, the monkey catches up and flings whatever missile happens to be at hand, straight at the offender's head, following the shot itself with a furious and sudden leap, which, if not stopped by the bars, would bring the animal full upon the head and shoulders of the person attacked. If nothing else is available, the monkey flings a handful of saw-dust, with violence and precision, thus preparing the way for the onset by partly blinding the enemy. Both the sudden leap and the missile are characteristic of monkey attack, though the last is the special weapon of the Chinese and Japanese apes. In the pine forests of their native country they fling the large and heavy pine-cones-not light fir-cones, but solid and substantial missiles-at the heads of intruders; and the pelting of coolies by the apes is a not unfrequent subject of Chinese and Japanese paintings. The Japanese ape occupies an outside cage at the opposite end of the house to that inhabited by the Tcheli monkey, which it much resembles.

In the large cages in the centre of the Monkey 
House the animals are mainly grouped geographically. African monkeys, such as the velvet, malbrook, grivet, and green monkey, are in one compartment, Capuchins and other South American monkeys in a second, Indian monkeys in a third. One of the most friendly and amusing is a little "bonnet-monkey," not much bigger than a rat. Its face is exactly like that of an old Chinaman, with the slanting eyes, flat, short nose, wrinkled and surprised cast of expression, long upper lip, and hair growing backwards with a parting. Another odd little monkey is the little Java pig-tail, "Bob." $\mathrm{He}$ is a most friendly little fellow, running up and catching hold of the keeper's arm the moment he comes near the cage, or putting its arms round his neck if he leans with his back against the wires. Bob keeps the whole cage-full in good spirits with his tricks. He is not the least afraid of any visitor, catching hold of a human hand or arm in the most familiar way, though his attention may be mainly engaged in what is going on among the monkeys.

Though so many species of monkeys are now known, there is always the chance of the discovery of some unknown and monstrous ape, because these are always animals living in the region of the great forests near the equator. Great forests are now well understood to be the most inaccessible portions of the earth. It is no paradox to say, that the range of life in the ocean abyss, where the explorer gropes for creatures which have invaded regions lying below 
miles of superincumbent ocean in eternal darkness and everlasting cold, may be better known in fifty years than the list of inhabitants of the Central African forest, with its horrible incubus of twilight gloom, and the matted tangle of encroaching vegetation, which rises solid and unbroken from the rotten soil beneath to the lowering and electric clouds and vapours that brood upon its upper surface. This forbidding region is probably the home of monkeys large and small, of strange forms and unknown habits, which will from time to time find their way to the Zoo, and astonish the visitors to the Monkey House as much as the first arrival of the ourang-outang and the gorilla. Even from the well-known Indian hills a monkey arrived lately which was quite new to the experience of connoisseurs; and it was at first pronounced to be a hybrid between a rhesus and a macaque. It is a large, solemn monkey, with thick "vandyke-brown" fur, and round, tranquil, brown eyes, as deliberate in its movements as the larger apes. Further information identified this monkey as a true macaque, from the little Himalayan State of Sikkim. The doubts as to its identity can hardly be matter for surprise, for the question of the possession of the State of Sikkim itself was only recently settled between the Indian and the Chinese Empires after a small frontier war, and protracted negotiations.

So much has been written on the questions of monkey temper and monkey talk, that the conclusions of one who has for twelve years watched them daily, 
fed them in health and disease, and has besides that form of insight into animal character which seems innate in some persons to a very high and exceptional degree, deserve some attention. Eustace Jungbluth, a German of Bremen, is the chief keeper of the Monkey Palace - tall, handsome, fair, with the figure of an athlete, and the sound sense of one who prefers to observe and think, than to think and make observation square with theory. $\mathrm{He}$ also speaks English, French, and Dutch well, and expresses himself with great clearness. So far as the present writer has been able to gather his views in conversation, he absolutely disbelieves in any form of universal monkey-speech, though each species has its own special sounds of fear or pleasure, which are naturally interpreted aright by others of the same kind. The Capuchin monkeys remain good-tempered always, as do many of the smaller species. But as a rule monkey-temper fails after the animals have been for four or five years in the Gardens, and they become uncertain and often unsafe. An ounce of fact is worth a pound of theory. A large monkey escaped in the evening when it was being transferred to another cage. It dodged the net, and was outside and had disappeared almost in a moment. It could not be found, and spent the night out. Next morning it was discovered in a tree, and shot before the Gardens opened. It had been sent to the Zoo because it was "troublesome," and it was not considered safe to leave it at large even for a morning. 


\section{LIZARDS AND CROCODILES AT} THE ZOO.

IT is hardly matter for surprise that the colubrine snakes, with their gorgeous colouring and wonderful form, or the poisonous cobras, rattlesnakes, and puffadders which inhabit the closed cases in the Reptile House at the Zoo, excite more interest and comment among visitors than the four-footed reptiles, ranging from the alligators of South America to the tiny "gecko" lizards of Southern Europe, which have their abode under the same roof. Yet there is something peculiarly interesting in these modern survivors of the ancient saurians which swarmed in the hot and steaming waters of a prehistoric world, and seem, like the elephants and rhinoceroses, to carry the imagination back to the circumstances and surroundings of a previous though still more ancient era. It may, perhaps, be taken as evidence of the unfitness of such survivals for modern times, that the only inhabitants of the Reptile House which seem to invite unqualified dislike and disgust are the crocodiles and alligators which swarm in the large oval tank 
in the centre. It seems at first somewhat strange that creatures, many of which are of a strength and ferocity almost equal to that of the largest carnivora, can be kept in safety within the slight barrier formed by the incurved railing which surrounds the pool; but the natural strength of the alligator is only equalled by its sluggishness, and the hideous beasts are content to doze and feed all day in the warm and steaming water. The art of crocodile culture is now fairly understood, and when the baby "basilisk" is transferred from the cool depths of the watering-pot in which he spends his infancy, in the nurseries behind the snakes' quarters, to the tropical temperature of the tank, it thrives apace. The monster alligator, which now measures some ten feet in length, came from the Mississippi when about twelve months old, nine years ago. Hideous, huge, and hidebound in armour of horn, it swings round like an enormous eft, and as it lies just beneath the surface of the water, shows, more clearly than any book can picture, the curious adaptation to surroundings of the carnivorous water-lizard. The eyes on their raised orbits are set like dormer-windows in the head. The nostrils are two tiny slits in a raised boss at the end of the nose; apparently the sluggish beast is a quick breather, for the respirations are at the rate of twenty-eight per minute, or nearly double those of a man at rest. Another alligator has been in the collection for twenty-two years, but does not yet equal the size of the later. comer, owing, it is 


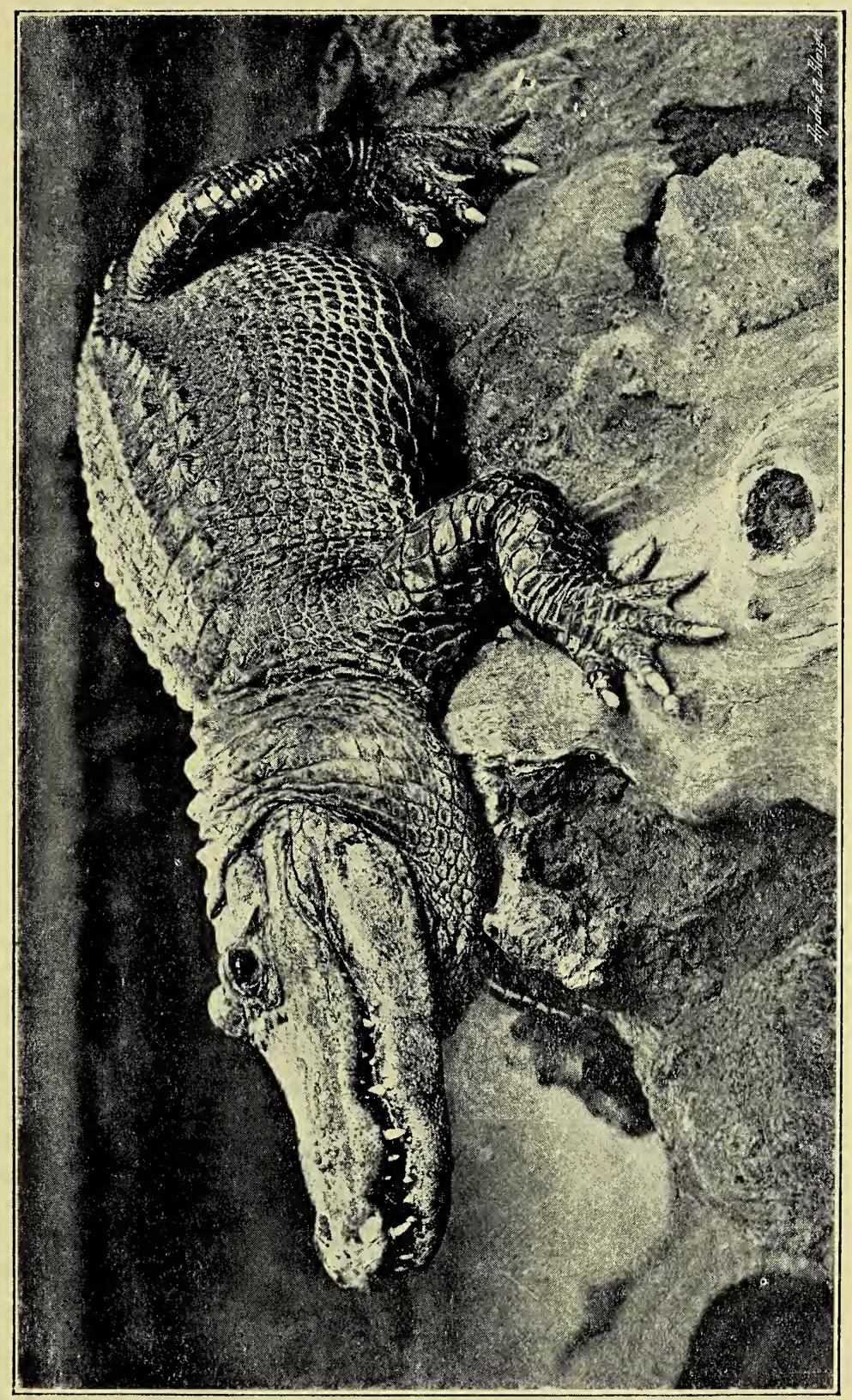



said, to the early days spent in the cold and cramped quarters provided before the building of the new house. It is, however, a formidable creature; and as it sprawls on its stomach across the big tree-stump in the centre, with its ugly webbed claws dangling on either side, its mouth partly open, and its tail drooping in the water, its appearance is sufficiently repulsive to deter the most well-meaning visitor from offering the charitable bun. Crocodiles from the Nile, India, and Ceylon share the waters with the alligators. The crocodile evidently bears the same analogy to the alligator as the frog to the toad. It is lighter in colour and in build, and a more active, as well as a more malicious creature. Neither is it so entirely hideous, though the lower jaw shows projecting tusks like those of a wild boar. The creature's eyes, celebrated in connection with the "crocodile tears," with which legend declared that it attracted its sympathizing victims to the bank of the stream, are highly "decorative," if not beautiful. The head, narrow and flat, resembles the head of a snake ; the nose is sharp, and the fixed and motionless eyes are of the palest dusty gold, set in a short horny pillar of a deeper golden brown. The crocodile's coat of armour is less complete than that of the alligator; and its quick, vivacious movements make it far more troublesome to the keepers when the tank has to be refilled and cleansed, than the big alligators, which will allow themselves to be used as steppinz-stones as the water ebbs away. The 
crocodiles and their kin exhaust the list of noxious lizards at the Zoo, with one curious exception. The heloderin, a fat and torpid lizard from Arizona, is supposed to be the sole existing member of its tribe which possesses not only the poison-glands which exist in most of the toads, but also the true poisonteeth, with a channel for the emission of the venom. The lizard is about $\mathrm{I} \frac{1}{2} \mathrm{ft}$. long, with a fat, fleshy body, a round tail ending in a blunt point, and a flat head with squared sides, resembling a small padlock. The whole body is covered with a curious coat of scales, like black and pink beads, arranged in an arabesque pattern. In its daily life it is a dull and stupid creature, feeding mainly on eggs, which it breaks and laps with its tongue. Its first and only victim was a guinea-pig, which was put into its cage with a view to testing the reports as to its poisonous nature, which were by no means universally credited. The lizard bit the guinea-pig in the leg, and the animal died in a minute and a half-almost as soon as after the bite of a cobra.

Eggs are favourite food with many lizards and snakes; but the "monitor," a very large and handsome lizard approaching the size of the half-grown crocodile, is perhaps the most remarkable eggswallower of the tribe. It bolts the eggs unbroken, and the oval morsel may be watched in its slow descent down the long neck until it disappears in the lower regions. Many of the smaller lizards in the house are almost unmatched for quaintness of 
form and beauty of colouring, among the inhabitants of the Zoo. It sometimes happens that the chameleons die in winter before the summer stock has arrived to take their place, as most of those brought from the Cape die when the vessels enter the cold atmosphere of the English Channel. But the "horned lizards" of California are hardly less amusing in form and habits than the true chameleons. Shaped like a miniature sole, their backs bristling with pinkish spikes like the thorns of a briar-rose, they bury themselves in the sand at the bottom of their cage until the head only projects, presenting an exact resemblance to one of the thorny "burrs" which lie scattered on the Californian desert. If possible, the lizard remains still until the spiders and other insects walk unsuspecting into its mouth; but at the Zoo, where insects are scarce, the horned lizards have to some extent abandoned concealment, and rush upon their prey with a suddenness and ferocity most amusing in such tiny creatures. The writer watched a violent contest between a horned lizard and a "gecko" for the possession of a mealworm, which was wriggling on the sand. The "gecko," one of the swift and agile little lizards which are so common in Southern Europe, was darting down from a branch above just as the horned lizard made its spring, and each seized the mealworm at opposite ends. In the tug-of-war which followed, the ground-lizard proved an easy winner; and the "gecko" retired defeated, to finish pulling off its old skin, which hung loosely round 
its shoulders like a jacket. The cast skin, which was of an exquisite, semi-transparent grey colour, like that of a moonstone, was pulled off by the lizard in long strips, by the aid of its teeth and feet. The toads perform this operation in a far neater manner, pulling their cast skins over their heads with their hands, as a football-player strips off his jersey.

Perhaps the tamest, if not the most beautiful among the smaller reptiles, are the odd little palm-lizards which have recently arrived at the Zoo. They are vegetable feeders, and their appetite for cabbage-leaves is so keen, and the diet supplied so liberal, that after a hearty meal they resemble a well-stuffed oval pincushion with a small lizard's head, feet, and tail attached to the padding. Yet, even in this condition, they are ready to eat if fresh food be offered to them, sitting contentedly in the visitor's hand, and "swelling visibly" as they munch their cabbage, like the lady who excited the alarm of Mr. Weller, senior, at the Temperance tea. A near neighbour of the palmlizards is the existing type of the impostor frog, who tried to inflate himself to the size of the bullock, according to the fable. Esop's frog, no doubt, lived in the swamps of Lake Copais; but the strange creature, which naturalists have named the "adorned ceratophorus," but which is nothing but an enormous fat round caricature of a frog, with a mouth wide enough to swallow a young chicken, lives in South America. His daily habit is to bury himself in the loose earth where small animals, such as rats, mice, 
LIZARDS AND CROCODILES AT THE ZOO 269 other frogs, and the young of ground-birds, ducks or chickens are likely to wander. Half covered with dry earth, the frog resembles a patch of greenish wet moss on wet mud. The chicken or rat which approaches this is immediately seized by an enormous mouth, which opens and shuts with a snap like the back of a watch. Like other selfish and greedy people, this frog is extremely short-tempered and resentful when its own comfort is interfered with: and when poked, and otherwise teased, swells its body out to nearly double its original size, and slowly hops with gasps and growls after its tormentor in a paroxysm of rage and excitement. 


\section{FROM THE ANIMALS' POINT OF VIEW. ${ }^{1}$}

$\mathrm{O}_{\mathrm{NE}}$ of the most curious and unconsciously paradoxical claims ever advanced for man in his relation to animals is that by which $\mathbf{M}$. Georges Leroy, philosopher, encyclopædist, and lieutenant des chasses of the Park of Versailles, the vindicator of Buffon and Montesquieu against the criticisms of Voltaire, explains in his Lettres sur les Animaux the intellectual debt which the carnivorous animals owe to human persecution. He pictures with wonderful cleverness the development of their powers of forethought, memory, and reasoning which the interference of man, the enemy and "rival," forces upon them, and the consequent intellectual advance which distinguishes the loup jeune et ignorant from the loup adulte et instruit. The philosophic lieutenant des chasses had before long ample opportunities for comparing the "affinities" which he had discovered

1 The immunity of the keepers at the Zoo from serious injury or attack by the animals in their charge is $\dot{a}$ priori evidence that the animals' point of view is not necessarily hostile. 
between civilized man and "instructed" wolves, in the experiences of the French Revolution; but without following his fortunes in those troublous times for game-preservers, we may perhaps return to the question of the natural relation of animals to man, which, as pictured by Rousseau to prove his à priori notions of a state of nature, so justly incurred the criticism of the practical observer and practised writer, M. Georges Leroy.

That man is, generally speaking, from the animals' point of view, an object of fear, hostility, or rapine, is to-day most unfortunately true. But whether this is their natural relation, and not one induced, and capable perhaps of change, is by no means certain. Savage man, who has generally been first in contact with animals, is usually a hunter, and therefore an object of dislike to the other hunting animals, and of dread to the hunted. But civilized man, with his supply of bread and beef, is not necessarily a hunter; and it is just conceivable that he might be content to leave the animals in a newly-discovered country unmolested, and condescend, when not better employed, to watch their attitude towards himself. The impossible island in The Swiss Family Robinson, in which half the animals of two hemispheres were collected, would be an ideal place for such an experiment. But, unfortunately, uninhabited islands seldom contain more than a few species, and those generally birds, or seabeasts; and in newly-discovered game regions, savage man has generally been before us with his arrows, 
spears, and pitfalls. Some instances of the first contact of animals with man have, however, been preserved in the accounts of the early voyages collected by Hakluyt and others, though the hungry navigators were generally more intent on victualling their ships with the unsuspecting beasts and birds, or on noting those which would be useful commodities for "trafficke," than in cultivating friendly relations with the animal inhabitants of the newly-discovered islands. Thus, we read that near Newfoundland there were " islands of birds, of a sandy-red, but with the multitudes of birds upon them they look white. The birds sit there as thick as stones lie in a paved street. The greatest of the islands is about a mile in compass. The second is a little less. The third is a very little one, like a small rock. At the second of these islands there lay on the shore in the sunshine about thirty or forty sea-oxen or morses, which, when our boat came near them, presently made into the sea, and swam after the loat." Curiosity, not fear or hostility, was, then, the emotion roused in the sea-oxen by the first sight of man. The birds, whales, and walruses in the Wargate Sea and near Jan Mayen's Land, were no less tame, and the sea-lions in the Southern Pacific, the birds that Barents first discovered in Novaya Zembla, and even the antelopes which the early explorers encountered in the least-inhabited parts of Central South Africa, seem all to have regarded the newly-discovered creature, man, with interest and without fear. Sir Samuel Baker, in his Wild Beasts 
and their Ways, remarks on the "curious and inexplicable fact that certain animals and birds exhibit a peculiar shyness of human beings, although they are only exposed to the same conditions as others which are more bold." $\mathrm{He}$ instances the wildness of the curlew and the golden plover, and contrasts it with the tameness of swallows and wagtails. The reason does not seem far to seek. The first are constantly sought for food, the latter are left undisturbed. Perhaps the best instance of such a contrast is that of the hawfinch and the crossbill, birds of closely allied form and appearance. The hawfinch, which is probably the shyest of English small birds, seems to have acquired a deep mistrust of man. But the crossbills, on the rare occasions when they descend from the uninhabited forests of the North into our Scotch or English woods, are absolutely without fear or mistrust of human beings, whom they see very probably for the first time. When animals do show fear on first acquaintance, it is probably due, not to any spontaneous dread of man as man, but because they mistake him for something else. "Nearly all animals," says Sir Samuel Baker, "have some natural enemy which keeps them on the alert, and makes them suspicious of all strange objects and sounds that might denote the approach of danger :" and it is to this that he attributes the timidity of many kinds of game in districts where they "have never been attacked by firearms." A most curious instance of this mstaiken identity occurred lately when Kerguelen 
Island was visited by H.M.S. Volage and a party of naturalists and astronomers, to observe the transit of Venus. There were large colonies of penguins nesting on the island, which, though the place is so little frequented by man, used at first to run away up the slopes inland when the sailors appeared. They apparently took the men for seals, and thus took what appeared the natural way of escaping from their marine enemies. They soon found out their mistake, for it is said that "when they became accustomed to being chased by men "--an experience for which the sailors seem to have given them every opportunity"the penguins acquired the habit of taking to the water at the first alarm." In another colony, the nesting females would settle down peacefully on their eggs if the visitors stood still. "The whole of this community of penguins (they numbered about two thousand) were subsequently boiled down into "haresoup' for the officers and men of H.M.S. Volage," writes the Rev. A. E. Eaton, "and very nice they found it." We may compare with this destruction of the penguins, the letter of Hakluyt on the voyage to Newfoundland by Antony Parkhurst, describing with high approval the business facilities for the fishing trade offered by the tameness of the great auks,called "penguins" in the passage:- "There are seagulls, musses, ducks, and many other kind of birdes store too long to write about, especially at one island named 'Penguin,' where we may drive them on a planke into our ship as many as shall lade her. These 
birds are also called penguins, and cannot flie; there is more meat in one of them than in a goose. The Frenchmen that fish neere the Grand Bank doe bring small store of flesh with them, but do victuall themselves alwayes with these birdes."

The point of view from which the lion or tiger looks on man, is perhaps not so far removed from that of the non-carnivorous creatures as might be supposed. Man is certainly not the natural food of any animal-except of sharks and alligators, if he is so rash as to go out of his native element into theirs -and if the item "man" were subtracted from the bill-of-fare of all the carnivora, they would never want a meal. The notion of the natural attitude of a lion to a young lady,-

"When as that tender virgin he did spye,

Upon her he did run full greedily,

To have at once devoured her tender corse,"

is still popular, but hardly correct. More probably the lion would get out of the way politely,-if we may judge by the pacific behaviour of those in our lastexplored lion-haunt, Mashonaland. M. Georges Leroy's contention for the natural affinity, or semisympathy, which should exist between man and the intelligent hunting animals, is no doubt partly reasonable. Leigh Hunt, when recording his impressions of a visit to the Zoological Gardens, was unpleasantly struck by the incongruity of the notion of being eaten by a wild beast,_- " the hideous, impracticable felloucreature, looking one in the face, struggling with us, 
mingling his breath with ours, tearing away scalp or shoulder-blade." But the "fellow-creature" is not nearly so impracticable as he is supposed to be. More human beings are probably killed by tigers than by any other wild beast, except by starving wolves. Yet this is what Sir Samuel Baker has to say on the subject-"There is a great difference in the habits of tigers. Some exist upon the game in the jungles; others prey especially upon the flocks belonging to the villagers. A few are designated ' man-eaters.' These are sometimes naturally ferocious, and having attacked a human being, may have devoured the body, and thus acquired a taste for human flesh; or they may have been wounded on more than one occasion, and have learnt to regard man as a natural enemy. But more frequently the 'man-eater' is a very old tiger, or more probably tigress, that, having hunted in the neighbourhood of villages and carried off some unfortunate woman, has discovered that it is far easier to kiil a native than to hunt jungle game." As a rule, the tiger is only anxious to avoid men; and it is noticed that in high grass tigers are more dangerous than in forests, because in the former they cannot be seen, neither can they see, until the stranger is close upon them. An ancient instance of the opposite behaviour is that recorded of the new colonists of Samaria, whom the lions attacked, "and slew some of them." A curious inversion of this experience occurred when the islands in the Brahmaputra, which were swarming with tigers, were first cultivated. 
The natives, mainly by the aid of traps set with a bow and arrow, killed off the tigers so fast that the skins were sold by auction at from eight annas to one rupee apiece. In this case, the tigers were the first aggressors by carrying off cattle. But it seems evident that there exists no à priori reason, founded in natural antipathy, why man and animals, if we could reconstruct a "state of nature" in which we could put civilized, not savage man, should not dwell together in profound peace, or at least in such peace as obtains between accidental neighbours. The only ground for quarrel that seems inevitable is the everlasting one between the shepherd and the wolf; and that, after all, is a question, not of prejudice, but of property. 
POSSIBLE PETS.

ThE number of animals which with ordinary tact and kindness can be tamed by man is so great, that the range of possible pets would seem almost coextensive with the limits of the animal world. But tame tigers must, as a rule, remain a luxury for Sultans and Sarah Bernhardts, and the sociable bear be left to the professional gentlemen who make a living from his society. We say "as a rule," not without reason, because there is hardly any limit to an Englishman's fancy for pets. The writer was requested last year to act as a friendly broker to bid for the bear which found its way so often to the London Police Courts after being exhibited before the Queen at Windsor. The would-be purchaser was a worthy butcher before whose shop the bear was being exhibited, while the writer heard its history from the genial and dirty foreigner who owned it. "Sir," said the butcher, "excuse the liberty; but would you kindly ask that Frenchman what he will take for the bear?" "Certainly," we replied, "if you will say why you want it; is it for professional purposes?" 
-for the bear was fat. "Oh, no! I should not think of such a thing," said the butcher. "I want him for a pet." "Very well; how high will you go?" we asked. "Up to ten pounds," the butcher replied. But though we did our best, the owner would not accept less than eight hundred francs, to the great disappointment of the would-be purchaser. What is required for an every-day pet is that it shall be beautiful and intelligent; that it shall neither be too large nor too delicate; and, if a bird, that it shall sing or talk-preferably both. The two first requirements will not go far to limit the choice. Beauty of form and harmony of colour are the almost inseparable attributes of that physical perfection which the natural life of animals demands; and he would be a rash man who classed any of the more highly organized animals as "stupid" without trial.

But there are "diversities of gifts," and the exquisite beauty of the silky little chinchilla must be held to compensate for the want of the lively cleverness of the coati-mundi or the Capuchin monkeys. The limits set by size and constitution are the main consideration in the choice of pets. Yet even so the possible range is very great, and might well extend far beyond the species which form the main body of those usually seen in this country. To begin with our native animals, who has seen a tame hare? Most school-boys have kept tame rabbits by the dozen - singularly uninteresting pets when shut up all day in a box munching cabbage-stalks-and generally 
turned over to younger sisters in favour of a terrier puppy after brief possession. Yet even after the experience of tame hares so charmingly told by Cowper, the most domestic of poets, the hare is neglected as a pet. Yet its form and fur are beautiful, and so far as the writer has been able to judge of this, perhaps one of the least carefully observed, except for persecution, of our wild animals, the hare is a clever, affectionate creature, as far above the rabbit in the scale of intelligence as it is in physique. Last spring, after a late fall of snow, an old hare brought her leverets from the hill, and hid them in a straw-stack near a farm, and remained constantly near them all day, coming to them regularly as soon as the twilight made it safe. They are bold as well as affectionate, and have been known to drive off a hawk which was carrying away a young one, springing up and striking the bird as it flew low above the ground; and their attachment to locality is so great, that even if kept at large, they would probably not leave their owner's grounds.

A charming little foreign pet for the house is the suricate, or meer-cat. This pretty creature, which, if we remember rightly, was among the number of Frank Buckland's animal companions, is an active and vivacious little fellow, some 10 in. long, with greenish-brown fur, large bright eyes, a short pointed nose and dainty paws, which, like the squirrel's or the racoon's, are used as hands, to hold, to handle, and to ask for more. Eloquent in supplication, 
tenacious in retention, the suricate's paws are expressive, plaintive, and wholly irresistible. The creature is made for a pet, and is so affectionate to its master that it can undergo any degree of "spoiling" without injury to its temper. A larger, more beautiful, and most charming creature, not unlike the suricate in some respects, though in no way related to it, is the brown opossum from Tasmania. "Sooty Phalanger" is the elegant name given to it by naturalists; but except when the specimen kept by the writer discovered that a chimney made a good substitute for a hollow tree for its midday sleep, there was nothing in its appearance to justify the scientific adjective. The fur is of the richest dark-brown, and covers its prehensile tail like a fur boa. Its head is small, with a pink nose and very large brown eyes; and it has a "compound" hand, with the claws on its fingers, and an almost human and clawless thumb, with the aid of which it can hold a wine-glass, or eat jam out of a teaspoon. That owned by the writer was, without exception, the most fearless and affectionate pet he has ever known. In the evening, when it was most lively, it would climb on to the shoulder of any of its visitors, and take any food given it. It had a mania for cleanliness, always "washing" its hands after taking food, or even after running across the room, and was always anxious to do the same office by the hands of any one who fed it. It made friends with the dogs, and would "wash" their faces for them, catching hold of an old setter's nose with its sharp 
little claws, to hold it steady while it licked its face. The staircase and banisters furnished a gymnasium for exercise in the winter, and in summer it could be trusted among the trees in the garden. This opossum is becoming scarce, owing to the demand for its fur; but there is little doubt that specimens could still be bought for a moderate sum. That owned by the writer cost three pounds. The American grey squirrel is a common and hardy species, which becomes very tame, though scarcely so pretty as our red squirrel; and the South American coatis, especially the small kind, are most amusing pets; though, like the mongoose, they need to be kept warm. All the coatis are sociable, lively creatures, quite omnivorous, and with as many odd tricks as a monkey. The mongoose, that "familiar" of Indian households, has such a natural bias for human society, that, according to Mr. Kipling, it will often come into a house from the jungle, and voluntarily enrol itself among the members of the family. It is a slim, active little animal, varying from a foot to nearly two feet in length, of a curious mottled silvery-grey colour, and so amazingly rapid in its movements that its victory over the cobra is not surprising. Provided that it is kept warm in winter, it will live well in an English home, and loses none of those domestic qualities which make it such a farourite in India. The marmot and the viscacha, or prairie-dog, are amusing little fellows, and if allowed the use of a small enclosure in which the marmots can burrow and 
make hay for the winter, and the viscachas make their "collections" of curiosities, either species would, no doubt, add to the interest of an English country house. But as both the marmot and the viscacha hibernate in winter, their owner must be prepared for their disappearance underground from Christmas until March.

There is only one monkey which we can thoroughly recommend as an indoor pet, the beautiful and intelligent little Capuchin. The marmosets, even more beautiful and equally pleasing, are too delicate for our climate, and die of colds and coughs after the first fogs of winter. But the lively little Capuchins may be kept for years in an English house; and no monkey approaches their good temper and pretty winning ways. They all have good round heads, with black fur on the top and light-brown on the cheeks. Some have pinkish faces, and others dark-brown skins, with eyes like brown jewels. Their faces are most expressive, and seldom still, for they take deep and abiding interest in everything in or about their cages. One kept in a large house in Leicestershire had learnt to put out burning-paper, which it did most adroitly by beating it with its hands or knocking it against the floor. Another, which was kept at the Zoo, would, if it got a match, collect a heap of straw, strike the match, light its bonfire, and dance round it. This dangerous accomplishment led to its removal from the cages on Saturdays and Bank-holidays, when the crowd makes it difficult to keep a watch on its movements. The 
Capuchin is so small, so pretty, and so clever, that it seems to embody all the good and none of the bad points of monkey nature.

No one who has seen pumas when kindly treated in captivity can doubt the justice of the impression that these friendly and beautiful cats at once produce, that they must be suited for pets and companions. The general verdict of South Americans as to their gentleness and natural liking for man, even when wild on the Pampas, is given in some detail in a later chapter on Animal Temper. There was at least one puma kept as a pet in this country, by Captain Marshall, the owner of a unique private menagerie at Marlow on the Thames. Reports of a gentleman, "with a tame lioness by his side," having been seen sitting by a lock gate on the Thames, evidently pointed to the taming, not of a lioness, which, however domesticated among those whom it knows, would be too dangerous and uncertain a creature to take abroad, but of a puma, which, being neither striped nor spotted, would be at once described as a "lioness" by the ordinary "man in a boat." This was the case, and the following is Captain Marshall's short account of his late pet, for unfortunately it died of livercomplaint before the writer could ask to make its acquaintance. "My big full-grown puma," writes its master, "was as tame as a cat. It was kept for months on a chain and collar, and could be led about. It would rest its head on my lap, and I could pull it about as much as I liked. I also had a 
baby one, but she was not tame." The lovely snow leopard, which came to the Zoo in I894, was a lady's pet. It had always been fed upon cooked meat, and was perfectly tame. The writer has patted it as it lay in its box in the Lion House, and it merely looked up exactly like a sleepy grey Angora cat. Yet this was a full-grown leopard, in perfect condition and health, living in the next cage to one of the black variety, which was almost the wildest creature in the menagerie.

Those who possess an aviary may be interested to hear that at the Zoo, blackcaps, whitethroats, gardenwarblers, and nightingales, all birds of passage, are living in excellent health through the winter; and one nightingale was singing on December 29, but the song, though very beautiful, was not a true nightingale's note, but largely borrowed from that of the bulbul in the next aviary, the bird being a young one, caught in the autumn. It is evident, from the experiment at the Zoo, that our summer warblers may be kept as pets; but the bird of all others suited for the aviary, but neglected as a rule in England, is the bulbul. The Persian variety has the finest song, but the Indian is an even prettier bird, and sings exquisitely. In appearance, the bulbuls are not unlike the Bohemian waxwing, with a black conical top-knot, cinnamon-coloured backs, red-and-white or yellow-andwhite cheeks, and white breasts, with some bright colour near the tail. The note is most liquid and beautiful, and the bird has a pretty habit of varying 
the volume of the sound, singing loudly in the open, and almost whispering its song to its master or mistress if confined in a room. We might do worse than follow the example of the Persians, and make the bulbul our favourite cage-bird, instead of the canary. 


\section{THE PARIS ZOOLOGICAL GARDENS} IN THE TWO SIEGES.

Here is an odd scene in the Jardin des Plantes at the end of April 1871. The communards were defending the ramparts, and a steady rain of shells had been pouring in from the Versaillist batteries for a week. Every one in Paris was "stale" from continued siege and bombardment. War had lost all its excitement, and nothing relieved its squalid discomfort. An order to impress all citizens for the National Guard had just been issued, and one of these, M. Henri de Goncourt, an author, a man of taste, and a man of peace, had wandered into the Jardin des Plantes, partly from sheer ennui, partly, as he would have us believe, in the hope that he might find an empty loose box of a deer or antelope, in which he could sleep, and escape the réquisition militaire of the omnipotent M. Pipe-en-Bois. He found a party of National Guards sauntering round the Gardens, conducted by a philosophical Republican, who halted his squad in front of the kangaroos' cages, and gravely took for his text the maternal virtues of "Citoyenne" 
Kanguroo, begging them, "with emotion," to observe the contrast of the animal, which always carried its infant in its pocket, with the indifference of "les femmes aristo" to their babies! The republican zeal for improving the occasion is typical of the frame of mind to which the average Parisian can always bring himself and his audience over any political or patriotic question, on the most trifling occasion, a kind of conscious insincerity which his hearers agree to share in order to enjoy the sentiment of the moment. But the time and occasion are not often so comical. The observer of the scene, M. de Goncourt, a writer steeped in the literary life of Paris, a life which the siege had starved and crushed, leaving the poor man in a state of acute mental starvation very curiously shown in his journal of the siege, declared that the animals which had survived the first siege, or had been introduced to the Gardens after the Prussian occupation, were almost as bored by the loss of their "public" as he was at the loss of his. "The animals," he says, "are silent. The elephant, abandonné de son public, leaning indolently against the wall, was eating his hay with the air of a man compelled to dine alone.

In the first siege, the animals of the Paris Zoo which could by any means be classed as "game" or venison early found their way into the butchers' and game-dealers' shops. As early as October 3 two large stags were exposed for sale; at the same time big tame carps, which had adorned the 
fountains in the Gardens, were rubbing their purple noses against the sides of a baby's bath, set upon the counter, and a young bear, freshly killed, its broad paws clenched in death, was hanging like a sheep from the hooks above, destined for auction by hungry Parisians on the following day. On the last night of the old year, in the shop of the butcher Roos, in the Boulevard Haussmann, far less appetizing viands were the subject of a sale, which for the moment was invested with an interest equal to that attending an auction of masterpieces of art at Christy's. The last batch of animals from the Jardin d'Acclimatation was on offer, to supply the materials for a New Year's dinner. The trunk of "Pollux," a young elephant, was the central attraction, and among a number of unfamiliar heads and horns, a shopman was pointing to a pile of camel steaks.

The butcher was concluding his speech, in the centre of a circle of women-

"It is forty francs a pound, for the filet or the ribs. Yes-forty francs. Dear, you say? Not at all; I do not see my way to making a penny on it. I counted on 3000 lbs., and he (the elephant) has only cut up into $2300 \mathrm{lbs}$. The feet-you ask the price of the feet :- are twenty francs; the other portions eight francs to fourteen francs a pound. Allow me to recommend the elephant sausage; there is onion in my sausage, ladies and gentlemen!"

De Goncourt was able to purchase two larks for his breakfast-like the toasted mice of the hero of 
Bulwer Lytton's Parisians, "dainty, but not nutritious." That evening he found, at Voisins, the famous elephant sausage, and he dined on $i t$.

The rarer animals from the Jardin d'Acclimatation in the Bois de Boulogne were transferred before the siege to the Jardin des Plantes. These were mostly bought by the proprietor of the English butcher's shop, M. Debos; he also bought the elephants of the Jardin des Plantes for 27,000 francs. "Personally, I have eaten the flesh of elephants, wolves, cassowaries, porcupines, bears, kangaroos, rats, cats, and horses," says the author of the Englishman in Paris. His views on these creatures as articles of food are only given at length in the case of the dog, cat, and horse. The last was supposed to have become a recognized part of the food supply of Paris in the year before the siege, but it never acquired any popularity. "It is very curious, but a positive fact nevertheless, that I have heard Parisians speak favourably afterwards of dog's and cat's flesh, even of rats baked in a pie; I have heard them say, that for once in a way, and under ordinary circumstances, they would not mind partaking of those dishes; I have never heard them express the same good-will towards horse-flesh. One thing is certain. At the end of the siege, the sight of a cat or dog was a rarity in Paris, while by the official reports there were thirty thousand horses left."

The same writer records the opinion of an officer who was most successful in "siege cookery" on the 
subject of the dog as food. This gentleman, aided by a soldier servant, had made an excellent dish of "larks," which turned out to be field-mice, slightly flavoured with saffron to disguise their musky taste. "You may disguise anything with saffron except dcg's flesh. His meat is oily and flabby; stew him, fry him, do what you will, there is always a castor-oil flavour remaining, which cannot be got rid of. The only way to minimize that flavour, to make him palatable, is to salt or rather pepper him; to cut him up into large slices and leave them a fortnight, bestrewing them very liberally with peppercorns. Then before cooking them, put them into boiling water for a time, and throw the water away."

All palates do not seem to have disliked dog so greatly. At Brebant's, where M. Renan and other leading writers dined regularly during the siege, a "saddle of mutton" was brought in. "We shall have the shepherd served up to-morrow," said M. Hébrard. It was explained that it was a "très belle selle de chien," and that this was the third time they had eaten dog.

"No, no," exclaimed M. Saint-Victor, horrified. "M. Brebant is a respectable man-he would have told us-horse, not dog."

"Dog or mutton," said Nefftzer, his mouth full, "I have never eaten a better rôti. If Brebant would give you rat, it is excellent, a mixture of pork and partridge."

During this dissertation poor M. Renan, who 
292 THE PARIS ZOO IN THE TWO SIEGES

appeared preoccupied and thoughtful, grew pale, then green, threw his five francs on the table, and left hurriedly.

The result of the compulsory experiments in food during the siege will not be much assistance to guide the work of acclimatization, or to aid in the discovery of a new meat, either from the menageries of the Zoological Gardens, or our beasts of burden, though all the needful accessories of good cooks, good wines, and good company were available to secure success. 


\section{O'THER BEASTS OF BURDEN.}

The failure of the Zoological Society to establish any new draught animal in this country seems to show that as long as an Englishman can get a horse, he tries to do without any other beast of burden. The use of dogs is no longer legal, and we have nearly discarded the sturdy ox, even for ploughing. A few are to be seen in Wiltshire and on the Cotswold Hills; in Berkshire there are some half-dozen teams, among them a famous quartette of red steers belonging to Sir William Throckmorton; and Mr. Beresford Hope's team of "sheeted" Dutch oxen, black giants with white "sheets" of identical shape, is one of the sights of the farm at Bedgebury in Sussex; but outside these counties we know of none in England.

Were we right to legislate against the use of dogs for draught: A careful inquiry has been made in Brussels, and the verdict is that dogs are more useful than horses for minor town traffic-quieter, cleaner, and cheaper. "The first distinctive institution that attracts the attention of a stranger in Belgium," writes the Consul, " is the working-dog. Liège is a city of great wealth and industry, employing as many horses 
as any other town of its size in Europe; and yet for every horse, at least two dogs are to be seen in its streets." In the early morning, we are told, the boulevards are literally alive with them. The butcher, the baker, the grocer, the porter, carriers of all kinds, engage the dog's services. His step is so much quicker than that of the horse, that he will in an hour cover twice as much ground, and he carries with him a greater burden in proportion to his size. Six hundred pounds is the usual weight for an ordinary dog, though a mastiff often draws as much again. They cost about $3 d$. a day to keep on black bread and horse-flesh, and draught-dogs are now carefully bred, mastiffs crossed with the bull-dog to give lungs and chest fetching the highest prices, averaging from $£_{4}$ to $£ 6$. The Consul concludes by stating his opinion that "there is not an article of merchandise, from a ton of coals to a loaf of bread, sold in our cities, which might not be more advantageously delivered by dogs than horses." The Consul is doubtless thinking of ordinary "tradesmen's" deliveries. It would be ridiculous to expect dogs to take the place of the brewers' dray horses, or the railway-goods horses,- - but his views certainly deserve consideration. In England, where their use was once common, we seem to Jook on dogs as only suitable for draught inside the Arctic circle. The absence of a strong shoulder and hard hoofs suggests cruelty in their employment. Nothing in Holland and Belgium gives an Englishman a keener sense of discomfort 
than seeing dogs in carts. His first impulse is to protest against it as ill-usage. In reply he will learn that a careful inquiry had been held many years ago; that Mr. Grantley Berkeley, whose personal affection for animals, as shown in his Memoirs, was almost a passion, had been consulted, and that the verdict had been in favour of continuing their use. Many months of careful observation confirmed this view. No animal so enjoys his work, or does it so willingly, as a dog. Except the elephant, no other animal can be trusted to work alone like the smugglers' dogs between France and Belgium, or collies watching. sheep. They are scarcely ever struck or beaten either in Holland or Belgium. They do not fight, and the only drawbacks to their use are their readiness to attack a stranger who approaches their cart when left in their charge, and the severe hydrophobia "scares" which their numbers at times produce. They are exuberantly happy in their daily work, and come of their own accord at the right hour to be harnessed. Small dogs in little carts are always ready and anxious to race against big ones; and though at the Hague the barking and galloping of dogs within the city-bounds is forbidden, as "furious driving" is here, the dogs, when returning with empty carts, may race as much as they please. Two little boys, with their cart drawn by a sturdy bull-terrier, used often to wait for and race a couple of half-bred mastiffs drawing a cart with two men, the owners running alongside, and jumping on when the carts 
-mere narrow shelves like all dog-carts, whether on wheels or sledges - were going at ten miles an hour. There may be cruelty, just as in the use of any other creature. But men are always hardest on a sluggish animal. One donkey suffers more than twenty dogs. The legislation which stopped their use in England was nominally humanitarian. But it has often been asserted, that it was chiefly due to the objection which persons who drove horses entertained for dog-carts, and to the country gentleman's dislike of dogs as enemies to game. We should be sorry to see dogs replace ponies in common use. But it should not be illegal to employ them. We have seen a little Pomeranian helping to pull its invalid master's chair, and evidently proud of its work. In this case, it would have been difficult for the policeman to put the law in force. In snow-time we have harnessed a setter and a retriever to a toboggan-sledge, and they enjoyed the fun quite as much as their master,indeed, they upset us at the first corner.

The English reliance on horses, big and little, is almost justified by the wonderful adaptation for manifold uses which careful breeding has produced. 'The work of the dog must, in civilized'countries, be limited to petty draught on well-made roads and in towns. In the Arctic circle he is a necessity to man as a beast of burden. When the Greenland dogs die, the Greenlander must become extinct. It is impossible for him to drag home the seals, sharks, white whales, and narwhals, which he shoots on the ice, without his 
dogs, or for the Eskimo to make his long migrations with his family and household goods to fresh huntinggrounds without their aid. If the epidemic of rabies which half-destroyed their teams had not been arrested by the ice-fiord of Jacobshaven, the Greenlanders would by now have been pensioners on Danish charity. It was noticed, as evidence of the absolute dependence of the Arctic man upon the services of the Arctic dog as a beast of burden, that whenever a native lost his dogs, he went very rapidly down-hill in the scale of Eskimo respectability, and became a sort of hanger-on to the fortunate possessor of a sledgeteam. Exactly the same degradation has been observed in the case of the Tartar who is too poor to keep his horse, and a corresponding rise in the social scale of the "foot" Indians of Patagonia, when a neighbouring tribe of horse-Indians lent them horses, and provided them with hunters to teach their use in the capture of game. On good ground, a team of six Eskimo dogs will draw a load of from eight to ten hundred-weight at a speed of seven miles an hour. Large teams, with light sledges and little except the driver to carry, are wonderfully rapid. Kane, the Arctic traveller, was carried for seven hundred miles at an average rate of fifty-seven miles a day. Lieutenant Schwatka sent two Eskimo with a double team of forty dogs, the sledge having its runners "iced" by pouring water over them, to the rescue of a half-frozen sailor, who was viewed from the ship at a distance of ten miles across an ice-covered bay just 
before nightfall. Two drivers sat on either side of the sledge, with knives to cut the harness of any dog that might stumble and be dragged to death, and the sledge was driven at perhaps the highest speed ever known. The dash of ten miles was accomplished in twenty-two and a half minutes. But creditable as such an achievement is to the half-starved descendants of the Arctic wolf, the strongest evidence against the use of the dog for general draught purposes is the fact, that wherever the surface, even in the snow regions, is sound and safe for any other creature than the light and active dogs, the reindeer, or, in the more southerly districts, the horse, at once takes its place. There is one exception, the great Thibetan mastiff, which stands apart. These dogs, the largest in size of any native and unimproved breed, cross the mountains regularly as beasts of burden, and bring their loads as far as Darjeeling. For size, courage, and general utility they are probably the finest race of dogs in the world.

But as a rule in Asia the dog is the draught animal of the inferior races. Mr. Nordenskiold, in his royage in the Vega to the Asiatic shore of the Behring Sea, noticed a marked difference between the "Dog Chukchs," the inhabitants of the coast, and the "Reindeer Chukchs" of the interior. The latter were better clothed and in better circumstances. Both showed great kindness to their animals, which is unusual among semi-savages. The "Coast Chukchs" always carried dog-shoes, neatly-made bags of soft leather, with straps attached, to put on 
their dogs' feet if cut by the sharp snow. The herd of a "Reindeer Cutch" came down from the pasture every morning to meet their master. The leading stag came first, and bade him good-morning by gently rubbing his nose against his master's hands. All the other deer were then allowed to do the same, the master taking each by the horn, and carefully examining its condition. The inspection over, the herd then wheeled, and returned to the pasture. It would be difficult to name another beast of burden so tame and so efficient as the reindeer. A good reindeer will travel one hundred miles a day over frozen snow, and can draw a weight of three hundred pounds; thus surpassing the dog by one-half in distance and two-thirds in drawing power. The loads carried by the camels of the Heavy Camel Corps across the Bayuda Desert were very little heavier than those drawn by the reindeer across the Northern steppes. Including the rider, the average weight was about three hundred and forty-two pounds. Even so, they were over-weighted, and the little Egyptian horses ridden by the Hussars, who accompanied the column, were less exhausted than the larger beasts when the forced march was completed. The llama, admirable as it was for climbing the step-roads of the Incas, which ruined Pizarro's horses, is only an inferior camel; and the yak, Thibetan goat, and buffalo are highly specialized forms, suited to particular climates and conditions. The water-buffalo is the one domestic animal which evolves the enthusiasm and affection of 
the Chinaman. He loves it as the Hindoo does his cow, and paddles by its side in the squashy ricefields, with a smiling contentment on his bland countenance, due to a feeling that in his buffalo he owns the one thing needful to make his husbandry a success and satisfaction. Of all the creatures of the flowery land, it is the only one which the Celestial takes with him into the countries of the barbarians into which he migrates. Long ago the Chinaman in Singapore and the Straits Settlements became a buffalo breeder, and now he has imported them into the Sandwich Islands. There also the trotting ox is now established, and is regularly ridden by the Kanaka boys. The breed is maintained in great purity, and for pace and size they match the best animals of the Indian plains.

But the elephant must still hold the first place as a beast of burden. His normal load is eight hundred pounds, so that in India he is reckoned equal to eight ponies, to five pack-mules or stout bullocks, and to three and one-third of a camel. Next to the elephant in general usefulness we should be inclined to place the "trotting ox" of India. "All Indian oxen can be trained to trot," says Mr. Lockwood Kipling. "The sloping quarter and straight hock may possibly account for something in their more horselike gait. One of the first things to strike a stranger is the hurrying ox. The rekla, a light twowheeled cart drawn by a pair of oxen, cheap, speedy, and convenient, is the hansom cab of the natives of 
Bombay. All through the Mahratta country the ox is the common draught-animal, differing in speed and size according to the work for which he is required. Cattle of the Nagore breed, used by rich men to draw their state carriages, used to be kept near Delhi for carrying despatches. Mr. Youatt was informed that they would travel with a soldier on their back fifteen or sixteen miles in the day, at the rate of six miles an hour. The Nagore cattle have none of the awkward swinging motion of the legs of the English cow. They bring their hind-legs under them in as straight a line as the horse. "They are very active," continues Mr. Youatt, "and can clear a five-barred gate with the greatest ease." One owner possessed a calf which would jump an iron railing higher than a gate, and a bull which would leap the same railing to go to water, and having drunk, leap back again.

Napoleon borrowed his idea of bullock transport for the first stages of his Russian campaign from the Indian army. But the Indian bullocks are shod, Napoleon's were not, and the bullock transport was ruined before the frontier of Poland was reached. But even if this important detail had received attention, it may be doubted whether a large experiment in the use of a new beast of burden ever succeeds in an old country. Natural selection never proceeds faster than when controlled by human necessity, and though the dog may be reinstated in the tradesman's carts, the ox continues to disappear from the dwindling area of arable land in this country. 


\section{THE SOLDIER'S CAMEL.}

"BaCtrian camels," says Major A. Leonard in his work on the Camel, its Uses and Management," "or those from Afghanistan, or any such cold climate, would thrive just as well in a re-mount depôt in England as they do at the Zoo. What in the world is to prevent their introduction into this country, and the formation of camel and mule transports? Nothing, that I can see."

Major Leonard speaks with the authority of one who has spent sixteen years as a transport officer, and if the suggestion which he makes, based as it is on the observation of the good health and long lives enjoyed by the northern camels at the Zoological Gardens, be adopted by the $W$ ar Office, the original intention of the founders of the Society, to make their Gardens an example of what was possible in the way of acclimatization, would be fulfilled in an unexpected quarter.

The reason for Major Leonard's suggestion is to be found in the failure in the management of our camel

${ }^{1}$ Longmans, Green and Co., London. 1874. 


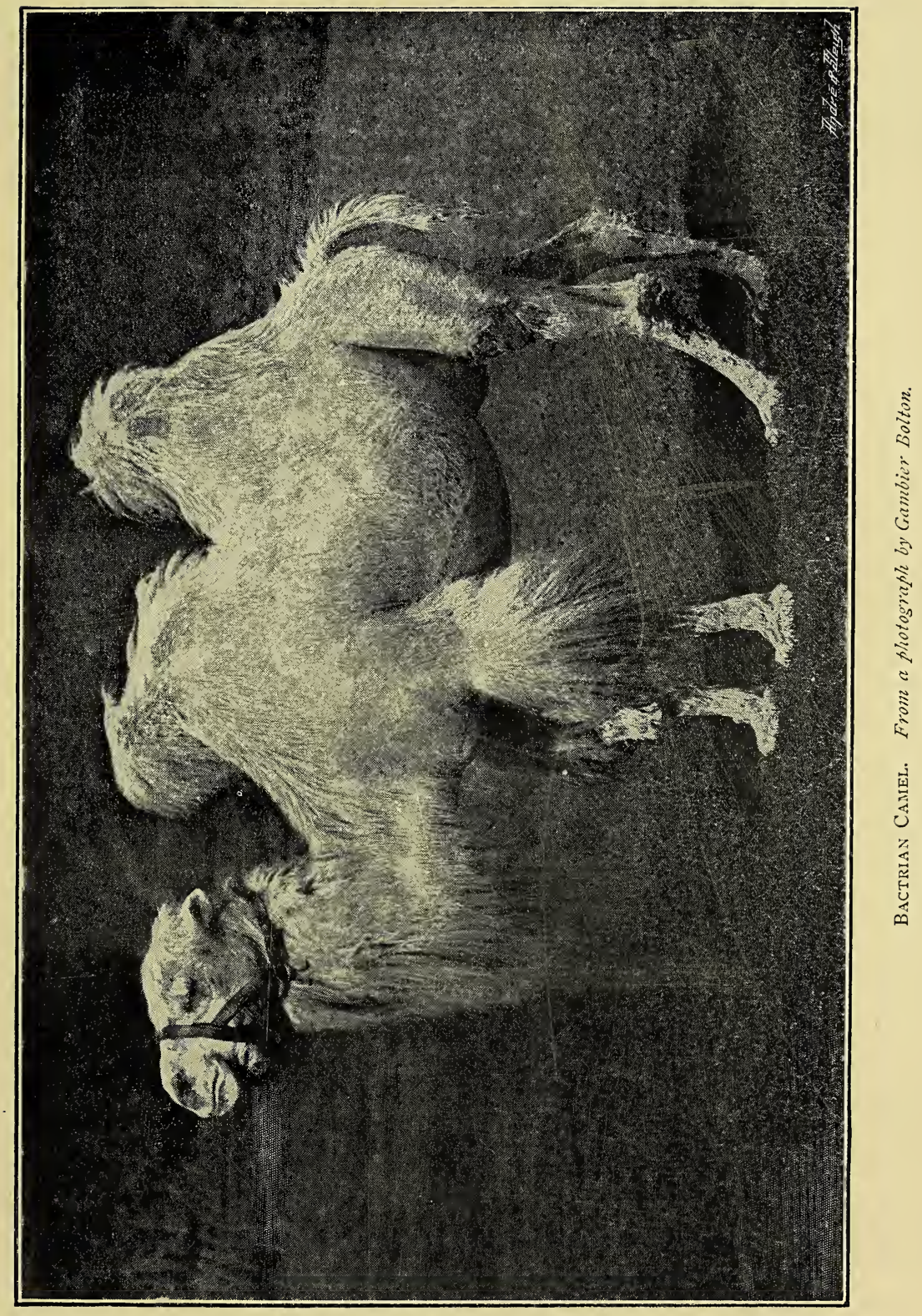



transport in war-time. The natural liking of Englishmen for domestic animals of all kinds is quite equalled by the skill they usually show in their management. Yet the sufferings of our transport animals in war are such as at any other time would cause a pang to the national conscience. It is a fact that the feeling of humanity, which will not tolerate the overcrowding of a cattle-ship, is scarcely shocked when, as in the Afghan War, twenty-thousand camels perish, mainly from mismanagement, or when a transport officer can write of the fate of those creatures in the Nile Expedition-"Seeing, as I have done, hundreds and thousands of camels die from sheer exhaustion, brought on by neglect and ill-treatment, arising from down-right stupidity, obstinacy, and ignorance, is enough to make one ashamed of having had any connection with the business." The push across the Bayuda Desert was a race against time; yet it hardly seems consonant with the usual fairness of Englishmen to their "mounts," that of the thousand camels used, probably not one survived the treatment it received; and Count Gleichen, writing after service with the Camel Corps throughout the war, says, "I am afraid we looked upon them as mere machines for carrying, and hardly thought of their sufferings from hunger and thirst as long as they could be whacked along." This was after the battle of Metemmeh. Of the same example of cruel and disastrous mismanagement Sir C. Rivers Wilson says-"The camels had been without water for from six to seven days, having been accustomed 
to water every second or third day. They were on one-third rations, which they did not always get. Fol thirty-seven hours they were tied down so tightly in the zeribah before Abu Klea, that they could not move a limb, and I doubt if they were fed at all during that time. Then for sixteen hours they were on the march, and tied down for another twenty-four hours without any food. The result almost justified the saying, that we thought we had found in the camel an animal which required neither food, drink, nor rest; we certainly acted as if the camel were a piece of machinery." Except during the time of battle, all this cruelty to the animals and waste of mobility in the force was unnecessary. The so-called "desert" was full of food and well supplied with water. On the day before the retreat from Metemmeh, a camel convoy of the friendly Kababish came in across the desert in perfect condition. "It made my mouth water," writes an officer, "to see these magnificent, well-fed brutes swinging along, each with its load balanced on its hump." His own beast had holes in its skin into which you could have put a cocoa-nut. Read in the light of these facts, the inimitable ballad in which Mr. Rudyard Kipling sums up the miseries of the commissariat-camel, and the incompetence of the uninstructed British private to manage it, is an invitation to substitute common-sense and kindness for ignorance and cruelty in the treatment of the four-footed army which helps to fight our battles.

Major Leonard has been engaged in this service in 
Afghanistan, South Africa, India, and the Soudan. That is in itself a credential for his book; for no one not possessed of an equable and reflective temper could have gone through his experiences and yet be enthusiastic over his branch of the profession, and, above all, over what he justly calls that "little-known and strangely unsympathetic animal," the camel. Yet Major Leonard's practical experience leads him to the conclusion that, of all transport animals, it is the best for military use in the East. Incidentally, he gives us an historical note on Mr. Rudyard Kipling's immortal ballad on the Commissariat Camel-

"The driver question in Afghanistan was enough to appal the heart of the stoutest transport officer. They deserted, and soldiers had to be told off to act as drivers. On December 20, I878, I had to leave I6 I bags of Commissariat stores on the ground, many of the drivers having deserted, and taken their camels with them. This is a common trick of the Sind drivers. They go back by a circuitous route, and in many cases -it is said-are re-engaged by the Commissariat."

The place assigned to the camel in this estimate need not raise any bright ideal of the creature as a travelling companion. Mr. L. Kipling's remark, that you might as well lavish your affections on a luggage-van as on a camel, still holds good. But there is a balance in favour of the camel when compared with other Oriental beasts of burden. The experiences of a single march, noted by Major Leonard, gives a glimpse of the comparative "cussedness" of different transport animals, 
which is as fresh as it is amusing. The occasion was the advance of the Candahar force from Quetta in the last Afghan War. At the crossing of the river Lora, at the foot of the Kojak-Amran range, the camels were swallowed up wholesale in the quicksands, owing entirely to their extraordinary stupidity. We quote this incident first, because the one serious drawback to the use of the camel consists precisely in this strange insensibility to danger-

"The river was not very broad, and not more than two feet deep in any part of the stream; but the bed was full of quicksands, in whose treacherous depths many an unfortunate camel perished. It is only natural to suppose, that by sheer force of example an ordinarily intelligent animal would have learnt to avoid the danger, by seeing those which preceded it sinking deeper and deeper out of sight. Yet these camels plodded steadily on into the quicksands, though those which had preceded them were disappearing so fast that in many cases only their necks and heads were visible."

Not a single horse, elephant, or mule, was lost in this way in crossing the ford, and they one and all displayed a marked and consistent caution which was clearly the result of reason--

"One elephant, which the officer commanding the 6-I I Battery of the Royal Artillery lent to assist in extricating some camels which were being engulfed in the quicksands, showed an amount of sagacity which was positively marvellous. It was with the utmost 
difficulty that we could get him to go near enough to attach a drag-rope to one camel I wanted to rescue. In spite of our being about fifty yards from the bank of the river, he evinced the greatest anxiety, while his movements were made with extreme caution. Despite coaxing, persuasive remonstrance, and at last a shower of heavy blows dealt upon his head by the exasperated mahout, this elephant stubbornly refused to go where he was wanted, but, with his trunk shoved out in front of him, kept feeling his way with his ponderous feet, placing them before him slowly, deliberately, and methodically, treading all the while with the velvety softness of a cat, and taking only one step at a time. Then suddenly he would break out into a suppressed kind of shriek, and retreat backwards in great haste. When the animal had nearly completed a circuit of the ground with the same caution and deliberation, he advanced to within ten yards of the poor camel, but not another inch would he move, though several men were walking between him and the camel without any signs of the ground giving way."

But if the camel is too mechanical, the elephant is too soft for the hardships of the baggage train or rough country. He requires good roads, a temperate climate, and meals not only "regular," but luxurious. Ten elephants out of eleven reached Candahar safely in I 878 , on a diet of chapatties, rice, sugar, and two bottles of rum apiece after their supper. No wonder "the faces of the men, and their remarks, as they looked on with watering mouths and overpowering 
envy, were worthy of a camp-ballad by Rudyard Kipling." Yet this is, we submit, an error on the right side, both in economy and efficiency. Which cost most, the elephants' comforts on the road to Candahar, or the ninety-two camels which dropped from exhaustion and hunger on the first day's march back from Metemmeh, where the day before 50,000 lbs. weight of stores had been flung into the Nile? The "patient ox" combines the cunning of the mule with a spirit of revenge which is generally attributed to the camel, though Count Gleichen states, that only one case of camel-bite was reported to him during the Nile expedition. A leading bullock on the Candahar march lay down six times, and when it was at last reluctantly agreed that the creature must be dying from exhaustion, it " rushed at a private and tossed him ten feet in the air, then on to the next man and sent him flying, and lastly at its own driver, whom it tumbled over like a ninepin, while the rest took refuge behind the wagons." The creature would not move in harness, and finally had to be unyoked and driven into camp. The mule is the handiest and hardiest, the donkey the least trouble, and the pony the pleasantest of all pack animals, according to Major Leonard's experience, the Spanish donkeys and Sicilian mules being perhaps the finest and most useful of their respective kinds. But though military opinion is, on the whole, in favour of the mule, he gives facts and figures to show that the camel, unmanaged as it is, is a still more economical and effective beast for military service. Its power 
of enduring hunger and thirst is greater, it carries do: never shod, and costs less to buy and less to keep; for food and water have to be carried for miles in desert country, while the camel browses on almost any shrub, and can make the ordinary caravan march from well to well.

This opinion must not rest on general considerations, for the good working example of the comparative efficiency of the two animals in a campaign is obtainable. Lord Roberts, on his march from Cabul to Candahar, covered a daily average of fourteen and a half miles for nineteen days. This was done with mules and ponies, the camels belonging to the regiments being exchanged for the former. In the Bayuda Desert the camels travelled thirty-four miles daily in the first march; and allowing for the two days' rest and two of fighting, nearly thirty miles a day in the second march of two hundred miles. But in this case the camels were starved, and worked to death. The difference between the careful treatment of the cavalry horse-Marbot's reminiscences of his life as a cavalry officer must have opened the eyes of many readers to the practical anxieties of that profession-and the ignorant neglect of the camel suggests a doubt whether the Englishman is really so adaptable as we are pleased to think. The two hundred pages which Major Leonard derotes to instruction in feeding, watering, loading, doctoring, equipping, and purchasing camels, contair so many "glimpses of the obvious" that the 
reference as to our general neglect of this indispensable animal for Asiatic warfare is irresistible.

The two great breeding grounds of the camel are the whole central zone of Asia north of the Himalayas, and the centre and northern fringe of the African Soudan. With the latter we are in touch through the frontier tribes of Egypt, and there is little doubt that we could make Egypt the nucleus of a camel transport unrivalled in the history of the world. But unless our officers and men have some training in their management, the suffering camels will continue to cause, as they have hitherto in our frontier wars, an embarrassed strategy, neglected sick, and an illsupported soldiery. A permanent camel transport service in Egypt and on the north-west frontier of India would probably save in our next considerable war, millions of money and hundreds of soldiers' lives. 


\section{THE CANADIAN BEAVER.}

INDIAN tradition ascribes the rescue of the world from its aqueous ages to the industry and intelligence of the beaver, the animal which first learnt to control and turn to account the opposing elements of land and water. The beavers were of gigantic size, before the Great Spirit smoothed them down to their present dimensions, after they had completed his work on the unfinished earth; and they, with their fellow-workers, the musquash and the otter, dived and brought up the mud, and with it made mountains and lakes, caves and cataracts, dividing the land from the waters, while the envious spirits of evil pelted the 'Titan beavers with gigantic rocks, which still strew the plains and valleys with monstrous boulders of misshapen stone. If the legend needed any justification beyond its picturesqueness and simplicity, a study of Mr. Martin's work on The History and Traditions of the Canadian Beaver ${ }^{1}$ would almost bear out the Indian belief, that the intelligence and mechanical skill of the beaver were prior

1 Edward Stanford : London. 
and superior to that of man in the developinent of the New World. The exaggerated descriptions of the beaver-lodges and engineering feats given by the early French Canadians, hardly deserve the author's condemnation; the works themselves are so complete and so ingenious, that the symmetrical additions of early explorers add but little to the facts which their incomplete observations only partially grasped. That a creature whose engineering structures were based, consciously or unconsciously, on principles only known to highly civilized man, should embellish them with conveniences known to half-civilized man, was a natural inference; and to credit the beaver with a wish to insert windows in the walls of his lodge was no great flight of fancy to men who had seen with their own eyes that the same animal could construct a dyke a mi'e long, with the precise section which human experience has determined to be that best adapted to resist the forces of pent-up water. $\mathrm{Mr}$. Martin has so well fulfilled the promise of his titlepage, to present an " exhaustive monograph popularly written" on the life and history of the beaver, that an attempt to follow the varied commercial, historical, and palæontological references in which the story of the beaver abounds, would be impossible. It will, perhaps, be sufficient to consider the main questions of the extraordinary intelligence exhibited by the animal, and the possibility of its preservation from the total destruction with which the species is now threatened. Șo far as the most careful modern 
observation shows, there is but one claim which has been seriously made for the beaver's sagacity which is matter for doubt. It has been asserted that the animal always cuts the trees it selects, so that they may fall towards the water. There is evidence that this is not always the case. But trees growing near the water naturally tend to lean towards the stream, and naturally extend the heaviest growth of branches over the water, where light and space are greatest, and the greater number of those cut by the beavers would probably fall in that direction without any special provision. But the inseparable features of a beavercolony, the dyke or "dam," and the less famous but almost equally wonderful "canal," suggests an estimate of brain-power or inherited instinct for mechanics which an exhaustive examination of the facts heightens rather than diminishes.

The object of the dam is to supply a temporary want, not a permanent necessity always present to the beaver-mind. In summer, the beavers wander up the streams, finding food without difficulty. In winter, they require a permanent supply of water at a certain level, in which they can swim beneath the ice, store their supply of branches for food so as to be accessible without exposing themselves, and keep a "moat" round their lodges. Left to itself, the stream would run low in winter, when the freezing of the snow and earth stops the water-supply. Hence the necessity for the dam to maintain it at a constant level. Such a train of arguments supposes 
a number of "concepts" in the beaver's brain which would occur to no other animal. To carry it out efficiently would puzzle most human beings not acquainted with engineering. Moreover, the work must be done with the material at hand, so that beaver-dams are found built of branches and mud, of grass, of sand, and of mud only. To get the wood to the water-side, the beaver clears paths, or "rollingways," cuts a water-channel to meet and assist in the transportation of the wood, and in some cases actually makes a long canal for water-carriage and safe travelling. "Though the beaver-canal is not so popularly known," writes Mr. Martin, "and is more easily reconciled with instinct, it must not be supposed that it is a minor feature in the performances of this animal; it is almost incredible that a work, so apparently artificial, could have remained unnoticed till I 868, when Mr. Morgan published his valuable notes, so amply illustrating the works of the American beaver. When the colony has been settled quietly for many years, and has cut all the desirable trees close at hand, and further supplies are sometimes hundreds of yards away, the necessity for clear rollingways and good canals is obvious." No doubt the necessity is obvious, but that does not explain the wonder that a small rodent animal should anticipate civilized man, and make a road to bring commodities to its city, instead of shifting to a fresh encampment like the Red Indian himself when supplies are exhausted. Our estimate of the individual intelligence 
of beavers must greatly depend on the power of adaptation shown by them in special cases. Mr. Martin seems to lean to the opinion that the creature is controlled by a dominant instinct, which makes its action almost automatic, and alleges this want of adaptability as an insurmountable obstacle to its domestication. The instances given of its behaviour in captivity hardly justify such a conclusion. A tame beaver, kept as a pet in a trapper's hut, "used to lie before the fire as contentedly as a dog. It was not till winter set in that it became a nuisance. Poor old Bill McHugh's house was well ventilated, an open chink between the logs being thought very little of by himself and his family; but the beaver was very impatient of such negligence, and used to work all night at making things air-tight and comfortable, without much discrimination as to the materials it employed. If Bill or his guests went to bed leaving their moccasins and tichigans drying before the fire, they were certain to be found in the morning stowed away in some chink or cranny; and stray blankets and articles of clothing were found torn up for the same purpose." That was contrary to our notions of housekeeping, but the beaver's wish to keep out the cold was not more "instinctive" than that of any squatter's wife on a Surrey heath. The preparations made to meet the severe cold of the winter of 1890 by the beavers at the "Zoo" in Regent's Park were an odd mixture of cleverness and what seems too like the stupidity of "instinct." Their "lodge" was 
partly their own building, and partly "subsidized" by the authorities. That is, it had a roof of corrugated iron supported by strong posts at the corners. The sides were carefully built up with branches set on end by the beavers themselves, and well plastered with mud, which they push in with their fore-paws and pat down hard. They not only carried the plaster up to the "eaves" of the house, but patted a quantity of mud down on the iron roof, a quite unnecessary labour, except on the assumption that there were joints in it which require filling. The whole was (rowned with a pile of branches, which served no useful purpose. Last year these beavers dug a canal from the stone-rimmed pond to one of the burrows running under their house. We were not able to see whether it actually joined the pond, or whether the rim of stone which divided it from the pool at the surface was continued downwards. In any case, they had managed to fill the canal with water, and had a clear waterway from the house to the edge of the pool. They were also busy cutting through a poplar stem; the largest chip of wood lying at its foot measured $3 \frac{1}{2}$ in. Another stump was being carefully gnawed into fine sawdust, which was probably intended for bedding.

Since then the beavers have been supplied with a fine new house of concrete, which will probably keep out their enemies the rats which invaded the old house, though it will leave less inducements to the animals to go on with their interesting building feats, Yet 
as soon as the new house was completed they at once set to work to scratch out a "canal" in the run, and managed to fill it partly with muddy water.

If the beaver is to be saved from extermination, some means for its artificial preservation must be found, though, from the failure of the attempts made in Prussia and elsewhere in Central Europe to save the species-so late as 1725 an edict was published in Berlin prohibiting the destruction of the beavers of the Elbe-Mr. Martin is not hopeful of success, even in Canada. Lord Bute's colony in the island from which he takes his title appear to have been less fortunate than was at first supposed. In I883, when it was desired to send specimens to the Fisheries Exhibiton, it was found that their numbers, as estimated by the work done, had been much exaggerated, and the enclosure was completely ransacked before a couple could be secured. One hundred and eighty-seven large trees were cut down by the beavers between 1874 and 1878 . In that time they dammed a pool seventy-eight yards long, and constructed seven dykes, one having an embankment of one hundred and five feet. But in spite of the difficulties which their engineering industry presents to their would-be preservers, proposals for a "beaverranch" are still being discussed in Canada ; and though experience forbids the hope that they can be kept for profit, sentiment may yet succeed in preserving the creature which has 'been adopted as the "totem" of the pale-faces' colony by the great Lakes. 


\section{THE TEMPER OF ANIMALS.}

The old theory that animal good-temper might be accounted for on the ground that animals are sensible of pleasure and pain, but not of advantage and disadvantage, was only a half-truth, for animals are subject to jealousy, and jealousy is the direct result of a feeling of personal disadvantage. But it draws attention to the fact that occasions for disagreement in the case of most animals are rare and unusual. Questions of domicile are almost the sole ground of discord in the animal world, with the exception of the fierce dissensions raised at pairing-time, and even in the last case combat is only general in the case of polygamous animals. Deer fight more fiercely than wolves, and wild sheep than lions; and though there is, or was, an eagle in the $Z_{0 o}$ which was caught locked in the talons of another eagle when fighting in the spring, the fiercest birds are usually friendly with their own species, and while ruffs and black-game fight like gladiators for their wives, the eagles and the peregrines as a rule mate in peace. Proximity, the severest trial to human temper, seldom ruffles the animal mind, and different species live in harmony together, each seeming, as in the case of the owls and 
the prairie-dogs, or rooks and starlings, rather to prefer than, shun the society of the other. The choicest spots for homes are naturally the source of warfare among birds, and other animals frequently fight for the possession of some favourite breedingplace. Badgers and foxes which have shared the same earth during winter often fight for sole possession in the spring, when the fox invariably wins, a result which would hardly be expected from the relative physique of the two animals. But such quarrels are only for the sake of rearing their young, not for selfish reasons; and even apprehended pressure of the food-supply rarely excites ill-will, except in the case of the largest carnivorous birds and animals, which require a wider range for hunting, and drive their young to other districts. The rodents and ruminants are less jealous; and that strong social and gregarious instinct which the existence of ill-temper as a permanent characteristic would inevitably destroy, keeps them together in peace and harmony. They love society, and not the least marked difference between the temperament of animals and men, is that animals do not by mere contact irritate, each other,a positive and not unimportant compensation for the absence of the gift of speech.

Since occasions of difference are so few, nothing but the assumption of an ancient and inbred malignity in animal minds, such as the author of Three Men in a Boat supposes in the case of fox-terriers to have been due to a double dose of original sin, could justify the view so generally held that animals are, as 
a rule, ferocious and ill-tempered, a notion summed up in Mr. Burnand's conclusion in Happy Thoughts, that most of the creatures with which he came in contact in the country were, "when not dangerous, always very uncertain." The exact contrary would be nearer the truth. Animal temper is naturally pacific, equable, and mild. Bad temper is the privilege of more highly organized natures; and the mild resentment of the placable tiger finds its development in the apoplectic fury of the mandril and the measured malice of mankind. Horace's suggestion, that Prometheus added to the ill-temper of man the strength of a mad lion, must be taken literally. The general law of good-nature in the animal world makes the exceptions all the more remarkable. Quarrelsome species appear among a friendly tribe, just as an illtempered individual does in a kindly species. The ruminants are a most peaceful race, yet deer are savage, and so is that handsome Indian antelope the nilgai. A tame stag is a very dangerous pet, and even the beautiful roebuck has been known to kill a boy in a wild fit of rage. But the fiercest and most vindictive of all, with the exception of the Cape buffalo, is the South African gnu, which never loses its ill-temper when tamed, and always remains among the few dangerous animals which the keepers at the Zoo have to deal with. Hardly less ill-tempered are the zebras and the wild asses, which suggests that human mismanagement is not entirely to blame for the occasional ill-temper and obstinacy of mules and donkeys. To the ill-tempered species we may add 
the buffalo and the two-horned black rhinoceros. The last is really ferocious, charging down on any creature, man or beast, without provocation, and capable of inflicting mortal wounds even on the lion, the elephant, or its own kind.

But among all the larger creatures of the animal kingdom, it is difficult to find more than a dozen species which are, as a class, ill-tempered, unless we include all those carnivorous animals which exhibit a certain ferocity in the capture of their prey. But it will be found that, apart from this law of their being, such animals are not, as a rule, either ill-tempered or malicious. On the contrary, their natural bias is towards good-nature, and it may be inferred that the fierceness exhibited by them when actually striking their prey, is rather a gradual development from a particular necessity than an essential part of their nature. The good-humour of the lions and other felide was well illustrated by a scene at the $\mathrm{Z}_{\mathrm{oo}}$ a few weeks ago. The young lion from Sokoto was much intent on breaking in the iron shutter which separates the house it now occupies from its former quarters next door. Apart from the very proper wish to assert a right to its former domicile, it had the irritating stimulus supplied by an ill-tempered and decrepit old leopard, which was growling on the other side of the shutter, and even went so far as to insert one of its longest teeth into the crack between the shutter and the wall, as a reminder to the lion of what was waiting for it on the other side. The lion was striking constant heavy 
blows on the door, and was so intent on its occupation as to disregard the call of its keeper. The keeper quietly attracted its attention by pulling its tail !- and the lion at once desisted, rubbed its face against the keeper's hand, and lay down to be stroked, patted, and have its mane caressed.

That good-tempered races contain very ill-natured individuals, raises the difficult question of temperament, A good authority on horses, Mr. Mayhew, endeavours to show that ill-temper among them is accidental, not innate. In his work, "jibbing" is shown to be due to brain-disease, shying to defective vision, and temper to the mismanagement of man. There is much truth, but also much error here. Those best acquainted with the nature of domesticated animals know how greatly the temperaments of individuals differ. Take, for instance, the case of three highly-bred young Jersey heifers, of which the writer has watched the up-bringing from their earliest days. They have never been frightened or struck; they have not even heard a rough word from their earliest days, even when they jumped the garden-fence and browsed on an apricot-tree. One is as gentle and domesticated as a well-bred cow can be, the others are ready with their horns at any or no provocation. The same is true of horses: some are so ill-tempered that they will kick or bite at any living thing that comes near them. It is as impossible to trace these dislikes to any known cause as it is to find a reason for the antipathy which cows have for hares. However great our liking for horses, we cannot deny that 
some of the best thoroughbreds are revengeful, quarrelsome, and liable to frightfully sudden fits of rage. No doubt this evil temper is often accompanied by splendid qualities of endurance. Chestnut horses, which have generally the most uncertain tempers, are perhaps the most high-couraged. But courage and temper are not always allied; and temper and human management are not necessarily connected. "Bendigo" and "Surefoot" were both trained in the "Seven Barrows" stable by the late Mr. Jousiffe, who always avoided any severity of treatment, and never ran his horses "light." Each as a three-year-old won a great race, "Bendigo" the Cambridgeshire, "Surefoot" the Two Thousand Guineas. Both carried off the Eclipse Stakes at Sandown, worth $\mathscr{E}_{\mathrm{I} \text { o,ooo, later }}$ in their career. Yet "Bendigo" had a perfect temper, while "Surefoot's" is well known to be ferocious. "Bendigo" would train himself, and however well he ran in trials on the White Horse Hill, his trainer knew that he would do still better on the race-course. In his last race, when he was just beaten when carrying a crushing weight, Watts gave him one stroke of the whip. But the horse was doing all he could, and the jockey did not touch him again. In the stable, the big brown horse was almost as friendly with strangers as he was with his devoted attendant, "Bendigo Pat," and the writer has seen no prettier sight than that of his trainer's little daughter hugging "dear old 'Bendy's' " nose. The horse had the courage and gentleness of a knight of romance. "Surefoot," on the other hand, under identical treat- 
ment, was dangerous in the stable, and savage even when running. In the actual race for the Derby, he tried to bite the jockeys on the horses in front of him, and when being put into the horse-box for the journey, gave more trouble than a Murcian bull. Yet this savage temper was not accompanied by unusual courage and endurance, and in severe races the even-tempered "Bendigo" was his undoubted superior. "Peter," another race-horse noted for his stubborn obstinacy, once gave an interesting objectlesson in temper as between man and horse at Ascot. The horse fought with his jockey (Archer) for twenty minutes at the post, but the indomitable good-humour of the jockey won. When the flag fell, the horse went off with a rush, but stopped in the middle of the race to kick. Archer neither moved nor struck him, and "Peter" then went on like the wind, and won! But horses of this temperament are the exception, not the rule; and the success with which we have developed power and courage, without producing animals like "Cruiser" or the celebrated "General Chassé," of whom his owner, Mr. Kirby, the dealer, who sold largely in Russia, used to say that "the Emperor Paul was nothing to him," is one of the triumphs of domestication. The union of reckless courage and habitual ferocity is rare in the animal world, and the general law of good-nature remains absolute and unquestioned. 


\section{CRIMINAL ANIMALS.}

"Mr. Gladstone narrowly escaped a serious accident when taking exercise in Hawarden Park. A cow, which had escaped from its owner when being driven to market, had taken refuge in the park, and attacked Mr. Gladstone when passing. Fortunately, though knocked down, Mr. Gladstone escaped unhurt."-Daily Paper.

The general view of good or bad in animal disposition is, no doubt, mainly determined by their behaviour to ourselves. That is the fixed opinion of the moral relation of animals to man. But there is every reason to believe that there are a few individuals among the many in all species which have some pronounced and inborn bias towards mischief and ferocity, which almost entitles them to a place in the "criminal classes" of animal society. No excuse, for instance, can be found for the cow which so nearly ended the hopes of Home-rule by knocking down the greatest of all Home-rulers, after spending a week or more in the hospitable security afforded to her by the park at Hawarden, after she had broken loose from her owners on the way to market. She was, in fact, a heifer, not a cow ; and so had no calf 
hidden in the fern whose protection might have been urged as an excuse for her ferocity; and her conduct must be ascribed to some such ancient and inbred malignity as possessed the "dun cow of Warwick." No doubt the last animal, if legend be true, was possessed by a deeper and darker instinct of hatred to the human race; for she used to mingle with the herds and entice the milkmaids to perform their kindly office by all kinds of endearments known to her race, and then most cruelly kill them, until the renowned Guy of Warwick rid the country of the monster, avenged the milkmaids, and earned himself a place in story. But the cow of Hawarden may in time win its way to the marvellous, and have a place in the great Gladstone myth by the side of "Joe"-or "Io"-once the friend, now the foe of the hero, whose legend is in after-ages to be identified with the rationalistic record of the promise of "three acres and a cow." The danger to which Mr. Gladstone was exposed, which was a very real one, suggests the question whether there is not some ground for supposing that, apart from questions or our own convenience, there are not some desperately wicked animals which are not only wicked per se, but quite conscious that they are doing actions which place them outside the pale both of human and animal consideration: We believe that there is not the least doubt of it, any more than there is a doubt whether certain so-called "criminal lunatics" richly deserve hanging. If animals had no power of self- 
control, it would be nonsense to speak of them as either good or bad. But they have the power of self-control when domesticated. That we know. It is only the knowledge that they have such power that induces a man to trust himself in a dog-cart behind a young horse, or to ride in a howdah on an elephant. But they must always have the same power when wild. If they had not, they could not be gregarious - a condition which could only be maintained by submission to a law of "live and let live," which is perhaps better understood by wholly wild animals than by semi-civilized man. Gregarious animals not only exhibit self-control to the extent of not showing temper towards each other, but even obey the command of their leader, when obedience to the command must be extremely irksome-witness Major Skinner's account of the elephant leader posting five videttes around the tank, at which the herd was then, and not till then, allowed to drink. The " rogue" elephant, which exhibits such unusual and malignant ferocity towards men as well as his own kind, may be, and often is, an animal driven from the herd by a strónger rival ; sometimes he is merely suffering from excitement, which passes away after a certain period. But this, though affording a reason for some of the abnormal conditions found in the actions of the "rogue" elephant, does not account satisfactorily for the strange reluctance of its own species ever to re-admit it to their society.

The "rogue" elephant, even when driven from one 
herd, is never admitted to another; and though Saunderson found them occasionally in company with another solitary of their own species, Sir J. Tennant records that, even when driven into the keddah, a "rogue" elephant was never allowed to enter the herd of captives with which he was enclosed. Good-temper is the fundamental condition of animal society, and it is probably to the lack of this, and the growing conviction that the "rogue" is an unclubable, unsociable fellow, that his exclusion is due. When separated from the wholesome discipline of society, his temper goes from bad to worse, and he joins the ranks of criminal animals. The wanton ferocity then developed is, perhaps, best shown by Colonel Saunderson's description of the state of things on the main road between Mysore and Uznand, caused by a creature called the "rogue of Kakankote." Policemen were planted at the entrance of the jungle to warn travellers to proceed only in parties, and even then the wretched Kurrabas who lived in the forest were from time to time caught, and pulled to pieces limb by limb, to gratifiy the ill-temper of the elephant. When mastered, the naturally ferocious elephant has been known to die of sheer fury. A noosed "rogue" in the keddah lay down and died, though those suffering from the excitement of "must" are often reclaimed. The ferocity of the "rogue" buffalo and " rogue" hippopotamus must probably be accounted for in the same way. They are individuals which have become intolerable to their own species, and, 
being outlawed from society, revenge themselves by the indulgence of their criminal bent.

Instances of this homicidal mania among the animals at the $\mathrm{Z}_{\mathrm{Oo}}$ are by no means common. The tact and good management which prevails in all the dealings of the keepers with their charges is largely responsible for this. But one unquestionable example of this type of animal aberration occurred some years ago, which might have had very serious consequences. The temper of all the wild asses is very uncertain, or rather very unreliable. This natural surliness took the form of absolute ferocity in the case of a very fine male zebra. The object of its especial dislike was not so much the occasional visitors to its stable, as the keeper whose duty was to feed it and arrange its stable. The viciousness was such that it would endeavour to climb the railings of its loose box in order to attack them. There was absolutely no ground for this animosity, for it had met with the same kind treatment and attention as the other creatures in the stalls. It was clearly a case of the "criminal instinct" prevailing. One Sunday morning, a Frenchman who had some work to do in the Zebra House accidentally left open the door which led into the box of this striped savage, and when another keeper advanced to drive it back it rushed at him open-mouthed, knocked him down, knelt on him, and would most probably have killed or maimed him if it had not been driven off by some of his fellow employés who most fortunately came to the rescue. 
Among domesticated animals, the consciousness of evil-doing is far more clearly existent than among their wild relations, where it can only be matter for probable conjecture and surmise. Perhaps the most convincing instances of the gratification of a consciously criminal instinct are to be found in the cases in which dogs, especially sheep-dogs, have been detected in the habit of going away to considerable distances at night and worrying the sheep in other folds, returning before daybreak to their own flock. In one case, a collie was seen by a shepherd to slip away from the fold early in the morning, and plunge into a stream, where he swam for a short time, came out, shook himself, and then galloped off in the direction of another farm, to which, on inquiry, the dog was found to belong. In the fold which it had just left, several sheep were found dying and dead, and it was surmised that the dog's bath had for its object the removal of the traces of its sanguinary amusement. In another case, two dogs were found to have been in the habit of slipping away at night, and returning quietly to their kennel after killing sheep at a distance of ten or twelve miles. In both instances, the flock of which they were the natural guardians was uninjured.

The secret gratification of the criminal instinct is not confined to sheep-dogs. In one case, a mastiff ran wild, and lived among the Cheviot Hills, killing sheep at night, and retiring to the roughest and most difficult ground during the day. Though more than once hunted by a pack of foxhounds, he always 
prevailed on them to spare him, lying down on his back and putting up his feet, as a puppy will when a big dog approaches him.

It is more difficult to account for the extreme viciousness of certain horses, creatures which have no hereditary tendency to cruelty, like the dog, whose ancestor, the wild hunting dog, is perhaps the most ferocious creature in the world. What, for instance, are we to say of an animal like "General Chassé," which commenced the day, when being led to York, by kneeling on his groom and trying to tear him to pieces, until a squad of labourers charged him, armed with sticks and forks? Or of "Merlin," who was obliged to be double chained to the rack in the painting-room when his portrait was taken by Mr. Herring, and afterwards made use of his liberty by killing his groom? Another horse could only be groomed during several seasons by a series of welitimed dashes with a birch-broom.

"King Pippin," a celebrated Irish horse, which ran early in the century, had a habit of rushing at and worrying any person who came within reach as he was being saddled, and if he had a chance would get his head round, seize his rider by the leg, and pull him off his back. When brought to the Curragh to run, no one would put a bridle on his head. A countryman volunteered to do so, when the horse caught him by the chest, shaking him as a dog does a rat. "Fortunately for the poor fellow," wrote an eye-witness of the scene, "his body was very thickly 
covered with clothes, as an Irishman on great occasions is fond of displaying the resources of his wardrobe, and if he has three coats will put them all on."

The celebrated "Whisperer," an old man named Sullivan, who had a strange power of taming vicious horses, was sent for. He remained shut up with the horse all night, and next day exhibited him on the course as quiet as a sheep. He won his race, and for three years remained docile. Then he suddenly gave way to his criminal instincts, and killed a man, for which he was shot.

But considering the great number of horses on training, and the accuracy with which their disposition and temper is known, the instances of homicidal tendency in the horse are singularly few. It will probably be found that bulls, and often cows, are responsible for nearly all the deaths deliberately caused by animals in this country. It is the fashion to laugh at people who are nervous about cattle. This is hardly fair or sensible. There can be no two opinions as to the power of full-grown cattle to catch or kill any person who has not some shelter at hand, though the owners who drive them along the roads never are willing to admit the possibility. An amusing instance of this, as well as of the local jealousies which ramble between people of different counties, even if only separated by an imaginary border-line, occurred to an acquaintance of the writer, just within the border of Cornwall where it marches with Devon. A farmer was driving cows down a narrow lane, when some foot 
passengers remonstrated. "Don't 'ee be a-veared, m'am," shouted the owner, "'em be a deal better behaved here than 'em be in Devon." In the case of the bull, a period of savageness generally occurs once or twice in its life, and in the number of fatal gorings inflicted by these brutes on the old labourers and boys who usually attend on them, a fair case could be made out for making compulsory some precautions in their transport along public roads. 


\section{A YEAR AT THE ZOO.}

The Report of the Council of the Zoological Society for the sixty-fourth year of the existence of its "Gardens" in Regent's Park will be read with interest by those whose curiosity extends beyond the menagerie which they see, to its management which is unseen. The public are only dimly aware of their debt to Dr. Sclater, the honorary secretary of the Zoological Society, and to Mr. Bartlett and his son, managers of the Gardens; and the glimpse of a twelvemonth's history - animal, personal, and financial -of' one of the most pleasing and popular out-door institutions of London, explains much that is not at first obvious in a visit to the $Z_{0 o}$. Among the most evident improvements of recent years is the great and growing beauty of the Gardens, the fine turf and flowers, and the other amenities which, apart from the interest inseparable from the natural history collections, have made possible in the precincts occupied by the Society a nearer counterpart of the out-door life enjoyed in the gardens of Continental capitals, than anywhere else in the Metropolis. The explanation of 
this, as well as of the curious and interesting details of the maintenance of a menagerie of $2,4 \mathrm{r} 3$ birds, beasts, and reptiles of all kinds and sizes, from the African elephant and Indian rhinoceros, down to the tiny lemmings and the last litter of dingo-puppies, is to be found in the financial Report for the year. It is a unique document, and deserves attentive study. Those whose custom it is to buy paper packets of broken bread and buns, duly labelled "Food for the animals," at the refreshment-stalls, or who know from experience that there is hardly any creature there, from the hippopotamus to the smallest monkey, which disdains to eat a raisin, will be astonished at the quantity and variety of the solid nutriment which has to be provided yearly for $65^{\circ}$ " beasts," I,39 I birds, and 366 reptiles; though those more conversant with the powers of consumption of "stock" in an ordinary farmyard would probably hesitate to take a feeding-contract at a lower figure. The year's cost for provisions consumed in the Gardens is a little under $\mathscr{L}_{4000}$ : 105 loads of clover, 153 loads of meadow-hay, I 30 quarters of oats, and 340 quarters of bran, may be put down roughly as the quantity of vegetable food required for the large antelopes, elephants, zebras, and wild sheep. Bread and milk are almost as safe a diet for most animals as for human beings, and 5000 quarterns of bread and 6000 quarts of milk represent the quantity of this wholesome food consumed at the Zoo. Most of the insect-eating birds, many monkeys, and certain snakes and lizards are egg-eaters; and nineteen thousand 
eggs probably account for twice that number of breakfasts supplied to the smaller occupants of the houses. The large carnivora, of which the collection contains so many and such fine examples, require stronger food, and are not stinted in their supply. The figures in this case suggest some interesting reflections on the ravages said to be due to wild beasts among flocks and game. No doubt these creatures, notably wolves and wild dogs, occasionally destroy more than they require to satisfy their hunger. But usually a lion or a tiger kills one animal, and feeds upon it so long as it lasts; after which it kills another victim, and no more. The total of carcasses eaten by all the lions, tigers, bears, hyenas, wolves, leopards, and other large carnivora in the Gardens during the year amounts to 230 horses and ${ }_{1} 5_{2}$ goats. If the number consumed in captivity bears any proportion to the loss of cattle caused by these creatures when wild, the reports of natives must be much exaggerated. The fishmonger's bill is naturally a heavy one, when not only seals, otters, and sea-lions, which will eat nothing else, but also numbers of piscivorous birds, and even the polar-bears, have to be provided with fresh flounders, whiting, and conger-eels daily,36,000 lbs. of whiting, 10,000 lbs. of "rough fish," 630 quarts of shrimps, and 2000 lbs. of flounders were consumed by the seals and other aquatic creatures. The live gudgeons, whose pursuit and capture form the daily excitement of the penguins in their glassfronted tank, do not appear in the list of food provided, 
any more than the army of mice and rats, and dozens of live frogs, which frolic behind the scenes in the Snake House. Unhonoured in their lives, their deaths are unrecorded, or figure darkly among "miscellaneous expenses." The fact is, that the rearing of tame mice and rats, and the capture and purveyance of live frogs, is an interesting and unexplored side-industry of London life. Breeding mice and white rats is an easy and lucrative addition to small incomes, carried on in back-yards and attics. The frogs, which are genuine wild animals, are captured by special emissaries employed by the "dealers," who go round to the mouse-farms and froggeries and collect the creatures, just as the poultry-men make their rounds to country farms and cottages. The Zoo is by no means the largest customer to the trade, which relies mainly on the "biologists" for its steady demand. Fruit is almost as necessary as fish at all seasons in the Gardens, and no visitor can have failed to notice the daintily-arranged "dessert" of sliced bananas, grapes, dates, and apples, which is served up to the rarer monkeys and fruit-eating birds. Thirteen thousand oranges, $2000 \mathrm{lbs}$. of grapes, I, $200 \mathrm{lbs}$. of dates, and $200 \mathrm{lbs}$. of raisins and currants, represent the fruiterer's bill ; the green-grocer comes last, with 2,64I bunches of tares, 4,500 bunches of greens, and 2,600 bundles of cress. Cherries, onions, melons, marrows, bananas, and figs vary the bill of fare, which we may close with the solid item of I 39 cwt. of carrots, and nearly two tons of ground nuts. To provide for the welfare of 
its animal pensioners, its works and repairs, its gardens, and to assist in the valuable scientific inquiries into animal structure carried out in the Prosector's Department, the Society employs, under the direction of the superintendent and his assistant, a head-keeper, twenty-two keepers, a prosector's assistant, clerks, a head-gardener, twenty-three helpers in the menagerie, twelve gardeners, artisans, firemen, messengers, and a butcher,-in all, nearly one hundred persons. At the Society's rooms in Hanover Square, the publication of the Zoological Record, containing a complete summary of all the Zoological inquiries of the year throughout the world, costs annually about $\mathscr{L} 450$. The last, and not the least, interesting item in the list of expenditure is that of $\mathscr{E} 843$ Igs. $6 d$. for the cost and carriage of animals, $\mathscr{L}_{5}$ oo of which represents the money paid for the young hippopotamus, whose comfortable figure and complacent demeanour have been not the least attraction of the Gardens during the season.

$\mathscr{E}_{23}, 8_{55}$ has been the total cost of the Zoo for the

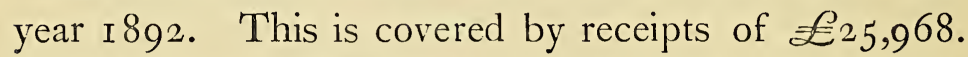
The form in which these moneys were received is perhaps less unusual than the items of expenditure; but it includes one considerable source of income which would scarcely be expected. "Fares" for rides on the elephants and camels reach the respectable amount of $£ 606$ I 7 s. $4 d$., a sum which seems nearly constant in the recent annual records of the $\mathrm{Z}$ oo. Admissions to the Gardens reached $£_{\text {I3,98I, an }}$ increase of $\mathscr{L}_{272}$ over last year; and the subscrip- 
tions of Fellows of the Society amount to over $\mathscr{E} 6,000$, which represents roughly the sum in which the public, after paying their entrance-fees, are indebted to the Society. Lastly, the assets at Regent's Park and in the offices at Hanover Square are valued

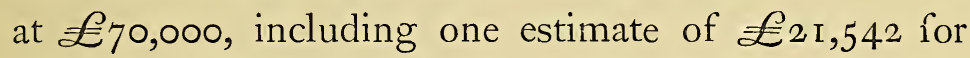
the animals in the menagerie, and another of $\mathscr{E}_{\mathrm{I} 5}, 600$ for the unrivalled library of Zoology owned by the Society.

With the exception of the young hippopotamus, which, in bulk at least, is a substantial addition to the assets of the Society, the arrivals in the Gardens were more than counterbalanced by the losses during the year. The obituary of the last giraffe has already been given; and it is interesting to notice that the Report corroborates the fear there expressed, that for the present there is no hope of obtaining a successor. "Owing to the closure of the Soudan by the Mahdists," we read, "the supply of this and other large African mammals, which were formerly obtained vi $\hat{a}$ Kassala and Suakim, has ceased, and so far as can be ascertained, there are now no living giraffes in the European market." Among the other deaths recorded are those of a lioness, a male cheetah, two common zebras, an Aard wolf, and a Beatrix antelope. More than sixty monkeys also succumbed to the intense cold of the winter. On the other hand, a large and varied progeny of young creatures was born in the Gardens during the year, and many hundreds of birds, animals, and reptiles were presented to the 
Society by donors of all ranks and conditions, from the Queen, whose gigantic ostrich occupies the empty giraffe-house, to the public-school boy with a taste for natural history, whose donation of a couple of "yellow-bellied toads," brought carefully to the Gardens in his coat-pocket, is duly acknowledged in close proximity to the gift of "Her Majesty the Queen."

THE END. 

Q 

